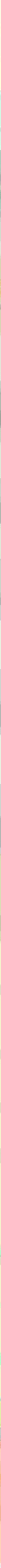

LINKING BIODIVERSITY, ECOSYSTEM SERVICES AND SOCIAL ACTORS TO PROMOTE AGROECOLOGICAL TRANSITIONS 



\section{Linking biodiversity, ecosystem services}

\section{and social actors to promote agroecological transitions}

Heitor Mancini Teixeira 
Thesis committee

Promotors

Prof. Dr M. Peña-Claros

Personal chair, Forest Ecology and Forest Management

Wageningen University \& Research

Prof. Dr I.M. Cardoso

Professor at the Soil Science Department

Universidade Federal de Viçosa, Brazil

Co-promotor

Dr F.J.J.A. Bianchi

Associate Professor, Farming Systems Ecology

Wageningen University \& Research

Other members

Prof. Dr N.P.R. Anten - Wageningen University \& Research

Dr R.B.A. Fernandes - Universidade Federal de Viçosa, Brazil

Dr C.J.M. Almekinders - Wageningen University \& Research

Dr P.A. Verweij - Utrecht University

This research was conducted under the auspices of the Graduate School for Soils and Plant Nutrition of Universidade Federal de Viçosa, Brazil, and the C.T. de Wit Graduate School for Production Ecology and Resource Conservation (PE\&RC), the Netherlands, and as part of the joint $\mathrm{PhD}$ program entitled FOREFRONT. 


\title{
Linking biodiversity, ecosystem services and social actors to promote agroecological transitions
}

\author{
Heitor Mancini Teixeira
}

\section{Thesis}

submitted in fulfilment of the requirements for the double degree of doctor between

\section{Universidade Federal de Viçosa}

by the authority of the Rector Magnificus, Prof. Dr D.D. da Silva

and

\section{Wageningen University}

by the authority of the Rector Magnificus, Prof. Dr A.P.J. Mol,

in the presence of the

Thesis Committee appointed by the Academic Boards of both universities

to be defended in public

on Friday 31 January 2020

at 1:30 p.m. in the Aula. 
Heitor Mancini Teixeira

Linking biodiversity, ecosystem services and social actors to promote agroecological transitions

287 pages.

Joint $\mathrm{PhD}$ thesis, Universidade Federal de Viçosa, Brazil, and Wageningen University, Wageningen, the Netherlands (2020).

With references, with summary in English and Portuguese.

ISBN 978-94-6395-252-1

DOI https://doi.org/10.18174/509697 




\section{Table of contents}

Chapter 1: General Introduction ..............................................................................

Chapter 2: Understanding Farm Diversity to Promote Agroecological Transitions.................33

Chapter 3: Farmers show complex and contrasting perceptions on ecosystem services and their management.

Chapter 4: Impact of agroecological management on biodiversity and soil-based ecosystem services in pasture and coffee systems in the Atlantic forest of Brazil

Chapter 5: Linking vegetation and soil functions during secondary forest succession in the Atlantic forest

Chapter 6: General Discussion 195

References .222

Summary.... 260

Sumário..... 266

Acknowledgments 274

Short Biography. 280

List of Publications... 282

PE\&RC Training and Education Statement. 284 


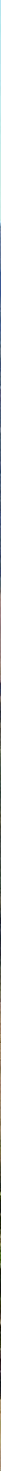


Chapter 1

\section{General Introduction}

Heitor Mancini Teixeira 
Chapter 1 
The landscape in Zona da Mata region (Brazil) can be understood as a dynamic mosaic of land uses, including secondary forest, pastures and coffee. Spatial patterns of such mosaics are determined by heterogeneous physical landscape features and shaped by the diversity of management practices and decisions made by individual farmers. Thus, a gradient of more biodiverse to overly simplified farms can be found in the region. These farming systems contribute differently to local livelihoods and to the provision of ecosystem services (ES). Currently, we lack understanding of the incentives that farmers have to manage agrobiodiversity, and the consequences of their management decisions for biodiversity and the provision of multiple ES.

In the following sections, I discuss the effects of human driven activities on biodiversity and ecosystem services and the role of agroecological transitions for developing more sustainable agroecosystems. I also describe the local context of Zona da Mata region, and end with the description of objectives of the thesis and the general methodology.

\section{Biodiversity and Ecosystem Services}

Biodiversity loss as a consequence of human driven activities is altering the functioning of ecosystems and substantially reducing the provision of ecosystem services (i.e. benefits derived from nature to people) (Cardinale et al., 2012; Hooper et al., 2012). Within agricultural systems, the dominant industrial model based on monocultures and external inputs is often associated to a variety of externalities that cause environmental and social degradation (Reynolds et al., 2014; Steffen et al., 2015). The indiscriminate use of pesticides can not only cause contamination of natural resources (Pirsaheb et al., 2017), but also threatening human health (Pirsaheb et al., 2015). The high use of mineral phosphorus and nitrogen in agriculture is one of the main causes 


\section{Chapter 1}

of disturbances on global biogeochemical flows, leading to the transgression of planetary boundaries, which are characterized as a "safe operating space for global societal development" (Steffen et al., 2015). Furthermore, the conversion of native forests into single-crop plantations is leading to soil degradation, climate change, erosion due to reduced soil cover, loss of habitats for wildlife, and increased $\mathrm{CO}_{2}$ emissions (Fearnside and Laurance, 2004; Liu et al., 2018; Ometto et al., 2011; Symes et al., 2018). Indeed, plant and animal species are extinguished at high rates, characterizing an ongoing global mass extinction with unknown and possibly irreversible consequences for planet earth and human well-being (Barnosky et al., 2011; Ceballos et al., 2017). In addition to its environmental impacts, homogeneous input-based systems are mostly developed through multinational corporatization and financialization, which often results in social degradation due to increased concentration of socio-economic power as well as preclusion of traditional and indigenous local knowledge and culture (Figueroa-helland et al., 2018). The many problems associated with the dominant mode of agriculture calls for a re-design of more sustainable agri-food systems, capable to provide human well-being and promote biodiversity conservation.

Despite the strong influence and dominance of the agro-industrial model, farmers operate in various social, political, cultural, economic and technological contexts. Differences in farm management among farmers can have an effect on the ecological structure and functioning of the landscape, and therefore, on the provision of multiple ecosystem services (Modernel et al., 2018; Schmitzberger et al., 2005; Tittonell et al., 2010). Farmers can manage their land to increase biodiversity as an efficient strategy to enhance the provision of ES, such as nutrient cycling, biological pest control, pollination, production diversification, amongst others (Iverson et al., 2014; Jackson et al., 2010; Smukler et al., 2010). In addition, the conversion from 
industrial to more diversified systems can have little or even no negative consequences for yield and productivity (Meylan et al., 2017; Pretty et al., 2018, 2006). However, it remains a challenge to understand what social, cultural, political and technological conditions are influencing farmers' knowledge and management decisions, as well as the effect of contrasting farm management practices on biodiversity and ultimately, the provision of ES (Balvanera et al., 2014; Pascual et al., 2017; Vuillot et al., 2016).

The ES framework (Figure 1.1.), consolidated by the Millenium Ecosystem Assessment, is useful to analyse the impact of land use change and biodiversity on human well-being (MEA, 2005). According to this framework, indirect and direct drivers can affect biodiversity, which in turn results in changes on the provision of ecosystem services that are crucial for human wellbeing. Such services can be classified into four categories: provisioning, regulation, cultural and supporting services. The framework considers humans as an integral part of the ecosystem, and dynamic interactions occur between humans and other components of the ecosystem. The ES framework is useful to inform the development of more sustainable agroecosystems because of three main reasons. First, it allows the integration of knowledge from ecological and social sciences as well as a broader and systemic perspective on agroecosystems beyond a productivist logic (Costanza et al., 2017a; Duru et al., 2015b; Mastrangelo and Laterra, 2015; Mulder et al., 2015). Second, it incorporates the views and perceptions of multiple stakeholders, including farmers and policy makers, making research outcomes more relevant and useful for implementation (Braat and Groot, 2012; Pascual et al., 2017; Smith and Sullivan, 2014). Third, it focuses on the interconnections between human and nature (Isbell et al., 2017b), allowing scientists and society to transform the conservation paradigm beyond protecting nature from human threats to "living with nature". In this new paradigm, humans are considered part of the 


\section{Chapter 1}

ecosystems, managing biodiversity for its intrinsic and cultural value, but also for the provision of services that are crucial for well-being (Isbell et al., 2017b; Turnhout et al., 2013). The ES framework has gained increasing scientific and social relevance in the last years and it has evolved into recent attempts of the Intergovernmental Platform on Biodiversity and Ecosystem Services (IPBES) to harness the role of multiple scientific disciplines, stakeholders and knowledge systems (Díaz et al., 2018; Díaz et al., 2015). Ultimately, the ES framework attempts to create an inclusive, interdisciplinary and action-oriented platform to inform the development of more sustainable and diversified agroecosystems capable to provide multiple ES.

Recommendations to develop sustainable agroecosystems should consider the assessment of current system states under realistic management scenarios. Such assessments are posed with the challenge to quantify ecological properties and processes related to the provision of ecosystem services. Although final ecosystem services are often assessed (Boerema et al., 2016), there is a need to further understand how management can be adapted to increase the provision of ES, as well as the mechanistic effects of biodiversity on ecological properties and process that contribute to ES provision (Birkhofer et al., 2015). 


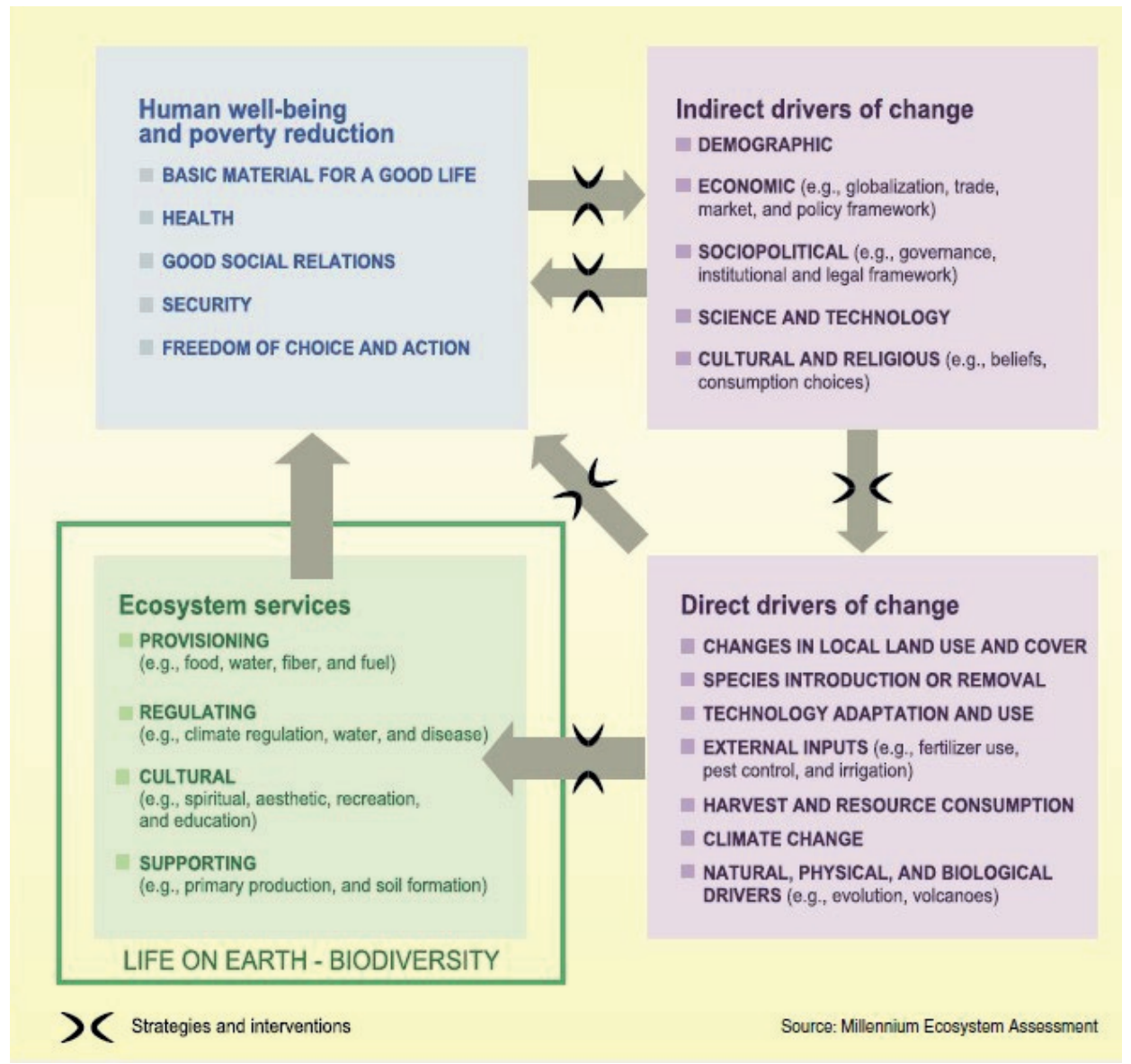

Figure 1.1. Ecosystem Services Framework. Changes in drivers that indirectly affect biodiversity, such as population, technology, and lifestyle (upper right corner of Figure), can lead to changes in drivers directly affecting biodiversity, such as the catch of fish or the application of fertilizers (lower right corner). These result in changes to ecosystems and the services they provide (lower left corner), thereby affecting human well-being. Different strategies and interventions can be applied at many points in this framework to enhance human well-being and conserve ecosystems. (Source: MEA, 2005)

Biodiversity is defined as "the variability among living organisms from all sources including terrestrial, marine and other aquatic ecosystems and the ecological complexes of which they are part; this includes diversity within species, between species and of ecosystems" (United Nations, 


\section{Chapter 1}

1992). Due to its broad definition and wide applicability, from genetics to ecosystems, biodiversity is embedded in different viewpoints and disciplines and can be considered as a boundary object (van der Sande et al., 2017b). To assess the relationship between biodiversity and ecosystem services, it can be helpful to identify relevant attributes of $\mathrm{BD}$ and their role (Oliver et al., 2015). Three diversity attributes, taxonomical, structural and functional diversity, can be used to explain ecological pathways in which vegetation can affect ecosystem services. Taxonomical diversity refers to species richness, and can be useful to understand the conservation value of land uses as well as the role of multiple species for the complementary use of resources. Structural diversity, typically defined as variance in height or size, refers to the ability of the system to efficiently capture water, carbon and nutrients (Ali et al., 2016). Functional diversity, defined as the range (i.e. quality) and abundance (i.e. quantity) of plant functional traits in a community, is useful to understand the response of plants to environmental factors and/or the effect of plants on ecosystem functioning (Díaz and Cabido, 2001; Wood et al., 2015). Moreover, functional traits may capture adaptations of plants to biotic and abiotic factors and may reflect trade-offs among contrasting plant functions (Garnier et al., 2007; Martin and Isaac, 2015). Structural and functional diversity are claimed to better explain ecosystem changes because of functional redundancy, as multiple species can fulfill similar functions in the system. Besides, vegetation structure, functional richness and composition can be better linked to ecological mechanisms than species diversity per se (Danescu et al., 2016; Díaz and Cabido, 2001). In this thesis, I use the ES framework to make an interdisciplinary and multilevel assessment of agroecosystems, considering different land uses, farm types and a gradient of management, ranging from simplified and industrial agricultural systems to diversified ones. The diversified agricultural fields were developed based on agroecological principles, and can 
indicate strategies to conserve and manage natural resources for the provision of multiple ecosystem services.

\section{Agroecological transitions}

Agroecology can be defined as "the integration of research, education, action and change that brings sustainability to all parts of the food system: ecological, economic, and social" (Gliessman, 2018). The agroecological approach is developed based on a systemic and integrative understanding of complex and sustainable agri-food systems. Thus, agroecology can be considered as a response to the dominant industrial mode of agriculture towards the integration between scientific and local knowledge of farmers for the development of biodiversity-based agroecosystems (Altieri and Nicholls, 2017; Botelho et al., 2015; Saylor et al., 2017) and that are capable to provide a wide range of ES (Bernard and Lux, 2017; Gliessman, 2018; Nicholls et al., 2016). Agroecological transitions represent a shift towards a new paradigm in agriculture and have been increasingly considered by society and international organisations as a promising approach to achieve sustainable and equitable food systems (FAO, 2018). To foster transition processes it is crucial to develop adequate management strategies and to create a favourable social and institutional environment. Such institutional environment should support new coordination strategies, equally involving policy-makers, farmers, consumers, extension agents and researchers (Berthet et al., 2016; Díaz et al., 2015; Fischer et al., 2017; Wezel et al., 2018).

The transition towards agroecology is challenging and goes beyond the biological diversification of farming systems and adoption of techniques that reduce environmental impacts without compromising farm economics (Beudou et al., 2017; Dendoncker et al., 2018). 


\section{Chapter 1}

It proposes to create new social dynamics at different scales, from household and communities to territories and policy-making. For instance, at the local scale agroecological transitions need social changes, such as more equal, fair and horizontal relationships between members of the family and community, including women and youth (Khadse, 2017; Mccune et al., 2017). At a larger scale, it is crucial to develop adequate public policies for small-scale farming, including the provision of land access (Copeland, 2018; Kepkiewicz et al., 2018; Mccune et al., 2017). Agroecological transitions also need new education and knowledge systems that respect and involve rural customs and culture as well as the use of counter-hegemonic, participatory, transdisciplinary and emancipatory methodologies of education and dissemination of knowledge (David and Bell, 2018; Mccune and Sánchez, 2018; Saylor et al., 2017). Moreover, strengthening local markets is essential for increasing the potential of agroecological transitions. Shorter market chains can bring consumers closer to producers and enable access to healthy and fair-priced food (Wezel et al., 2018). Despite the broad social and environmental call and the increasing number of scientific studies on agroecological transitions (Beudou et al., 2017; Blesh and Wolf, 2014; Dupré et al., 2017; Guzmán et al., 2013), there is still limited knowledge on how to successfully implement agroecological transitions as well as its social and ecological impacts. Therefore, it becomes important to use interdisciplinary, systemic and multi-level approaches to understand the ecological and social drivers that enable a transition towards agroecology as well as to identify or design effective agroecological management strategies that are able to provide biodiversity conservation and multiple ES (Dendoncker et al., 2018).

\section{The case of Zona da Mata}

The study was conducted in the Zona da Mata region, located in the south-eastern part of Minas Gerais state, Brazil (Figure 1.2.). The region belongs to the Atlantic forest biome, one of the 
most threatened and biodiverse ecosystems in the world (Myers et al., 2000). The average temperature in the Zona da Mata is $19^{\circ} \mathrm{C}$, average precipitation is $1300 \mathrm{~mm}$, with $3-4$ dry months per year. Altitude ranges from 200 to $1800 \mathrm{~m}$ (Golfari, 1975). The main soil type is classified as Oxisols, which are highly weathered, deep, well-drained, acidic and with low nutrient concentration (Nunes et al., 2001).

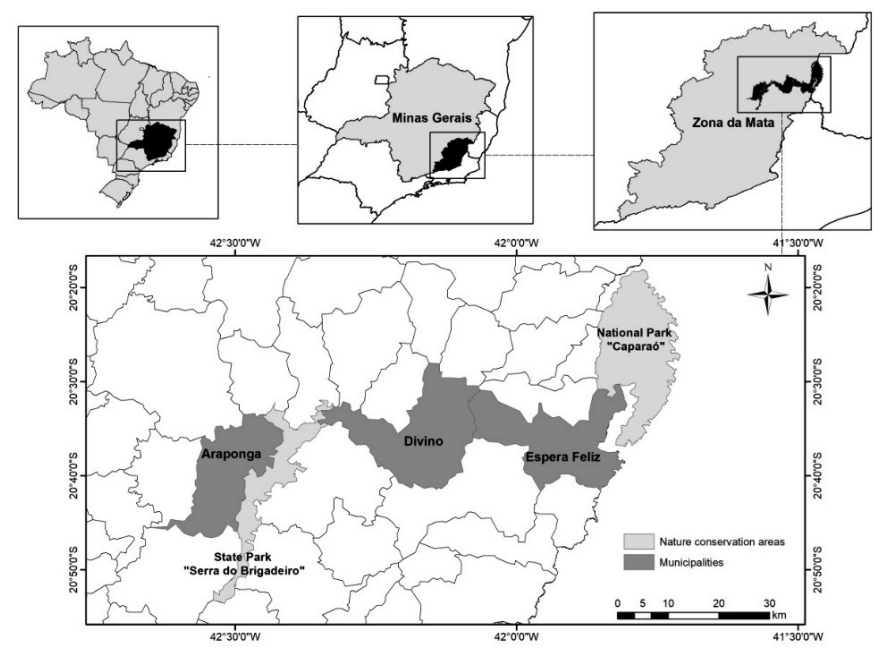

Figure 1.2. Map of studied municipalities in Zona da Mata, Minas Gerais, Brazil. Two protected areas of the region are also shown.

The history of Zona da Mata is filled with conflicting interests over the use of the land. In the past, the region was dominated by native indigenous communities, who were oppressed and nearly extinguished with the arrival of the Portuguese colonizers in the eighteenth century. After the colonization, in the nineteenth century, the land was divided among aristocratic landlords from other parts of the country. The farms were stablished based on slave labour of black Africans, and coffee cultivation became the main cash crop. In the initial growing years, coffee used to be intercropped with annual crops, such as maize, beans and rice. Other crops were also 


\section{Chapter 1}

cultivated on the farms, such as sugar cane, pumpkin and cassava. In this period, Zona da Mata became the most important agricultural region in the state of Minas Gerais, due to the success and quality of coffee production (Valverde, 1958). After the abolishment of slavery in Brazil in 1888 , lack of labour became a major problem on the farms, together with the fact that coffee fields were exhausted, after many years of production under poor management conditions, with low adoption of conservationist practices and low organic matter input. In the beginning of the $20^{\text {th }}$ century, coffee production started to decline and became restricted to higher altitudes and the middle and upper parts of the hills. Pastures replaced coffee in areas too degraded for coffee cultivation, leading to great areas dominated by grasses as Brachiaria spp. and Melinis minutiflora. Forest was kept only in restricted areas, especially on the top of the hills. Since there were no more slaves, landlords were forced to contract labour (Valverde, 1958). This was mainly done in two ways: hiring rural workers per day of work or signing a contract with sharecroppers. Sharecroppers were allowed to live and work on a portion of the land, and in compensation the agricultural production had to be divided with the landlord. Usually the sharecroppers paid $50 \%$ to $60 \%$ of their yields to their landlords in exchange for using the land. The workers often lived in poor conditions, were subjected to the orders of the landlords and had little autonomy. Within decades, diverse social dynamics in the region led to the division of land, mainly through heritage and land acquisition by rural workers (Valverde, 1958; Van den Berg et al., 2018). Governmental policies in the 1960 `s encouraged farmers to intensify coffee production by establishing monocultures and increased use of external inputs, such as pesticides and fertilizers, based on the green revolution model. Despite of the strong influence of the green revolution, many farmers still preserved traditional aspects of their peasant culture, such as diversification of crop production, seed saving, social cerimonies, exchange of products among farmers and shared labour days. Nowadays, according to the most recent national agricultural 
census in Brazil, family farms represent around $82 \%$ of the total number of farms in the Zona da Mata and cover $41.9 \%$ of the agricultural land, whereas non-family farms cover $58.1 \%$ (IBGE, 2006). The system of sharecropping and contracted labour per day of work are still common.

Currently, the area is dominated by three main land uses: coffee, pasture and forest. Coffee, as a commodity, is still the main cash crop for the majority of farmers and is often intercropped by family farmers with maize, beans, cassava, pumpkin and other crops. Pastures cover large areas in the landscape and cattle ranching is an important activity for the production of milk. Forest patches are often located in protected or less accessible areas. Although less expressive in terms of area, other land uses are also important, such as annual crops (maize and beans) and homegardens. Annual crops are produced for self-consumption, animal feed and selling at the market. Homegardens host a high diversity of plant and animal species and play a key role for the food sovereignty of the families (Oliveira, 2015). Eucalyptus plantations are present in small patches and provide wood for on-farm use or the market (Cardoso et al., 2001).

The loss of soil quality due to conventional management, prompted initiatives by farmers in Zona da Mata to develop strategies for conserving natural resources, enhancing ES provision and reducing the dependency on external inputs. A process of agroecological transition was initiated in Zona da Mata in the 1980 's, as a collective effort to seek for more sustainable management practices in agriculture. The transition was initiated by family farmers organized in Rural Unions and other organisations in joint collaboration with lecturers, professors and students of the Federal University of Viçosa (UFV) and technicians from the NGO Center of Alternative Technologies in Zona da Mata (CTA-ZM). 


\section{Chapter 1}

As part of the participatory process of agroecological transition in Zona da Mata, there are several ongoing initiatives and organisations that work in cooperation, but with different focuses (Silveira et al., 2018). For instance, groups working with gender issues aim to give visibility and support the work of rural women. The rural youth organised themselves to discuss the role of young people in the countryside, contributing to the process of repeasantization and to rethink local customs to be more inclusive of diverse populations, generations and gender (Goris et al., 2019). Within the farmers' unions and cooperatives, public policies to strengthen agroecology are discussed at the regional and national level to enhance family farmers` access to credit, markets and technical training (e.g. courses on homeopathy, use and maintenance of rural equipment, pruning, etc.) (Van den Berg et al., 2018). There is also a diversity of groups and projects from the UFV and the local NGO CTA-ZM working together with farmers on a great variety of topics related to management, such as sustainable animal production, management of homegardens, landrace seed saving, water management, access to markets, and agroforestry systems, among others (Silveira et al., 2017). All the agroecological knowledge developed in co-creation by a great variety of actors in Zona da Mata is shared and strengthened during peasant-to-peasant exchange meetings (Zanelli et al., 2015) as well as regional and national events, such as the National Agroecology Meeting (i.e. "Encontro Nacional de Agroecologia") (Petersen et al., 2013).

One of the main agroecological management strategies that has been successfully adopted by a group of farmers in Zona da Mata is the establishing of agroforestry systems (AFS) (Cardoso et al., 2001). These systems are characterized by natural regeneration of native trees in combination with planted trees, including a mixture of fruit, exotic and native species (Souza et al., 2012a; Fernandes, 2007; Siqueira, 2008). Recent studies in the region indicated that the 
General Introduction

presence of trees in coffee agroforestry systems can support ecological functions, and enhance the provision of ES, such as the natural suppression of pests and diseases (Chavassieux, 2012; Moreira, 2012; Rezende et al., 2014), soil conservation and nutrient cycling, conservation of water resources (Carneiro, 2013; Sousa, 2014), carbon sequestration (Oliveira, 2013), and production diversification (Souza et al., 2010).

Shade trees need to be managed to increase the synergies and minimize the trade-offs among ES. In the initial trials with AFS in Zona da Mata region in the 1990's, some trade-offs were associated with the increase of density and diversity of trees in the systems, such as increased hand labour and sharp decline in coffee production. To reduce these trade-offs, participatory research with farmers and practical trials over the years enabled the redesign of the systems. Although AFS were considered as a viable strategy for income generation and conservation of natural resources (Souza et al., 2012b, 2010), it remains relevant to further assess the influence of management practices and biodiversity on multiple ES considering not only coffee, but also other land uses such as pastures and forest.

The Zona da Mata (Figure 1.3) is an excellent case study because of the presence of a long-term agroecological movement as well as the diversity of agroecosystems, farm types and management strategies. This allows to assess the links between social actors, biodiversity and ecosystem services to inform the impact of agroecological transitions and ultimately, the development of more sustainable agroecosystems. 


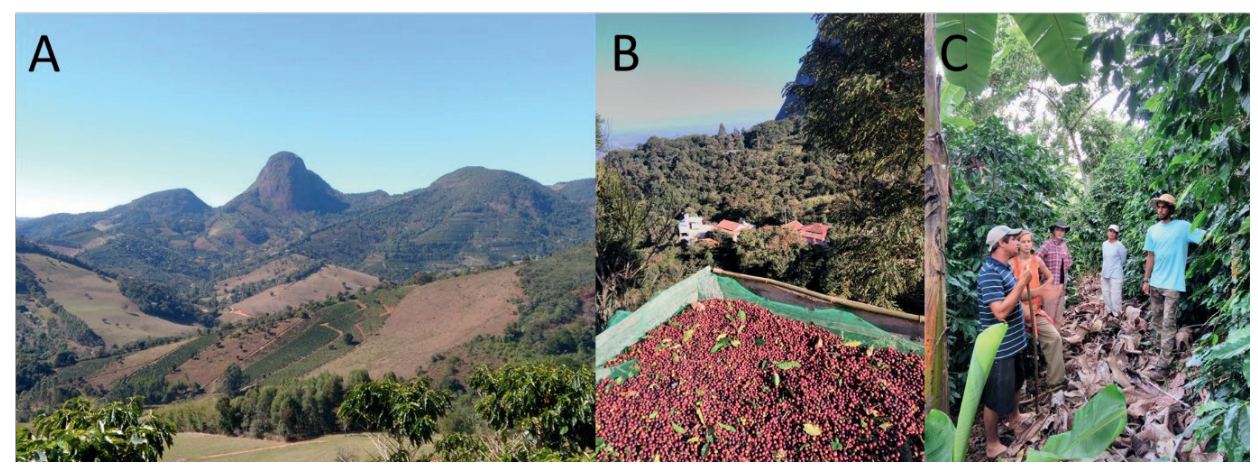

Figure 1.3.A. Landscape in Zona da Mata showing different land uses; B. Coffee harvest in Zona da Mata; C. Discussion with a farmer in his coffee agroforestry system.

\section{The FOREFRONT Program}

This $\mathrm{PhD}$ thesis is part of the interdisciplinary and cross-country research program entitled FOREFRONT ("Nature's benefits in agro-forest frontiers: linking actor strategies, functional biodiversity and ecosystem services"). The program applies the concept of agro-forest frontier to study changing landscapes. The concept of frontier applies to particularly dynamic areas where both deforestation and reforestation can occur. The FOREFRONT is focused on three sites of two Latin American countries, Brazil and Mexico. The three sites represent a diversity of social processes, institutions and practices shaping land use change and land use conflicts. The landscape approach entails an integrated vision of land use planning, policies, management decisions and relationships to maintain the resilience, productivity, biodiversity and sustainability of landscapes for the benefit of the people and nature (ecosystem services, nature's benefits to people). For an integrated vision it is crucially important to take into account the increasing complexity of land issues and the multiple (and often competing) claims on land. The program has three main objectives: (i) to identify and understand ecological and social drivers that shape agro-forest frontier landscapes and their ecosystem services; (ii) to explain temporal 
changes in the social-ecological system and their consequences for landscape configurations; and (iii) to design adaptive strategies to balance and optimize the supply of ecosystem services in changing landscapes.

While PhD candidates worked on individual projects, the projects were linked via joint activities of the FOREFRONT program. The collaboration process included international and local workshops attended by students and staff members, as well as frequent meetings among $\mathrm{PhD}$ candidates. The collaborative process allowed exchange of knowledge from different scientific disciplines. Moreover, it enabled to build complementary and synergetic links among the different projects, which together represent an interdisciplinary framework to assess the links between social actors, biodiversity, land use change and ecosystem services at multiple temporal and spatial scales.

\section{Thesis Objectives}

The main objective of this thesis is to assess the relationship between farmers' perceptions, biodiversity and ecosystem services to inform the transition to more sustainable agroecosystems capable to provide better quality of life and conservation of natural resources. We used an interdisciplinary framework (Figure 1.4) to address the following specific objectives:

1- To assess farm diversity and its implications for management and for promoting agroecological transitions (Chapter 2).

2- To understand and contrast farmers' perceptions on ecosystem services and their management (Chapter 3).

3- To assess the direct and indirect impacts of management on biodiversity and ecosystem services in coffee and pastures (Chapter 4). 


\section{Chapter 1}

4- To assess the relationship between biodiversity and soil functions during secondary forest succession (Chapter 5).

\section{6- Research methodology}

For assessing the relationship between social actors, biodiversity and ecosystem services, I conducted a multilevel analysis of agroecosystems within a framework that combines a variety of socio-ecological approaches (Table 1.1; Figures 1.4 and 1.5). First, different farm types were identified based on social, cultural, political and technological contexts. The farm typology was informed by quantitative data about farm structural and management variables combined with participatory data obtained from workshops conducted with local farmers (Chapter 2). Farmers of different farm types can have contrasting perceptions and knowledge on their agroecosystems, which may affect the applied management strategy. Therefore, once the main farm types were identified I assessed and contrasted farmer's perceptions on ES using Fuzzy Cognitive Maps. Perception patterns were then linked to farm structure and management (Chapter 3). Depending on the management strategy applied by farmers, different outcomes in terms of biodiversity and ecosystem services can be expected. The effects of management on ecosystem services can be direct or indirect. Thus, in chapters 4 and 5, I selected different land uses for a more in-depth ecological analysis on the links between biodiversity and ecosystem services. In chapter 4 , I selected coffee and pastures of representative farms of different farm types. I used interviews to quantify field management practices and crop productivity. Soil based ecosystem services were assessed using litter and soil biological, chemical and physical indicators. 


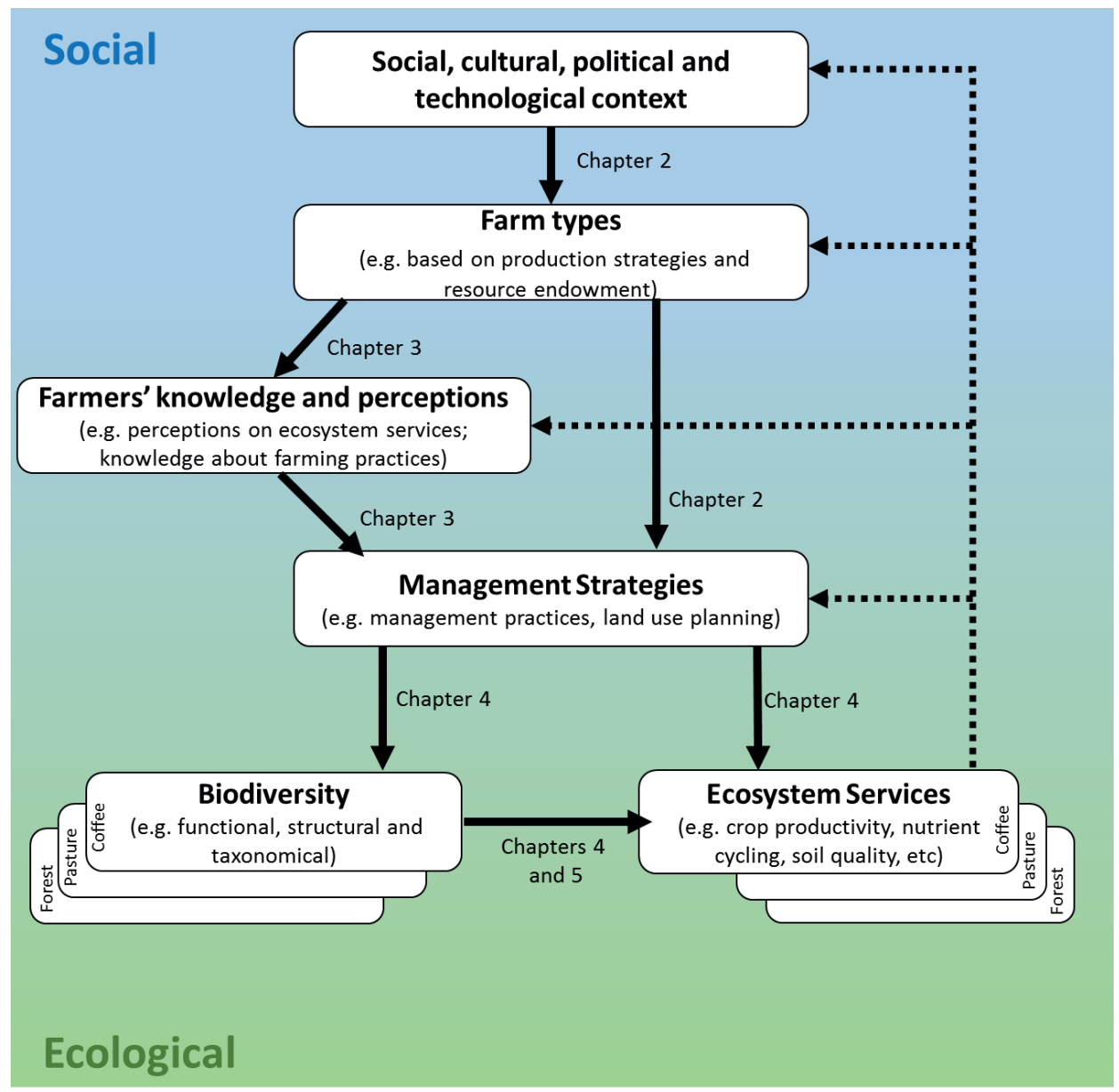

Figure 1.4. Conceptual framework showing the interactions among different components of the study. The framework considers both social and ecological aspects of agroecosystems to explain the links between biodiversity, ecosystem services and social actors. First, different farm types can be identified based on social, cultural, political and technological contexts. Farmers of different farm types can have contrasting perceptions and knowledge on their agroecosystems, which may affect the applied management strategy. Depending on the management strategy applied by farmers, different outcomes in terms of biodiversity and ecosystem services can be expected. The effects of management on ecosystem services can be direct or indirect. There is a feedback loop between ecosystem services and the other components of the study (i.e. dashed arrows), since farmers and other social actors can change their decisions and management strategies depending on the desired outcomes in terms of ecosystem services. 


\section{Chapter 1}

Plant taxonomical and structural diversity was assessed using the point interception method for all plants, and a tree inventory was conducted to assess non-herbaceous species. Leaf traits were measured for assessing functional diversity and composition (e.g. functional richness and CWM's). In Chapter 5, I assessed forest patches in different successional stages using variables related to the vegetation and soil. Forest inventory data and leaf trait data were combined to assess forest patches in terms of taxonomical, structural and functional diversity. Soil and litter measurements were used as indicators for soil ecosystem functions.

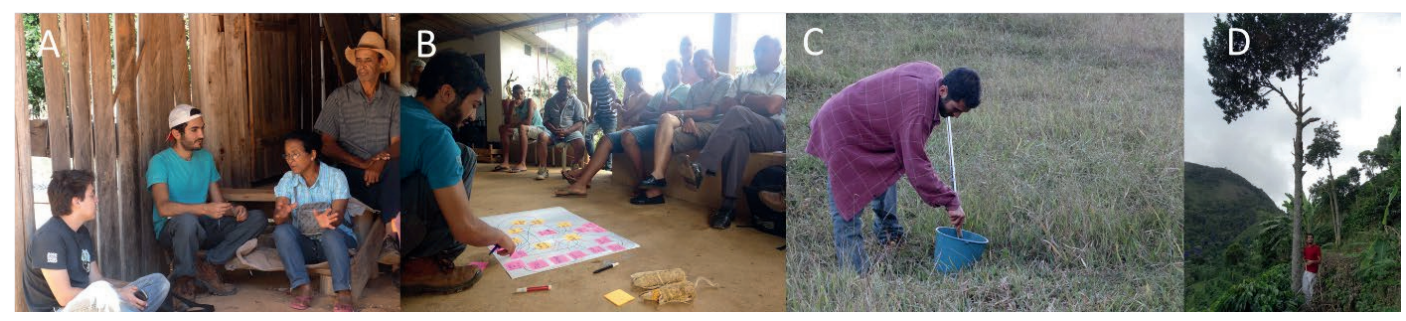

Figure 1.5A. Interview with farmers; B. Participatory workshop with farmers; C. Soil sampling in a pasture system; D. Tree measurement in a coffee system.

Table 1.1. Multilevel assessment of agroecosystems performed in this thesis using different social and ecological methodological approaches ( $\mathrm{ES}=$ ecosystem services, $\mathrm{CWM}=$ community weighted mean).

\begin{tabular}{|c|c|c|}
\hline Level of assessment & Methodological Approach & Chapter \\
\hline Diversity of farming systems & $\begin{array}{l}\text { Farm typology combining participatory workshops } \\
\text { with farmers and quantitative data on farm structural } \\
\text { and functional characteristics }\end{array}$ & 2 and 3 \\
\hline $\begin{array}{l}\text { Social demand and perception on } \\
\text { ES }\end{array}$ & Fuzzy cognitive maps & 3 \\
\hline Management practices & Interview with farmers & 4 \\
\hline Ecosystem functions/services & $\begin{array}{l}\text { Soil/litter chemical, physical and biological measures; } \\
\text { interviews with farmers }\end{array}$ & 4 and 5 \\
\hline Plant Biodiversity & $\begin{array}{l}\text { Forest and tree inventories and leaf traits } \\
\text { measurements. Three diversity attributes were } \\
\text { assessed: Taxonomical (e.g. species richness); } \\
\text { structural (e.g. variance in height) and functional (e.g. } \\
\text { functional traits richness and trait CWM) }\end{array}$ & 4 and 5 \\
\hline
\end{tabular}


Along the research project, I used a collaborative approach for engaging with local actors. Therefore, participatory methodologies were not only used to generate scientific data that can be combined with more quantitative and ecological analyses, but also to involve farmers and their knowledge in the research process to make results more effective on the ground. Indeed, the development of collaborative science involving researchers from different fields and also local actors is claimed to be crucial for making the ecosystem services approach operational (Díaz et al., 2015; Díaz et al., 2018; Pascual et al., 2017). However, there are major challenges that need to be considered for applying such an approach. First, it requires partnerships with local actors and stakeholders based on trust, mutual respect and fine-tuned goals. Therefore, the participatory process in this thesis benefitted from the long-term collaboration among farmers and scientists in Zona da Mata. Second, it requires appropriate methodological strategies that can involve a diversity of social actors and allow the participatory construction of knowledge. In this thesis, the use of participatory approaches was an important pillar of the research process, which is further explored and discussed in the following chapters.

\section{Thesis outline}

In chapter 1 I discussed the ecosystem services (ES) framework and its relevance for studies that seek to assess agroecological transitions using integrative and interdisciplinary approaches. I also present our study area, the Zona da Mata region, where an ongoing process of agroecological transition is taking place. The information described in the chapter culminated in the research objectives, general methodology and thesis outline (Figure 1.4).

In chapter 2 we developed a participatory and quantitative farm typology to characterize the diversity of farming systems in Zona da Mata, Brazil. We identified patterns and divergences 


\section{Chapter 1}

among farm types and the implications for promoting agroecological transitions to increase agrobiodiversity and provision of ES. The farm types identified in this chapter are important for selecting representative farms in the following chapters of the thesis.

In chapter 3 we selected three farm types and assessed farmers` perceptions on ES using fuzzy cognitive maps and analysed the linkages between farmers` perceptions, farm management and agrobiodiversity.

In chapter 4, we conducted an in-depth ecological study on the links between biodiversity and the provision of ES in pastures and coffee fields considering representative farms from three selected farm types. Three main components of the agroecosystems were considered: soil quality, plant diversity (taxonomical, structural and functional) and management.

In chapter 5, we assessed how biodiversity and soil functions recover during secondary forest succession in abandoned agricultural areas. We also explored the possible ecological mechanisms that can explain the response of soil functions to vegetation change.

In the final chapter (General discussion) I discussed the outcomes and implications of the thesis as a whole. I highlight the links among biodiversity, ecosystem services and social actors to generate insights that can inform practice, science and policy towards the design of more sustainable and functional landscapes 
General Introduction 


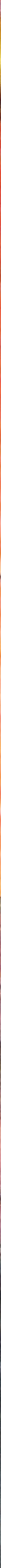




\section{Chapter 2}

\section{Understanding Farm Diversity to Promote Agroecological Transitions}

This chapter was adapted and published as:

Heitor Mancini Teixeira, Leonardo van den Berg, Irene Maria Cardoso, Ardjan J. Vermue, Felix J. J. A. Bianchi, Marielos Peña-Claros and Pablo Tittonell, 2018. Sustainability, 10: 4337. 


\title{
Chapter 2
}

\begin{abstract}
Agroecology is increasingly promoted by scientists, non-governmental organisations (NGO's), international organisations and peasant movements as an approach to foster the transition to sustainable and equitable food systems. The challenges to agroecological transitions are not the same for all farmers, as they can face different social and bio-physical conditions. We developed a farm typology combining participatory and quantitative methodologies to assess and categorise farm diversity and its implications for developing strategies to promote agroecological transitions. The participatory typology was developed during workshops to acquire insights on local farmers' perceptions and knowledge, and to generate hypotheses on family farm diversity. The participatory-based hypotheses were tested in the quantitative farm characterisation, which provided information on household characteristics, production strategies, land use, participation in public policies and extension services. Farms were located in Zona da Mata, Minas Gerais, Brazil, which harbour a wide diversity of farmers and where different actors have been engaged in agroecological transitions for the past 30 years. Our main findings were: (i) In the face of agroecological transitions, farmers differ in their management strategies, practices and principles; (ii) farmers identified as agroecological typically had stronger engagements in a network composed of farmers' organisations, universities and NGO's; (iii) agroecological farms showed great potential to provide a wide range of ecosystem services as they featured a higher crop diversity and a higher number of crops for selfconsumption; (iv) to promote agroecology, it is crucial to recognise peasant knowledge, to change the dominant discourse on agriculture through social movement dynamics, and to generate support from public policies and funds; and (v) participatory and quantitative methodologies can be combined for more precise and relevant assessments of agroecological transitions.
\end{abstract}


Farm diversity and agroecological transitions

\section{Introduction}

Agroecology as an approach to foster the transition to food systems that conserve resources and improve human well-being (Beudou et al., 2017; Blesh and Wolf, 2014; Dupré et al., 2017), has been increasingly promoted by scientists (Nicholls and Altieri, 2018; Silici, 2014), NonGovernmental Organisation (NGOs) (Oxfam, 2014), international organisations (FAO, 2018), and peasant movements (La Via Campesina, 2015). Agroecology advocates for small-scale, autonomous, resilient and efficient farming systems, that also value human rights (including women, youth and indigenous people), local cultures, social participation and food traditions (FAO, 2018). At the farm level, agroecology favours practices based on multi-functionality and biodiversity to reduce the dependence on external agrochemical inputs and to enhance ecological processes (Bonaudo et al., 2014; Duru et al., 2015a). Agroecological practices are knowledge intensive and tailored to local ecological conditions and cultural knowledge (Cardoso et al., 2001; Van den Berg et al., 2018). Agroecological practices can be technically oriented, such as composting or biocontrol and/or more socially oriented and promote, for instance, gender equality or local culture. Policies can advance agroecology by supporting agroecological research and the development of agroecological practices, and by ensuring that farmers have access to and security over land, and access to markets that valorise agroecological farmers and their produce (Copeland, 2018; Kepkiewicz et al., 2018; Mccune et al., 2017).

The agroecological transition is defined as the gradual change that farmers undergo to adapt and move from more conventional towards agroecological farming principles, encompassing technological, societal, institutional and organisational changes in the food system (Gliessman, 2016; Tittonell, 2014). Agroecological transitions are often developed within a group of farmers at the community, municipality, regional and/or even international levels (Guzmán et al., 2013), 


\section{Chapter 2}

and may influence the ways how farmers organise themselves, value their traditional culture, and relate to each other and other stakeholders. Although the transition to agroecology follows general principles, each particular farm has a unique way to adopt and adapt practices and management strategies. Therefore, the challenges towards agroecological transitions are not the same for all farmers as farmers differ in objectives and values (Teixeira et al., 2018b), and are embedded in different social and ecological contexts (Kuivanen et al., 2016a; Weltin et al., 2017).

To assess the implications of farm diversity for promoting agroecological transitions, two main challenges need to be addressed. The first challenge refers to a conceptual and empirical understanding of how to assess the diversity of farmers within transition processes. Earlier studies have sought to understand the diversity of farmers through the notion of "farming styles" or "farm typologies", which distinguish different groups of farmers on the basis of the strategies that they pursue, as well as farm structural variables (Cortez-Arriola et al., 2015; Kansiime et al., 2018; Kuivanen et al., 2016a; Schmitzberger et al., 2005). Farmers are embedded in different social networks that expose them to particular discourses, but that also grant farmers access to particular resources, information on farming practices, and public policies (van der Ploeg, 2008; Weltin et al., 2017). It is not clear how practices, discourses and policies associated with different farming types favour or hamper agroecological transitions and what types of interventions could best advance the transition for different farm types. The second challenge refers to an adequate methodological approach to understanding the relation between farm typologies and transition processes. Several researchers have argued that classifying and characterizing different types of farms in a way that is both precise and relevant requires the use of both quantitative and qualitative indicators and methods (Modernel et al., 2018; Righi et al., 
Farm diversity and agroecological transitions

2011). Others added that for a precise and relevant characterisation, researchers must engage with farmers' own knowledge, values and aspirations (Leeuwis and Van den Ban, 2004). To derive a meaningful farm typology it is important to use indicators that reflect the farmers' purposeful actions, which requires the thorough knowledge of farmers' intent and perceptions. Participatory methodologies can be used to convey local knowledge and to stimulate farmers involvement in the research, increasing the effectiveness and applicability of the results (Kuivanen et al., 2016b; Méndez et al., 2017). It is not clear, however, how participatory methodologies, and what combination of quantitative and qualitative methods, can best be used to understand how farm diversity relates to practices, discourses and policies.

In this study we assess how agroecological practices and principles are associated with different farm types within a process of agroecological transition. We assess variations between farm types and describe implications for promoting transitions. We also discuss how and why quantitative and participatory methodologies can be combined for more precise and relevant assessments to understand and promote agroecological transitions. The research questions are: (i) How do farm types differ in agricultural practices and management? (ii) How conducive are different farm types for fostering agroecological transitions? (iii) How can different research methodologies contribute to the understanding of farm diversity to promote agroecological transitions? For this purpose, we developed and evaluated a farm typology combining participatory and quantitative methodologies, analysing data collected in the Zona da Mata, Minas Gerais, Brazil. The Zona da Mata is a suitable area to conduct this research because although different actors were engaged in agroecological transitions for the past 30 years (Cardoso et al., 2001), the region still harbours a wide diversity of farming systems. The agroecological transition is driven by farmers and their organisations in cooperation and 


\section{Chapter 2}

partnership with the University of Viçosa (UFV), the socio-environmental NGO Centro de Tecnologias Alternativas da Zona da Mata (CTA-ZM), and other organisations and social movements present in Zona da Mata (Cardoso et al., 2001).

\section{Methods}

\subsection{Study Region}

The Zona da Mata region is located in the south-eastern part of the state of Minas Gerais, Brazil. It is part of the Atlantic rainforest biome, considered the 5th biodiversity hotspot in the world, due to its unique and threatened fauna and flora (Myers et al., 2000). The area is mountainous, leading to a diverse set of bio-physical conditions, limiting mechanisation and favouring small scale farming. The average temperature in the region is $19{ }^{\circ} \mathrm{C}$, average precipitation is 1300 mm, with 3-4 dry months per year. Altitude ranges from 200 to $1800 \mathrm{~m}$ (Golfari, 1975). The main soil type is classified as Oxisol, which is highly weathered, deep, well-drained and acidic.

The region was populated by native indigenous communities, who were colonised and nearly extinguished with the arrival of the Portuguese crown in the eighteenth century. After the colonisation, at the beginning of the nineteenth century, the land was divided among aristocratic landlords from other parts of the country. The farms were stablished based on the slave labour of black Africans, and coffee cultivation became the main cash crop in the region. When slavery was abolished in 1888 , lack of labour became a major problem on the farms (Freire, 2009). Another problem was the decline of soil fertility, which resulted from many years of coffee production under poor management conditions with low adoption of conservationist practices and low nutrient input. At the beginning of the twentieth century, coffee production started to decline. Degraded coffee plantations were replaced by pastures, leading to great areas of 
pastures dominated by grasses, such as Brachiaria spp. and Melinis minutiflora. Since there were no more slaves, landlords were forced to contract labour. This was done mainly in two ways: Hiring rural workers per day of work or signing a contract with sharecroppers. Sharecroppers were allowed to live and work on a portion of land, and in compensation the agricultural production had to be divided with the landlord. The workers used to live in poor conditions, were subjected to the orders of the landlords and had no autonomy. Within decades, diverse social dynamics in the region led to the division of land, mainly through heritage and land acquisition by rural workers (Valverde, 1958). Nowadays, family farms represent around $82 \%$ of the total number of farms in the region while more than a half of the land is owned by medium and large-scale farmers (IBGE, 2006), and sharecropping is still common. To be considered a family farm according to the Brazilian law, the following criteria must be met: (i) Farm size is less than 96 ha of land; (ii) farm labour and management is predominantly provided by family members; and (iii) the main family income comes from rural activities (LEI N¹1.326. Brazil, 2006). The mountainous relief and current predominance of family farmers led to a diverse landscape in Zona da Mata, which can be understood as a dynamic mosaic of land uses, dominated by pastures, coffee fields and secondary forest patches.

The study is conducted in three municipalities of Zona da Mata: Divino, Araponga and Espera Feliz. These municipalities have a strong tradition with coffee production and are part of a longterm participatory process of agroecological transition, which started in the 1970s (Cardoso et al., 2001). The municipalities also connect two important nature conservation areas: The national park "Caparaó" and the state park "Serra do Brigadeiro" (Figure 2.1). 
Chapter 2

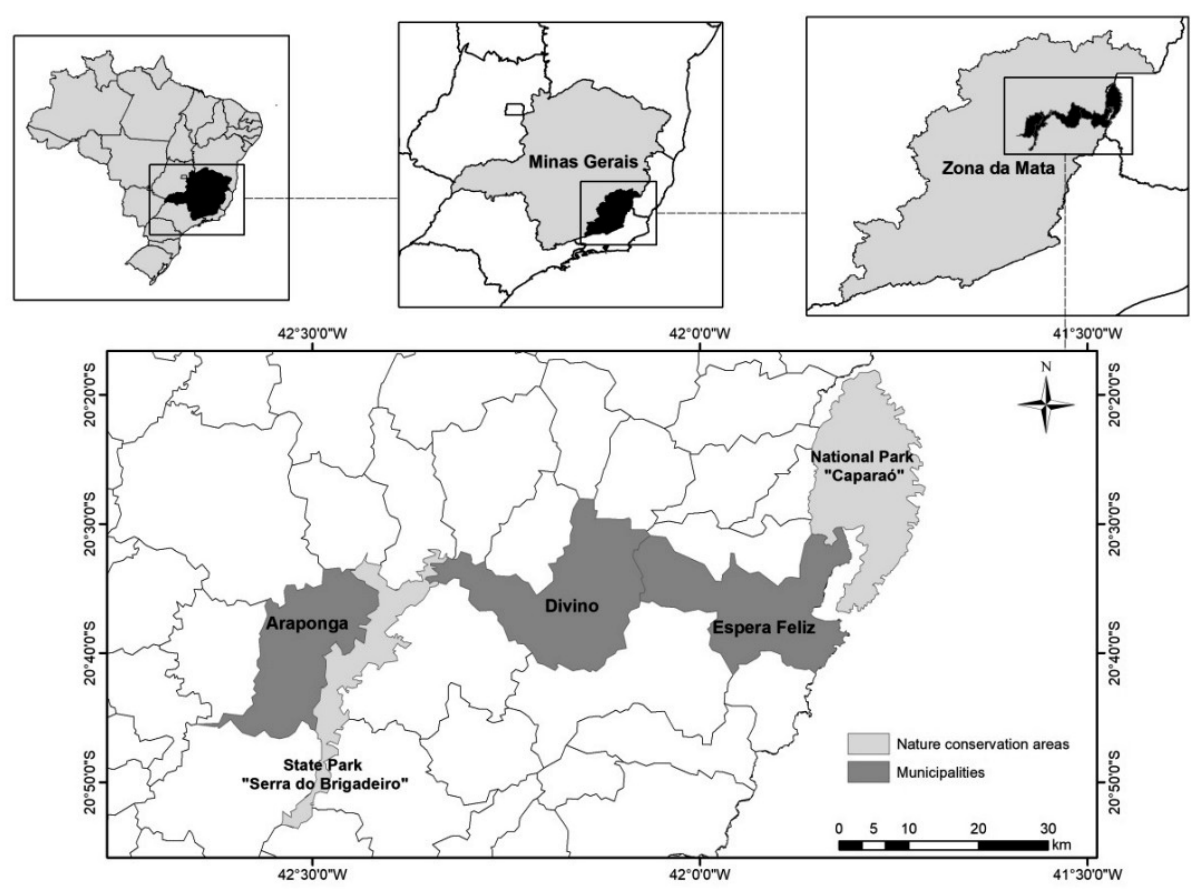

Figure 2.1. Map of studied municipalities in Zona da Mata, Minas Gerais, Brazil. The two protected areas of the region are also shown.

\subsection{Farm Typology Construction}

A farm typology was constructed using two complementary methods: A participatory typology through workshops with farmers in the three municipalities, and a quantitative analysis based on the characterisation of farming systems. The participatory typology was used to gain insights on farmers' perceptions and knowledge, and to generate hypotheses on family farm diversity in Zona da Mata region. The participatory-based hypotheses were subsequently tested in the quantitative farm characterisation, which provided information on household characteristics, production strategies, land use, participation in public policies and extension services. 
Farm diversity and agroecological transitions

\subsubsection{Participatory Typology}

The participatory typology was informed by three workshops, one in each municipality (Figure 2.2). These workshops were embedded in a long-term action research process in the Zona da Mata region (Souza et al., 2012a). The workshops involved young to old local farmers and representatives of local organisations. The number of farmers participating in each of the three workshops was 18, 20 and 34, respectively, for a total of 72 participants. During the workshops, farmers were divided into two or three groups of 6-15 persons. The process in each group was facilitated by one or two researchers. During the workshops, farmers and scientists actively participated in a process of co-creating knowledge, whereby scientists withheld from providing their opinion, but facilitated and systematised the process based on farmers' perceptions and knowledge.

The indicators and criteria for characterising farm diversity defined during the participatory workshops in each municipality were recorded, compiled and systematised in a matrix to characterise a regional typology. The importance of each indicator was not weighed, although some indicators can play a more important role than others to characterise the different farmer types. During the systematisation, we only selected information that was common to the three municipalities. After the systematisation, the results were presented to farmers in each municipality to validate the results obtained for the region. Finally, based on the results of the participatory workshops, we created hypotheses on family farm diversity.

The workshops for developing the farm typology were in embedded in an action research process, in which researchers participated in activities together with farmers, such as visiting and working in their fields, participating in meetings, workshops and social events. Furthermore, 


\section{Chapter 2}

we shared the knowledge generated by this study in formal and informal ways, fostering reflections and discussions and promoting the exchange of knowledge.

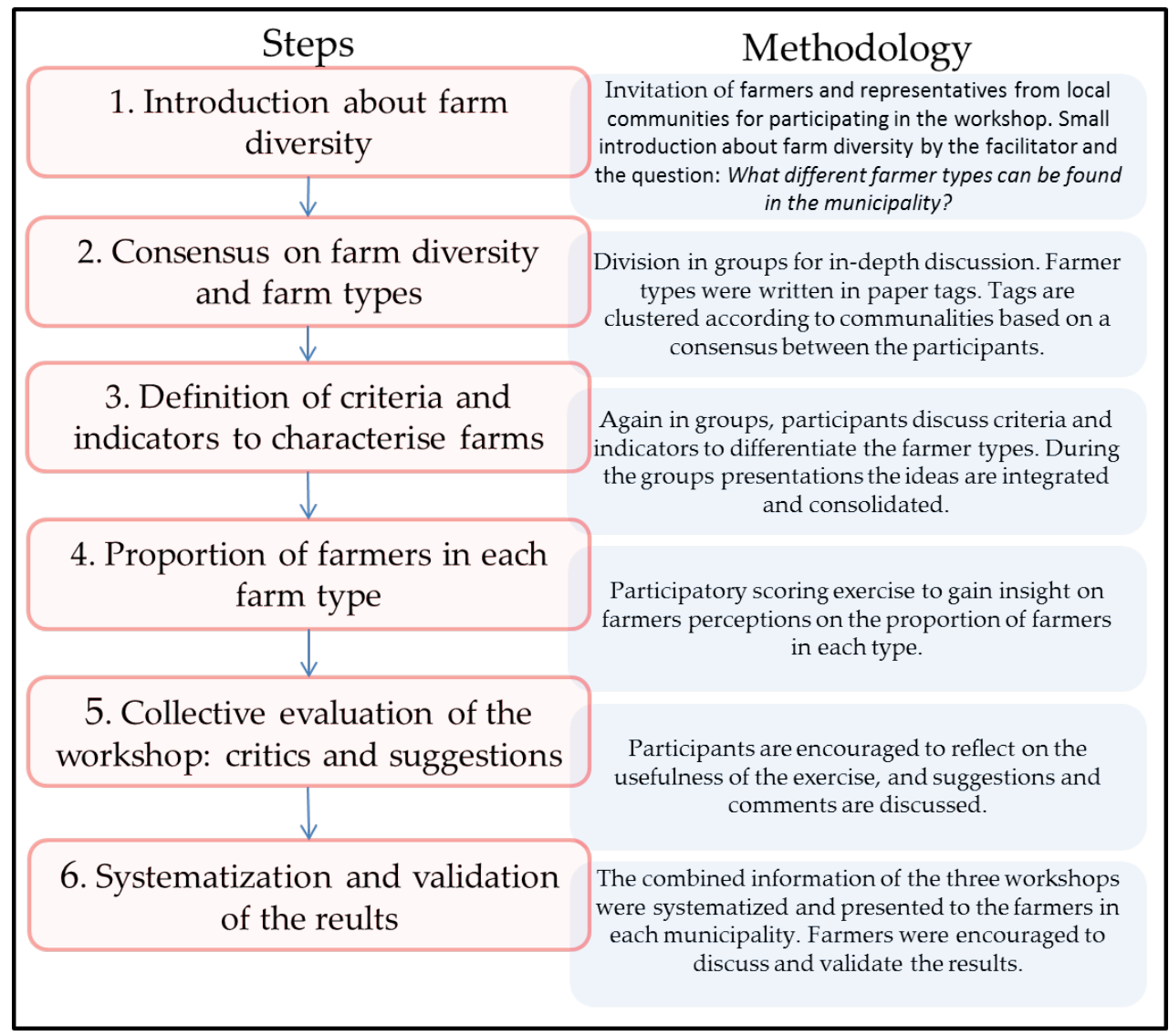

Figure 2.2. Steps of the participatory methodology developed in our study, which was used to understand farmers' perspectives on farm diversity in the Zona da Mata.

\subsubsection{Farm Characterisation and Quantitative Typology}

The quantitative typology was based on a data set of 115 family farming systems selected by the family farmers' unions, which are active in each of the three municipalities, to capture the 
diversity of family farming systems in the region (Figure 2.1). The unions approached random families of their network, indiscriminately of farmers did or did not participate in the participatory typology workshops. As the unions are responsible for public services, such as rural retirement, they have contact with a great proportion of family farmers in the municipalities. Only family farmers were selected for the quantitative analysis, because they represent the largest proportion of farmers $(82 \%)$ in Zona da Mata (IBGE, 2006) and are considered prime targets of agroecological transitions, since they own land, and, therefore, have more autonomy to manage the land and are more interested to conserve the ecological capital based on local and traditional knowledge (Bernard and Lux, 2017; van der Ploeg, 2014). Data collection was conducted in partnership with the local NGO CTA-ZM and researchers in 2015 and 2016 as part of a publicly funded assessment to characterise agroecosystems based on functional and structural farm variables. The information was obtained by Participatory Rural Appraisal (PRA) techniques, including semi-structured interviews, transect walks on the farm, participatory mapping of the farm and mapping of the gender division of labour (Chambers, 1994; Tittonell et al., 2005).

Based on the outcomes of the participatory workshops, data availability and consistency, we selected seven meaningful quantitative variables to categorise farm households in terms of farm structural, management and social aspects (Appendix Table 2.A). The variables were: (i) n.policies — number of public policies in which households participated; (ii) n.CTA—number of extension projects from the local NGO (CTA-ZM) in which households were engaged; (iii) n.prod — number of crop products produced on the farm; (iv) n.pract—number of agroecological practices and principles adopted on the farm; (v) age — age of the household head (in years); (vi) farm.area—farm area (in hectares); and (vii) n.consumed—number of food items produced on 


\section{Chapter 2}

the farm consumed by the family. The variables n.CTA and n.policies are used, respectively, as proxies for the extend of involvement in social networks and participation in public policies. To assess the number of adopted agroecological practices (n.pract), we used a checklist of practices that were previously defined by technicians of the CTA-ZM in collaboration with family farmers of the region (Appendix, Table 2.B).

\section{Multivariate Analysis and Farm Classification}

Principal component analysis (PCA) was used to generate non-correlated principal components (PC's), and cluster analysis for grouping farms into clusters based on their position on the PCA axes (Kuivanen et al., 2016a; Modernel et al., 2018; Tittonell et al., 2010). We did not include the variable "number of food items produced on the farm consumed by the family" in the multivariate analysis, because it was strongly correlated with the variable "number of crop products" obtained on the farm (correlation coefficient $>0.9$; Appendix Figure $2 . A$ ). The first two axes of the principal component were considered for the subsequent cluster analysis. These two axes were selected according to the Kaiser criterion, which indicates the selection of any axis with eigenvalues greater than 1. For the cluster analysis, we used a hierarchical, agglomerative clustering algorithm using Ward's method to define the number of groups (k). The final set of clusters was based on the inherent structure (i.e., the mean value of each variable for each cluster) aiming at intra-cluster homogeneity and inter-cluster heterogeneity (Appendix Figure 2.B). In addition, after classifying the farms according to the cluster analysis, we developed a binary recursive partitioning tree classification model to visualise decision rules for predicting the classification of farms on the different farm types according to the six selected variables. 
Farm diversity and agroecological transitions

\section{Characterisation of Different Farm Types}

We tested whether farm types defined in the cluster analysis explained variation in the seven quantitative variables listed earlier. We used one-way ANOVA and Tukey post-doc tests for variables with normal distributions and homogeneous variances, and the non-parametric Kruskal-Wallis test and post-doc Dunn test when this was not the case. For proportional data we used Pearson's Chi-squared and Fischer tests. p-values are mentioned throughout the manuscript.

\section{Agroecological Practices and Principles}

We used neural network analysis to assess the agroecological practices and/or principles associated with each farm type (Tittonell et al., 2010) and that can affect the provision of ecosystem services (Mulder et al., 2015). The neural network was constructed based on a presence/absence table representing the adoption (or not) of 25 types of agroecological practices and principles on each farm (Appendix, Table 2.C). These 25 practices were taken from the above mentioned checklist. The association of each of the 25 practices with the farm types were visualised using the software Gephi 0.9.2 (Bastian and Heymann, 2009). The closer the distance between each practice to the specific farm type in the neural network, the more affinity the farm type has to such practice. All the statistical analyses were conducted in R (version 3.3.3).

\section{Results}

\subsection{Participatory Typology}

Six main farmer types were identified during the participatory workshops: Agroecological family farmers, traditional family farmers, conventional family farmers, part-time farmers, large scale farmers and landless farmers (Table 2.1 and Appendix Table 2.C). Based on the 


\section{Chapter 2}

participatory scoring exercise, $54.1 \%$ of the farmers are considered family farmers that own land, $22.6 \%$ landless farmers, $13.3 \%$ large-scale farmers and $10 \%$ part-time farmers. Among the family farmers, $19.6 \%$ of the farmers are conventional family farmers, $18.3 \%$ are traditional family farmers and $16.2 \%$ are agroecological family farmers.

Table 2.1. Overview of the consolidated criteria and indicators for characterizing the six different farm types based on the information obtained in the three municipalities during the participatory workshops for constructing the typology. Relative strength for each criterion, according to the farm type: + (small); ++ (medium); +++ (large); NR (not relevant for the specific farm type).

\begin{tabular}{|c|c|c|c|c|c|c|}
\hline & $\begin{array}{l}\text { Agroecological } \\
\text { Family } \\
\text { Farmers }\end{array}$ & $\begin{array}{l}\text { Traditional } \\
\text { Family } \\
\text { Farmers }\end{array}$ & $\begin{array}{l}\text { Conventional } \\
\text { Family } \\
\text { Farmers }\end{array}$ & $\begin{array}{l}\text { Part- } \\
\text { Time } \\
\text { Farmers }\end{array}$ & $\begin{array}{l}\text { Large- } \\
\text { Scale } \\
\text { Farmers }\end{array}$ & $\begin{array}{l}\text { Landless } \\
\text { Farmers }\end{array}$ \\
\hline Size of the farm & + & + & + & + & "+++ & 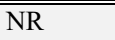 \\
\hline External inputs & + & $+/++$ & $++/+++$ & $++/+++$ & +++ & +++1 \\
\hline Organic inputs & +++ & + & + & + & + & +1 \\
\hline $\begin{array}{l}\text { Equipment and } \\
\text { machinery }\end{array}$ & + & + & $+/++$ & $+/++$ & +++ & $+++^{1}$ \\
\hline Market-oriented & + & + & ++ & +++ & +++ & +++1 \\
\hline Distance to town & NR & NR & NR & + & NR & NR \\
\hline $\begin{array}{l}\text { Age of the main } \\
\text { householder }\end{array}$ & NR & +++ & NR & NR & NR & NR \\
\hline off-farm income & + & + & + & +++ & + & + \\
\hline Resource endowment & $+/++$ & $+/++$ & $+/++$ & $+/+++$ & +++ & + \\
\hline Land ownership & + & + & + & + & + & NR \\
\hline Hired labour & + & + & $+/++$ & ++ & +++ & NR \\
\hline Family labour & +++ & +++ & +++ & + & + & +++ \\
\hline $\begin{array}{l}\text { Participation in social } \\
\text { organisations }\end{array}$ & +++ & + & + & + & + & + \\
\hline Forest conservation & ++ & + & ++ & + & $+/++$ & $+/++{ }^{1}$ \\
\hline Pastures with trees & ++ & + & + & + & + & +1 \\
\hline Grazing intensity & + & + & $+/++$ & +++ & +++ & +++1 \\
\hline $\begin{array}{l}\text { Intensive coffee } \\
\text { weeding }\end{array}$ & + & ++ & $+/++$ & ++ & ++ & ++1 \\
\hline Coffee with trees & +++ & + & + & + & + & +1 \\
\hline $\begin{array}{l}\text { Presence of } \\
\text { homegarden }\end{array}$ & +++ & +++ & ++ & + & + & $+/++$ \\
\hline Crop diversification & +++ & ++ & + & + & + & $+/++$ \\
\hline $\begin{array}{l}\text { Indigenous local } \\
\text { knowledge }\end{array}$ & +++ & +++ & ++ & + & + & $+/++/+++$ \\
\hline
\end{tabular}

${ }^{1}$ In most cases landless farmers are subjected to the orders of the land owners. 
Agroecological family farmers have a high level of autonomy and a strong connection with nature. They have diversified production systems, make little use of external inputs, do not use pesticides, use landrace seeds and adopt innovative farming practices. Agroecological farmers are part of a social network that includes farmers' organisations, religion-based organisations, universities and NGO's. Traditional family farmers still hold peasant characteristics, such as the use of landrace seeds, cultivation of diversified home gardens for self-consumption and rely on family labour, which contributes to their autonomy and food sovereignty. They often make use of traditional practices considered, nowadays, harmful to the environment, such as fire and intensive weeding. Traditional farmers make little or moderate use of pesticides and chemical fertilisers, especially in coffee systems. Conventional family farmers have a strong focus on coffee production. Conventional farms are less diversified than agroecological or traditional family farms, and strongly rely on pesticides and chemical fertilisers. A large proportion of food for household consumption is often purchased. Conventional farmers were early adopters of 'Green Revolution' technologies and are often part of a network consisting of suppliers of chemical inputs and government extension services. Part-time farmers have off-farm jobs besides their farming activities. Their main farming activity is coffee production for the market, which may be combined with the production of other crops. Their parallel jobs are often related to farming activities, such as commercialisation of agricultural inputs and cash crops. Part-time farmers can have a strong opinion on the benefits of agrochemical inputs and were found to promote the Green Revolution discourse amongst family farmers. Large-scale farmers have large farm areas, high coffee productivity with the high use of external inputs and hired labour. Both large-scale and part-time farmers adopt practices that can be considered conventional, such as intensive use of pesticides, fertilisers and monocultures. However, they may adopt some agroecological practices, as long as they are economically feasible and profitable, such as the 


\section{Chapter 2}

use of manure, mowing instead of intensive uproot weeding and introduction of one or two tree species in the coffee fields and pastures. Large-scale and part-time farmers often set themselves as examples of the wealth that can be attained when following the principles of intensive agriculture. Together, they can also control parts of the coffee supply chain and hold high positions in the public administration of the municipality. Landless farmers do not own land and work as land labourers on other farms. They are hired by landlords and therefore do not have any autonomy with regards to land management decisions.

The participatory typology and associated discussion yielded four hypotheses on family farm diversity, which were further explored in the quantitative analysis: (i) Agroecological family farms have higher crop diversification, higher food-security, higher adoption of organic farming practices and higher social participation than conventional and traditional family farms; (ii) The household head of traditional family farms is older than in conventional and agroecological family farms; (iii) Agroecological, traditional and conventional family farms do not differ interms of farm size; and (iv) Traditional family farms have higher crop diversification and higher food-security than conventional family farms, but lower than agroecological family farms. These hypotheses were developed to be further tested and explored in the quantitative typology.

\subsection{Quantitative Typology}

\subsubsection{Multivariate Analysis and Farm Type Classification}

The quantitative typology was based on a dataset comprising 115 full time family farmers owning land. Farmers were selected by the farmers' unions present in each municipality. Therefore, the other farmer types identified in the participatory exercise (i.e., large-scale, part- 
Farm diversity and agroecological transitions

time and landless farmers) were not included. The first two axes of the PCA combined $48.1 \%$ of the variance in the dataset (Figure 2.3 and Appendix Figure 2.C), reflecting the inherent variability of farming systems. The variables number of public policies, number of CTA projects, number of crop products and number of agroecological practices were strongly negatively correlated $(\mathrm{R}>0.5)$ with the first principal component $(\mathrm{PC} 1)$, while age of household head and farm area were strongly positively correlated $(\mathrm{R}>0.5)$ with the second component (PC 2) (Appendix Table 2.D). The cluster analysis based on the first two PC axes grouped family farms in three clusters (Figure 2.3). The first cluster match agroecological farms $(n=35 ; 30.4 \%)$, with a positive correlation with number of crop products, adoption of agroecological practices and participation in extension projects and public policies (hypothesis i). The second cluster can be interpreted as traditional family farms $(n=17 ; 14.8 \%)$, with a relatively high age of the household head and positioned in between the other clusters in the horizontal axis (hypotheses ii and iv). The third cluster match with conventional family farms $(n=63 ; 54.8 \%$; Figure 2.3$)$. The participatory-based hypotheses (i), (ii) and (iv) were confirmed by the multivariate analysis. However, the hypothesis that all family farm types had similar farm size (iii) was rejected, since large farm size was strongly correlated with traditional farms.

The agglomerative nesting process used to cluster the 115 farms (Figure 2.3) shows that, although the level of dissimilarity (or distance) between the clusters was quite high, three main groups of family farmers could be distinguished, in agreement with those identified through the participatory typology (Table 2.1). 


\section{Chapter 2}

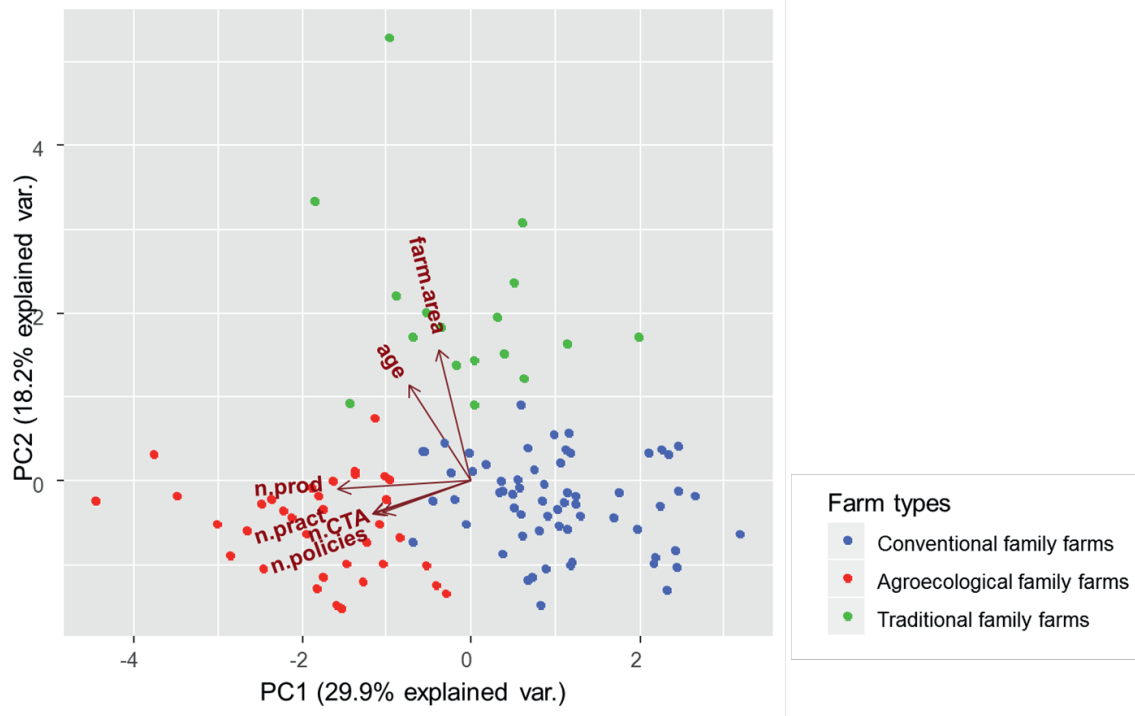

Figure 2.3. PCA output based on a dataset of 115 family farms. Colours indicate different farm types according to the cluster analysis classification (see text and Appendix Figure 2.B for more explanation). n.policies - number of public policies in which households participated; n.CTA - number of extension projects from the local NGO (CTA) in which households were engaged; n.prod-number of crop products produced on the farm; n.pract-number of agroecological practices and principles adopted on the farm. Age — age of the household head, in years; farm.area—farm area, in hectares.

The classification tree model used four of the six variables included in the analysis to separate the three groups of family farmers (Figure 2.4 ). Number of crop products ( $>23.5$ crop products per farm) and participation in at least one CTA project were the emerging indicators to identify agroecological family farms, while larger farm area (either $>7.75$ or $>16$ hectares) and age of the household head $(>38)$ were the indicators selected to distinguish traditional family farms from the other two types. Participation in public policies and number of agroecological practices adopted did not play a role at classifying farmers according to the binary tree model; yet these indicators were closely correlated with number of crop products and participation in CTA projects. In some cases, characteristics of conventional family farms and the two other farm types seemed to be relatively subtle. For instance, seven conventional farms had more than 23.5 
Farm diversity and agroecological transitions

crop products, but as they did not participate in any CTA project, they were classified as conventional farms. Moreover, five conventional farms had areas between the thresholds of 7.75 and 16 hectares, but were not classified as traditional farms because the age of the household head was less than 38 years.

\subsubsection{Farm Types Characterisation}

The proportions of farms that are beneficiaries of public policies (Pearson's Chi-squared test, $p$ $<0.01$ ) and CTA projects (Fisher's test, $\mathrm{p}<0.001$ ) were significantly different among farm types. All agroecological family farmers have participated in at least one project from CTA and almost $70 \%$ of agroecological family farmers benefitted from at least three to four public policies. On the contrary, the majority of conventional and traditional family farmers did not participate in CTA projects and had less access to the benefits of public policies. Almost one third of traditional family farmers did not participate in public policies and about $60 \%$ of the conventional family farmers had access to the benefits from one or two public policies (Appendix Tables 2.E and 2.F). 


\section{Chapter 2}

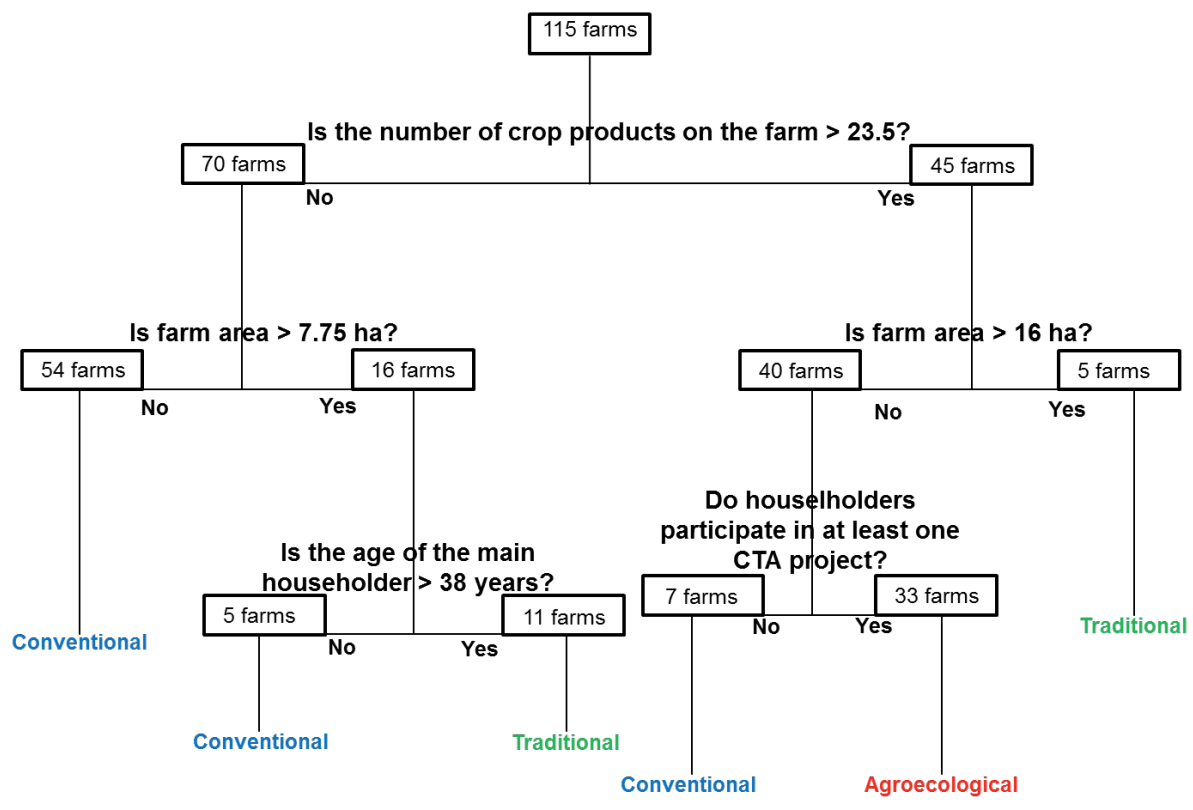

Figure 2.4. Tree model displaying threshold values for the classification of farm types based on the variables used in the multivariate analysis. The boxes represent the number of farms following (or not) the established criteria. The terminal nodes represent the final farm type classification according to the tree model. The misclassification error rate of the model is 0.06097 (7/115). CTA stands for Centre of Alternative Technologies of Zona da Mata, a local NGO working with family farmers.

Agroecological farms grew a larger number of crops (ANOVA, $\mathrm{p}<0.0001$ ), implemented more agroecological practices and principles (Kruskal-Wallis, $\mathrm{p}<0.0001$ ), and consumed a greater diversity of crops produced on farm (ANOVA, $\mathrm{p}<0.0001$ ) than conventional and traditional family farms (Figure 2.5). Traditional and conventional family farms have, however, adopted some agroecological practices and grow a lower, but still considerable, diversity of crops and of products consumed (Figure 2.5). Besides, the household head of agroecological family farms are significantly older (Kruskal-Wallis, $\mathrm{p}<0.0001$ ) than conventional family farmers (Figure 2.5), which suggests that younger farmers may be more inclined to follow a market-oriented production orientation. Finally, the differences among traditional and the other two family farm 
types indicated by the participatory typology were confirmed by significantly older household heads (Kruskal-Wallis, $\mathrm{p}<0.0001$ ) and larger farm sizes (ANOVA, $\mathrm{p}<0.0001$ ) associated with traditional family farmers (Appendix Tables 2.G and 2.H).
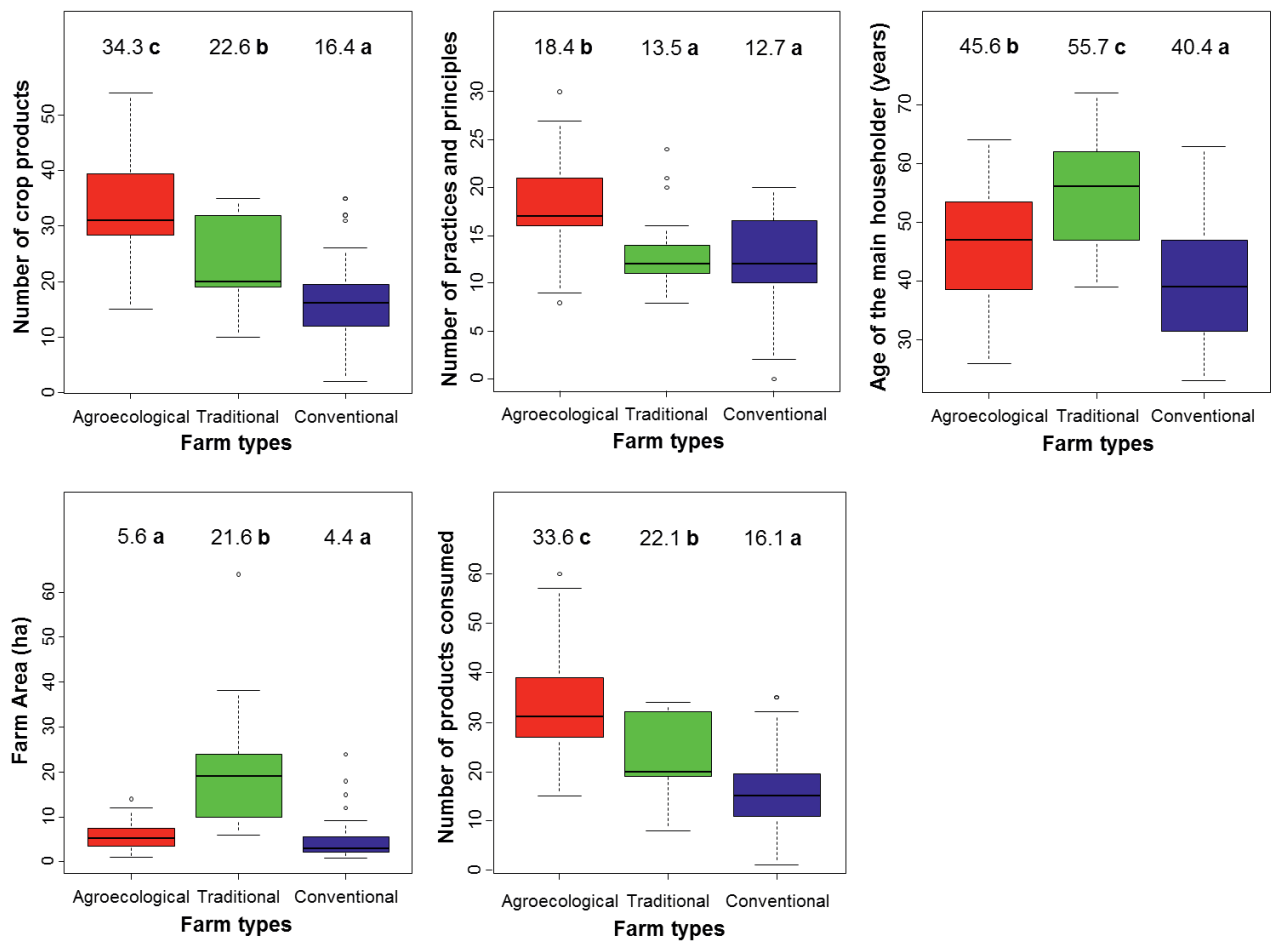

Figure 2.5. Boxplots of agroecological, traditional and conventional farmers for five farming system social characteristics. The black line that divides the box represents the median. The end of the boxes represents first and third quartiles, whiskers indicate the minimum and maximum values (excluding outliers) and outlier values are represented separately by the small circles. Mean values and letters indicating statistically significant differences are indicated above the boxplots. Age the household head and number of agroecological practices and principles were analysed using Kruskal-Wallis, and number of crop products consumed, number of crop products and farm area using ANOVA. 


\section{Chapter 2}

\subsubsection{Association between Farm Diversity and Agroecological Practices and Principles}

The neural network analysis showed variable degrees of association between agroecological practices and principles and the three types of family farms (Figure 2.6 and Appendix Table 2.I).

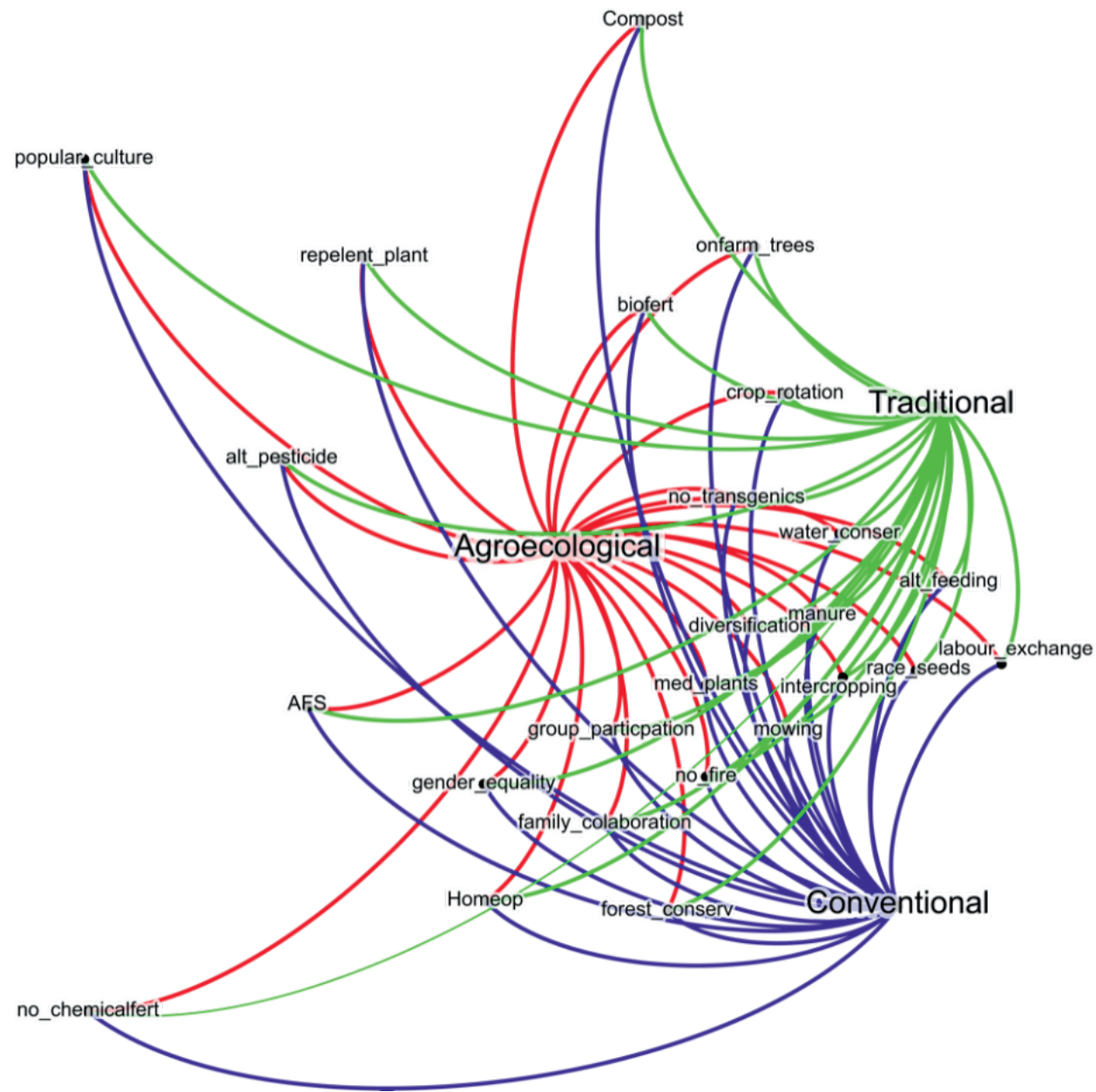

Figure 2.6. Neural network representing the association between the different farm types with each agroecological practice and principle. The closer the practice/principle to the specific farm type, the more affinity the farm type has to such practice/principle. Compost $=$ Composting of organic residues; 
repelent $\_$plant $=$Presence of plants used to repel pests; onfarm_trees $=$Presence of on-farm trees scattered around the house, around or within the fields; biofert = Use of biofertilisers originated from organic material; crop_rotation $=$ Presence of crop rotation systems; alt_pesticide = Use of alternative pesticides originated from organic material; AFS = Presence of agroforestry systems; no_transgenics = No use of transgenic seeds and crops; alt_feeding = Alternative on-farm feed production (e.g., sugar cane, tree residues, grasses, banana, fruits); manure = Use of animal manure as plant fertilisers; diversification = Presence of more than ten crops in the farming system; med_plants = Cultivation and use of medicinal plants; intercropping = Presence of intercropping systems (e.g., maize and beans); mowing = Predominance of coastal mechanical mowing for weeding instead of uprooting weeds; no_fire $=$ No use of fire to manage the fields; no_chemicalfert $=$ No use of chemical fertilisers; race_seeds $=$ Use of at least one variety of local seeds varieties; forest_conserv = Presence and conservation of forest patches on the farm; homeop = Use of homeopathy for humans, animals, soil and/or plants; water_conser = Conservation of water springs present in the farm; family_colaboration = Most family members actively contribute to farm management; gender_equity $=$ Recognition of the women's work importance; group_participation = Participation in social organisations, such as farmers unions, associations and cooperatives; labour_exchange = Labour exchange with other farmers in the community; popular_culture = Participation and organisation in events to celebrate and reinforce the local culture.

Agroecological family farms appeared at the centre of the network, while conventional and traditional farms had a peripheral position, reflecting the expected general higher association of agroecological farms with all the practices and principles included in the analysis. Practices, such as composting, use of bio-fertilisers and alternative pesticides, cultivation of repellent plants, the presence of agroforestry systems, and local culture valorisation appeared on the upper left hand-side of the network. These socio-ecological indicators were more distant from traditional and conventional family farms and more closely associated with agroecological farms, indicating a more advanced stage of agroecological transition. Gender equity and group participation were also more closely associated with agroecological farms. There was a set of practices, such as the use of manure, exchange of labour days, family collaboration, use of landrace seeds, use and cultivation of medicinal plants and intercropping that were shared across the three family farm types. There were also practices (e.g., mechanical weed mowing or forest conservation) more commonly associated with conventional and agroecological family farmers than with traditional farmers. Moreover, alternative animal feeding to complement grazing and 


\section{Chapter 2}

presence of on-farm scattered trees were more common among agroecological and traditional family farms than for conventional farms.

\section{Discussion}

The participatory and statistical typologies of farm households in the Zona da Mata distinguished three main types of family farms: Conventional, traditional and agroecological ones. We showed that certain practices commonly labelled as agroecological were common in all family farms (e.g., intercropping and use of manure), while other indicators, such as the engagement with social organisations, NGO's, local culture, and public policies were distinctive features of agroecological farms. This reinforces the idea that agroecology needs to be defined not only by practices, but also by principles and social relations.

\subsection{Agroecological Practices and Principles}

Family farmers differed in terms of farm management and adoption of agroecological practices and principles, and the association between these and the farm typology was revealed through the neural network analysis (Figure 2.6). The use of chemical fertilisers was common in all family farm types. Agroecological farms also adopted other practices to maintain soil fertility, including the use of compost, biofertilisers, and agroforestry. These practices reduce the need to apply chemical fertilisers and generate other benefits for the soil, such as increased organic matter content, reduced soil erosion and improvement of soil biological and physical quality (Barman et al., 2017; Leakey, 2014). Alternative practices for biological control were also more common in agroecological farms, such as the use of plant extracts to manage pests and diseases, and the cultivation of repellent plants (Batish et al., 2008; Castro et al., 2017). Social capital was also stronger amongst agroecological farms, which is reflected in higher group participation and 
Farm diversity and agroecological transitions

gender equity. Indeed, social capital may contribute to farmers' ability to self-organise, claim rights and access knowledge and information (Khadse, 2017; Schwendler and Thompson, 2017).

Some agroecological practices that have their roots in peasant traditions (Copeland, 2018) are still present amongst family farms. They include intercropping, exchange of labour days, the use of landrace seeds and the use and cultivation of medicinal plants. Building upon these practices can be a good strategy for policies and extension services to support a process of agroecological transition, because farmers are already accustomed to, and have knowledge of them (Altieri and Toledo, 2011). Alternative animal feeding practices and the presence of onfarm scattered trees are associated with the management of multi-species home gardens which are often encountered on traditional and agroecological farms. Home gardens are often managed without external inputs and supported by biodiversity-mediated processes and resources produced within the farming system, such as manure and plant residues. This makes farmers more autonomous in terms of producing food, both for self-consumption and for the market (Kamiyama et al., 2016; Mohri et al., 2013). In addition, traditional knowledge about plants and animals is preserved and put in practice in home gardens (Fenetahun et al., 2017). Women manage home gardens and therefore play an important role in maintaining ancestral knowledge related to agroecological practices (Díaz-reviriego et al., 2018).

According to the participatory typology, the use of fire and intensive weeding were more common in traditional farms. Before the Green Revolution, these practices were considered beneficial for crop production, and fire was applied to reduce labour requirements (Dean, 1997). Nowadays, some agroecological practices are also broadly adopted in conventional farms (e.g., 


\section{Chapter 2}

mechanical mowing instead of uproot weeding), which can generate the same benefits as fire and intensive weeding, while reducing soil erosion and improving nutrient cycling and water conservation. Furthermore, conventional family farmers were more likely to conserve forest patches on their farms than agroecological and traditional farmers, probably because they acquired land that already contained forest. While currently there are strict laws that can penalise farmers for deforestation, family farmers are typically not motivated to restore new forest areas. Reforestation is a challenge for family farmers because of reduced land availability and little knowledge on restoration strategies and their possible benefits. While environmental laws are needed to maintain the reminiscent forest patches, these currently do not provide efficient incentives for smallholder farmers to restore land by managing native vegetation. For instance, farmers are discouraged to stimulate regrowth of native vegetation because they can be punished in case they need to cut or manage the trees in the future (FAO, 2013). This indicates a need for (i) adjusted policies that better incentivise farmers to conserve native vegetation, in combination with (ii) an engagement process with farmers to understand and strengthen multiple ecosystem services derived from the forest, and (iii) the development of native vegetation management and conservation strategies that fit farmer's realities through extension programs and activities from the agroecological movement.

\subsection{Farm Diversity and Implications for Agroecological Transitions}

Farming systems in the Zona da Mata are inherently complex and diverse (Figures 2.5 and 2.6). Despite the aim of typology approaches to identify discrete groups, in reality farm diversity can best be understood as a continuum where different farm types can co-evolve, interact and overlap (Browder, 1995). In fact, agroecological transitions may also be understood as a process in which farmers move along an infinite continuum, and it is therefore difficult to draw a sharp 
Farm diversity and agroecological transitions

line that separates agroecological from non-agroecological farmers, as well as a specific end point of transition. In our study, this is evidenced by the fuzzy boundaries between conventional, traditional and agroecological farms (Figures 2.4-2.6). Indeed, there was great variation within each farm type, for instance in terms of the wide set of practices adopted by farmers in the same type. Nevertheless, farm types can be understood as reference points in the same continuum and our typology was able to make explicit the diversity of farming systems, and to reveal clear and useful general patterns that provide insights on how to assess and foster transition processes. The quantitative typology showed that farms with converging characteristics that reflect high agrobiodiversity, food security and social engagement were statistically clustered in one type (Figures 2.3 and 2.6). Therefore, we can consider these farms to be more advanced in the agroecological transition process and to have a presumably high potential for the provision of a wide range of ecosystem services (Perfecto and Vandermeer, 2015). By engaging with social organisations, family farmers may be able to share and access knowledge and participate in interactions with other stakeholders which can foster the transition towards more agroecological systems (Khadse et al., 2018; Petersen and Silveira, 2017). In Zona da Mata, farmers categorised as agroecological, who in the past were either landless, conventional or traditional family farmers, were part of a social movement and a network that brought together farmers, churchbased organisations, local NGOs (CTA), the Federal University of Viçosa, and other organisations (Cardoso et al., 2001) (Table 2.1 and Figure 2.3). Through this movement, they were able to contest the mainstream discourse of the Green Revolution and construct an alternative agroecological discourse that recognises farmers' own knowledge and resources (Van den Berg et al., 2018). Through this movement, traditional practices were revalued and new agroecological practices constructed through on-farm experiments, participatory research and peasant-to-peasant learning exchanges (Cardoso et al., 2001; Méndez et al., 2017). 


\section{Chapter 2}

The movement also allowed farmers to participate and co-construct a variety of public policies, including the Land Credit Policy, the Food Acquisition Programme and the National School Feeding Program (Figure 2.3). These policies enabled farmers to access land and to create local markets that gave more value to agroecological products (Wittman et al., 2017). The maintenance and development of adequate policies and funds to better support more sustainable and equitable food systems could accelerate the expansion of agroecological networks and activities (Miles et al., 2017). For instance, the significant lower age of the household head of conventional compared to agroecological family farmers (Figure 2.5) indicates the need to support young farmers in the process of transitions, providing them access to credit and ecologically-based extension services.

Amongst family farms, the traditional farms were led by older household heads that tended to hold larger areas of land (Figure 2.5), as the heritage process resulting in the division of the land to their heirs was not yet concluded. In our study the average farm size of family farms was 7.3 ha, while data from the national census show that the average farm size in the three municipalities is 9.3 ha for family farmers and 47.10 ha for non-family farmers (IBGE, 2006). Our results suggest that traditional family farmers could be an important target of agroecological transitions as they have heirs who will take their place in the farm and still hold many peasant characteristics that are supportive of agroecology, such as indigenous knowledge, strong community networks, high agrobiodiversity, conservation of landrace seeds and food selfsufficiency (Altieri and Merrick, 1987) (Table 2.1, Figures 2.5 and 2.6). 
Both part-time and large scale farmers appeared as a less suitable target for agroecological transitions, because of their view on nature as a commodity (Teixeira et al., 2018b), as well as strong market-orientation and economical focus. However, large scale and part-time farmers can still be motivated to adopt agroecological practices that have no negative impact on cash crop production. For instance, reducing the use of chemical pesticides, mowing instead of intensive weeding, abandoning the use of fire and implementing water harvesting structures may be considered interesting by more market-oriented farmers. However, adoption of these practices will only result in a small transition shift, as it does not include social, cultural and organisational aspects that are also part of agroecology (Pimbert, 2016).

Farmers only made significant advances towards agroecology once they had legal land rights (Rosset, 2013). Several agroecological farmers acquired land through the government's Land Credit Policy (Reydon et al., 2015) and through locally organised arrangements that purchase land collectively (Campos, 2006). The importance of policies and movements that promote land rights, such as the Land Credit Policy, need to be re-affirmed nationally and internationally, as these policies are being dismantled and movements criminalised by the current government. The landless movement is also present in the Zona da Mata region and requires support as a way to promote an agrarian reform. Brazil is one of the countries with the greatest land concentration in the world which is associated with negative externalities, such as rural poverty and social exclusion (Reydon et al., 2015). Critically, access to land should be followed by programmes that allow farmers to exchange and acquire knowledge of agroecological farming. Otherwise there is a risk that these farmers will follow the principles set by the dominant discourse on market-oriented agriculture (Pahnke, 2015). 


\section{Chapter 2}

\subsection{Typology Construction for Agroecological Transitions}

To our knowledge, this is the first study that developed farm typologies specifically to understand and analyse a long-term process of agroecological transition, focusing on changes at farm level. Following previous research in the region (Cardoso et al., 2001; Souza et al., 2012a), we used participatory methods to interest farmers to participate in a collective process of co-creation of knowledge (Méndez et al., 2017). This was also important to generate a collective understanding of agroecology. This collective understanding is relevant to increase awareness about agroecological ideas, farms and practices, as well as to identify opportunities and barriers for promoting agroecological transitions (Mccune and Sánchez, 2018). Participating farmers reported that the process allowed them to better understand and reflect upon their own reality, which may have implications for their future management choices. The outcomes of the participatory typology did not always match with empirical statistics. For instance, the proportion of family farmers in Zona da Mata in our study (54.1\%) was lower than reported in the national census ( $82 \%)$. This discrepancy can be explained by the fact that landless farmers were considered as a separate category in our participatory workshops and not in the national census. The number of landless farmers in the national census is also probably underestimated, due to difficulties to interview rural workers who do not own land. While our participatory approach allowed the collection of detailed context specific data, it was based on the perceptions of farmers, which does not necessarily accurately represent the reality.

The participatory typology offers a qualitative, broad and holistic view on farm diversity, typical of indigenous knowledge systems (Pascual et al., 2017), while the statistical typology takes a relatively reductionist approach based on a few variables. Nevertheless, the quantitative analysis allowed the further exploration and testing of the general patterns that emerged from the 
participatory typology. The outcomes of the quantitative analysis brought insights about the relationships between farm structural and social variables and the position of farmers on a transition continuum among conventional, traditional and agroecological systems. Although the tree classification model provided useful quantitative information on thresholds to be used as reference values for further categorisation and/or monitoring of agroecological transitions, it should be examined carefully, as farm types featured great variation and fuzzy boundaries. The only major discrepancy between the categorisation made by the two approaches was the farm size among family farmers. In the quantitative typology, farm size was higher in traditional than in the two other family farm types. In contrast, no differences on farm size among family farmers were shown in the participatory workshops, probably because the differences between family and large-scale farms were much more prominent, or because farmers do not perceive this variable as relevant. We also suggest that quantitative variables that reflect participation in social networks must be considered in future studies on agroecological transitions. In our case, although the variable "n.CTA—number of extension projects from CTA in which households were engaged" was endogenous to our own data set, it represents the engagement of farmers in a network, or a movement. Although our effort is a first step towards identifying and developing indicators that account for social and network engagement, we recognise the limitation of the variable "n.CTA" as there are different ways and degrees for participating in a movement. The level of participation or engagement needs to be better captured as we have shown that it plays an important role in agroecological transitions.

\section{Conclusions}

We combined participatory and quantitative methodologies to highlight contrasting characteristics among farm types, including differences in terms of farmers' agroecological 


\section{Chapter 2}

practices and principles. Our study revealed how farmers perceived the different types of farms in the region and what are the implications of farm diversity for the strategies to promote agroecological transitions. Our main findings are:

(i) In the face of agroecological transitions, farmers differ in their management strategies, practices and principles;

(ii) Farmers identified as agroecological were strongly engaged in a network composed of farmers' organisations, universities and NGO's;

(iii) Agroecological farms showed great potential to provide a wide range of ecosystem services as they featured higher crop diversity and higher number of crops for self-consumption; (iv) To promote agroecology, it is crucial to recognise peasant knowledge and change the dominant discourse on agriculture through social movement dynamics, as well as to generate support from public policies and funds; and

(v) Participatory and quantitative methodologies can be combined for more precise and relevant assessments of agroecological transitions

To further assess why and how each agroecological practice is adopted, indicators of the intensity of adoption need to be developed. Future work should address how agroecological practices and principles are constructed and disseminated, considering infra and suprahousehold drivers, interconnections among social and ecological variables, as well as the influence of organisations, local culture and knowledge. The promotion of agroecological transitions must place farmers and their knowledge at the centre. In addition, farmer organisations, scientists, policy-makers and technicians must get together to facilitate knowledge exchange and dissemination, as well as to incorporate agroecology in national and 
Farm diversity and agroecological transitions

international political agendas towards more equitable, sustainable and autonomous agriculture and food systems.

Acknowledgments: We would like to thank farmers, farmer organisations', CTA-ZM and the agroecology movement in Zona da Mata for making this research possible. This research is part of the FOREFRONT programme, funded by the Interdisciplinary Research and Education Fund (INREF) of Wageningen University and Research. We thank and acknowledge the contributions of all members of the FOREFRONT program, forming together a truly interdisciplinary research team. We thank FAPEMIG, CNPq and the Ministry of Agrarian Development of the former federal Brazilian government for the funding support. 


\section{Chapter 2}

\section{Appendices}

Table 2.A. List of candidate variables for the multivariate analysis. PCA = Principal Component Analysis.

\begin{tabular}{|c|c|c|c|}
\hline Variable & Description & Unit & $\begin{array}{l}\text { Included in } \\
\text { the PCA? }\end{array}$ \\
\hline farm.area & Farm area & hectares & Yes \\
\hline age & Main household age & years & Yes \\
\hline n.prod & Number of crops & $\begin{array}{l}\text { no. of } \\
\text { crops }\end{array}$ & Yes \\
\hline n.pract & Number of agroecological practices adopted & $\begin{array}{l}\text { no. of } \\
\text { practices }\end{array}$ & Yes \\
\hline n.CTA & $\begin{array}{l}\text { Number of extension projects from the local } \\
\text { NGO (CTA) in which households were } \\
\text { engaged }\end{array}$ & $\begin{array}{l}\text { no. of } \\
\text { projects }\end{array}$ & Yes \\
\hline n.policies & $\begin{array}{l}\text { Number of public policies in which } \\
\text { households participated }\end{array}$ & $\begin{array}{l}\text { no. of } \\
\text { public } \\
\text { policies }\end{array}$ & Yes \\
\hline n.consum & $\begin{array}{l}\text { Number of food items consumed by the } \\
\text { family }\end{array}$ & $\begin{array}{l}\text { no. of } \\
\text { food } \\
\text { items }\end{array}$ & No \\
\hline
\end{tabular}


Table 2.B. Description of agroecological practices and principles

\begin{tabular}{ll}
\hline & \multicolumn{1}{c}{ List of agroecological practices and principles } \\
\hline \hline practice & Description \\
compost & Composting of organic residues \\
\hline repelent_plant & Presence of plants used to repel pests \\
\hline onfarm_trees & Presence of on-farm trees scattered around the house, around or within the fields \\
\hline biofert & Use of biofertilisers originated from organic material \\
\hline crop_rotation & Presence of crop rotation systems \\
\hline alt_pesticide & Use of alternative pesticides originated from organic material \\
\hline AFS & Presence of Agroforestry System \\
\hline no_transgenics & No use of transgenic seeds and crops \\
\hline alt_feeding & Alternative on-farm feed production (e.g. sugar cane, tree residues, grasses, banana, fruits) \\
\hline manure & Use of animal manure as plant fertilisers \\
\hline diversification & Presence of more than ten crops in the farming system \\
med_plants & Cultivation and use of medicinal plants \\
\hline intercropping & Presence of intercropping systems (e.g. maize and beans) \\
\hline mowing & Predominance of mowing instead of uprooting weeds \\
\hline no_fire & No use of fire to manage the fields \\
\hline no_chemicalfert & No use of chemical fertilisers \\
\hline race_seeds & Use of at least one variety of local seeds varieties \\
\hline forest_conserv & Presence and conservation of forest patches on the farm \\
\hline Homeop & Use of homeopathy for humans, animals, soil and/or plants \\
\hline water_conser & Conservation of water springs present on the farm \\
\hline family_colaboration & Most family members actively contribute to farm management \\
\hline gender_equity & Recognition of the women`s work importance \\
\hline group_participation & Participation in social organisations, such as farmers unions, associations, and cooperatives \\
\hline labour_exchange & Labour exchange with other farmers in the community \\
popular_culture & Participation and organisation in events to celebrate and reinforce the local culture. \\
\hline & \\
\hline
\end{tabular}


Chapter 2

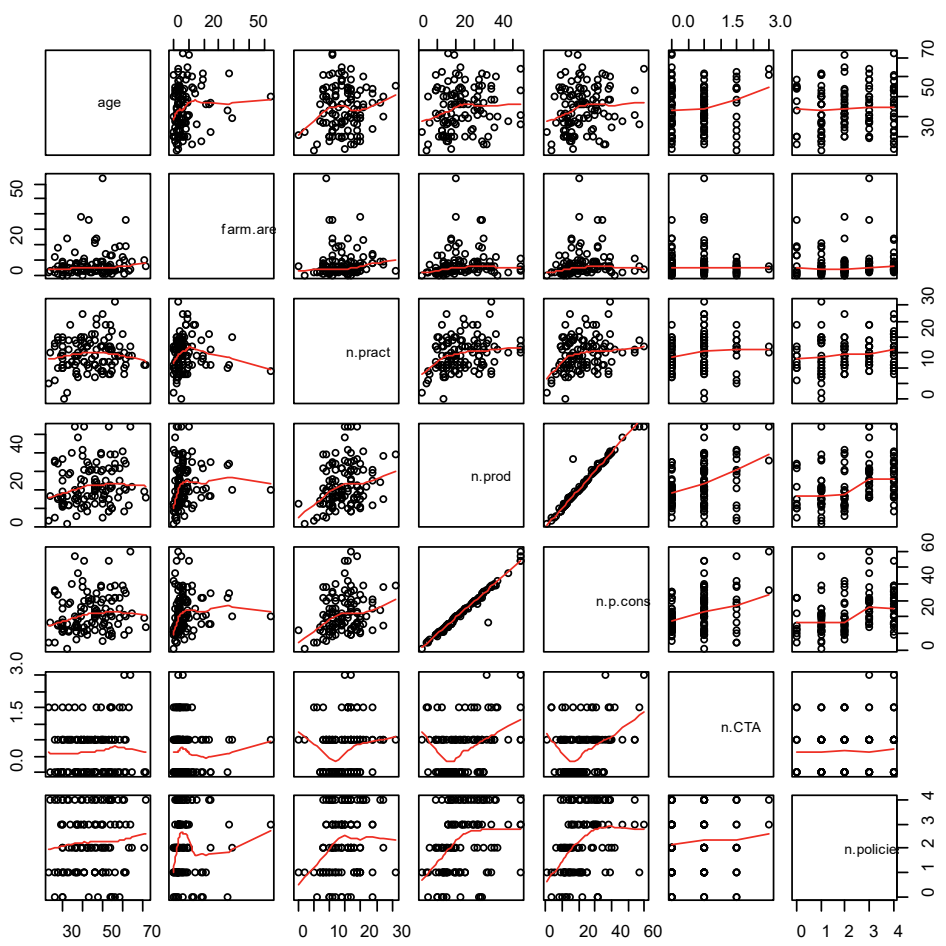

Figure 2.A. Matrix of scatterplots with candidate variables for the multivariate analysis. 
Farm diversity and agroecological transitions

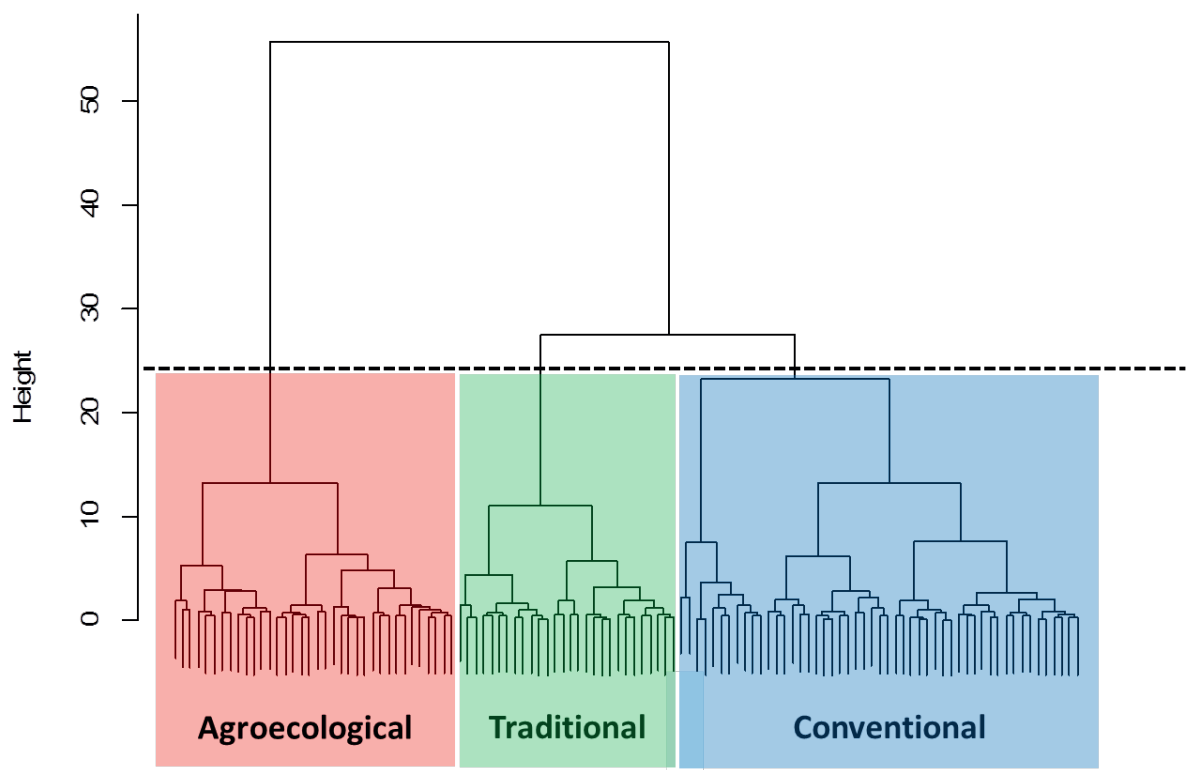

Figure 2.B. Cluster Dendrogram used to select the number of clusters. The dashed line displays the cutoff point that gave the three-cluster solution. The height shown in the vertical axis indicates the level of dissimilarity between merged clusters in different points of the dendrogram. 


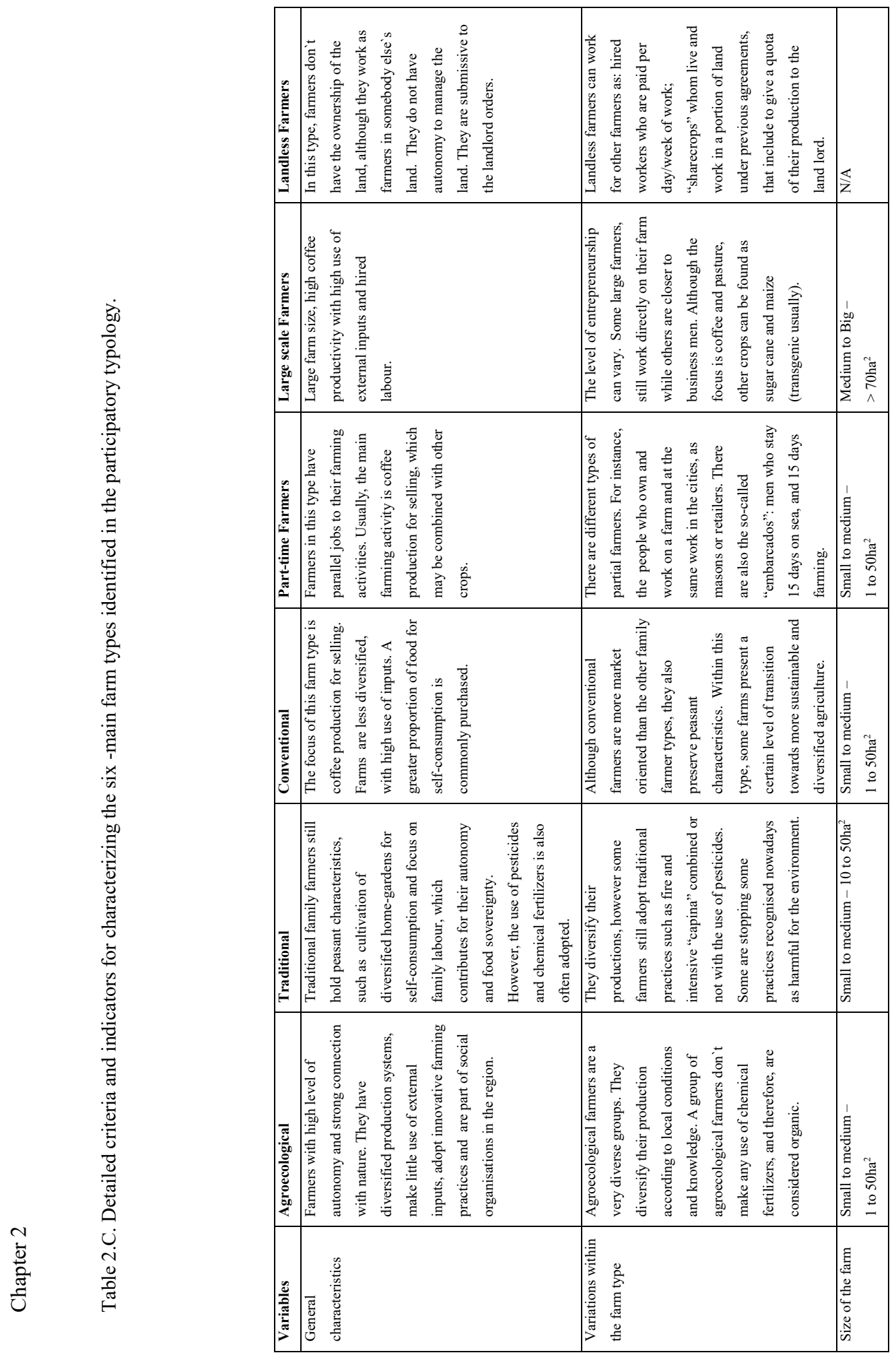

웅 


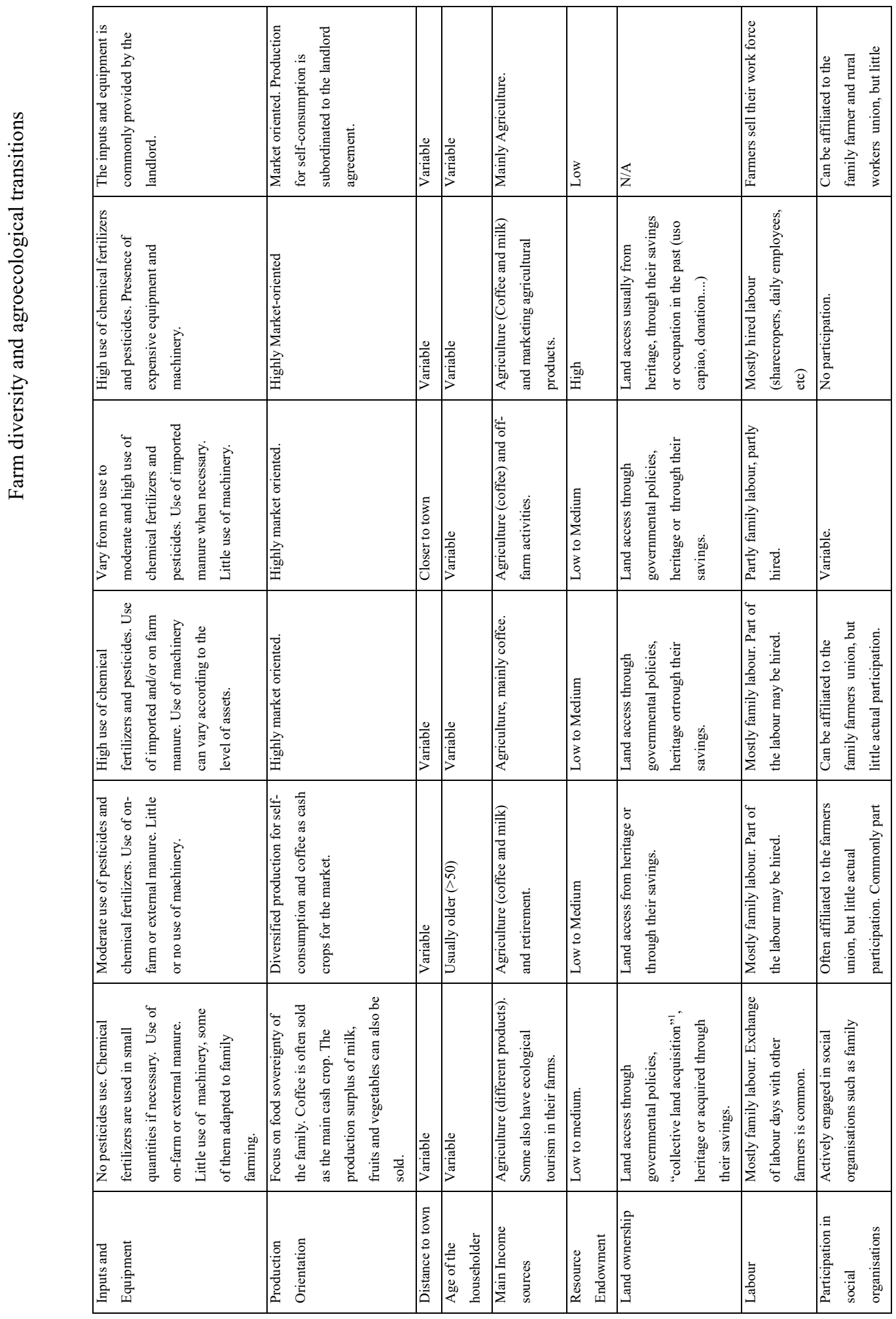




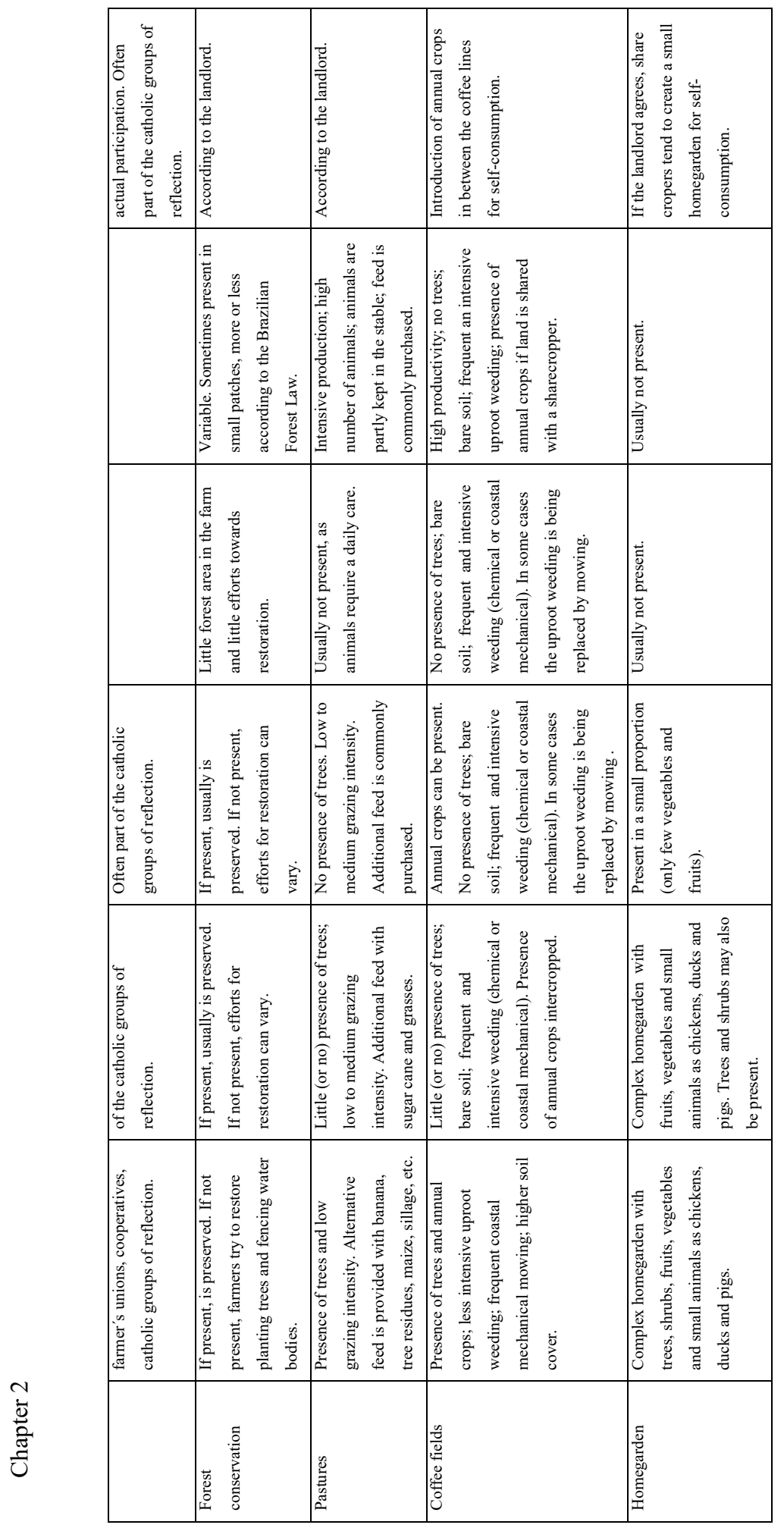


Farm diversity and agroecological transitions

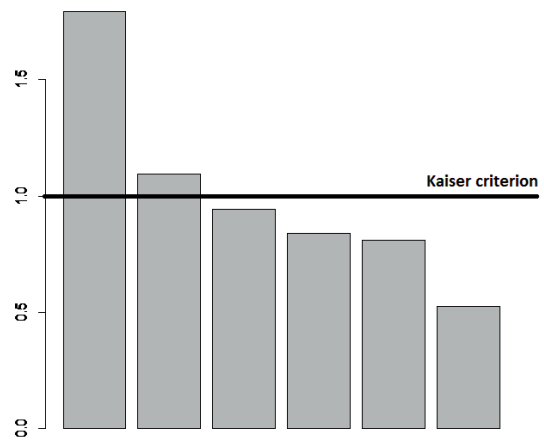

Figure 2.C. Eigenvalues of the PCA

Table 2.D. Correlation matrix between the principal components (PC's) and the variables used in the multivariate analysis.

\begin{tabular}{llll}
\hline Variables & PC1 & PC2 & PC3 \\
\hline \hline age & -0.37554 & $\mathbf{0 . 5 8 3 4 3 9}$ & -0.25941 \\
farm.area & -0.18688 & $\mathbf{0 . 8 0 0 1 9}$ & 0.218673 \\
n.pract & $\mathbf{- 0 . 5 8 6 2 6}$ & -0.18811 & 0.103478 \\
n.prod & $\mathbf{- 0 . 8 0 0 5 7}$ & -0.04888 & 0.010233 \\
n.CTA & $\mathbf{- 0 . 5 8 9 1 9}$ & -0.19782 & $\mathbf{- 0 . 6 1 9 2 7}$ \\
n.policies & $\mathbf{- 0 . 5 3 5 6 7}$ & -0.1917 & $\mathbf{0 . 6 5 8 1 7}$ \\
\hline
\end{tabular}

Table 2.E. Proportion of farmers in each farm type participating of CTA-ZM projects. Proportions are significantly different among all farm types according to Fisher's test $(\mathrm{p}<0.001)$. CTA-ZM stands for the local non-governmental organisation: Centre for Alternative Technologies of Zona da Mata.

\begin{tabular}{llll}
\hline $\begin{array}{l}\text { Number of CTA } \\
\text { projects }\end{array}$ & $\begin{array}{l}\text { Conventional } \\
(\%)\end{array}$ & $\begin{array}{l}\text { Agroecological } \\
(\%)\end{array}$ & $\begin{array}{l}\text { Traditional } \\
(\%)\end{array}$ \\
\hline \hline 0 & 66.7 & 0 & 58.8 \\
1 & 27 & 65.7 & 41.2 \\
2 & 6.4 & 28.6 & 0 \\
3 & 0 & 5.7 & 0 \\
\hline
\end{tabular}


Chapter 2

Table 2.F. Proportion of farmers in each farm type accessing public policy benefits. Proportions are significantly different among all farm types according to Pearson`s Chi-squared test $(\mathrm{p}<=0.01)$

\begin{tabular}{llll}
\hline $\begin{array}{l}\text { Number of public } \\
\text { policies }\end{array}$ & Conventional (\%) & Agroecological (\%) & Traditional (\%) \\
\hline \hline 0 & 7.9 & 0 & 29.4 \\
1 & 33.3 & 14.3 & 17.7 \\
2 & 25.4 & 17.1 & 23.5 \\
3 & 17.5 & 28.6 & 17.7 \\
4 & 15.9 & 40 & 11.8 \\
\hline
\end{tabular}

Table 2.G. Means, standard errors, statistical test and p-values for the five variables used to characterise family farmers in the Zona da Mata, Brazil.

\begin{tabular}{lllccc}
\hline Variable & test & p-value & Conventional & Agroecological & Traditional \\
\hline \hline $\begin{array}{l}\text { Number of crop } \\
\text { products }\end{array}$ & ANOVA & $\begin{array}{l}2.00 \mathrm{e}- \\
16^{* * *}\end{array}$ & $16.4 \pm 7.2 \mathrm{a}$ & $34.3 \pm 10.2 \mathrm{c}$ & $22.6 \pm 7.9 \mathrm{~b}$ \\
$\begin{array}{l}\text { Number of } \\
\text { agroecological practices }\end{array}$ & $\begin{array}{l}\text { Kruskal- } \\
\text { Wallis }\end{array}$ & $\begin{array}{l}4.18 \mathrm{e}- \\
06^{* * *}\end{array}$ & $12.7 \pm 4.5 \mathrm{a}$ & $18.4 \pm 5.1 \mathrm{~b}$ & $13.5 \pm 4.4 \mathrm{a}$ \\
$\begin{array}{l}\text { Age of the household } \\
\text { head }\end{array}$ & $\begin{array}{l}\text { Kruskal- } \\
7.18 \mathrm{e}-\end{array}$ & $40.4 \pm 9.9 \mathrm{a}$ & $45.6 \pm 10.1 \mathrm{~b}$ & $55.7 \pm 9.5 \mathrm{c}$ \\
\hline Wallis & $06^{* * *}$ & & & \\
Farm area (ha) & ANOVA & $\begin{array}{l}2.27 \mathrm{e}- \\
15^{* * *}\end{array}$ & $4.4 \pm 4.1 \mathrm{a}$ & $5.62 \pm 3.1 \mathrm{a}$ & $21.6 \pm 14.9 \mathrm{~b}$ \\
$\begin{array}{l}\text { Number of crop products } \\
\text { consumed }\end{array}$ & ANOVA & $\begin{array}{l}3.79 \mathrm{e}- \\
15^{* * *}\end{array}$ & $16.1 \pm 7.3 \mathrm{a}$ & $33.6 \pm 11.2 \mathrm{c}$ & $22.1 \pm 8 \mathrm{~b}$ \\
\hline
\end{tabular}

Table 2.H. Results from the ad-hoc and post-doc tests for five selected variables. * Significant at $\mathrm{p}<$ $.05 ; * *$ Significant at $\mathrm{p}<.01 ; * * *$ Significant at $\mathrm{p}<0.001$.

\begin{tabular}{|c|c|c|c|c|c|c|}
\hline \multirow[b]{2}{*}{ Variables } & \multirow[b]{2}{*}{$\begin{array}{l}\text { Ad-hoc } \\
\text { test }\end{array}$} & \multirow[b]{2}{*}{ p-value } & \multirow[b]{2}{*}{$\begin{array}{l}\text { Post- } \\
\text { doc } \\
\text { test }\end{array}$} & \multicolumn{3}{|l|}{ p-values } \\
\hline & & & & $\begin{array}{l}\text { agroecological } \\
\text {-conventional }\end{array}$ & $\begin{array}{l}\text { traditional- } \\
\text { conventional }\end{array}$ & $\begin{array}{l}\text { traditional- } \\
\text { agroecological }\end{array}$ \\
\hline n.prod & ANOVA & $2.00 \mathrm{e}-16^{* * *}$ & Tukey & $0 * * *$ & $0.01977^{*}$ & $0.00001 * * *$ \\
\hline n.pract & $\begin{array}{l}\text { Kruskal- } \\
\text { Wallis }\end{array}$ & $4.179 \mathrm{e}-06^{* * *}$ & Dunn & $0^{* * *}$ & 0.3985 & $0.0006^{* *}$ \\
\hline Age & $\begin{array}{l}\text { Kruskal- } \\
\text { Wallis }\end{array}$ & 7.177e- $06^{* * *}$ & Dunn & $0.0110^{*}$ & $0 * * *$ & $0.0028 * *$ \\
\hline farm.area & ANOVA & $2.27 e-15^{* * *}$ & Tukey & 0.65266 & $0^{* * *}$ & $0 * * *$ \\
\hline n.p.consumed & ANOVA & $3.79 e-15 * * *$ & Tukey & $0 * * *$ & $0.03426^{*}$ & $0.00005 * * *$ \\
\hline
\end{tabular}


Table 2.I. Proportion of farmers adopting each agroecological practice per farm type

\begin{tabular}{|c|c|c|c|c|}
\hline \multirow[b]{2}{*}{ Practices } & \multirow[b]{2}{*}{ Description } & \multicolumn{3}{|c|}{$\%$} \\
\hline & & $\begin{array}{c}\text { Agro- } \\
\text { ecological }\end{array}$ & $\begin{array}{l}\text { Trad- } \\
\text { itional } \\
\end{array}$ & $\begin{array}{c}\text { Conven- } \\
\text { tional } \\
\end{array}$ \\
\hline popular_culture & $\begin{array}{l}\text { Participation and organisation in events to } \\
\text { value and reinforce the local culture. }\end{array}$ & 28.6 & 5.9 & 4.8 \\
\hline repelent_plant & Presence of plants used to repel pests & 45.7 & 11.8 & 12.7 \\
\hline composting & Composting of organic residues & 31.4 & 17.6 & 9.5 \\
\hline alt_pesticide & $\begin{array}{l}\text { Use of alternative pesticides originated } \\
\text { from organic material }\end{array}$ & 51.4 & 23.5 & 14.3 \\
\hline onfarm_trees & $\begin{array}{l}\text { Presence of on-farm trees scattered } \\
\text { around the house, around or within the } \\
\text { fields }\end{array}$ & 57.1 & 41.2 & 20.6 \\
\hline AFS & Presence of agroforestry system & 42.9 & 35.3 & 19 \\
\hline biofert & $\begin{array}{l}\text { Use of biofertilisers originated from } \\
\text { organic material }\end{array}$ & 54.3 & 35.3 & 25.4 \\
\hline no_transgenics & No use of transgenic seeds and crops & 88.6 & 41.2 & 41.3 \\
\hline gender_equity & $\begin{array}{l}\text { Recognition of the women`s work } \\
\text { importance }\end{array}$ & 62.9 & 47.1 & 34.9 \\
\hline no_chemicalfert & No use of chemical fertilisers & 22.9 & 0 & 11.1 \\
\hline water_conser & Conservation of water springs on the farm & 74.3 & 47.1 & 46 \\
\hline group_participation & $\begin{array}{l}\text { Participation in social organisations, such } \\
\text { as farmers unions, associations, and } \\
\text { cooperatives }\end{array}$ & 82.9 & 64.7 & 46 \\
\hline Homeop & $\begin{array}{l}\text { Use of homeopathy for humans, animals, } \\
\text { soil and/or plants }\end{array}$ & 45.7 & 52.9 & 28.6 \\
\hline med_plants & Cultivation and use of medicinal plants & 82.9 & 70.6 & 55.6 \\
\hline family_colaboration & $\begin{array}{l}\text { Most family members actively contribute } \\
\text { to farm management }\end{array}$ & 74.3 & 52.9 & 50.8 \\
\hline diversification & $\begin{array}{l}\text { Presence of more than ten crops in the } \\
\text { farming system }\end{array}$ & 94.3 & 64.7 & 61.9 \\
\hline manure & Use of animal manure as plant fertilisers & 100 & 94.1 & 73 \\
\hline alt_feeding & Alternative on-farm feed production & 74.3 & 76.5 & 55.6 \\
\hline no_fire & No use of fire to manage the fields & 85.7 & 64.7 & 71.4 \\
\hline intercropping & $\begin{array}{l}\text { Presence of intercropping systems (e.g. } \\
\text { maize and beans) }\end{array}$ & 85.7 & 70.6 & 69.8 \\
\hline crop_rotation & Presence of crop rotation systems & 48.6 & 23.5 & 36.5 \\
\hline labour_exchange & $\begin{array}{l}\text { Labour exchange with other farmers in } \\
\text { the community }\end{array}$ & 65.7 & 58.8 & 63.5 \\
\hline mowing & $\begin{array}{l}\text { Predominance of mowing instead of } \\
\text { uprooting weeds }\end{array}$ & 77.1 & 70.6 & 76.2 \\
\hline race_seeds & $\begin{array}{l}\text { Use of at least one variety of local seeds } \\
\text { varieties }\end{array}$ & 80 & 88.2 & 77.8 \\
\hline forest_conserv & $\begin{array}{l}\text { Presence and conservation of forest } \\
\text { patches on the farm }\end{array}$ & 57.1 & 47.1 & 65.1 \\
\hline
\end{tabular}




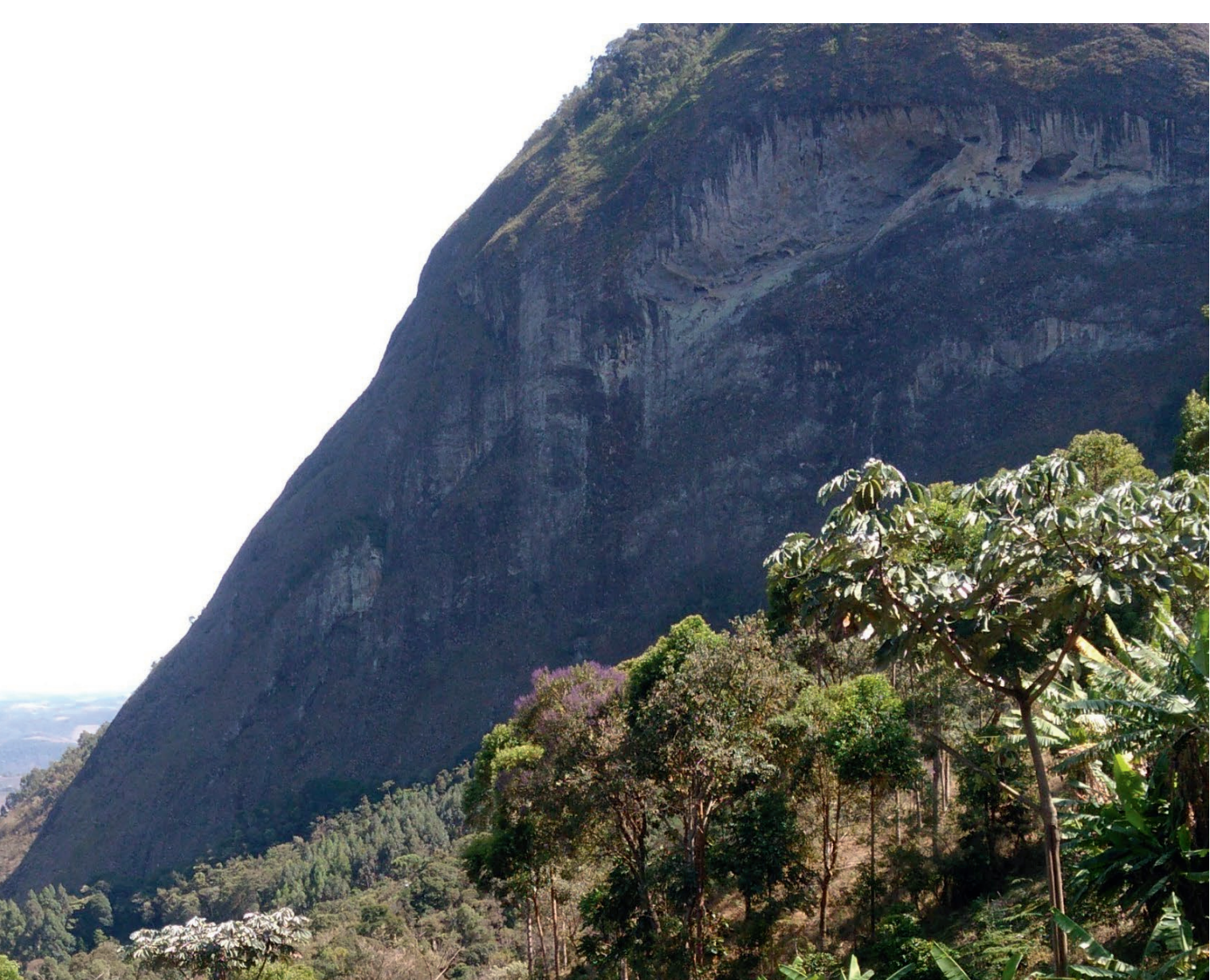

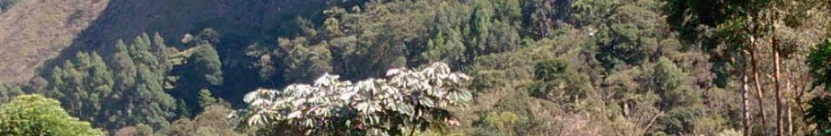

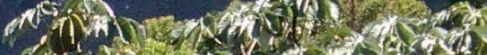

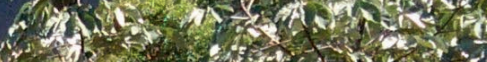
3. (1.5.

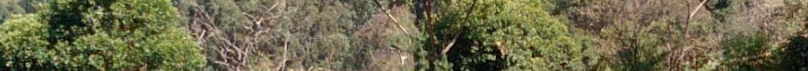

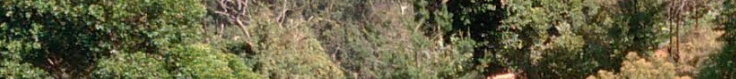

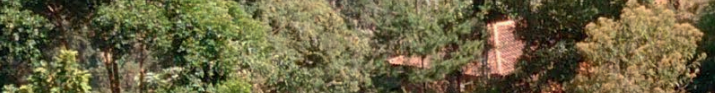

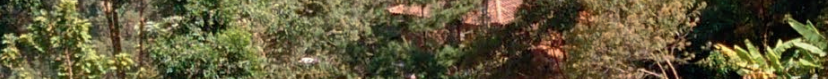

a $10+8=20$ 1.1. Lav itr.

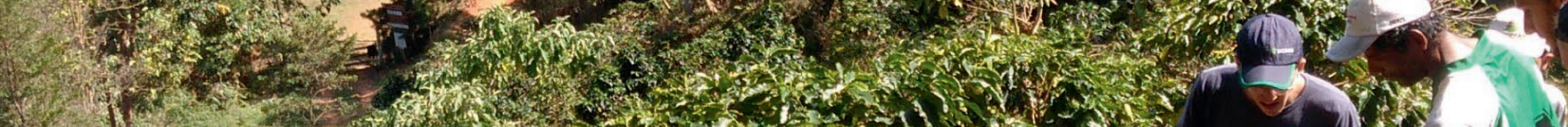

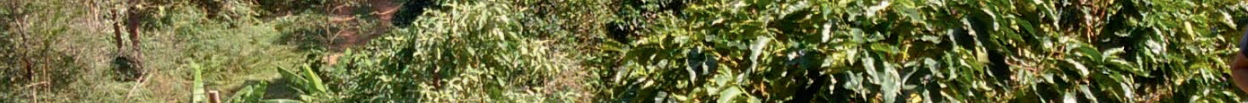

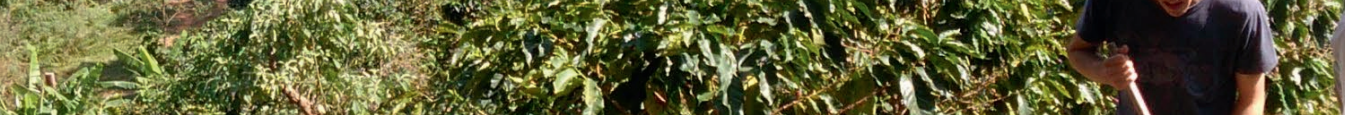

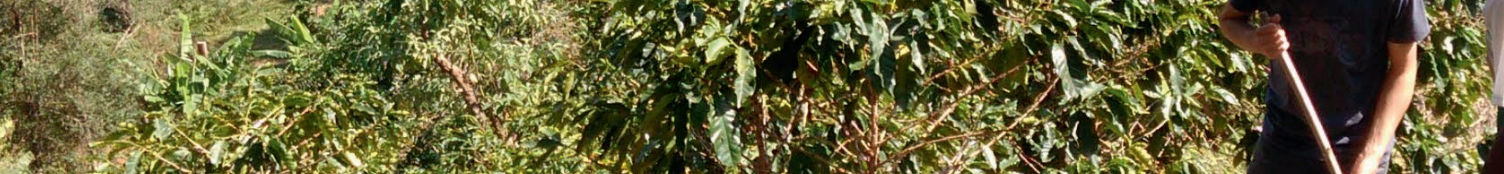
4.

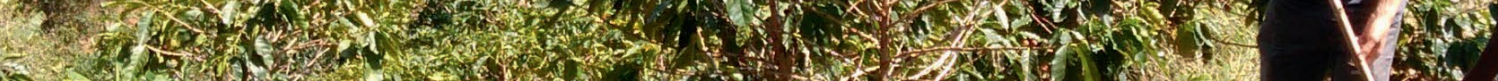
(2) 4 3.

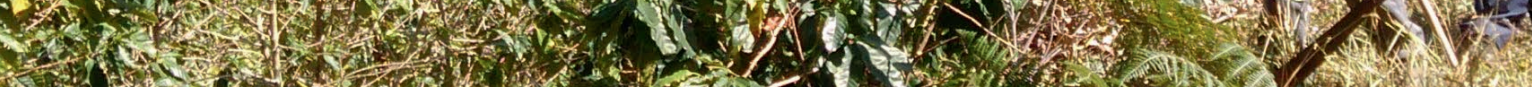

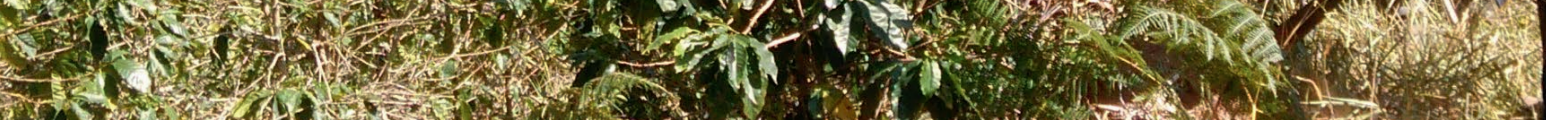
20.3.2. 


\section{Chapter 3}

\section{Farmers show complex and contrasting perceptions on ecosystem services and their management}

This chapter was published as:

Heitor Mancini Teixeira*, Ardjan J. Vermue*, Irene Maria Cardoso, Marielos Peña-Claros, Felix J.J.A. Bianchi, 2018. Ecosystem Services, 33: 44-58.

* Both are first co-authors and have equally contributed to the development of this paper 


\title{
Chapter 3
}

\begin{abstract}
Agricultural systems are complex socio-ecological systems that are managed by farmers to achieve desired outcomes, including food production and other ecosystem services (ES). While farm management is a key factor for ES provision, farmers may widely differ in their awareness, ambition and skills to manage their systems. Currently there is a lack of understanding of farmers' perception on ES, and how this is related to their management. We studied the management and perception of large scale farmers, conventional family farmers and agroecological family farmers in the Zona de Mata region in Brazil. Farmers were interviewed and constructed fuzzy cognitive maps (FCM) of their perception on ES. The FCM analysis revealed that in general, the perception of farmers on ES is highly complex and interconnected. Yet, agroecological family farmers showed a more complex perception on ES, which is associated with more diversified and autonomous agroecosystems. Both agroecological and conventional family farmers had a strong peasant identity, recognising more cultural ecosystem services than large scale farmers and relied more on production for consumption. Initiatives that aim to strengthen on-farm ecosystem services provision should be sensitive to farmer's perceptions and may need to consider using specific strategies for different farmer types.
\end{abstract}


Farmers'perceptions on ecoystem services

\section{Introduction}

With the expansion of human-dominated land use (Foley et al., 2011), agroecosystems hold an increasing share of the global biodiversity (Baudron and Giller, 2014). This has also consequences for the associated provision of ecosystem services (ES), which are broadly defined as the benefits people obtain from nature (MEA, 2005). The ES framework can be useful to systematically identify the multiple benefits provided by agroecosystems, while accounting for the interests of different stakeholder groups, encompassing ecological and social dimensions and exploring the linkages between science, policy and practice (Braat and Groot, 2012). According to the preferences and aspirations of social actors, the provision of particular ES can be recognised and prioritized (Caceres et al., 2015; Lamarque et al., 2014). Since farmers are directly responsible for taking decisions and managing agroecosystems, strategies for promoting the delivery of multiple ES should consider their needs and perceptions to be socially acceptable and transformative (Bernués et al., 2016; Duru et al., 2015b). Yet, farmers constitute a very diverse group of actors (Torquebiau et al., 2012) and their management is influenced by a myriad of factors, including assets, ambitions, social networks, policies, markets, but also by their understanding and perception of the functioning of their agroecosystem. Although farmer's mental constructions may have a great influence on their practices (Vuillot et al., 2016), little is known about farmer's perceptions of ES and how this is related to agroecosystem management (Lamarque et al., 2014; Lescourret et al., 2015; Smith and Sullivan, 2014)

Farmers often have deep experimental knowledge of their systems, in which multiple ES are managed simultaneously. This is challenging because of the many positive, negative and nonlinear relationships among different ES and management practices (Lescourret et al., 2015). Managing multiple ES requires a knowledge-intensive, holistic approach that takes into account 


\section{Chapter 3}

the interactions among economic, social, cultural and ecological aspects (Smith and Sullivan, 2014). Although research efforts have increasingly focused on integrated assessments of ES bundles (Boerema et al., 2016; Costanza et al., 2017a), the factors underlying the social-cultural valuing of multiple ES and their interactions remains under-explored (Caceres et al., 2015; Costanza et al., 2017a). The social-cultural valuing is especially relevant for supporting, regulating and cultural ES, because these services are more difficult to quantify in economic terms (Chan et al., 2012) and their valuation can vary more strongly according to perceptions of social actors (Hein et al., 2016).

The study of farmers' perceptions of ES in relation to their management practices should take their personal aspirations, values and beliefs into account, as well as the functional and structural variables of the farm, such as production orientation and farm size (Vuillot et al., 2016). This requires methodologies that can capture the most important ES and their interactions according to farmers, as well as to identify relevant management and socio-ecological variables (Bennett et al., 2015; Díaz et al., 2011). Here we used fuzzy cognitive maps (FCM) as an integrated research tool to assess how farmers perceive and value the entire bundle of multiple and interconnected ES, and how this perception and valorisation influences their management of the agroecosystem. FCM is a semi-quantitative modelling tool that has been developed to assess and compare knowledge from non-technical experts (Özesmi and Özesmi, 2004)and has been successful in integrating social and ecological sciences (Jetter and Kok, 2014; Kok, 2009; Papageorgiou and Salmeron, 2013). FCM are simple to use in participatory settings (van Vliet et al., 2010), and suitable to deal with inherently complex and subjective concepts (Chan et al., 2012; Reyers et al., 2013). 
Farmers'perceptions on ecoystem services

The objectives of this study were (i) to understand farmers' perceptions on the management and provision of multiple ecosystem services, (ii) to contrast perceptions among farmers belonging to different farm types, and (iii) to explore the linkages between farmers' perceptions, agrobiodiversity and production orientation. For this purpose, the FCM was combined with a farm characterization and on-farm assessment of agrobiodiversity indicators to link farmers' perceptions with farm structural and functional variables.

\section{Material and Methods}

\subsection{Study area}

The study was conducted in the Zona da Mata region, in the South-Eastern part of Minas Gerais, Brazil. It is located in the Atlantic rainforest biome, which is considered the fifth biodiversity hotspot in the world, hosting many unique endemic and threatened species (Myers et al., 2000). The landscape is hilly and is commonly described as a 'sea of hills', because of its geomorphology (Greenfield, 1977). In the eighteenth century, the existing indigenous communities in Zona da Mata faced several conflicts, were colonized and nearly extinguished by the Portuguese invaders. After the colonization, in the nineteenth century, Brazilian aristocratic landlords from other parts of the country were granted great portions of land and established, among other crops, coffee plantations based on slave labour. In the initial growing years, coffee was intercropped with annual crops, such as maize, rice and beans. Since the abolishment of slavery, diverse social dynamics led to the division of land, mainly due to heritage processes as well as land acquisition by landless rural workers (Valverde, 1958). Nowadays, there is a predominance of family farmers, who diversify the use and management of the land in the Zona da Mata. As a result, the region consists of a mosaic of different land uses: pasture, which is often extensive and degraded; coffee, the most important and labour 


\section{Chapter 3}

intensive cash crop, commonly intercropped with maize, beans, cassava and other crops; and forest fragments, often located in protected or less accessible areas. Although homegardens usually only occupy small areas of the farm, they are important for the food sovereignty of the families and host a high diversity of plant and animal species (Oliveira, 2015). There are a variety of national and state public policies targeting family farmers that provide access to credits, market, land and education. However, the development of these policies is challenging and their effectiveness is limited because of bureaucracy, limited involvement of farmers in the creation process, and uncertainty about the continuity of these policies due to governmental changes.

The study was conducted in the three municipalities Araponga, Divino and Espera Feliz, which connect two nature conservation areas: the state park "Serra do Brigadeiro" and the National Park "Caparaó" (Figure 3.1). The municipalities have a unique history of participatory partnerships between the University of Viçosa (UFV), the socio-environmental NGO Centro de Tecnologias Alternativas da Zona da Mata (CTA-ZM), and family farmers' organisations, which along with social and political movements, have resulted in a strong agroecological awareness among family farmers (Cardoso et al., 2001; Cardoso and Mendes, 2014). 
Farmers'perceptions on ecoystem services

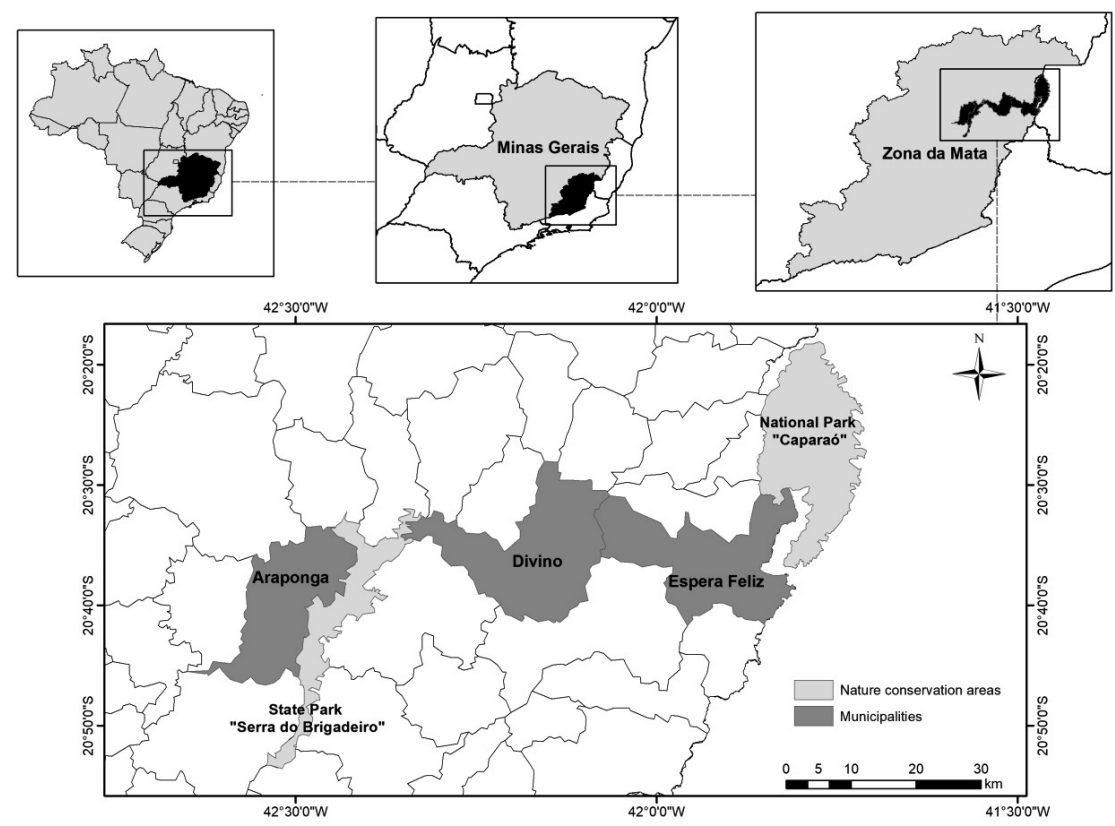

Figure 3.1. Map of studied municipalities in Zona da Mata and areas of nature conservation.

\subsection{Subject definition and selection}

Three farmer types were selected for this study: agroecological family farmers, conventional family farmers (including sharecroppers), and large scale farmers (Teixeira et al., 2018a). Agroecological family farmers did not use synthetic pesticides and were active in social organizations (e.g. unions). Besides selling their coffee to retailers, agroecological family farmers often have access to alternative markets, such as an institutional market supported by public policies, self-organised market fairs, direct selling to the consumers and in small shops. Conventional family farmers mainly sell their coffee to retailers as their main source of income and rely strongly on the use of external inputs. In conventional and agroecological family farms (i) farm labour and management was predominantly provided by family members; (ii) the farm 


\section{Chapter 3}

area was less than 96 hectares; and (iii) the main family income came from rural activities (according to the Brazilian law $n^{\circ} 11.326$ on family farming from 2006). Public policy does not recognise differences between conventional and agroecological family farmers, unless their products are certified as organic. Large scale farms are characterized by farm sizes exceeding 96 ha, reliance on contracted labour and a strong market-orientation. Coffee is managed intensively with high use of inputs and pasture is managed more extensively.

Farmers were selected for interviews using snowball sampling (Klingen et al., 2016; Lamarque et al., 2011), for which we received the first contacts from farmer unions. Once we had a starting point in a municipality, we continued asking farmers to connect us with nearby people in the community representing our focal farmer categories. To avoid remaining stuck in a single social network, we also randomly visited farmers without prior connections. This procedure resulted in the selection of ten agroecological family, nine conventional family and five large scale farmers, which approximately represent the different categories of farmers in the region. The levelling off of new number of factors mentioned per interview across the farmer types confirmed that the sample size of agroecological and conventional farmers were adequate, while this was not the case for large scale farmers (Appendix 3.A) (Özesmi and Özesmi, 2004). However, the relatively low number of large scale farmers reflect the fact that this group encompasses only $18.4 \%$ of farmers in the Zona da Mata (IBGE, 2006).

\subsection{Interviews and fuzzy cognitive map construction}

We conducted individual interviews with farmer families because farm management decisions are usually taken in the family setting. The interviews were centred around the question: "what benefits do you obtain from nature?" We used this starting point to construct a FCM of the 
Farmers'perceptions on ecoystem services

farmer's belief system, consisting of key factors that drive a system and arrows that represent perceived causal relationships among factors. Arrows are weighted with a score representing the strength of associations often linguistically assessed by stakeholders (Papageorgiou and Salmeron, 2013).

The interview consisted of five steps to guarantee that all relevant factors (nodes of the network) were included and that both direct and indirect benefits and beneficial and detrimental effects were addressed. In the first step, an A0 sheet of paper was presented to farmers with a post-it in the centre stating 'Nature's benefits'. Farmers were asked to state what direct benefits they got from their land and nature. The keywords were identified by the facilitator, written on additional post-its and placed on the sheet (Figure 3.2). This included direct services such as production for consumption and the market, water and autonomy. In the second step, farmers were asked what is needed to provide these benefits. This resulted in additional factors placed on the map, and connections between the factors on the post-its were drawn to indicate the associations with other factors. In the third step farmers were asked about negative influences on the provision of ES, if these had not already been mentioned during steps one and two. The fourth step involved the quantification of the strength of the connections (weight of arrows). Farmers could choose from a positive or negative value ranging from 1 to 5 , where 1 is a weak influence and 5 is a strong influence (Figure 3.2). In the fifth step farmers were asked whether there were still factors missing and whether the map represented their personal vision. If this was not the case yet, additional amendments were made until the map reflected the farmers' perception. 


\section{Chapter 3}

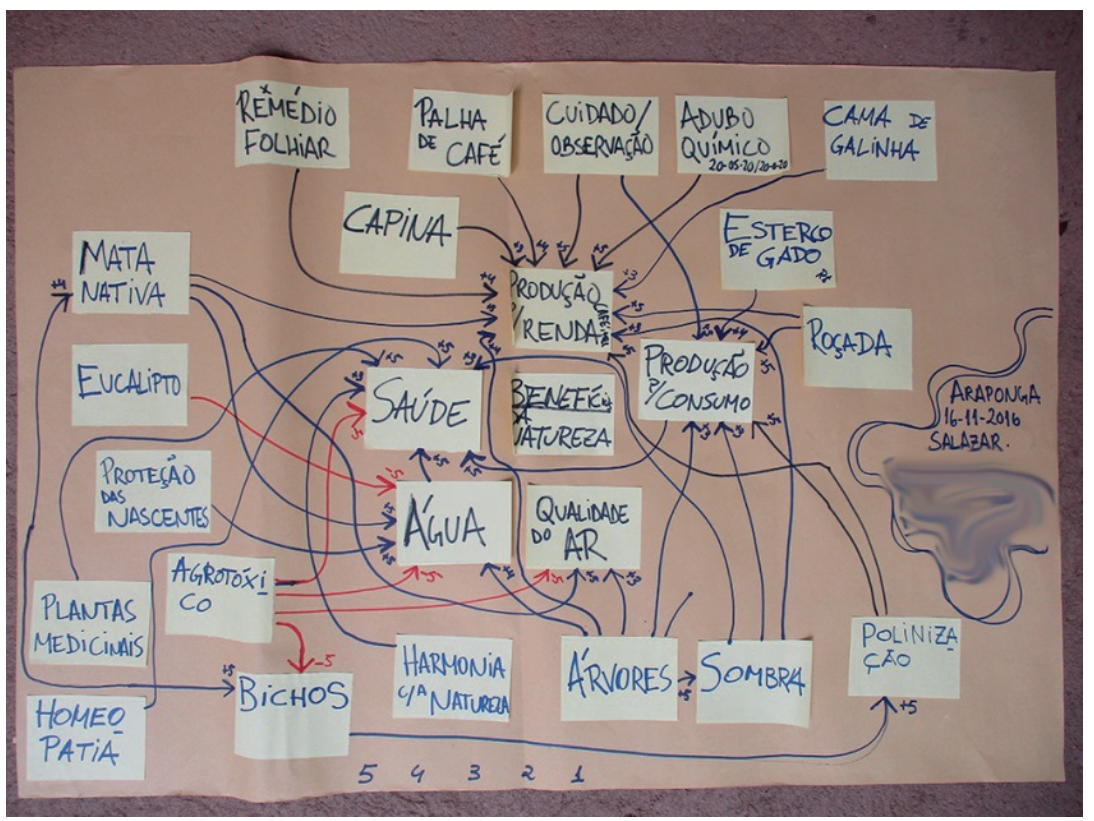

Figure 3.2. Example of a fuzzy cognitive map constructed together with an agroecological farmer in Araponga on 16-11-2016.

The interviews were complemented by an assessment of farm structural and functional variables, including: (1) the number of crop types used for self-consumption and for the market, where vegetable gardens were counted as a single unit; (2) the number of different products sold on the market; (3) number of coffee plants, (4) land area (ha), and (5) the number of tropical livestock units (TLU). For the number of TLU we only considered cattle, and not poultry. We also recorded the number of participants and the duration of the interviews.

\subsection{Fuzzy Cognitive Map analysis}

Fuzzy Cognitive Maps (FCM) were constructed together with farmers in each farm and analysed by assessing the following FCM indices: number of factors (nodes), connections (arrows) and 
the type of factors (transmitter, receiver and ordinary variables). Transmitter variables only have outgoing arrows, indicating a forcing factor, which cannot be influenced by other factors in the system. Receiver variables only have ingoing arrows, indicating that these factors can be controlled by other factors in the system. Ordinary variables have both in- and outgoing arrows, indicating factors that can both be influenced and have an influence on other factors in the system (Özesmi and Özesmi, 2004). The FCM indices were calculated using graph theory (Özesmi and Özesmi, 2004). The cognitive map data were coded into adjacency matrices in the form $A(D)=[a i j]$, where the elements aij represent the strength of a connection from vertex i to vertex $\mathrm{j}$, with zero values meaning no connection (see Appendix 3.B for an example). The identified factors (nodes, variables v) are both listed on the vertical axis (vi) and on the horizontal axis (vj). The strengths (weights) of the arrows on the A0 sheets were rescaled to a range from 0.1 to 0.9 (positive connections) and -0.1 to -0.9 (negative connections) for input in the FCM model (Kok, 2009). The centrality of factors was determined by the sum of absolute weights of in- and outgoing arrows. In addition, factors were categorised as direct ES, intermediate ES, ecosystem component, external input, management practice or socioeconomic aspect. Direct ES are final services from which humans can directly benefit, which includes provisioning and cultural ES, while intermediate ES include regulating and supporting ES, which have a mediating function to generate direct ES.

The FCM from individual farmers were combined to obtain one social FCM for each farmer type (agroecological family, conventional family and large scale farmers) and one social FCM at regional level, including all 24 farmers. The social FCM is created by merging the factors and summing the connections between the same factors of all farmers in the group. The weight of the connections was divided by the number of farmers per group to derive mean centrality 


\section{Chapter 3}

scores. Positive and negative connections between the same factors cancelled each other out. To improve the visual presentation of the social FCM (Figures 3.3a, b and c), factors were only included when mentioned by at least two farmers, or had a weighted centrality score higher or equal to 0.50 . The centrality scores of the factors (nodes) and relative weighs of connections (arrows) derived from the social maps are mentioned throughout the text. Statistical analyses were based on all factors and connections of the social FCM, which are not necessarily depicted in Figure 3.3.

\subsection{Statistical analysis}

To assess differences on perceptions and agroecosystem management among farmer types, FCM indices and farm structural and functional variables were analysed with parametric and non-parametric statistical tests. ANOVA was used for normally distributed data with equal variances, and otherwise by Kruskal-Wallis tests when normality criteria were not met. Normality was assessed using a Shapiro-Wilk test with 0.05 significant levels and a Q-Q plot; equal variances were assessed using Levene's test. Significant ANOVA tests were followed up with a pairwise comparisons between groups using a Games-Howell post-hoc test, recommended for unequal variances and group sizes (Field, 2017). Significant Kruskal-Wallis tests were further analysed by pairwise comparisons using a Dunn test with a Benjamini \& Hochberg (BH) adjustment for false discovery rate control (Benjamini and Hochberg, 1995). We used logistic regression analysis for binomially distributed variables, which were followed by a post-hoc test with a Bonferroni adjustment. Factors that were significant at the $\mathrm{P}<0.10$ level were further analysed using a rotated Principal Components Analysis (PCA) to assess the associations with farm structural and functional variables. A Pearson's correlation matrix was 


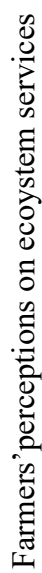

宅号

过

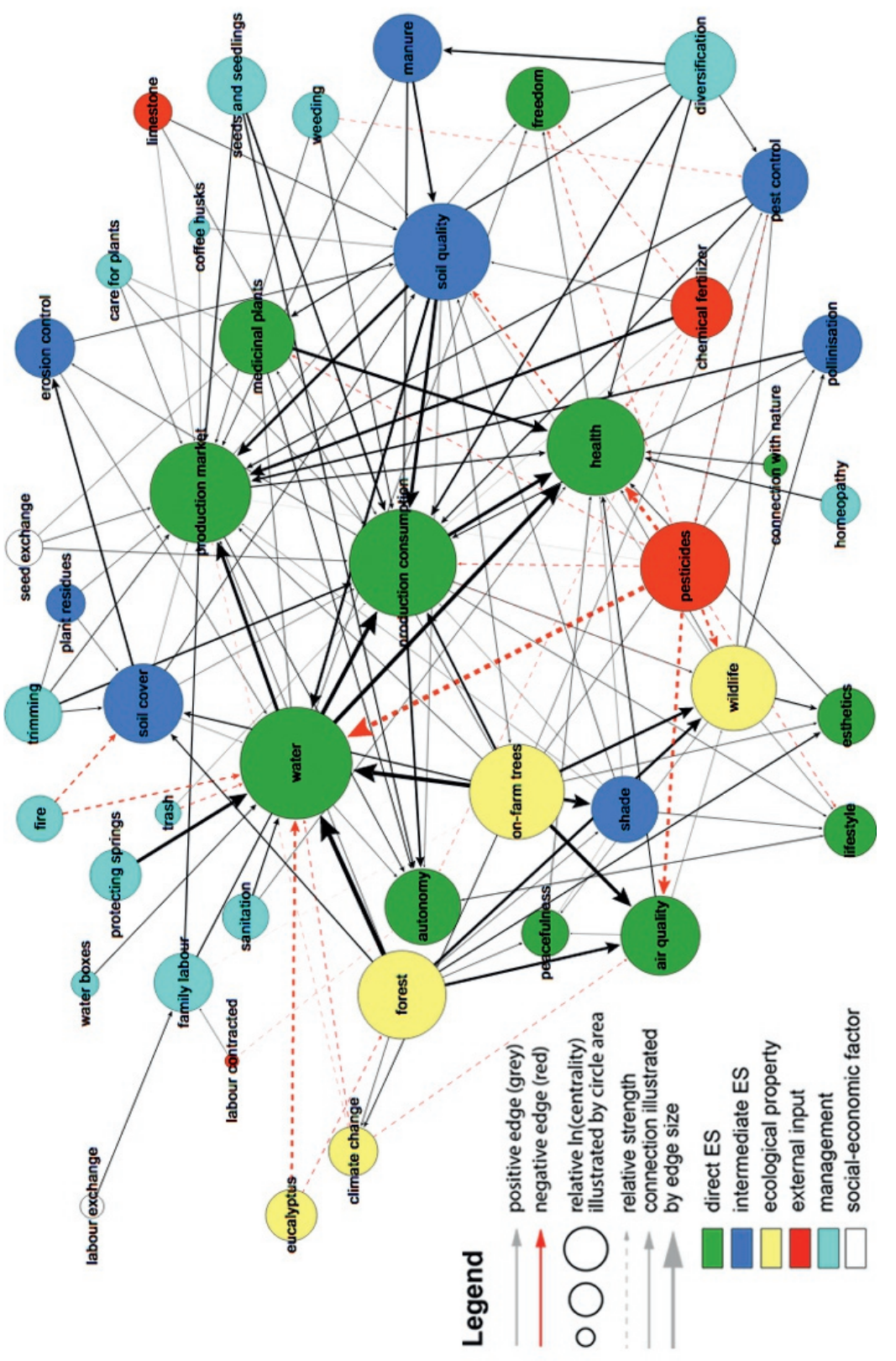

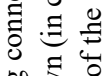

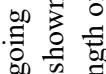

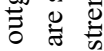

흥ํํ류

$\Xi \wedge 1 \frac{\pi}{0}$

पे

苟离泀

矛

苛

完 壳

吉芯芯

焉

空突冚

㐘

位泀兽

11 ฮี

$\Xi \gtrsim$

氙 豈

言 总

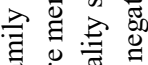

密

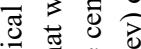

हू요

웅 क्ञ

总㥕

पू

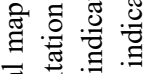

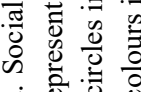

๙ 잉

m. సٓ

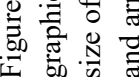



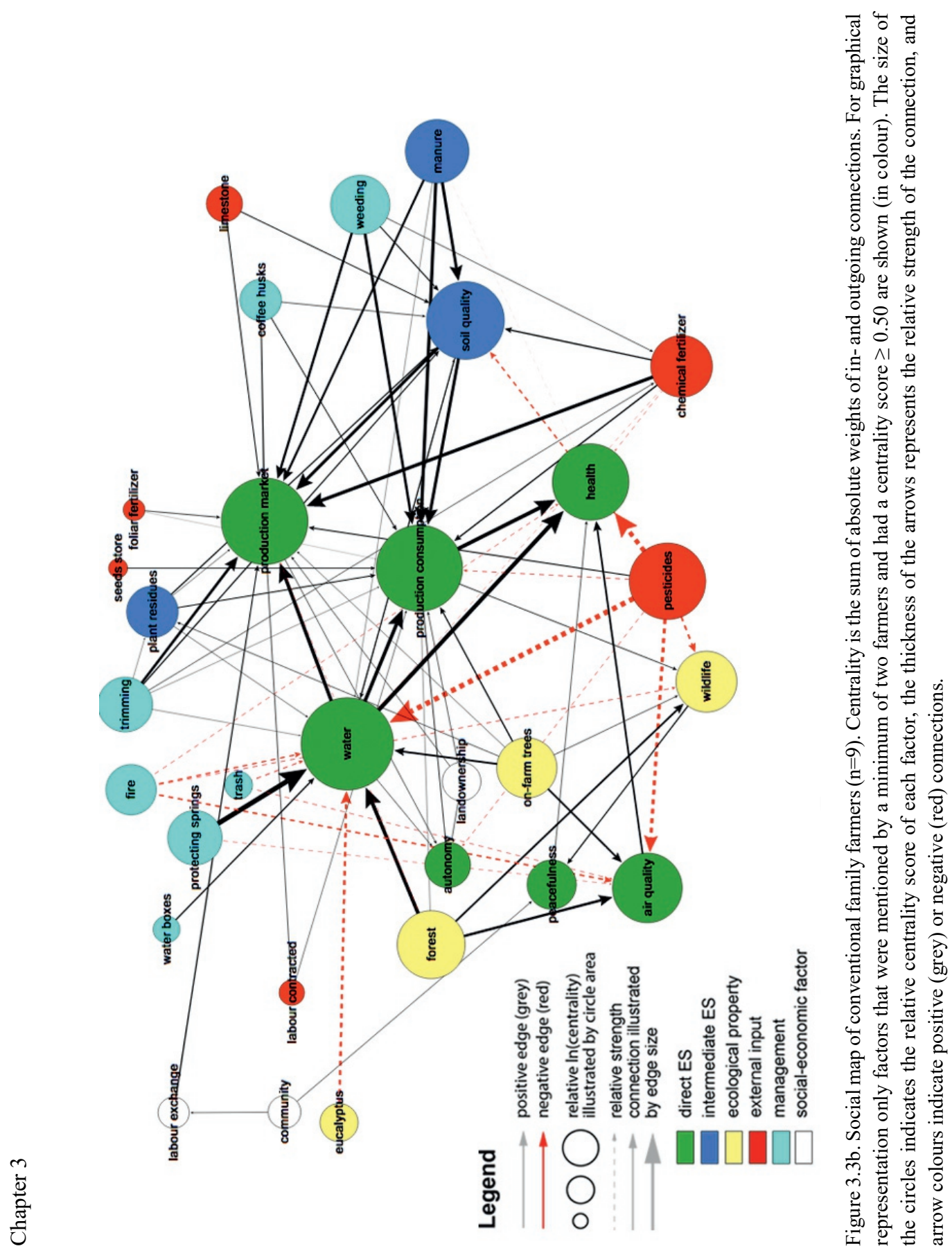
0
0
0
0
0
0
0
0
0
0
0
0
0
0
0
0
0
0
0
0
0
0
0
त
I

总芯

竎造总

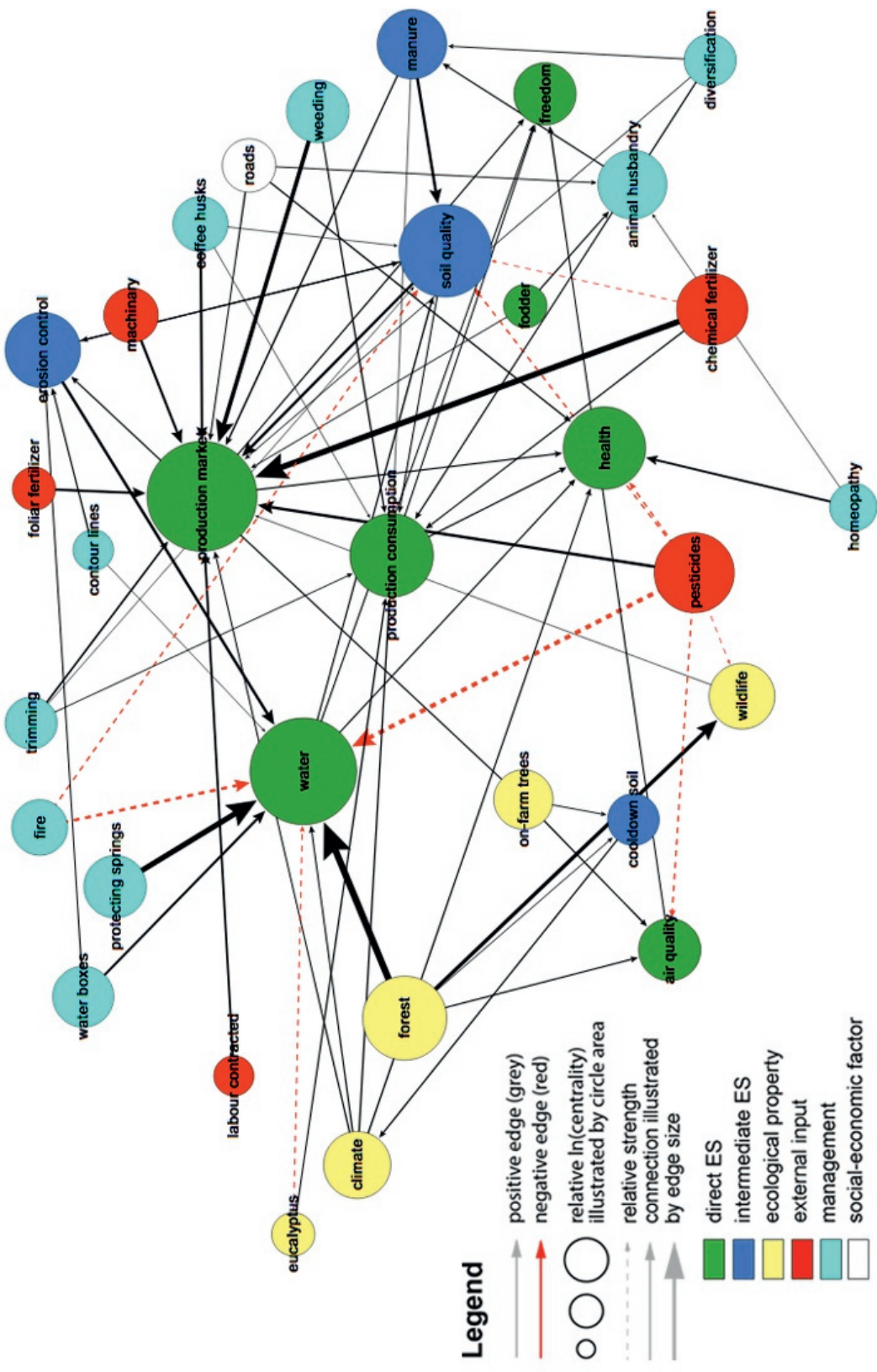

氖

कo

现

웡

○ $\cong \Xi$

突

ठิ

두

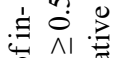

응

营

司资

节 范

需

苍焉

氙

氠

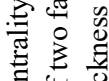

过

穴寻

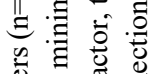

ब

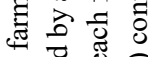

品

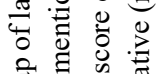

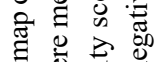

豞产哥

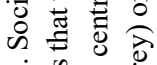

ஸे

ஸे

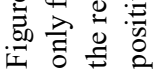




\section{Chapter 3}

computed to exclude any cases of multicollinearity $(\mathrm{R}>0.8)$ or singularity (majority of $\mathrm{R}<$ 0.3). The number of extract components were based on the screen plot (see Appendix 3.C) and a minimum of three communalities with a score $>0.7$ (Appendix 3.C) (Field, 2017). We use a significance level of $\mathrm{P}<0.05$ unless otherwise indicated and report $\mathrm{p}$-values of post-hoc tests throughout the text. The statistical analyses were conducted in SPSS v.23.0 (Mac) and R 3.3.2 (Mac).

\section{Results}

In 24 interviews farmers identified a total of 104 different factors and 363 connections (Appendix 3.D). The factors were categorised as direct ES (18), intermediate ES (16), ecosystem properties (13), external inputs (10), management practices (31) and socioeconomic aspects (16). The FCM highlighted that agroecological family, conventional family and large scale farmers differed in their perceptions of the agroecosystem. Agroecological family farmers identified significantly more connections per FCM than conventional family and large scale farmers $(\mathrm{p}=0.006$, and $\mathrm{p}=0.005$, respectively; Table 3.1$)$ and more ordinary variables (i.e. factors with both in and out-going arrows; $\mathrm{p}=0.005$, and $\mathrm{p}=0.003$, respectively; Table 3.1 ), indicating that agroecological family farmers have more complex perception of their system. Agroecological family farmers mentioned significantly fewer external inputs than conventional family $(\mathrm{p}=0.023)$ and large scale farmers $(\mathrm{p}=0.007$; Table 3.1). Both agroecological and conventional family farmers recognised significantly more direct ES than large scale farmers ( $p=0.002$, and $p=0.007$, respectively; Table 3.1 ). No significant differences were found among farmer types for number of ecosystem components, management and socioeconomic factors. 
Farmers'perceptions on ecoystem services

Table 3.1. Overview results FCM indices, number of factors per category and additional indicators between farm types. 'Marginally significant at $\mathrm{p}<.1$; * Significant at $\mathrm{p}<.05$; ** Significant at $\mathrm{p}<.005$

\begin{tabular}{|c|c|c|c|c|c|}
\hline & $\begin{array}{l}\text { Statistical } \\
\text { test }\end{array}$ & p-value & $\begin{array}{l}\text { Agroecological } \\
(n=10)\end{array}$ & $\begin{array}{l}\text { Conventional } \\
(n=9)\end{array}$ & $\begin{array}{l}\text { Large-scale } \\
(n=5)\end{array}$ \\
\hline & & & $\overline{\mathrm{x}} \pm \mathrm{SE}$ & $\overline{\mathrm{x}} \pm \mathrm{SE}$ & $\overline{\mathrm{x}} \pm \mathrm{SE}$ \\
\hline $\begin{array}{l}\text { Interview time } \\
\text { (minutes) }\end{array}$ & $\begin{array}{l}\text { Kruskal- } \\
\text { Wallis }\end{array}$ & 0.282 & $64 \pm 4.4$ & $60 \pm 4.7$ & $47 \pm 4.0$ \\
\hline Factors (nr.), $N$ & ANOVA & $0.099^{\circ}$ & $22.7 \pm 1.6$ & $19.8 \pm 1.8$ & $21.2 \pm 1.2$ \\
\hline $\begin{array}{l}\text { Connections (nr.), } \\
C\end{array}$ & $\begin{array}{l}\text { Kruskal- } \\
\text { Wallis }\end{array}$ & $0.004^{* *}$ & $37.0 \pm 2.1^{\mathrm{a}}$ & $29.3 \pm 2.3^{b}$ & $26.2 \pm 2.2^{b}$ \\
\hline $\begin{array}{l}\text { Transmitter } \\
\text { variables (nr.), } T\end{array}$ & $\begin{array}{l}\text { Kruskal- } \\
\text { Wallis }\end{array}$ & $0.093^{\circ}$ & $11.5 \pm 1.7$ & $12.0 \pm 1.7$ & $14.4 \pm 0.9$ \\
\hline $\begin{array}{l}\text { Receiver } \\
\text { variables (nr.), } R\end{array}$ & $\begin{array}{l}\text { Kruskal- } \\
\text { Wallis }\end{array}$ & 0.976 & $2.7 \pm 1.3$ & $2.8 \pm 1.2$ & $2.4 \pm 0.9$ \\
\hline $\begin{array}{l}\text { No. of ordinary } \\
\text { variables, } O\end{array}$ & $\begin{array}{l}\text { Kruskal- } \\
\text { Wallis }\end{array}$ & $0.002 * *$ & $8.5 \pm 1.6^{\mathrm{a}}$ & $5.0 \pm 1.0^{\mathrm{b}}$ & $3.3 \pm 1.3^{b}$ \\
\hline Direct ES (nr.) & $\begin{array}{l}\text { Kruskal- } \\
\text { Wallis }\end{array}$ & $0.005^{* *}$ & $6.20 \pm 0.42^{\mathrm{a}}$ & $5.67 \pm 0.26^{\mathrm{a}}$ & $3.40 \pm 0.51^{\mathrm{b}}$ \\
\hline $\begin{array}{l}\text { Intermediate ES } \\
\text { (nr.) }\end{array}$ & $\begin{array}{l}\text { Kruskal- } \\
\text { Wallis }\end{array}$ & $0.058^{\bullet}$ & $3.40 \pm 0.69$ & $1.33 \pm 0.37$ & $2.40 \pm 0.68$ \\
\hline $\begin{array}{l}\text { Ecosystem } \\
\text { component (nr.) }\end{array}$ & $\begin{array}{l}\text { Kruskal- } \\
\text { Wallis }\end{array}$ & 0.337 & $2.70 \pm 0.40$ & $2.11 \pm 0.26$ & $2.60 \pm 0.25$ \\
\hline Management (nr.) & $\begin{array}{l}\text { Kruskal- } \\
\text { Wallis }\end{array}$ & 0.385 & $6.80 \pm 0.76$ & $6.22 \pm 0.74$ & $7.80 \pm 0.20$ \\
\hline $\begin{array}{l}\text { Socioeconomic } \\
\text { (nr.) }\end{array}$ & $\begin{array}{l}\text { Kruskal- } \\
\text { Wallis }\end{array}$ & 0.944 & $1.20 \pm 0.51$ & $1.00 \pm 0.37$ & $1.00 \pm 0.32$ \\
\hline $\begin{array}{l}\text { External input } \\
\text { (nr.) }\end{array}$ & $\begin{array}{l}\text { Kruskal- } \\
\text { Wallis }\end{array}$ & $0.010 *$ & $2.40 \pm 0.27^{\mathrm{a}}$ & $3.44 \pm 0.34^{\mathrm{b}}$ & $4.00 \pm 0.32^{\mathrm{b}}$ \\
\hline $\begin{array}{l}\text { Crop diversity } \\
\text { (nr.) }\end{array}$ & ANOVA & $0.008 *$ & $19.9 \pm 3.3^{\mathrm{a}}$ & $9.1 \pm 1.5^{\mathrm{b}}$ & $8.2 \pm 2.4^{b}$ \\
\hline $\begin{array}{l}\text { Types of products } \\
\text { sold }\end{array}$ & $\begin{array}{l}\text { Kruskal- } \\
\text { Wallis }\end{array}$ & $0.013^{*}$ & $11.7 \pm 4.5^{\mathrm{a}}$ & $1.44 \pm 0.9^{\mathrm{b}}$ & $1.8 \pm 0.6^{\mathrm{ab}}$ \\
\hline $\begin{array}{l}\text { Total number of } \\
\text { coffee plants (nr.) }\end{array}$ & $\begin{array}{l}\text { Kruskal- } \\
\text { Wallis }\end{array}$ & $0.004 * *$ & $11,560 \pm 99.9^{a}$ & $9,056 \pm 67.0^{\mathrm{a}}$ & $\begin{array}{l}100,000 \pm \\
265.2^{b}\end{array}$ \\
\hline Farm size (ha) & $\begin{array}{l}\text { Kruskal- } \\
\text { Wallis }\end{array}$ & $0.003 * *$ & $9.0 \pm 2.9^{\mathrm{a}}$ & $5.2 \pm 1.8^{\mathrm{a}}$ & $107.6 \pm 9.3^{\mathrm{b}}$ \\
\hline $\begin{array}{l}\text { Tropical } \\
\text { Livestock Unit, } \\
T L U\end{array}$ & $\begin{array}{l}\text { Kruskal- } \\
\text { Wallis }\end{array}$ & $0.003 * *$ & $3 \pm 1.3^{\mathrm{a}}$ & $4.6 \pm 2.0^{\mathrm{a}}$ & $131.6 \pm 66.1^{b}$ \\
\hline
\end{tabular}

The analysis of farm structural and functional variables showed that agroecological family farmers had a significantly higher number of crops than large scale farmers $(p=0.023)$ and 


\section{Chapter 3}

conventional family farmers $(\mathrm{p}=0.024)$, and also sold significantly more products than conventional farmers ( $\mathrm{p}=0.005$; Table 3.1 ). Yet, the number of products sold by agroecological and large scale farmers was not significantly different (Table 3.1).

The PCA indicated a relatively clear grouping of agroecological family, conventional family and large scale farms (Figure 3.4).

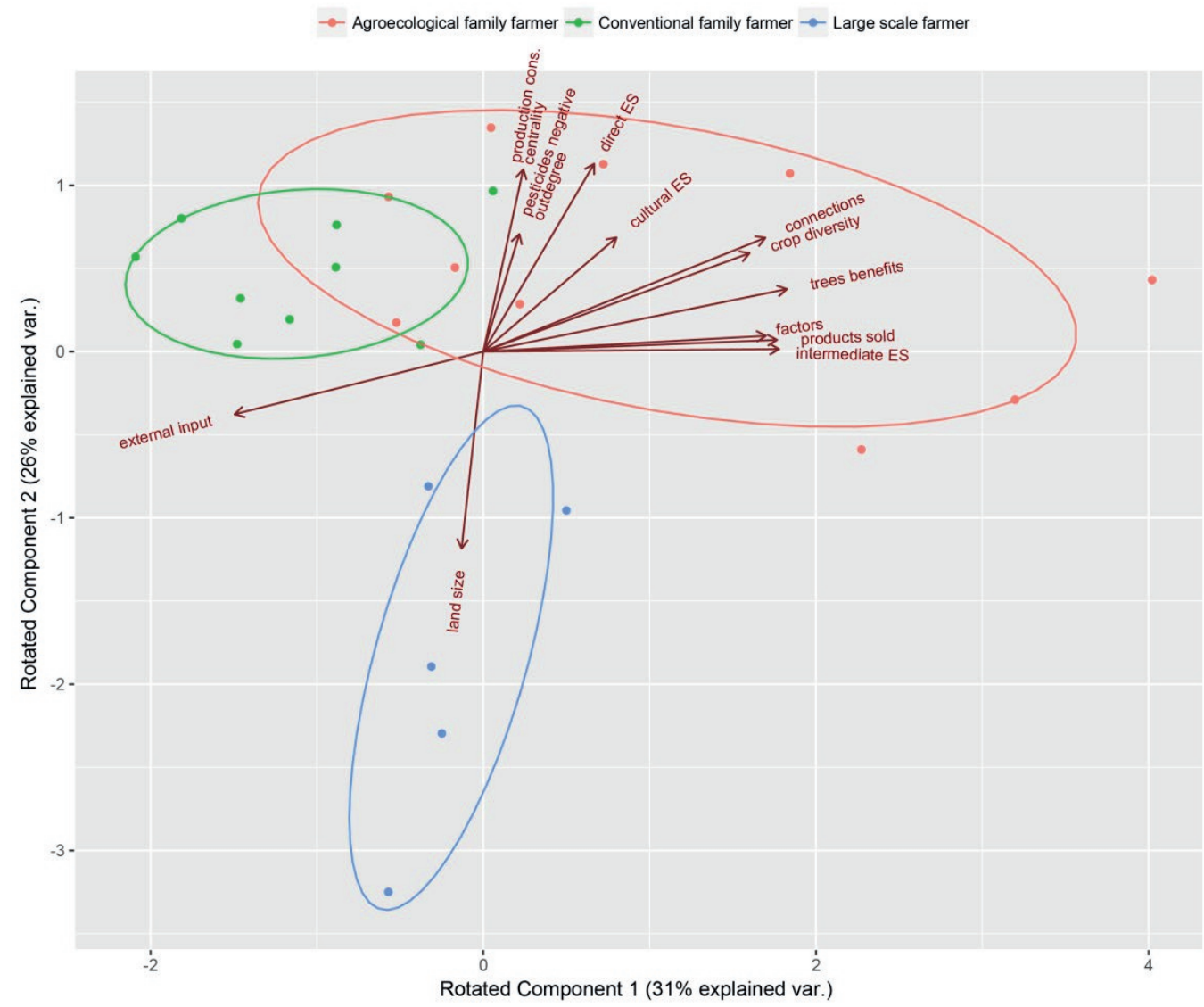

Figure 3.4. Rotated PCA of all (marginally) significant results from the fuzzy cognitive maps indicators, agrobiodiversity indicators and farm size. Factors with multicollinearity $(\mathrm{R}>0.8)$ or singularity (majority of $\mathrm{R}<0.3$ ) were excluded from the analysis. 
The first PCA axis explained $31 \%$ of the total variation, and was strongly correlated to the number of factors mentioned in the FCM, crop diversity, products sold and trees benefits ( $\mathrm{R}>0.60$; Appendix 3.C). This axis can be interpreted as complexity of perception and farming systems, with agroecological farmers on the right and conventional farmers on the left side of the spectrum. The second axis explained $26 \%$ of the total variation and separated large farmers from family farmers. This axis can be interpreted as farm size, with family farming along the upper end and large scale farming along the lower end of the spectrum.

\section{Interpretation of social FCM per farm type}

The FCM revealed seven major themes that are detailed below (Table 3.1 and 3.2, Figure 3.3a, b, c): importance of water, role of trees, pesticides, peasant farming (labour and food sovereignty), cultural ES, ecosystem components and intermediate services.

\subsection{Importance of water}

Water was mentioned by all 24 farmers, and it was the most central factor for agroecological and conventional family farmers, and the second most central factor for large scale farmers. There has been a long drought from 2012 to 2016, resulting in springs drying up and reduced yields. This finding shows the importance and the dependence of farmers on water as a primary ES. There was a significant difference between family (agroecological and conventional) farmers and large scale farmers in how water is perceived to affect other factors in the system (logistic regression, Table 3.2). Ninety-five percent (18/19) of family farmers considered water to be an ordinary variable (having both in- and outgoing arrows), compared to $40 \%(2 / 5)$ of large farmers. The other three large farmers consider water as a receiver variable, which has no direct influence on other factors in the system. Based on the community representation of all 


\section{Chapter 3}

farmers, the five most important factors that positively influenced water were forest (a relative weight of 0.65$)$, protecting springs $(0.64)$, trees $(0.35)$, soil quality $(0.21)$ and water boxes used to collect water $(0.21)$. These factors represent $74 \%$ of the total positive indegree of water (the sum of absolute weights of positive ingoing arrows). The three strongest negative factors influencing the availability and/or quality of water were pesticides (-0.67), Eucalyptus trees (0.28 ) and fire (-0.22). These factors represent $72 \%$ of the total negative indegree of water. Water is considered most important for health (relative weight 0.52 ), production for consumption (0.43) and production for the market (0.40), representing $80 \%$ of the total outdegree of water (the sum of absolute weights of outgoing arrows).

\subsection{Role of trees}

The factor "trees" include all trees in and surrounding arable fields and homegardens. Trees were mentioned by 15 out of the 24 farmers. There was a significant difference regarding the role of trees between farmer types. The centrality of trees is higher for agroecological family farmers than for conventional family $(p=0.036)$ and large scale farmers $(p=0.021)$. Agroecological family farmers also recognised more benefits from trees than conventional family $(\mathrm{p}=0.0127)$ and large scale farmers do $(\mathrm{p}=0.025$; Table 3.2$)$. This difference highlights the perceived multi-functionality of trees in agroecosystems by agroecological family farmers. For instance, the benefit of shade provided by trees was only mentioned by agroecological family farmers, and the benefit of trees on water, production for consumption and wildlife was only recognised by agroecological and conventional family farmers, but not by large scale farmers. All farmer types recognised the positive effect of trees on air quality and indirectly on soil quality, through soil cover, plant residues and erosion control. Based on the community representation of all farmers, trees contribute most to air quality and water (both a relative 
weight of 0.35$)$, production for consumption (0.20), wildlife (0.19) and shade (0.18). These represent $70 \%$ of all outdegree of trees.

\subsection{Pesticides}

Pesticides were mentioned by all 24 farmers. Agroecological and conventional family farmers perceived a stronger negative influence of pesticides on ecosystem properties and the delivery of ES than large scale farmers ( $p=0.019$ and $p=0.035$, respectively; Table 3.2). Agroecological family farmers do not apply pesticides, whereas conventional family farmers apply pesticides themselves and large farmers often hire employees to do so. Large scale farmers recognised significantly more positive benefits of pesticides than agroecological family farmers $(p=0.007$; Table 3.2). For the community of farmer types, the main identified negative impacts of pesticides were on health (a relative weight of -0.70$)$, water $(-0.67)$, air quality $(-0.37)$, wildlife $(-0.23)$ and soil quality $(-0.19)$. These represent $89 \%$ of all negative outdegree of pesticides.

\subsection{Peasant farming: labour and food sovereignty}

Agroecological and conventional family farmers had a significantly smaller farm size, lower number of coffee plants and Tropical Livestock Units than large scale farmers (Table 3.1). The community dynamics of agroecological and conventional family farmers were different from large scale farmers. For instance, family farmers made use of their social network to acquire labour, mentioning labour exchange, family and the community as means to maintain agricultural production, whereas large scale farmers only referred to contracted labour. The production for consumption (food sovereignty) was significantly more central for agroecological family farmers than large scale farmers ( $p=0.023$; Table 3.2). Large scale farmers 


\section{Chapter 3}

typically did not produce their own food, whereas all family farmers in this study had at least a small homegarden to produce food for home consumption.

Table 3.2. Summary of statistics used for the interpretation of social maps per farm type. Centrality is the sum of absolute weights of in- and outgoing connections (see Figure 3.4). 'Marginally significant at $\mathrm{p}<.1 ; *$ Significant at $\mathrm{p}<.05 ; * *$ Significant at $\mathrm{p}<.005$.

\begin{tabular}{|c|c|c|c|c|c|}
\hline FCM interpretation & Statistical test & p-value & $\begin{array}{l}\text { Agroecological } \\
(\mathrm{n}=10)\end{array}$ & $\begin{array}{l}\text { Conventional } \\
(\mathrm{n}=9)\end{array}$ & $\begin{array}{l}\text { Large-scale } \\
(\mathrm{n}=5)\end{array}$ \\
\hline & & & $\overline{\mathrm{x}} \pm \mathrm{SE}$ & $\overline{\mathrm{x}} \pm \mathrm{SE}$ & $\overline{\mathrm{x}} \pm \mathrm{SE}$ \\
\hline Water (centrality) & ANOVA & 0.976 & $6.56 \pm 0.52$ & $6.33 \pm 0.52$ & $4.90 \pm 0.85$ \\
\hline $\begin{array}{l}\text { Water considered as an } \\
\text { ordinary variable } \\
\text { (yes/no) }\end{array}$ & $\begin{array}{l}\text { Logistic } \\
\text { regression }\end{array}$ & $0.015^{*}$ & $90 \%$ & $100 \%$ & $40 \%$ \\
\hline Trees (centrality) & Kruskal-Wallis & $0.030^{*}$ & $3.17 \pm 0.60^{\mathrm{a}}$ & $1.18 \pm 0.48^{b}$ & $0.64 \pm 0.40^{\mathrm{b}}$ \\
\hline $\begin{array}{l}\text { Benefits from trees } \\
\text { (nr.) }\end{array}$ & Kruskal-Wallis & $0.017^{*}$ & $4.10 \pm 0.77^{\mathrm{a}}$ & $1.22 \pm 0.49^{\mathrm{b}}$ & $0.80 \pm 0.49^{b}$ \\
\hline $\begin{array}{l}\text { Pesticides (negative } \\
\text { outdegree) }\end{array}$ & Kruskal-Wallis & $0.047^{*}$ & $-2.59 \pm 0.24^{\mathrm{a}}$ & $-2.61 \pm 0.23^{\mathrm{a}}$ & $\begin{array}{l}-1.18 \pm \\
0.49^{\mathrm{b}}\end{array}$ \\
\hline $\begin{array}{l}\text { Pesticides (positive } \\
\text { outdegree) }\end{array}$ & Kruskal-Wallis & $0.018^{*}$ & $0.07 \pm 0.05^{\mathrm{a}}$ & $0.17 \pm 0.18^{\mathrm{ab}}$ & $0.38 \pm 0.27^{\mathrm{b}}$ \\
\hline $\begin{array}{l}\text { Production } \\
\text { consumption } \\
\text { (centrality) }\end{array}$ & Kruskal-Wallis & $0.052^{\circ}$ & $5.14 \pm 0.73^{\mathrm{a}}$ & $4.56 \pm 0.40^{\mathrm{ab}}$ & $1.78 \pm 1.16^{\mathrm{b}}$ \\
\hline Cultural ES (nr.) & Kruskal-Wallis & $0.043^{*}$ & $1.60 \pm 0.22^{\mathrm{a}}$ & $1.00 \pm 0.29^{\mathrm{ab}}$ & $0.40 \pm 0.25^{\mathrm{b}}$ \\
\hline Forest (centrality) & Kruskal-Wallis & 0.745 & $2.24 \pm 1.85$ & $1.76 \pm 1.02$ & $1.86 \pm 0.35$ \\
\hline Wildlife (centrality) & Kruskal-Wallis & 0.323 & $2.00 \pm 0.52$ & $1.22 \pm 0.48$ & $0.84 \quad 0.38$ \\
\hline
\end{tabular}

\subsection{Cultural ES}

Agroecological family farmers identified significantly more cultural ES as compared to large scale farmers $(\mathrm{p}=0.014$; Table 3.2), but there was no significant difference between agroecological and conventional family farmers. The most important cultural ES for the community of farmers as a whole were autonomy (centrality score of 0.72 ), freedom $(0.57)$, lifestyle (0.42), peacefulness (0.40) and aesthetics (0.38), representing $93 \%$ of the total cultural ES. For agroecological family farmers, autonomy (centrality score of 1.32) was by far the most central factor out of all cultural ES, for conventional family farmers it was the third highest 
cultural ES (0.54) and large farmers did not mention autonomy at all, indicating that this is not a concern for them.

\subsection{Ecosystem components}

For the community of farmers, the three most central ecosystem components were forest (centrality score of 1.97$)$, trees (1.87) and wildlife (1.47), representing $79 \%$ of the centrality of all ecosystem components combined. Based on the centrality scores, no significant differences were found for the centrality of forest and wildlife among farmer types (Table 3.2).

\subsection{Intermediate $E S$}

Intermediate services were recognised as ordinary variables in $81 \%$ of all cases, indicating that farmers recognised both (i) how intermediate ES can be influenced (managed) by other factors in the system, and (ii) how they exert an influence on other factors (mostly direct ES) in the system. Soil quality has the highest centrality score (2.97) of all intermediate ES mentioned by all farmer types. Agroecological farmers recognised 20 different factors influencing soil quality, conventional farmers 9, and large farmers 11 factors. Based on the social FCM for all farmers, soil quality is most strongly influenced by manure (score of 8.6 ), pesticides (-4.5), limestone (3.5), plant residues (including tree`s residues) (2.7) and water (2.7), representing 50\% of all indegree of soil quality. Soil quality influences production (both for the market and selfconsumption; score of 9.9) and water (5.0), representing 73\% of all outdegree of soil quality. Only agroecological farmers recognised soil cover (5/10) and pollination (3/10) as an intermediate ES, with a centrality score of 0.64 and 0.27 , respectively. Four out of ten agroecological farmers and one out of nine conventional farmer recognised natural pest control as an intermediate ES. 


\section{Chapter 3}

\section{Discussion}

Our study shows that (i) the perception of farmers on ES and their management is highly complex and interconnected, (ii) agroecological family, conventional family and large scale farmers have different perceptions of ES, and (iii) a more complex perception on ES is associated with more diversified and autonomous agroecosystems.

\subsection{Farmer's perceptions on ES provision}

The FCM showed that farmer's perceptions on ES and their management is complex, in particular for agroecological farmers. Asking farmers about their perceived benefits of nature without an a priori defined list of options brought forward a multiplicity of services that farmers value from their agroecosystems (Figure 3.3, Appendix 3.D). Farmers did not use specifically the concept of biodiversity as an ES, but would identify ecosystem components, such as onfarm trees, forest and wildlife, to provide intermediate services dependent on biodiversity, such as pest control, pollination, erosion control and seed dispersal. This is in line with most recent frameworks in which biodiversity and ecosystems have their own intrinsic value, but at the same time contribute to human well-being through the provision of ES (Díaz et al., 2015). These results also showed that farmers understand the complex and interconnected relationships between several ES and different aspects of the agroecosystem, such as management, ecosystem components and external inputs (Figure 3.3). Consequently, studies that focus in one or two ES in isolation can only provide a limited understanding of the inherent complexity of the subject (Berthet et al., 2016). This is particularly relevant for assessments of realistic management scenarios because these scenarios encompass social and ecological multiplicities emerging from the interactions among local actors, agricultural management, natural conditions, and ecosystem properties and functions (Balvanera et al., 2014). In addition, farmers identified direct and 
Farmers'perceptions on ecoystem services

intermediate services that benefit themselves (excludable), such as production for consumption, health and autonomy, but also services that serve society as a whole (non-excludable), such as water provision, production for the market, air quality and aesthetics (Fisher et al., 2009). Most cultural ES identified were intrinsic to being a farmer, such as autonomy, lifestyle and learnings from nature (Chan et al., 2012).

\subsection{Contrasting farmers' perceptions}

Agroecological family farmers, conventional family farmers and large scale farmers showed contrasting perceptions of ES. The differences in perceptions between family farmers and large scale farmers can be explained by the distinction between peasant farming and capitalist farming (van der Ploeg, 2008). The peasant way of farming is characterised by a co-production with nature, building upon a resource base in which diversification strategies increase ES delivery, enhance agroecosystems resilience, reduce the reliance on external inputs, generate a variety of income streams from multiple crops, and increase food sovereignty (Bennett et al., 2015; van der Ploeg, 2010). Indeed, both agroecological and conventional family farmers recognised more direct ES, and produced more food for home consumption than large scale farmers, for instance in home gardens. Family farmers also recognised a stronger negative impact of pesticides (Table 3.2) than large scale farmers, since they apply pesticides in the field themselves (conventional family farmers) or used to do so in the past (agroecological family farmers). In the case of conventional family farmers (including sharecroppers) this reflects a paradoxical situation in which the negative consequences of pesticides are recognised, but farmers continue using chemical pesticides because they do not see an alternative or are pressured by their landlords, who do not tend to recognise the negative impacts of pesticides on health. Large scale farmers with a more entrepreneurial way of farming had a stronger focus on commodity production and 


\section{Chapter 3}

a less complex perception of the interactions between agroecosystem components than family farmers. This can in part be explained by low diversity of the cropping systems of large scale farmers, which were often monocultures of a limited set of crops. While our study confirms earlier findings about the differences between family and capitalist farming in terms of farm size, market-orientation, resource endowment and reliance on contracted labour (Vanhaute and Cottyn, 2017), we also show that family and capitalist farmers differ in their perception of the complexity of agroecosystems and the associated ES. Depending on the land tenure arrangement, peasants tend to conserve nature as a long-term investment in the ecological capital of the farm. The adoption of agroecological practices allow farmers to produce agricultural goods and services, while safeguarding the ecological capital for future generations (van der Ploeg, 2014). In contrast, large-scale farmers tended to see land, labour and nature as commodities that can be replaced or sold in case of obsolescence. As a consequence, large-scale farmers tended to focus on maximizing cash crop production at the short term, neglecting possible negative impacts on production potential on the longer term, and the provision of other ES, such as soil quality, health, air quality and water provision. In future studies, it would also be interesting to focus on the perception of farmers working as employees at large scale farms. This could give new insights on the connection of this specific group of farmers with land and nature, as well as the power relationship between landlords and employees.

Conventional family farmers in Zona da Mata still embody many traditional aspects of peasant farmers, such as home gardens for food self-sufficiency, a strong reliance on the community for labour and a close connection to nature. Yet, their farming practices are moving towards an entrepreneurial way of farming with high external inputs and a loss of autonomy. The remaining peasant identity of conventional family farmers could be an important basis for enhancing the 
transition towards agroecological farming practices. The persistence of the peasant way of farming in Zona da Mata can be explained by two factors. First, the hilly landscape hampered agricultural mechanization and the spread of the associated Green Revolution practices (Souza et al., 2012a). This may have limited the capitalist way of farming in the region. Second, the peasant identity in the Zona da Mata region has been strengthened by the action of Grassroots Ecclesial Communities (Comunidades Eclesiais de Base, CEBs). The CEBs, which originated during the end of the dictatorship in Brazil in the 1980`s, made agroecological concepts meaningful to farmers within a religious and political context by the organisation of reflection groups (Botelho et al., 2015). The reflection groups have been active in the municipalities included in our study and may have therefore influenced the perception of conventional and agroecological family farmers by encouraging farmers to claim the right to land and autonomy, strengthen community building and self-organisation, respect culture, nature and human rights, and embrace Christian religion (Cardoso and Mendes, 2014). During the construction of the FCMs, many farmers mentioned God as the most important overarching factor, which was connected to all identified factors. Due to practical constraints it was not possible to include the perceived interconnectedness of God with the other factors in the FCM.

The interaction between the limited uptake of Green Revolution practices and the activity of grassroots organisations has resulted in a relative widespread adoption of agroecological practices among family farmers in the Zona de Mata, but the uptake is often lower in regions of Brazil that have been more conducive for the Green Revolution approach. 


\section{Chapter 3}

\subsection{From perception to diversification}

The transition towards agroecology in the Zona da Mata allowed the co-creation of knowledge based on peasant experience and creativity, and contributions from researchers and extension services (Cardoso et al., 2001; Souza et al., 2012a). The co-creation process was led by farmers organisations and was supported by a participatory approach similar to the peasant-to-peasant methodology (Rosset et al., 2011) in which scientific and empirical knowledge was combined and extended (Zanelli et al., 2015). The generated knowledge is based on peasant culture as well as the understanding of ecological processes, species interactions and relationships between ecosystem structure and function. This knowledge base was reflected in the FCM by the fact that agroecological family farmers recognised a higher number of intermediate services and benefits from trees, a higher number of connections between agroecosystem components, and relied less on external inputs in comparison to conventional family and large scale farmers (Tables 3.1 and 3.2). The positive correlation between farmer's perception of the complexity of the agroecosystem in the FCM and the number of crops grown and products sold, indicates that the generation of agroecological knowledge can contribute to the development of diversified agroecosystems and the associated ES (Duru et al., 2015b). These results also reflect the higher level of food sovereignty among agroecological family farmers, who gained control over land and adopted farming practices that allow to break free from the dominant agri-food system. For instance, agroecological family farmers conserve and propagate native crop varieties, cultivate and use medicinal plants, use ecological water treatment, produce a variety of crops for selfconsumption and have established agroforestry systems in their farms. To foster the process from perception to diversification, involvement of social organisations is indispensable, such as farmers unions and NGO`s, to empower farmers, to develop actionable knowledge to support 
agroecological innovation (Geertsema et al., 2016), and ultimately contributing to diversified agreocosystems and food sovereignty.

For developing effective policies to promote biodiversity-based agriculture and support a peasant way of farming, the creation of a bottom-up process to stimulate farmers ` participation and representation may be beneficial (Bernués et al., 2016; Vuillot et al., 2016). For instance, the National Program of School Feeding in Brazil (PNAE), promoted the dialogue between family farmers and the government to enable the commercialization of a diversity of agricultural products to schools (Mossmann et al., 2017). Family farmers are often limited to sell only few types of products due to market constraints, as was the case of conventional family farmers in our study, and are therefore discouraged to produce a diversity of crops and promote agrobiodiversity (Wittman et al., 2017). In addition, reform of environmental laws may be needed to strengthen the agrobiodiversity in agroecosystems. For instance, family farmers express the desire to manage native on-farm trees, but management of native trees is restricted by a law that aims to conserve these trees. Although farmers recognise the benefits and functions of trees on the farm (Table 3.2), farmers are discouraged to introduce native trees because they are afraid to be punished in case the trees need to be managed or cut (FAO, 2013). Ultimately, policies need to be sensitive to farmers needs and perceptions in order to be socially accepted and implemented successfully. For instance, our study shows that for the interviewed farmers, water was the most important ES. This highlights the need for programs and projects aiming at water conservation through practices already familiar to farmers (based on the FCMs), such as fencing water springs, planting on-farm trees, enabling natural regeneration of forest patches, improving soil quality and reducing the use of pesticides. 


\section{Chapter 3}

The variation in the farmers' perceptions on ES that we found in our study triggers the question to what extent current extension programs match with the way how farmers understand their agroecosystem. Extension services often focus on increasing the productivity of cash crops and advise on operational decisions (Dogliotti et al., 2014). Yet, family farmers have empirical local knowledge and often value multiple benefits from their agroecosystems beyond food production for the market, indicating that there is a need for more integrative and holistic extension programs. To inform such programs, it would be worthwhile to explore the trajectories of different farmer types to further investigate the process of knowledge construction in connection to value systems and culture, including spirituality. Finally, from an ecological perspective, it is crucial to understand the interactions between ES, ecosystem properties, functional diversity and management, aiming to optimize the delivery of multiple ES in agroecosystems.

\subsection{Reflection on methodology}

The FCM proofed to be an effective participatory tool that allowed to capture farmers perception and knowledge on the interactions between social and ecological components for the provision of ES in agroecosystems. The number of interviews conducted and the average number of factors and connections obtained with the FCM in this study are in line with previous studies in social environmental research (Özesmi and Özesmi, 2004). However, most variables did not follow a normal distribution, which resulted in a loss of statistical power associated with the use of non-parametric tests (Field, 2017). Despite the limited statistical power, we identified significant differences among different farmer types. Furthermore, we constructed social FCMs by aggregating individual FCMs. This is a commonly used method that can be helpful to reveal and contrast patterns found in different actor groups (Jetter and Kok, 2014). Given that the social FCMs are created by merging the factors and connections raised by all farmers in the group, this 
can lead to overly complex representation of the perception of an individual farmer. Therefore, the interpretation of the social FCM needs to take into account potential artefacts associated with the merging of individual farmer responses into group responses. Nevertheless, in our study the group responses provided a fair representation of the responses from individual farmers, which was confirmed during workshops to present and validate the results to the farmers in the three municipalities, and therefore we are confident that the analysis at the group level provides credible and relevant insights.

\section{Conclusions}

Our study highlights the diversity of farmer's perceptions on ES and their management. Understanding the differences and similarities between the diverse visions on quality of life and the factors involved in the provision of ES is an important step to engage with different stakeholders and associated knowledge systems within an ES and biodiversity framework. Initiatives that aim to strengthen on-farm ES should be sensitive for farmer's perceptions and may need to consider using specific strategies for different farmer types. Large scale farmers with a more capitalist way of farming may become interested in diversified cropping systems if these are more profitable and more stable than monocrops, and when crop management can be mechanized. For family farmers, the agroecology movement has played a pivotal role in creating awareness about ES and develop and disseminate actionable knowledge for the management of diversified agroecosystems. Yet, promoting family farmers' access to knowledge, credit and extension services, and at the same time valuing and (re)signifying the peasant identity and culture remains crucial. The involvement of social organisations may help to engage, empower and give voice to family farmers. Support by policies and institutions is also needed to promote 


\section{Chapter 3}

farm diversification strategies and provide favourable socio-economic conditions for farmers to move towards agroecological, autonomous and diversified agriculture.

\section{Acknowledgement}

We acknowledge support through the Interdisciplinary Research and Education Fund (INREF) of Wageningen University through its programme FOREFRONT. We thank Pablo Tittonell for helpful discussion to develop the initial idea for this paper. Foremost, we would like to thank the farmers, farmer organisations', CTA-ZM and the agroecology movement in Zona da Mata for making this research possible. This work would not have happened without the great involvement of all members of the FOREFRONT project, forming together a truly interdisciplinary research team. 
Farmers'perceptions on ecoystem services 
Chapter 3

\section{Appendices}

\section{Appendix 3.A}

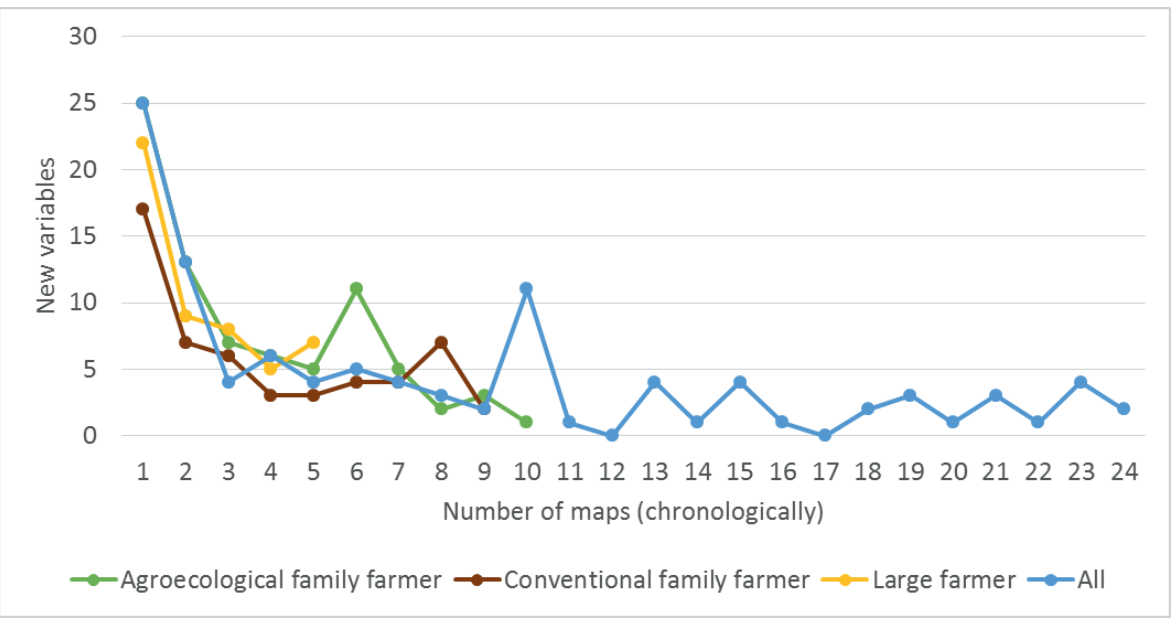

Figure 3.A1. Accumulation curves of the number of new variables per interview to assess the saturation in responses per farmer type. 
Farmers'perceptions on ecoystem services

Appendix 3.B. Example of coding the results of the fuzzy cognitive map to the adjacency matrix. The selected section of the fuzzy cognitive map is taken from Figure 3.2.

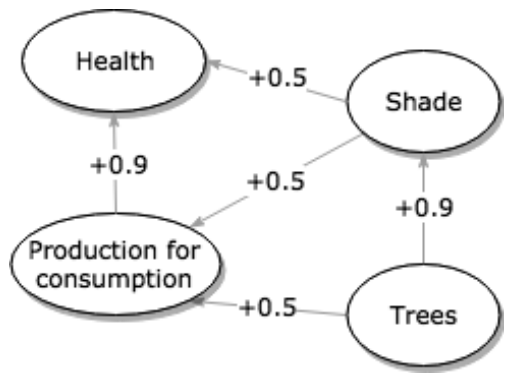

Health Prod.consump. Shade Trees

\begin{tabular}{lllll}
\hline \hline Health for & 0 & 0 & 0 & 0 \\
$\begin{array}{l}\text { Prod. fonsumption } \\
\text { consude }\end{array}$ & 0.9 & 0 & 0 & 0 \\
Shade & 0.5 & 0.5 & 0 & 0 \\
Trees & 0 & 0.5 & 0.9 & 0 \\
\hline
\end{tabular}




\section{Chapter 3}

\section{Appendix 3.C}

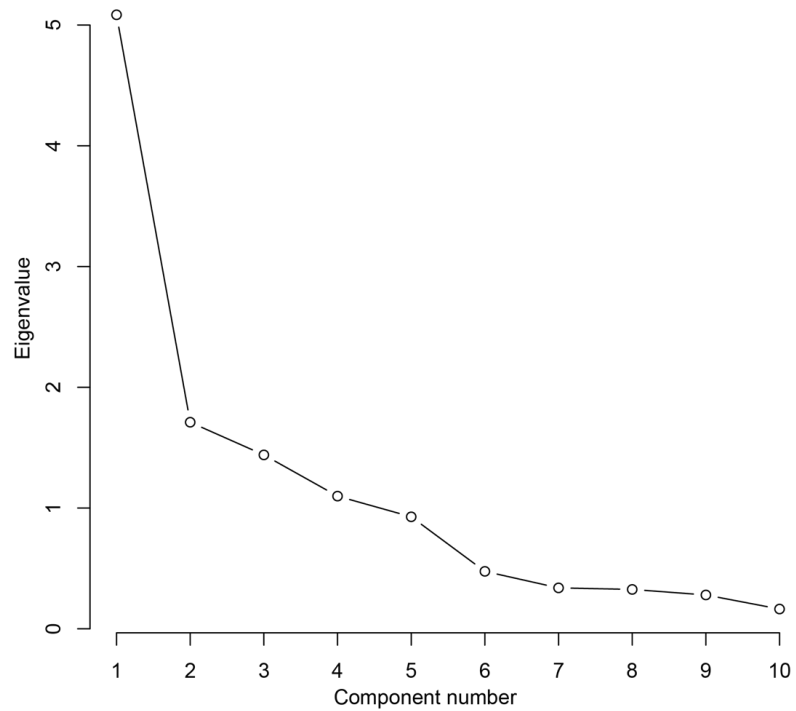

Figure 3.C1. Screen plot for selecting the number of components in the Principal Component Analysis (Figure 3.4). 
Farmers'perceptions on ecoystem services

Table 3.C2. Correlation coefficients of selected variables with PCA axis 1 and 2 as shown in Principal Component Analysis (Figure 3.4).

\begin{tabular}{lll}
\hline & \multicolumn{2}{c}{ PCA axes } \\
\hline \hline & 1 & 2 \\
\hline Factors & 0.706 & 0.069 \\
Crop diversity & 0.665 & 0.427 \\
Products sold & 0.733 & 0.051 \\
Trees benefits & 0.758 & 0.272 \\
$\begin{array}{l}\text { Production consumption } \\
\text { centrality }\end{array}$ & 0.1 & 0.791 \\
Direct ES & 0.277 & 0.815 \\
Intermediate ES & 0.738 & 0.011 \\
External input & -0.621 & -0.272 \\
Cultural ES & 0.333 & 0.495 \\
Pesticides negative & 0.09 & 0.51 \\
outdegree & & 0.494 \\
Connections & 0.704 & -0.855 \\
Land size & -0.054 & \\
\hline
\end{tabular}


Chapter 3

Appendix 3.D. Centrality scores of all the factors present in the social Fuzzy Cognitive Maps per farm type.

\begin{tabular}{|c|c|c|c|c|c|}
\hline $\begin{array}{l}\text { Agroecological } \\
\text { family farmers }\end{array}$ & & $\begin{array}{l}\text { Conventional } \\
\text { family farmers }\end{array}$ & & $\begin{array}{l}\text { Large scale } \\
\text { farmers }\end{array}$ & \\
\hline Concepts & $\begin{array}{l}\text { Centr } \\
\text { ality }\end{array}$ & Concepts & $\begin{array}{l}\text { Centr } \\
\text { ality }\end{array}$ & Concepts & $\begin{array}{l}\text { Centr } \\
\text { ality }\end{array}$ \\
\hline water & 6.38 & water & 6.33 & production market & 5.64 \\
\hline $\begin{array}{l}\text { production } \\
\text { consumption }\end{array}$ & 5.14 & production market & 4.67 & water & 4.90 \\
\hline production market & 3.94 & $\begin{array}{l}\text { production } \\
\text { consumption }\end{array}$ & 4.56 & soil quality & 2.64 \\
\hline health & 3.40 & soil quality & 2.93 & forest & 1.86 \\
\hline soil quality & 3.28 & pesticides & 2.78 & $\begin{array}{l}\text { production } \\
\text { consumption }\end{array}$ & 1.78 \\
\hline trees & 3.11 & health & 2.76 & health & 1.72 \\
\hline pesticides & 2.39 & air quality & 1.94 & pesticides & 1.56 \\
\hline forest & 2.30 & forest & 1.77 & erosion control & 1.26 \\
\hline wildlife & 2.01 & manure & 1.39 & chemical fertilizer & 1.06 \\
\hline soil cover & 1.54 & chemical fertilizer & 1.27 & manure & 0.98 \\
\hline air quality & 1.53 & wildlife & 1.22 & animal husbandry & 0.94 \\
\hline autonomy & 1.32 & trees & 1.18 & climate & 0.90 \\
\hline medicinal plants & 1.31 & weeding & 1.09 & wildlife & 0.84 \\
\hline diversification & 1.05 & trimming & 0.87 & freedom & 0.72 \\
\hline manure & 0.95 & protecting springs & 0.86 & air quality & 0.72 \\
\hline shade & 0.88 & plant residues & 0.74 & protecting springs & 0.72 \\
\hline pest control & 0.85 & fire & 0.69 & weeding & 0.72 \\
\hline freedom & 0.77 & peacefulness & 0.66 & water boxes & 0.68 \\
\hline chemical fertilizer & 0.71 & lifestyle & 0.58 & trees & 0.64 \\
\hline
\end{tabular}


Farmers'perceptions on ecoystem services

\begin{tabular}{|c|c|c|c|c|c|}
\hline erosion control & 0.66 & autonomy & 0.54 & fire & 0.54 \\
\hline pollinisation & 0.64 & coffee husks & 0.43 & coffee husks & 0.52 \\
\hline family labour & 0.62 & landownership & 0.38 & machinary & 0.52 \\
\hline seeds and seedlings & 0.62 & eucalyptus & 0.37 & roads & 0.50 \\
\hline esthetics & 0.59 & calcium & 0.33 & cooldown soil & 0.46 \\
\hline trimming & 0.58 & community & 0.28 & diversification & 0.46 \\
\hline lifestyle & 0.48 & freedom & 0.26 & trimming & 0.46 \\
\hline eucalyptus & 0.46 & labour exchange & 0.26 & homeopathy & 0.38 \\
\hline protecting springs & 0.45 & family labour & 0.26 & generating work & 0.36 \\
\hline climate change & 0.42 & pest control & 0.23 & silage mais & 0.36 \\
\hline peacefulness & 0.38 & erosion control & 0.21 & trash & 0.36 \\
\hline fire & 0.36 & trash & 0.21 & eucalyptus & 0.32 \\
\hline sanitation & 0.36 & rain & 0.20 & feed & 0.32 \\
\hline weeding & 0.36 & ox cart & 0.20 & foliar fertilizer & 0.32 \\
\hline knowledge & 0.32 & water boxes & 0.20 & esthetics & 0.32 \\
\hline biodigestor & 0.28 & labour contracted & 0.19 & $\begin{array}{l}\text { animal } \\
\text { medication }\end{array}$ & 0.28 \\
\hline intercropping & 0.27 & esthetics & 0.18 & contour lines & 0.28 \\
\hline climate & 0.27 & seed dispersal & 0.18 & labour contracted & 0.28 \\
\hline homeopathy & 0.27 & foliar fertilizer & 0.16 & water resevoirs & 0.24 \\
\hline plant residues & 0.27 & wood & 0.13 & $\begin{array}{l}\text { plowing along } \\
\text { contour lines }\end{array}$ & 0.24 \\
\hline calcium & 0.26 & seeds store & 0.13 & calcium & 0.18 \\
\hline microorganisms & 0.25 & homeopathy & 0.10 & climate change & 0.18 \\
\hline cultural valorisation & 0.25 & wastage & 0.10 & deplete swamp & 0.18 \\
\hline seed exchange & 0.25 & clearing the soil & 0.08 & plant residues & 0.18 \\
\hline care for plants & 0.23 & deplete swamp & 0.08 & shade & 0.18 \\
\hline generating work & 0.23 & product exchange & 0.08 & soil analysis & 0.18 \\
\hline debt & 0.18 & silence & 0.08 & animal comfort & 0.14 \\
\hline
\end{tabular}


Chapter 3

\begin{tabular}{|c|c|c|c|c|c|}
\hline $\begin{array}{l}\text { teachings from } \\
\text { nature }\end{array}$ & 0.18 & swales & 0.08 & bureaucracy & 0.10 \\
\hline $\begin{array}{l}\text { waste water } \\
\text { treatment }\end{array}$ & 0.18 & terraces & 0.08 & clearing the soil & 0.10 \\
\hline organic matter & 0.18 & $\begin{array}{l}\text { working } \\
\text { independently }\end{array}$ & 0.08 & slurry & 0.10 \\
\hline rain & 0.18 & health clinic & 0.06 & subcontractors & 0.10 \\
\hline seed dispersal & 0.18 & machinary & 0.06 & silage grasses & 0.06 \\
\hline water boxes & 0.16 & soil analysis & 0.06 & & \\
\hline trash & 0.15 & pasture & 0.03 & & \\
\hline nutrients & 0.15 & & & & \\
\hline community & 0.14 & & & & \\
\hline $\begin{array}{l}\text { connection with } \\
\text { nature }\end{array}$ & 0.14 & & & & \\
\hline contour lines & 0.14 & & & & \\
\hline labour exchange & 0.14 & & & & \\
\hline transgenics & 0.14 & & & & \\
\hline Handcrafts & 0.12 & & & & \\
\hline coffee husks & 0.12 & & & & \\
\hline adapted seeds & 0.09 & & & & \\
\hline agribusiness & 0.09 & & & & \\
\hline deplete swamp & 0.09 & & & & \\
\hline landownership & 0.09 & & & & \\
\hline over grazing & 0.09 & & & & \\
\hline rotation and fallow & 0.09 & & & & \\
\hline labour contracted & 0.09 & & & & \\
\hline $\begin{array}{l}\text { dependence on the } \\
\text { market }\end{array}$ & 0.07 & & & & \\
\hline foliar fertilizer & 0.07 & & & & \\
\hline path design & 0.07 & & & & \\
\hline
\end{tabular}


Farmers'perceptions on ecoystem services

\begin{tabular}{|l|l|}
\hline recycling & 0.07 \\
\hline spontaneous plants & 0.07 \\
\hline $\begin{array}{l}\text { typography of } \\
\text { pasture }\end{array}$ & 0.07 \\
\hline darkness & 0.05 \\
\hline nitrogen fixation & 0.05 \\
\hline planting in tires & 0.05 \\
\hline swales & 0.05 \\
\hline
\end{tabular}

\begin{tabular}{|l|}
\hline Legend \\
\hline direct service \\
\hline intermediate \\
service \\
\hline ecological \\
property \\
\hline management \\
\hline external input \\
\hline social-economic \\
\hline
\end{tabular}




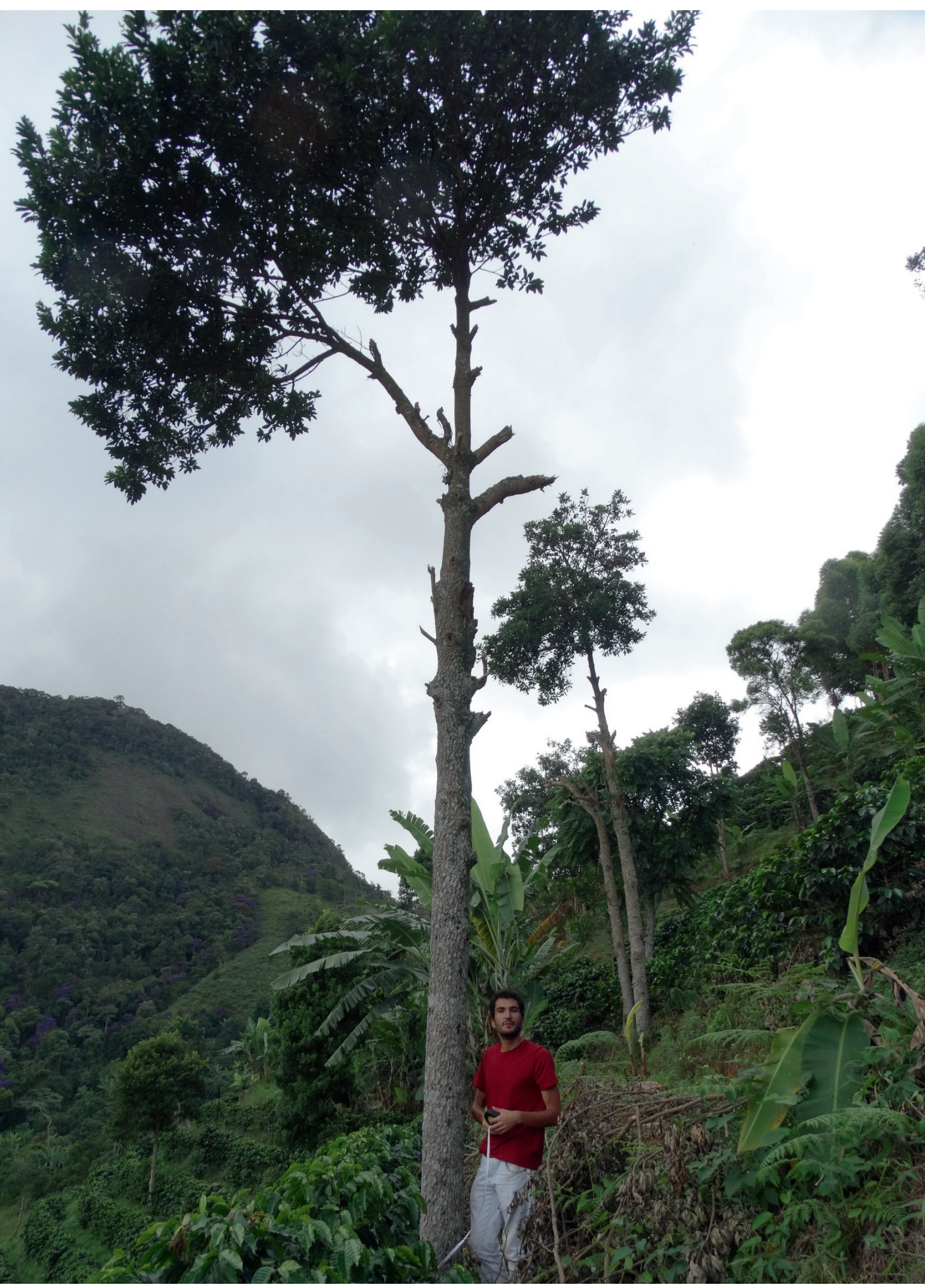




\section{Chapter 4}

\section{Impact of agroecological management on biodiversity and soil-based ecosystem services in pasture and coffee systems in the Atlantic forest of Brazil}

To be submitted as:

Heitor Mancini Teixeira, Felix J.J.A. Bianchi, Irene Maria Cardoso, Pablo Tittonell, Marielos Peña-Claros, 2019. 


\title{
Chapter 4
}

\begin{abstract}
The development of more sustainable agroecosystems need to combine the reduction of input use with other management practices that foster ecological processes to enhance soil quality and crop development. We assessed the direct and indirect impacts of farmers' management practices on biodiversity, soil quality and crop productivity in coffee and pasture fields belonging to different types of farms: agroecological, conventional, and large-scale. The study was carried out in twelve farms in the Zona da Mata, Brazil. For each of the total of 24 fields (twelve pastures and twelve coffee) we recorded 41 variables associated with management practices, indicators of plant diversity (taxonomical, structural and functional diversity) and soil quality (biological, chemical and physical properties). The direct and indirect effects of management on plant diversity, soil quality and in the case of coffee, crop productivity, were assessed using structural equation models. In the case of pastures, we found that increased plant diversity due to agroecological management resulted in higher soil quality, probably due to higher soil litter cover and plant structural heterogeneity. Yet, agroecological management practices also had a direct negative effect on soil quality, which indicates that increased biodiversity in pastures needs to be combined with better management practices than currently adopted. In the case of coffee, we show that despite the higher weeding intensity and higher use of external inputs in large-scale and conventional coffee farming systems, these practices did not result in increased soil quality or coffee productivity as compared to agroecological systems. In contrast, agroecological coffee management was associated with increased plant diversity, which, in turn, was positively associated with soil microbial biomass carbon. Our results highlight a causal pathway of agroecological management leading to increased plant diversity and, in turn, maintenance or increase in soil quality. While no causal link between agroecological coffee management and coffee productivity could be demonstrated, the biodiversity-mediated pathway resulted in similar coffee productivity in agroecological farms as compared to conventionally managed farms, which relied on pesticides and higher inputs of mineral nutrients. We conclude that agroecological management can be a viable strategy to maintain soil fertility and achieve satisfactory crop yields without the use of agrochemicals and intensive weeding.
\end{abstract}


Management, biodiversity and ecosystem services

\section{Introduction}

The development of more sustainable agroecosystems need to combine the reduction of input use with other management practices that foster ecological processes to enhance soil quality and crop development (Duru et al., 2015a; Nicholls and Altieri, 2017; Palomo-Campesino et al., 2018). Particularly in developing countries, the adoption of conservation management practices has been successful to maintain or even increase crop yields while improving natural resource use efficiency (Pretty et al., 2006). Increasing plant diversity can enhance soil regulatory functions and the provision of other ES, and therefore lies at heart of the transition to more sustainable systems (Duru et al., 2015b; Isbell et al., 2017a). For instance, increased canopy cover can regulate air temperature and soil humidity, creating favourable conditions for the development of soil organisms (Gomes et al., 2016; Martius et al., 2004). In addition, plant leaf traits can influence litter decomposition, nutrient cycling and soil cover (Bakker et al., 2011; Mendonça and Stott, 2003). The assessment of how a set of combined management practices can directly and indirectly influence plant diversity and ES provision can inform the development of more sustainable agroecosystems.

Among a variety of approaches that promote biodiversity-based systems, agroecology has been increasingly recognised by scientists and society due to its capacity to integrate practice, science and movement (Wezel et al., 2009). The adoption of agroecological practices is a process based on general principles and experimentation, where different actors come together to share knowledge and find adaptive solutions for local environmental and agricultural challenges (Bonaudo et al., 2014; Mccune et al., 2017). Research focusing on differences between agroecological and conventional farms suggest that agroecological systems can better provide food security, soil quality, resilience and habitat quality for biodiversity (Chavarria et al., 2018; 


\section{Chapter 4}

Garibaldi et al., 2017; Holt-Giménez, 2002; Olimpi and Philpott, 2018; Souza et al., 2012b). Despite the advancements to understand the impact of agroecological management on biodiversity and ecosystem services (FAO, 2018; Liere et al., 2017; Palomo-Campesino et al., 2018), the interactions among multiple components of agroecosystems (i.e. management, plant diversity, soil quality and crop productivity) remain poorly understood, particularly in real life management situations where agroecological transitions are currently taking place. For example, very few studies have assessed the effect of taxonomical, structural and functional attributes of plant diversity on the ES provision in agricultural systems, although this approach has been used for carbon related ES in forested systems (Finegan et al., 2015; van der Sande et al., 2017a).

The characterization of system components, such as management, plant diversity and soil quality can be based on a set of variables that capture the complexity of agroecosystems, which is especially relevant in realistic management scenarios (Birkhofer et al., 2015). The management component can have a direct effect on biodiversity and soil functioning, and consists of combined practices that are applied for different purposes (Jezeer et al., 2018; Mas and Dietsch, 2003; Rahn et al., 2018). For instance, weeding can be done with different intensities and methodologies (e.g. chemical herbicides, manual removal of weeds and mechanical weed control); fertilizer application may entail different doses of manure, chemical fertilizers and/or other inputs; and pest management may involve application of different types and doses of pesticides (Jezeer et al., 2018; Rahn et al., 2018). Yet, a particular practice may have multiple purposes, such as the implementation of native and fruit trees in agricultural fields. Trees can contribute to a variety of functions and services, such as nutrient cycling, temperature regulation, provision of wood and fruits, carbon storage and pest control (Tscharntke et al., 
2011). Therefore, focussing on just a single agroecosystem component or practice may be insufficient to capture the overarching impacts of applied management practices on agroecosystems (Mas and Dietsch, 2003).

In the case of plant diversity, indicators of taxonomical, structural and functional diversity can be combined to better determine plant responses to management as well as the effect of plants on ecosystem functioning (Balvanera et al., 2014; Díaz and Cabido, 2001). Taxonomical diversity can be used to assess the conservation value of land uses as well as the role of diversified systems to increase the complementary and efficient use of resources. The structural diversity of agroecosystems, typically defined as variance in height can influence the efficiency to capture water, carbon and light, and, in turn, ecosystem functioning (Ali et al., 2016). Other components related to the structure of agroecosystems can also be relevant, such as canopy cover and total biomass (Gomes et al., 2016; Henry et al., 2009). Trait-based functional diversity can be used to further assess the functional response and effect of diversity on ecosystem functioning based on trait dominance (e.g. community weighed means - CWM) and variance (e.g. functional richness) (Faucon et al., 2017; Lavorel, 2013; Wood et al., 2015). For instance, CWM values of leaf nitrogen content can help to understand both the effects of nitrogen fertilization on plant nutrition (Buchanan et al., 2019) as well as the consequences of nitrogen concentration on the efficiency of nutrient cycling and the associated soil fertility (Bakker et al., 2011).

Soil quality is influenced by the interplay of chemical, physical and biological soil factors (El Mujtar et al., 2019). However, although soil chemical and physical indicators are commonly used by farmers and scientists, biological indicators are often under-represented in soil quality 


\section{Chapter 4}

assessments (Bünemann et al., 2018). Soil organisms are suggested to be very sensitive to ecosystem change and to play a central role in ecosystem functioning, and therefore, including biological indicators can help to better understand soil responses to biodiversity and management as well as the relationship between soil biology, chemistry and physics (Faucon et al., 2017).

The objective of this paper is to assess how a set of management practices used in coffee and pastures influences plant diversity, soil quality and, in the case of coffee, crop productivity. First, the relationships between indicators for management, plant diversity and soil quality were explored using multivariate analysis. Then, structural equation models were used to assess the direct and indirect effects of management practices on plant diversity, soil quality and, in the case of coffee, crop productivity. The study was conducted in Zona da Mata, Minas Gerais, Brazil, where coffee is the main cash crop for farmers and pasture is the dominant land use, covering about $70 \%$ of the landscape. The Zona da Mata is a suitable location for conducting this kind of research because of the ongoing process of agroecological transition that was initiated in the 1970's as a joint initiative of farmers' organisations, a local NGO (Centro de Tecnologias Alternativas - CTA-ZM) and the University (Universidade Federal de Viçosa UFV) (Cardoso et al., 2001). Moreover, previous studies in the region have established a farm typology that help to understand the local context and to select representative farms that configure a gradient of management strategies (Teixeira et al., 2018a). 
Management, biodiversity and ecosystem services

\section{Material and Methods}

\subsection{Study site}

The study was conducted in Araponga, Divino and Espera Feliz, which are three municipalities located in Zona da Mata, Minas Gerais, Brazil. These municipalities connect two important nature reserves (Caparaó National park and Brigadeiro state park - Figure 4.1) and are part of the Atlantic rainforest biome, which is considered the fifth biodiversity hotspot in the world (Myers et al., 2000). The landscape in Zona da Mata can be understood as a dynamic mosaic of land uses (Vandermeer and Perfecto, 2007) predominated by pastures, coffee fields and secondary forest patches. The area is mountainous, leading to heterogeneous bio-physical conditions, limiting mechanization and predominance of family farmers (Valverde, 1958). The average temperature in the region is $19^{\circ} \mathrm{C}$ and the average precipitation is $1300 \mathrm{~mm}$ (Golfari, 1975). The main soil type dominating the upper slopes is classified as Oxisol, which is highly weathered, deep, well-drained and acidic (Sarcinelli et al., 2009).

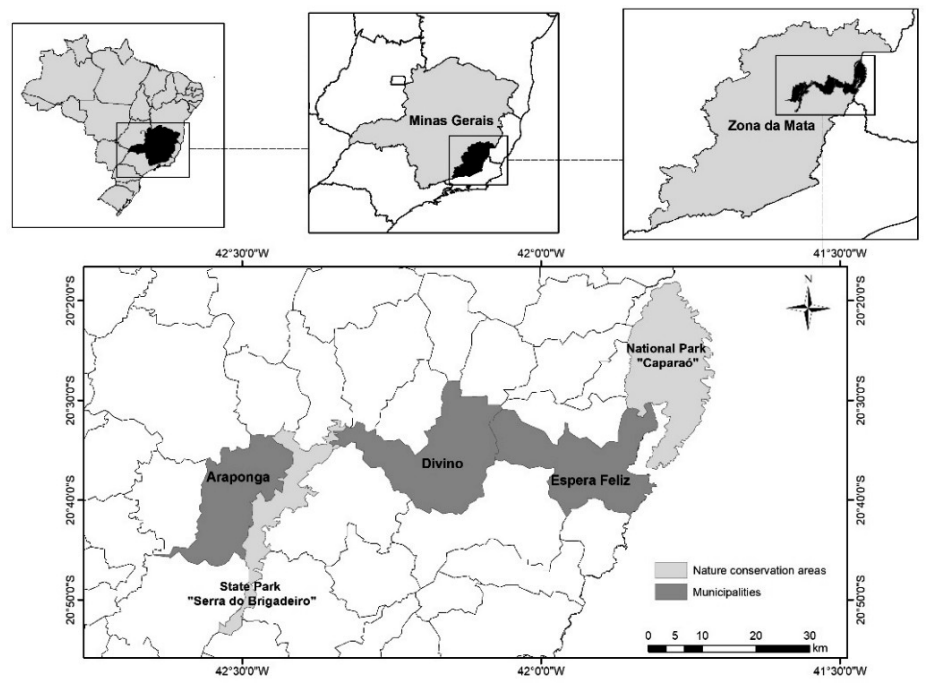

Figure 4.1. Map of the three studied municipalities in Zona da Mata, Minas Gerais, Brazil. Two important nature conservation areas are also shown. 


\section{Chapter 4}

\subsection{Selection of farms}

Twelve farms were initially selected as case studies based on a farm typology previously developed in the region (Teixeira et al., 2018a). The typology helps to understand and take into account a diversity of management strategies and social-economic conditions faced by farmers. Three main farm types were considered for the present study: agroecological family farms, conventional family farms and large-scale farms. Agroecological family farms are characterized by the adoption of innovative farming practices, low use of external inputs and high crop diversity. Agroecological farmers also have a strong engagement in social networks and movements. Conventional family farms have low crop diversification, high use of external inputs and a strong focus on coffee production. Large-scale farms have large farm area and depend on contracted labour. Four farms per farm type were identified. In each farm, one coffee field and one pasture were selected for the study, for a total of 24 fields ( 2 land uses x 3 farm types $\mathrm{x} 4$ farms $=24$ fields). Only coffee plantations that were older than 7 years were selected to standardize the size of coffee plants, and we included only pastures that were actively managed during the sampling period. Furthermore, all fields were located on the convex upper slopes to minimize variation in soil conditions. When coffee plantations and pastures that met our selection criteria were not available on the same farm, a representative field with comparable management was selected nearby. This was the case in five different farms

\subsection{Field management and productivity}

Field management and productivity in coffee and pasture were assessed by conducting interviews with farmers and land owners. The following information was collected for each field: age of the field (years), mowing intensity (hours/ha/year), weeding intensity (hours/ha/year), pesticide input (g/ha/year), mineral nutrient input (kg/ha/year; N, P, K and Ca), 
organic nutrient input (kg/ha/year; N, P, K) and use of manure $(\mathrm{kg} / \mathrm{ha} /$ year). Coffee productivity ( $\mathrm{kg} / \mathrm{ha} /$ year) was assessed based on the average yields of the previous two years. Information on cattle stocking density (\#/ha) and cattle grazing intensity (days/year) was obtained for pastures.

\subsection{Plant diversity assessment}

Plant diversity in each of the 24 fields was assessed along a 90-m linear transect, starting at the bottom edge of the field in the uphill direction. The starting point of the transect at the bottom edge was randomly drawn using the Random Number App. In the case of coffee, the transect was perpendicular to the coffee plant rows, starting in between coffee plants located in the same row, with the first two coffee rows being skipped to reduce edge effects.

The survey was conducted by assessing the vegetation at $5 \mathrm{~m}$ on both sides along the linear transect, covering an area of $900 \mathrm{~m} 2(90 \times 10 \mathrm{~m})$. All trees, palms, shrubs, giant herbs and treelets with diameter at $1.3 \mathrm{~m}$ height $(\mathrm{DBH}) \geq 5 \mathrm{~cm}$ were recorded. The crown area of each individual was estimated based on the average of crown diameter measured in two perpendicular directions. Tree crown cover and tree density were calculated for each plot. DBH and height was assessed for 20 coffee plants. For this purpose, we divided the plot in ten equally sized subplots and randomly selected two coffee plants in each subplot.

The linear transect was also used for the point interception method, which allowed to assess taxonomical, structural and functional diversity of plant species regardless of their size, as well as soil cover and litter depth along the transect. In coffee plantations and pastures we sampled the vegetation at 2 and 1-m intervals, respectively. At each sampling point, we placed a stick 


\section{Chapter 4}

with a diameter of $2.5 \mathrm{~mm}$ and the plant species and height of each individual whose leaves touched the stick was recorded. In case that the plant species could not be identified in the field, samples were taken and stored as exsiccates (dried and flatten plant material) for further identification with the help of botanical manuals (Lorenzi, 2016, 2008), experts and the herbarium collection of the Universidade Federal de Viçosa, Minas Gerais, Brazil. For the assessment of grasses we applied two rules. First, we did not take into account inflorescences for the vegetation height measurements because inflorescences are only present during part of the season, and are often taller than the rest of the plant. In this way we avoided overestimation of plant height. Second, tussocks were considered as separate individuals when they were separated at the base, even when they might have had the same root system. The standard deviation of height was used as a proxy of structural diversity. Number of plant species found in each transect and Shannon-Weiner index were used as proxies of taxonomical diversity. Soil cover and litter thickness (of every plant material covering the soil) were assessed at each sampling point. Soil cover was recorded as presence/absence data and litter depth was measured with a ruler.

For the functional diversity assessment we measured ten leaf traits that are associated to plant responses to light and fertilization as well as plant effects on ecosystem productivity, litter production and nutrient cycling. In total, we assessed 64 plant species representing on average $92.35 \%$ (range $84-100 \%$ ) of the vegetation cover in each transect according to the point interception method. Five mature, healthy, vigorous and sun-lit individuals of each species in each plot were sampled to provide plant material for assessing functional leaf traits following standard protocols (Pérez-Harguindeguy et al., 2013). The leaf petiole was included in the assessment, and in the case of compound leaves, the leaflet was considered as the unit of 
Management, biodiversity and ecosystem services

analysis. A SPAD meter was used to obtain leaf chlorophyll content (Chlo). Leaves were flatten and photographed, and leaf area (LA) calculated with the software ImageJ, based on pixel counting. Leaf thickness (LT) was obtained using a digital micrometer. Leaf fresh mass was measured using a precise scale of five decimal places. Then leaves were dried in the oven at $65^{\circ} \mathrm{C}$ until constant weight to obtain leaf dry mass. Leaf dry matter content (LDMC) was calculated dividing dry mass (mg) by fresh mass (g). Specific leaf area (SLA) was calculated as leaf area $(\mathrm{cm} 2)$ divided by leaf dry mass $(\mathrm{g})$. We used a penetrometer built with a flat-end nail attached to a syringe and a water-basin on top to punch fresh leaf laminas. The total weigh necessary to punch the leave was converted to Newton and divided by the nail surface to obtain values of specific force to punch (FtP, N/cm2). Leaf nitrogen (leaf_N) was determined using the sulfuric digestion method (Carmo et al., 2000). Leaf phosphorus (leaf_P), potassium (leaf_K) and calcium (leaf_Ca) content were measured using Nitric-Perchloric Digestion (Carmo et al., 2000). For leaf nutrient content we had three replicates per species per plot. All leaf trait analyses were performed at the laboratory of Soil Fertility and the laboratory of Soil Organic Matter, both at Universidade Federal de Viçosa (UFV). As we expected intraspecific variation in leaf traits among fields we used the species average trait values separately for each transect. Functional trait data at species level was scaled to the community level using indices of functional diversity and functional composition. As an indicator of functional diversity, the multi-trait index functional richness (Fric) was calculated based on the volume filled by the community in the trait space (Cornwell et al., 2006). For functional composition the aggregate value of leaf traits in each plot was measured using community weighed mean (CWM) for each leaf trait (Lavorel et al., 2008). All diversity indices were calculate using the FDiversity software and FD package in R 3.3.3. 


\section{Chapter 4}

\subsection{Soil quality assessment}

For the soil quality assessment the transect lines were subdivided in three segments, each $30 \mathrm{~m}$ long. In each segment we collected three disturbed soil sub-samples from the $0-15 \mathrm{~cm}$ soil layer. The three soil sub-samples were mixed thoroughly and stored in closed plastic bags to form one composite sample per segment. All soil samples were collected during the dry season (JunAug/2017). Soil clay content was determined using the pipette method with sodium hydroxide as a dispersant (Embrapa, 2011). Soil organic matter (SOM) was determined using the WalkleyBlack chromic acid wet oxidation method (Walkley and Black, 1933). Soil pH was measured in water. Soil phosphorus and potassium were determined using Melich-1 extract, while soil calcium and magnesium using $\mathrm{KCl}$ extract. Acidic cations content $(\mathrm{H}+\mathrm{Al})$ was obtained using calcium acetate as extract. Soil total nitrogen was determined by automated combustion. Soil base saturation $(\mathrm{V})$ was calculated as the percentage of the soil exchange sites (CEC) occupied by the basic cations, potassium $(\mathrm{K})$, magnesium $(\mathrm{Mg})$ and calcium $(\mathrm{Ca})(\mathrm{V}=[100 \mathrm{x}$ $(\mathrm{Ca}+\mathrm{Mg}+\mathrm{K})] /(\mathrm{Ca}+\mathrm{Mg}+\mathrm{K}+\mathrm{H}+\mathrm{Al}))$.

An identical sampling design was applied to collect soil samples for the assessment of microbiota. For the microbiological analysis, soil samples were taken from the $0-5 \mathrm{~cm}$ layer in each segment, and samples were immediately stored in a cooler box at $4{ }^{\circ} \mathrm{C}$. In the laboratory, the carbon of the microbial biomass was assessed using the fumigation-extraction method (Vance et al., 1987).

\subsection{Data Analysis}

All the variables included in the study were grouped in three categories: management, biodiversity and soil quality (Table 4.1). A separate multivariate principal component analysis 
Management, biodiversity and ecosystem services

(PCA) was performed for each category (management, biodiversity and soil quality) and for each land use (coffee and pasture). The PCA's allowed to reduce the dimensionality of the data and to generate non-correlated principal components (Appendix 4.A) that conceptually represent gradients of management, biodiversity and soil quality. The coordinates of each sample unit (field) according to the principal components were used as indicator values in the following analysis.

The first axes (PC1) of the PCA's for management and biodiversity, and the first two axes (PC1 and PC2) of the soil quality PCA were used to determine the direct and indirect effects of management on biodiversity and soils using structural equation models. The first two axes of the soil quality PCA`s were selected instead of just PC1 because of the relatively low variance explained of PC1 for coffee systems, and because PC1 was associated with soil fertility and PC2 with carbon, potassium and phosphorus. In the case of pastures, PC1 was associated with soil biological and chemical quality and PC2 with soil texture (Appendix 4.B). Separate structural equation models were developed for pastures and coffee fields. In each model, we tested direct effects of management on biodiversity, direct effects of biodiversity on soil quality, direct and indirect effects of management on soil quality, and in the case of coffee, direct and indirect effects of management, biodiversity and soil quality on coffee productivity. Coffee productivity was the only variable which was not included in the previous multivariate analysis because it was our final response variable. The comparative fit indexes (CFI) of the models for coffee and pasture were 1.0 , exceeding the criterion of $\mathrm{CFI}>0.95$, indicating that the models were acceptable (Appendix 4.C; Schreiber et al., 2006). The strength of causal relationships between variables was assessed using standardized parameter values, and relationships were considered significant when the p-value was $\leq 0.05$ (Appendix 4.D; Gana and Broc, 2018). The residuals of 


\section{Chapter 4}

the correlational units obtained by subtracting the observed and model-implied matrices were checked to confirm that the model was not over or under-predicting the association between variables (|res>0.1|) (Appendix 4.E; Gana and Broc, 2018).

To illustrate the patterns found in the structural equation models we used simple linear regressions to assess the bivariate relationship among variables.

\section{Results}

The principal component analyses revealed how twelve pasture and twelve coffee fields belonging to three different farm types (conventional, agroecological and large-scale) are positioned in a gradient of management, biodiversity and soil quality. We only report correlation coefficients between the variables and the principal components (PCA loadings) if larger than 0.45 or lower than -0.45 (Appendix 4.B).

\subsection{Management}

In the case of coffee, the management gradient was captured by the first principal component (PC1), which explained $47.8 \%$ of the variance (Figure $4.2 \mathrm{~A})$. The variables pesticide use ($0.83)$, mineral $\mathrm{N}, \mathrm{K}$ and $\mathrm{Ca}$ input (-0.8; -0.72 and -0.71 , respectively), weeding intensity $(-0.65)$ and age of the field (-0.63) were negatively correlated with the first component (PC1), while tree density $(+0.91)$, mowing intensity $(+0.86)$, organic $\mathrm{N}$ and $\mathrm{P}$ input $(+0.74$ and +0.71 , respectively) and total manure $(+0.47)$ were positively correlated with PC1. All agroecological coffee fields were positively associated with PC1 whereas all conventional and large-scale fields were negatively associated (Figure 4.2A). Therefore, PC1 can be understood as a gradient of agroecological management practices, ranging from more conventional to ecologically-based 
Management, biodiversity and ecosystem services

management. In the case of pastures, PC1 explained $49.8 \%$ of the variability and can also be interpreted as a gradient agroecological management practices. The variables tree density $(+0.95)$ and mowing intensity $(+0.88)$ were strongly positively correlated with PC1 and grazing intensity (-0.87) was strongly negatively correlated. Agroecological fields were positively associated with PC1, whereas conventional and large-scale fields were negatively associated with PC1 (Figure 4.2B).

\subsection{Biodiversity}

For both coffee and pastures, PC1 was interpreted as a gradient of increased plant diversity explaining $45.8 \%$ and $34.9 \%$ of the variation, respectively. In coffee and pastures, species richness $(+0.97 ;+0.93)$, Shannon index $(+0.92 ;+0.84)$, tree cover $(+0.86 ;+0.77)$, variance in height $(+0.83 ;+0.87)$ and litter thickness $(+0.53 ;+0.77)$ were positively correlated with PC1, whereas bare soil was negatively correlated $(-0.69 ;-0.5)$ (Figure 4.2C and 4D). However, different patterns were observed for coffee and pastures in terms of functional diversity and composition. In coffee systems, functional richness $(+0.85)$, leaf area CWM $(+0.78)$ and leaf phosphorus CWM (+0.51) were positively correlated with PC1, while leaf chlorophyll CWM ($0.88)$, leaf dry matter content CWM (-0.84) and leaf calcium CWM (-0.58) were negatively correlated (Figure 4.2C). In the case of pastures, leaf nitrogen CWM $(+0.83)$, leaf thickness CWM $(+0.54)$, leaf dry matter content CWM $(+0.53)$ and leaf calcium CWM $(+0.52)$ were positively correlated with PC1 (Figure 4.2D). In both coffee and pastures, all agroecological fields were positively associated with PC1, which was not the case for conventional and largescale fields. 


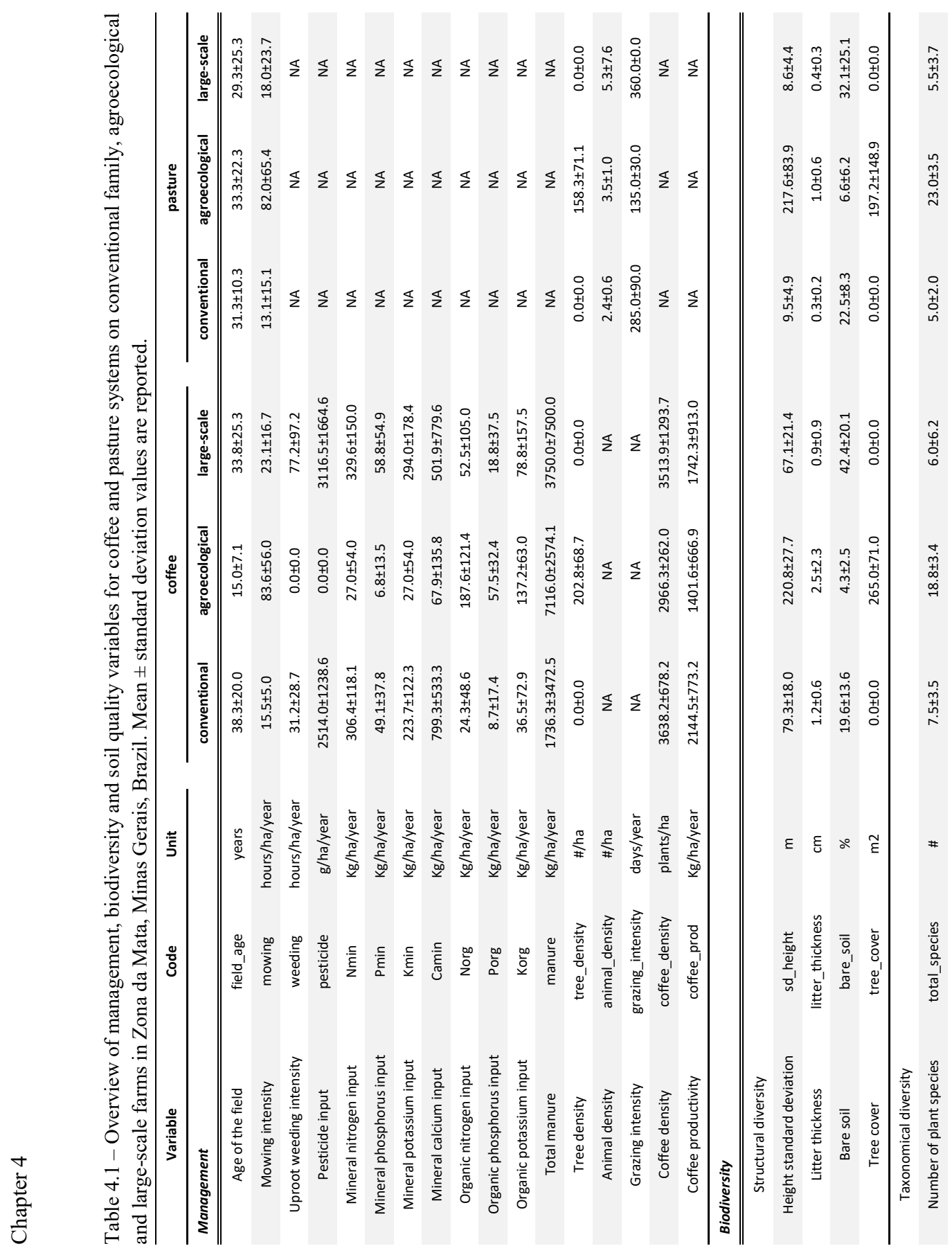




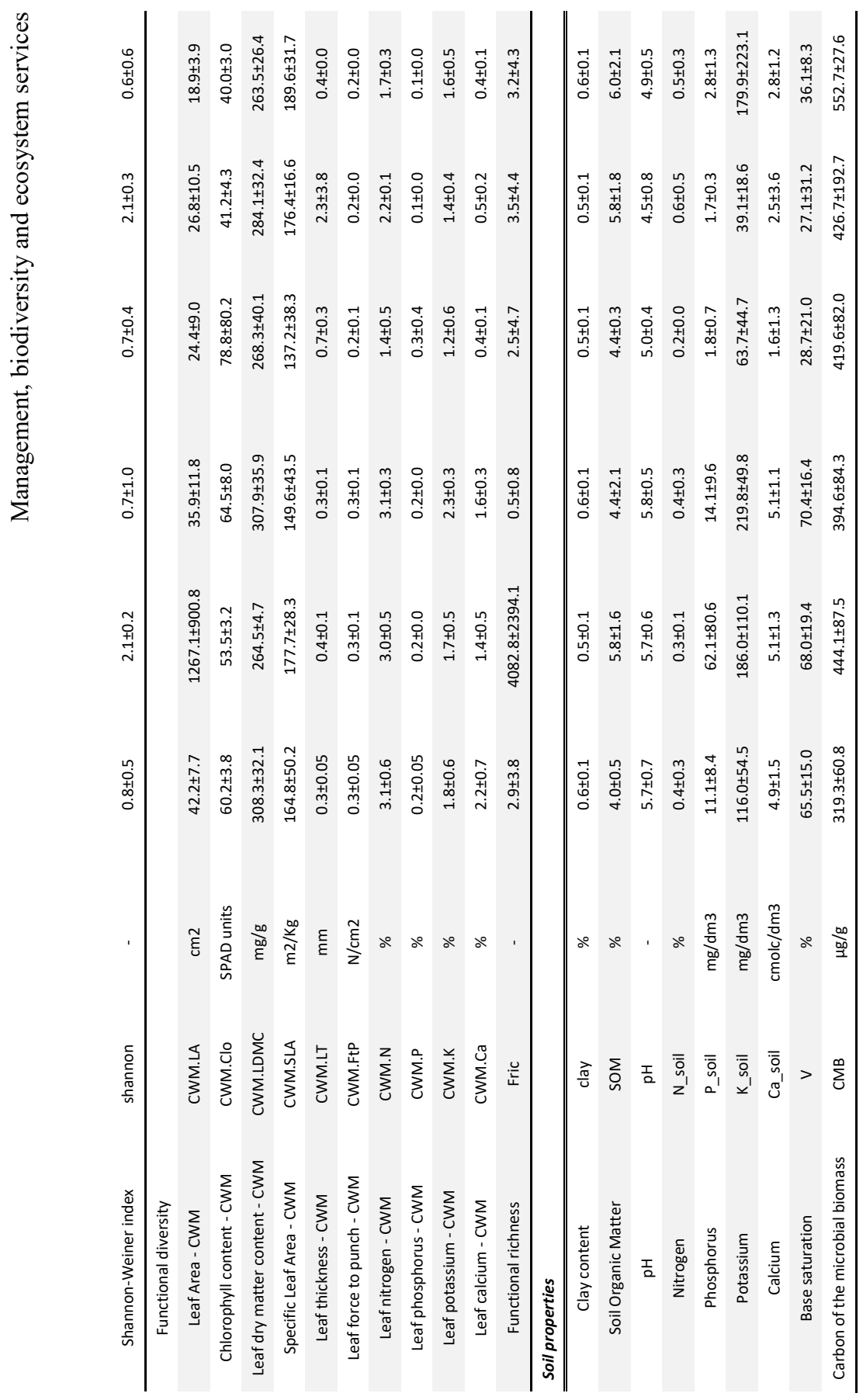




\section{Chapter 4}

\subsection{Soil quality}

In the case of coffee, the first two PCA axes (PC1 and PC2) account together for 59.4\% of the variability in the data set. Soil PC1 can be interpreted as a soil chemical quality gradient, as it was positively correlated with soil $\mathrm{pH}(+0.95)$, base saturation $(+0.95)$, soil calcium $(+0.55)$ and soil phosphorus $(+0.46)$, and negatively correlated with soil organic matter $(-0.51)$ and soil nitrogen (-0.51). In contrast, PC2 can be interpreted as a soil biological quality gradient, as it was strongly positively correlated with carbon of the microbial biomass $(+0.86)$. PC2 was also positively correlated to soil phosphorus $(+0.64)$, soil potassium $(+0.60)$ and soil organic matter $(+0.46)$. There is no clear separation among farm types considering their position in PC1 (soil chemical quality gradient). Regarding the position along the PC2 axis (soil biological quality gradient), agroecological fields tend to have high score values in contrast to conventional fields. Large-scale fields do not show a clear tendency.

In the case of pastures, PC1 and PC2 explained together $74.4 \%$ of the variance. Soil PC1 can be interpreted as a biological and chemical soil quality gradient, as it was positively correlated with soil calcium $(+0.92)$, base saturation $(+0.90)$, soil $\mathrm{pH}(+0.84)$, carbon of the microbial biomass $(+0.81)$, soil organic matter $(+0.80)$, soil phosphorus $(+0.65)$ and soil potassium $(+0.62)$. In contrast, soil PC2 was more strongly positively correlated with soil clay content $(+0.94)$, and can be interpreted as a soil textural gradient. Conventional fields are positioned in the left lower part of the graph (low score values for PC 1 and 2), whereas agroecological and large-scale fields did not show a clear pattern. 
Management, biodiversity and ecosystem services

\section{Coffee}
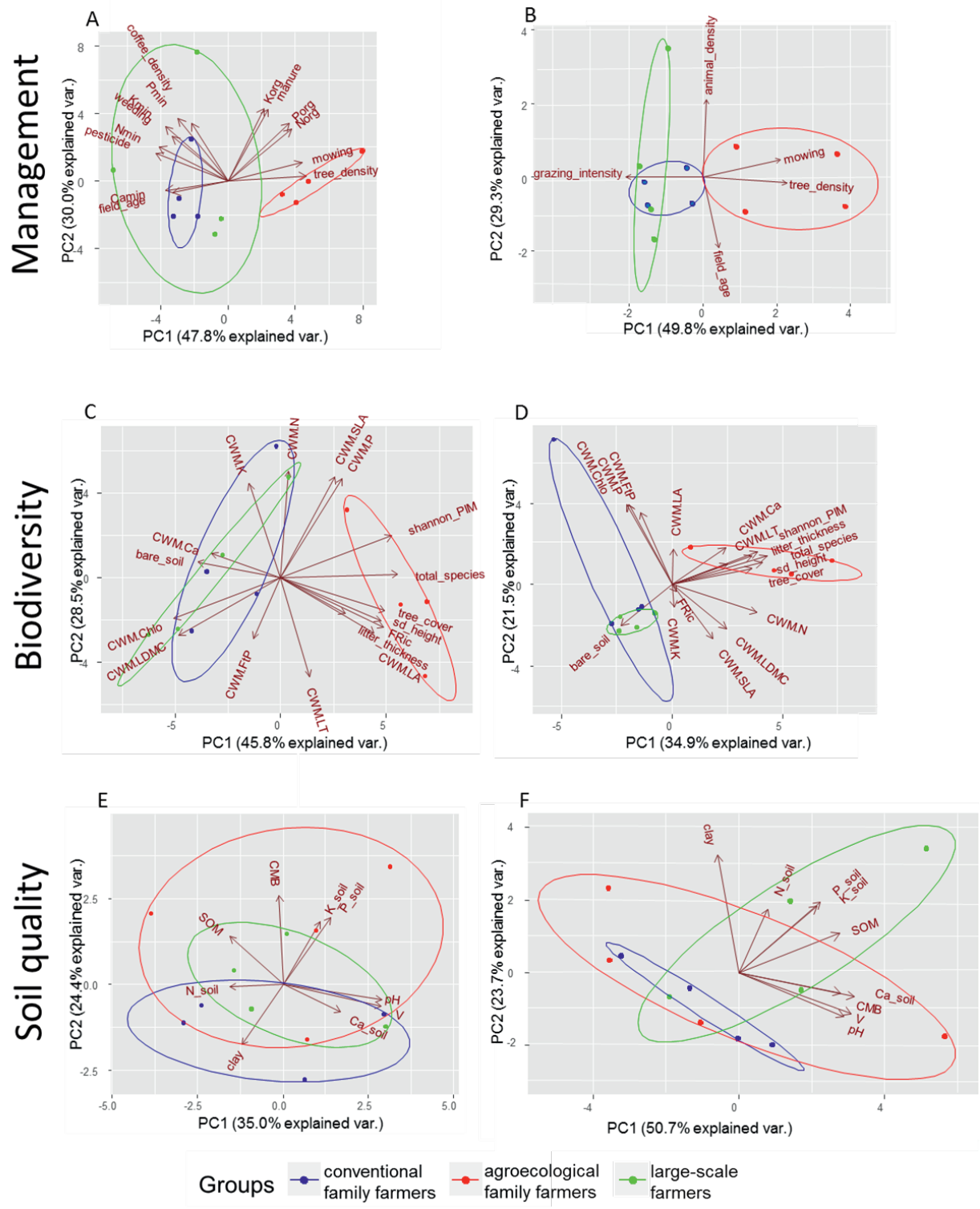

Figure 4.2. Results of Principal Component Analyses for variables associated with management, biodiversity and soil quality. Separate analyses were performed for coffee $(n=12)$ and pastures $(n=12)$. 


\section{Chapter 4}

3.4. Direct and indirect effects of management on biodiversity, soil quality and coffee productivity

The structural equation model for coffee indicated that agroecological management had a positive effect on biodiversity $(+0.793)$, which in turn had a positive effect on soil biological quality (soil PC 2) (+0.726; Figure 4.3). All other tested relationships were non-significant. In the case of pastures, agroecological management had a positive effect on biodiversity $(+0.755)$, which in turn had a positive effect on soil biological and chemical quality (soil PC 1) $(+1.027$; Figure 4.3). Surprisingly, agroecological management with lower grazing intensity also had a direct negative effect on soil biological and chemical quality $(+1.254)$.

\section{Coffee}

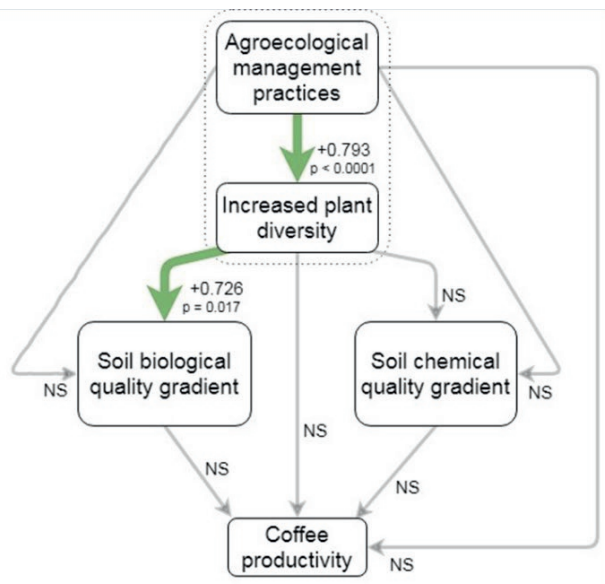

Pasture

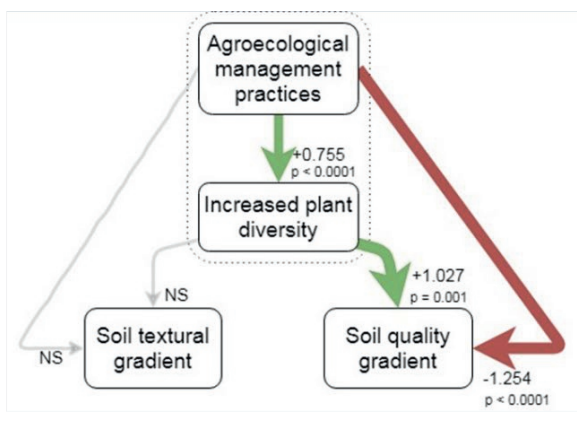

Figure 4.3. Structural equation models showing the direct and indirect effects of management on biodiversity and soil quality for coffee and pasture. In the case of coffee, coffee productivity is included as a final response variable. Standardized coefficients and significant $p$-values $(p<0.05)$ generated by the model are displayed for each green (positive associations) and red arrow (negative associations). Nonsignificant associations are represented by grey arrows. 
Linear regressions were used to illustrate the patterns found in the structural equation models. The results indicated that the increased plant diversity gradient had a positive association with agroecological management practices in the case of coffee $(\mathrm{p}=0.002)$, and also pastures $(p=0.004)$ (Figure 4.4A and D). In the case of coffee, the soil biological quality gradient was positively associated to increased plant diversity gradient $(\mathrm{p}=0.014)$ and coffee productivity had no significant association with soil chemical quality gradient (Figures $4.4 \mathrm{~B}$ and $\mathrm{C}$ ). In the case of pastures, there was no significant association between the soil quality and increased plant diversity, and between soil quality and agroecological management practices.
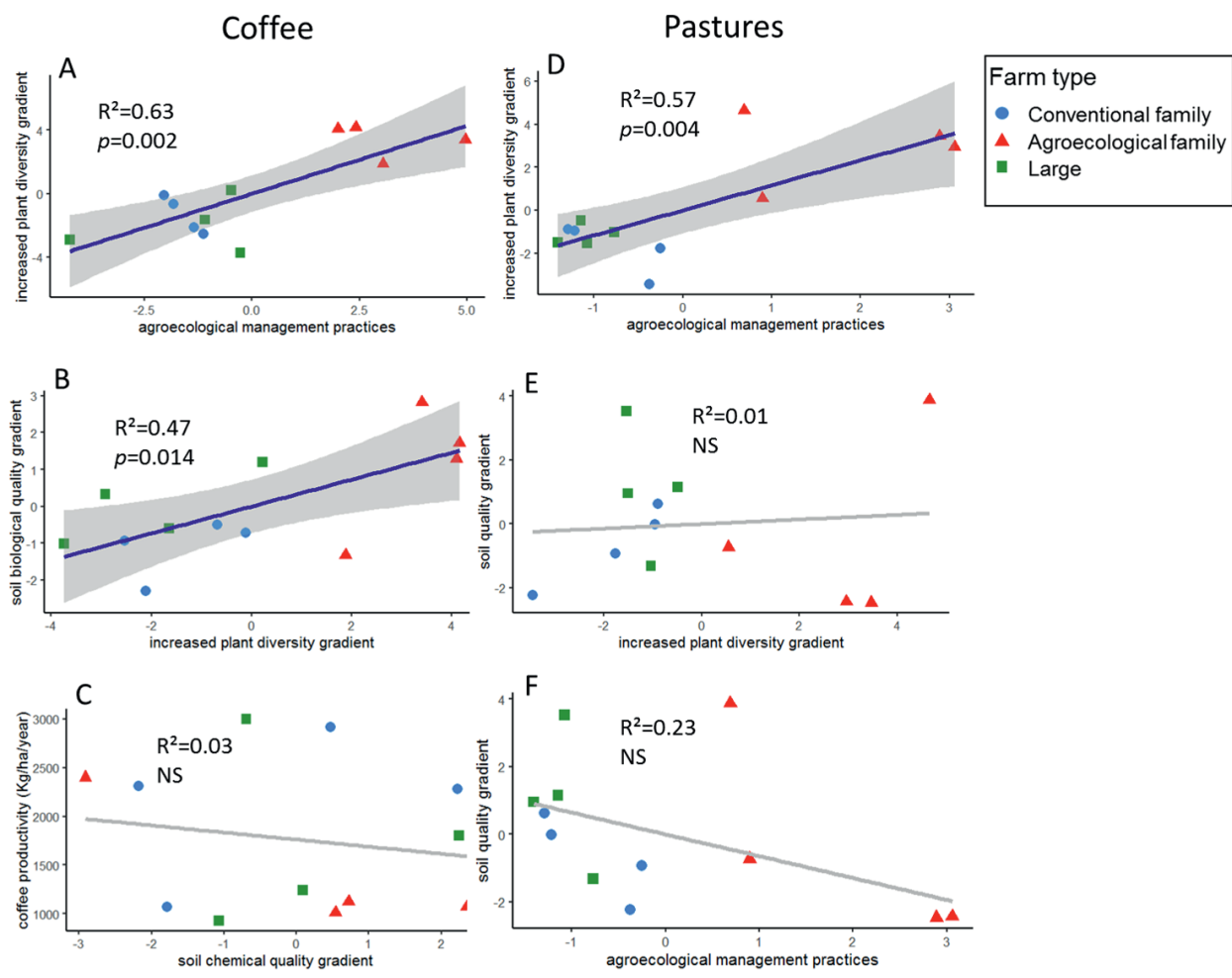

Figure 4.4. Bivariate relationships to illustrate the patterns found in the structural equation models both for coffee and pasture. 
Chapter 4

\section{Discussion}

We show that despite the higher weeding intensity and higher use of external inputs in largescale and conventional coffee farming systems, these practices did not result in increased soil quality or coffee productivity as compared to agroecological systems. In contrast, agroecological coffee management relied on increased plant diversity to maintain coffee productivity and soil chemical fertility and increase soil microbial biomass carbon in coffee fields (Figures 4.3 and 4.4). The higher plant diversity found in agroecological systems can also increase the provision of other ecosystem services, which were not assessed in the current study.

Even though pastures in Zona da Mata may be considered as a "neglected land use", as these are often extensively managed and farmers invest very little in their management (i.e. no use of inputs), we found a clear gradient of agroecological management practices (Figure 4.2B). Agroecological management practices were positively associated with tree density, and structural and taxonomical plant diversity (Figure 4.3), while conventional and large-scale fields had higher grazing intensity and less mowing (Figure 4.2B and D). The higher biodiversity associated with agroecological management in pastures resulted in increased soil fertility. Yet, agroecological management practices also had a direct negative effect on soil quality, which indicates that increased biodiversity in pastures needs to be combined with better management practices than currently adopted (Figure 4.3).

\subsection{Direct and indirect effects of management on plant diversity, soil quality and crop yield}

We found no effect of management practices on soil chemical fertility or coffee productivity (Figure 4.3). Our results suggest that despite the higher weeding intensity and more intensive use of external inputs in large-scale and conventional coffee systems, this did not result in 
increased soil chemical quality nor coffee productivity (Figure 4.2A and 4.3). In contrast, agroecological management relied more strongly on biodiversity to maintain similar levels of coffee production and soil nutrients, and even higher levels of soil biological quality (Figure 4.3). This is probably because the higher species diversity was associated with higher soil cover, structural heterogeneity and functional diversity (Figure 4.2C), creating favourable conditions for macro and microorganisms to recycle nutrients and carbon (Duru et al., 2015b; Faucon et al., 2017; Lange et al., 2015; Lemanceau et al., 2015). For example, the higher species richness in coffee systems was positively associated with microbial biomass carbon, and litter thickness was positively associated with soil organic matter (Appendix 4.F). These findings challenge the current role of industrial inputs and intensive weeding for obtaining a successful agricultural production (Catarino et al., 2019; Hassanali et al., 2008; Lechenet et al., 2017). Even in cases when yield is reduced in agroecological systems, reduced costs of external inputs and machinery can compensate the yield gap (Jezeer et al., 2018; Uphoff, 2017). Furthermore, agroforestry and diversified coffee systems can provide additional income from other products rather than coffee, such as fruits and wood (Souza et al., 2010). Beyond economic costs, reducing the dependency on pesticides is urgent to reduce impacts on the environment and human health (Chaza et al., 2018; Dromard et al., 2018; Müller et al., 2017; Rodríguez et al., 2017). Especially in developing countries, our findings are confirmed by large-scale studies, which reinforce that sustainable and agroecological practices can not only increase or maintain similar yields as conventional practices, but also improve the natural, human and social capital of the farms (Pretty, 2008; Schutter, 2010; Tully and Ryals, 2017).

In the case of pastures, we did not assess animal productivity, which limits the scope of our analysis. Still, we found that increased biodiversity due to agroecological management in 


\section{Chapter 4}

pastures did have a positive effect in soil quality, probably due to higher plant structural heterogeneity and soil litter cover (Figure 4.3, Appendix 4.F; Cardozo Junior et al., 2018). Surprisingly, agroecological management practices also had a direct negative effect on soil fertility. Although these associations were only observed in the structural equation models, and not in the bivariate linear regressions (Figure 4.4E and F), the negative relationship between agroecological management practices and soil quality in pastures may be explained in different ways. First, the lower grazing intensity associated to agroecological management may result in lower carbon and nutrient input from animal manure and urine, as well as lower below ground input of organic matter conditioned by the process of root die-off as a consequence of grazing (Sato et al., 2019). Second, conventional and large-scale systems displayed high cover of exotic grasses such as Brachiaria spp. These exotic grasses have a short but dense root system, which can result in increased soil nutrient concentrations and soil microbial biomass in the superficial soil layer (Gichangi et al., 2016). Nevertheless, soil physical indicators, such as water infiltration rate, compaction, density and porosity are expected to be negatively correlated with more intensive grazing and should be further explored in future studies (Bonetti et al., 2019; Vandandorj et al., 2017). Water was identified by farmers in Zona da Mata as one of the most important ES (Teixeira et al., 2018b) and the soil physical indicators are crucial to understand water dynamics in pastures, which is of major importance for avoiding problems such as soil erosion and water run-off in mountainous areas (Roesch et al., 2019). Our results indicate that increased biodiversity in pastures can be a good strategy to enhance ecosystem services, but it needs to be combined with better management practices than currently adopted. Therefore, more action-oriented research is needed to inform sustainable pasture management considering the provision of multiple ecosystem services as this has been a largely overlooked aspect in Zona de Mata. 
Management, biodiversity and ecosystem services

\subsection{Contrasting plant diversity attributes}

Agroecological systems displayed higher plant species richness, which was positively associated with structural diversity (i.e. variance in height), soil cover and litter thickness in both pastures and coffee systems (Figure 4.2C and D). Agroecological farmers adopt practices aiming to increase local plant diversity, such as planting or regenerating trees and mowing the spontaneous vegetation (Figures 4.2A, B, C and D). Previous studies in Zona da Mata show various benefits of tree canopy cover, such as temperature regulation (Gomes et al., 2016), biological control (Moreira et al., 2019; Rezende et al., 2014), environmental filter against exotic weeds (Ramos et al., 2015), production diversification (Souza et al., 2012b) and soil quality (Cardoso et al., 2003b). In addition to trees, agroecological farmers also allowed the spontaneous vegetation to grow, and controlling it with mowing instead of intensive uproot weeding or herbicides (Figure 4.2A). In contrast to uproot weeding and herbicide use, mowing can increase plant diversity (Figure 4.3) and associated ecosystems services. For instance, less intensive weeding strategies can lead to diversified plant communities, which may support pollinators and natural enemies of pests (Kovács-Hostyánszki et al., 2017). Therefore, as a cascade effect, higher planned biodiversity could result in more associated biodiversity, as new species can be attracted to the area, generating higher multi-trophic diversity both above and below ground (Duru et al., 2015b; Scherber et al., 2010). Previous studies show that higher plant taxonomic diversity was positively associated with diversity of birds, insects, and soil microorganisms (Naeem et al., 2012), including mycorrhiza fungi (Cardoso et al., 2003a). Furthermore, taxonomical diversity was positively associated with variation in vegetation structure, which can play an important role for ecosystem functioning as diversified agroecosystems with high structural heterogeneity may efficiently capture and recycle resources, such as water and light, due to niche differentiation (Nair, 2017; Yachi and Loreau, 


\section{Chapter 4}

2007). Furthermore, as diversified systems were associated to higher soil litter cover (Figure 4.2C and D), they may have good potential to provide associated soil functions, such as water infiltration and erosion control (Liu et al., 2018; Lohbeck et al., 2017; Nzeyimana et al., 2017).

In the case of coffee, taxonomic and structural diversity were also strongly positively correlated to functional richness (Figure 4.2C), suggesting high occupation of the niche space and limited niche overlap among species (Díaz and Cabido, 2001). This was not the case for pastures (Figure 4.2D), which indicates that an increase in the number of plant species was not strongly associated with an increase in functional richness. This can be explained by the high cover of different grass species that have similar leaf functional traits, suggesting that grass species perform similar functions in the system. For both coffee and pastures, differences in functional composition (i.e. CWM's) among systems were mostly observed in biodiversity PC2, which explained $28,5 \%$ and $21.5 \%$ of the variance in coffee and pastures, respectively. In both cases, PC2 was not useful to detect differences among farm types. In the case of coffee, the variation in CWM values reflects the leaf economic spectrum (Salguero-Gómez et al., 2016; Wright et al., 2004), ranging from systems dominated by soft and nutrient rich leaves (high SLA and N, P and $\mathrm{K}$ content) to systems dominated by more conservative species, with tougher leaves (high FtP, LT and LDMC). In the case of pastures, no clear pattern could be detected probably because of the similarity of functional trait values among grass species. In addition, other factors than farm diversity (e.g. altitude) may be influencing changes in functional composition (Sandel et al., 2016), which is beyond the scope of the present study. 
Management, biodiversity and ecosystem services

\subsection{Soil quality indicators}

Differences in soil quality among the three farm types was less prominent than differences in management and biodiversity, both in pastures and coffee (Figures 4.2E and F). The limited contrast in soil quality between farm types may be explained by the fact that most of the indicators that we used were associated with soil chemical quality. Agroecological practices, such as tree intercropping, abandon or reduce the use of agrochemicals, mowing instead of intensive weeding, and use of manure (Figure 4.2A) are aimed not only to provide nutrients for the soil, but also enhance nutrient cycling (Duarte et al., 2013), improve water infiltration (Meylan et al., 2017; Pires et al., 2017), increase soil cover and organic matter, and enable favourable conditions for the development and activity of soil microbiota (Rigal et al., 2019; Tully and Ryals, 2017). For instance, the practice of mowing allow weed roots to remain in the soil and the mown aboveground plant material to serve as mulch to cover the soil. The decomposition of roots and higher soil cover can lead to higher soil organic matter (Appendix 4.F) and nutrient mineralisation (Matos et al., 2011), and therefore enhance soil quality.

When focusing on the relationship among soil variables in coffee systems, the soil PC1 shows that systems with higher soil $\mathrm{pH}$, base saturation and calcium content have less organic matter and nitrogen. These results indicate that the application of limestone can increase $\mathrm{pH}$ and calcium availability, but it does not result in increased organic matter. Therefore, liming as an isolated practice may not be sustainable, since organic matter is a crucial component to guarantee soil quality in the long-term. Furthermore, overuse of limestone to regulate soil $\mathrm{pH}$ can have detrimental effects for soil organic carbon stocks in the top soil due to increased biological activity and mineralisation of soil organic matter (Haynes and Naidu, 1998; Paradelo et al., 2015). Using appropriate doses, long-term net effects of liming on soil organic matter are 


\section{Chapter 4}

expected to be positive due to soil structure improvement, especially if carbon inputs are high (Haynes and Naidu, 1998; Paradelo et al., 2015). However, this seems not to be the case in Zona da Mata, suggesting that farmers need to apply more accurate doses of limestone when necessary, as well as provide enough carbon to the soil. Soil PC2 shows the positive correlation between phosphorus, potassium, soil organic matter and microbial carbon biomass, indicating the role of microorganisms to cycle $\mathrm{P}$ and $\mathrm{K}$ and make these nutrients available for plants (Kaur et al., 2018; Meena et al., 2016). In the case of pastures, soil quality PC1 indicated a positive correlation among all variables, except for clay content, which is more strongly correlated with soil PC2. The contrast between soil $\mathrm{pH}$ and organic matter that occur in coffee systems may not have been observed in pastures because farmers did not apply any kind of inputs to regulate $\mathrm{pH}$ or to add nutrients. Therefore, the positive correlation among biological and chemical soil variables in pastures reinforces the role of carbon and microorganisms to cycle nutrients and improve soil fertility.

\section{Conclusions}

This is the first study to our knowledge that empirically tests the direct and indirect effects of changes in management (from conventional to agroecological) on biodiversity, soil quality and crop productivity. The approach allowed us to explore the complex management of agroecosystems by combining a multiple set of indicators. This is especially important when assessing realistic management scenarios, which involve multiple practices that may impact different aspects of the agroecosystem. Our results show that the positive effect of agroecological management on soil quality is mediated by increased plant diversity, highlighting the role of biodiversity for the sustainability of agroecological systems. Besides, the reduced use of industrial inputs and mowing intensity in agroecological coffee fields did not 
significantly reduce soil fertility and crop yield. Therefore, we suggest that agroecological practices that promote biodiversity, soil quality and farmers`autonomy can be efficient to maintain satisfactory crop yields and soil fertility without the need of intensive use of external inputs and weeding. Future studies are needed to further understand the direct and indirect impact of agroecological management on multiple ecosystem services, considering other regions, countries and cropping systems. For that, it is necessary to combine efforts of researchers from different disciplines to capture the complex provision of interconnected ecosystem services that occur at field, farm and landscape levels.

\section{Acknowledgments}

This work is part of the FOREFRONT programme, funded by the Interdisciplinary Research and Education Fund (INREF) of Wageningen University \& Research. We thank Stichting Het Kronendak, FAPEMIG and CNPq for the additional funding support. We thank Tales Theodoro, Lisa Freitag, Bruna Carolina da Silva Goulart and other students for their help with the biodiversity assessment and the measurements of soil variables and functional traits in the lab. We specially thank all the farmers whom shared their knowledge and provided shelter and food during fieldwork. Finally, we would like to thank the CTA-ZM and farmer organisations' in Zona da Mata for supporting our research. 
Chapter 4

\section{Appendices}

Appendix 4.A - Variance explained by each principal component in the Principal Component Analyses (Figure 4.2).
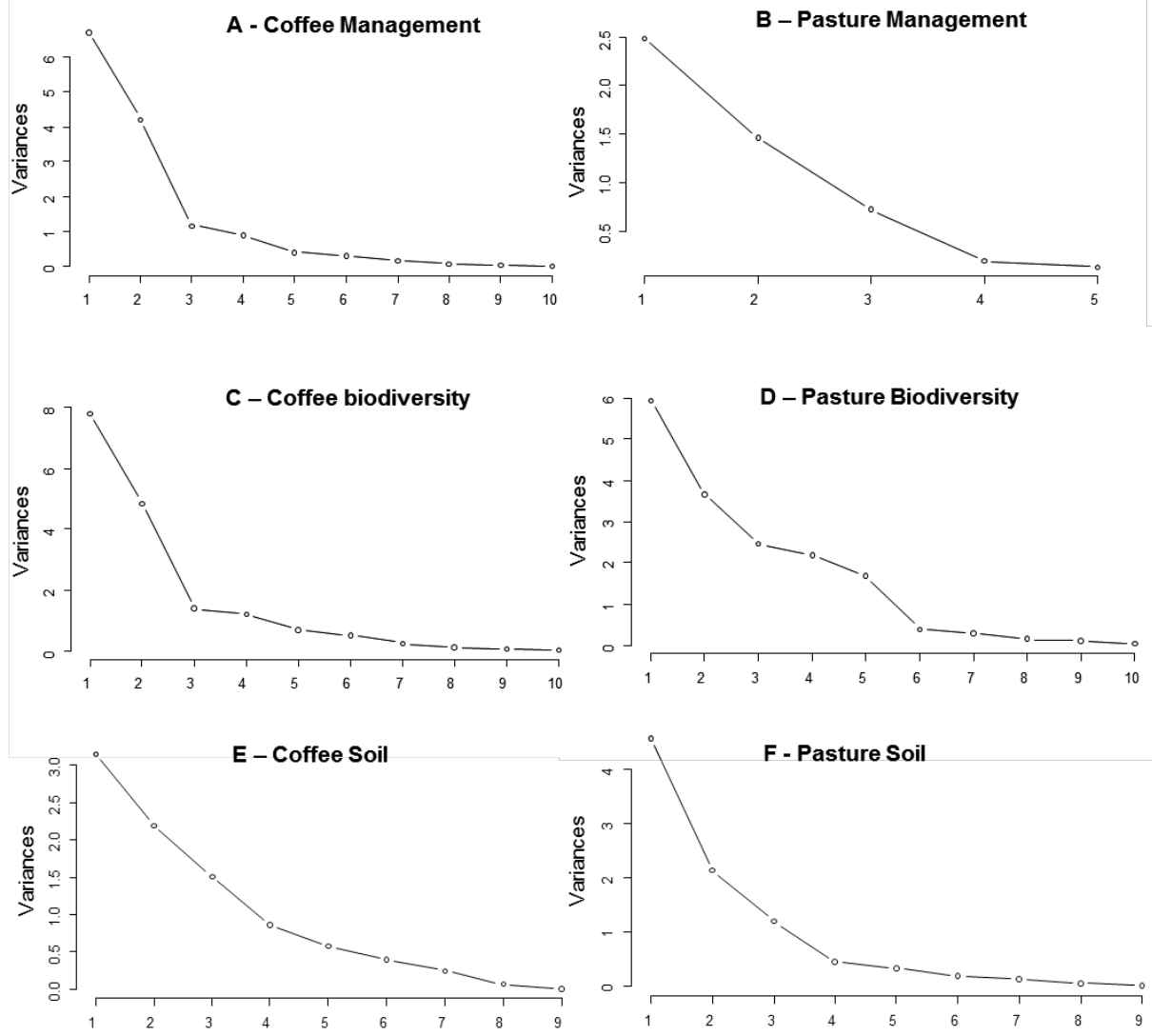
Management, biodiversity and ecosystem services

Appendix 4.B - Correlation coefficients of selected variables with PC1, PC2 and PC3 as shown in Principal Component Analyses (Figure 4.2). Coefficients $\geq 0.45$ or $\leq-0.45$ are marked in bolditalic.

\begin{tabular}{|c|c|c|c|c|c|}
\hline \multirow[t]{2}{*}{ coffee management } & \multicolumn{5}{|c|}{ pasture management } \\
\hline & PC1 & PC2 & & PC1 & PC2 \\
\hline field_age & -0.64 & -0.13 & field_age & -0.18 & -0.80 \\
\hline weeding & -0.65 & 0.51 & mowing & -0.89 & 0.20 \\
\hline mowing & 0.86 & 0.22 & animal_density & -0.04 & 0.88 \\
\hline Nmin & -0.80 & 0.39 & grazing_intensity & 0.87 & 0.01 \\
\hline Pmin & -0.57 & 0.73 & tree_density & -0.95 & -0.06 \\
\hline Kmin & -0.72 & 0.63 & & & \\
\hline coffee_density & -0.41 & 0.67 & & & \\
\hline Camin & -0.71 & -0.10 & & & \\
\hline manure & 0.47 & 0.84 & & & \\
\hline Norg & 0.74 & 0.60 & & & \\
\hline Porg & 0.71 & 0.67 & & & \\
\hline Korg & 0.42 & 0.85 & & & \\
\hline pesticide & -0.83 & 0.32 & & & \\
\hline tree_density & 0.91 & 0.06 & & & \\
\hline \multirow[t]{2}{*}{ coffee biodiversity } & & & pasture biodivers & & \\
\hline & PC1 & PC2 & & PC1 & PC2 \\
\hline sd_height & 0.83 & -0.36 & sd_height & -0.88 & -0.24 \\
\hline tree_cover & 0.86 & -0.27 & tree_cover & -0.78 & -0.17 \\
\hline shannon_PIM & 0.92 & 0.34 & shannon_PIM & -0.84 & -0.35 \\
\hline total_spēies & 0.97 & 0.03 & total_species & -0.93 & -0.30 \\
\hline litter_thickness & 0.53 & -0.30 & litter_thickness & -0.77 & -0.31 \\
\hline bare_soil & -0.69 & 0.13 & bare_soil & 0.50 & 0.43 \\
\hline CWM.LA & 0.78 & -0.46 & CWM.LA & -0.02 & -0.38 \\
\hline CWM.Chlo & -0.88 & -0.34 & CWM.Chlo & 0.42 & -0.85 \\
\hline CWM.LDMC & -0.84 & -0.48 & CWM.LDMC & -0.53 & 0.47 \\
\hline CWM.SLA & 0.45 & 0.83 & CWM.SLA & -0.40 & 0.57 \\
\hline CWM.FtP & -0.23 & -0.51 & CWM.FtP & 0.30 & -0.77 \\
\hline CWM.LT & 0.24 & -0.82 & CWM.LT & -0.54 & -0.22 \\
\hline CWM.N & 0.07 & 0.88 & CWM.N & -0.83 & 0.29 \\
\hline CWM.P & 0.51 & 0.81 & CWM.P & 0.43 & -0.86 \\
\hline CWM.K & -0.26 & 0.78 & CWM.K & -0.02 & 0.24 \\
\hline CWM.Ca & -0.58 & 0.20 & CWM.Ca & -0.52 & -0.39 \\
\hline FRic & 0.85 & -0.41 & FRic & -0.05 & 0.08 \\
\hline \multirow[t]{2}{*}{ coffee soil quality } & & & pasture soil quali & & \\
\hline & PC1 & PC2 & & PC1 & PC2 \\
\hline CMB & 0.04 & 0.86 & CMB & -0.81 & 0.16 \\
\hline pH & -0.95 & -0.14 & $\mathrm{pH}$ & -0.84 & 0.35 \\
\hline P_soil & -0.46 & 0.64 & P_soil & -0.65 & -0.56 \\
\hline K_soil & -0.36 & 0.60 & K_soil & -0.62 & -0.53 \\
\hline Cā_soil & -0.56 & -0.26 & Cā_soil & -0.92 & 0.20 \\
\hline $\mathbf{V}$ & -0.95 & -0.22 & $\mathrm{~V}$ & -0.90 & 0.33 \\
\hline SOM & 0.51 & 0.46 & SOM & -0.80 & -0.31 \\
\hline clay & 0.40 & -0.58 & clay & 0.17 & -0.94 \\
\hline N_soil & 0.51 & -0.02 & N_soil & -0.23 & -0.51 \\
\hline
\end{tabular}


Chapter 4

Appendix 4.C - Results of the structural equation models for the direct and indirect effects of management on biodiversity, soil quality and in the case of coffee, coffee productivity. Standardized Root Mean Square Residual (SRMR) and Comparative Fit Index (CFI) are given as parameters for assessing the fit of each model (Figure 4.3). Values of SRMR $\leq 0.08$ and CFI $\geq 0.95$ indicate good model fit.

\begin{tabular}{lll}
\hline & SRMR & CFI \\
\hline \hline Coffee model & 0.001 & 1 \\
Pasture model & 0 & 1 \\
\hline
\end{tabular}


Appendix 4.D - Results of the structural equation models for the direct and indirect effects of management on biodiversity, soil quality and in the case of coffee, coffee productivity. Standardized estimates (regression coefficients), standard errors, z-statistic and p-values are given for all relationships tested in each structural equation model (Figure 4.3).

Model A - Coffee

\begin{tabular}{llcccc}
\hline response variable & \multicolumn{1}{c}{$\begin{array}{c}\text { explanatory } \\
\text { variable }\end{array}$} & $\begin{array}{c}\text { standardized } \\
\text { estimate }\end{array}$ & $\begin{array}{c}\text { standard } \\
\text { error }\end{array}$ & $\begin{array}{c}\text { z- } \\
\text { statistic }\end{array}$ & $\begin{array}{c}\text { p- } \\
\text { value }\end{array}$ \\
\hline \hline coffee_prod & $\sim$ coffee_soil_carbon & -0.448 & 0.332 & -1.352 & 0.177 \\
coffee_prod & $\sim$ cofee_soil_nutrients & -0.193 & 0.273 & -0.707 & 0.480 \\
coffee_prod & $\sim$ coffee_bio_index & -0.071 & 0.507 & -0.139 & 0.889 \\
coffee_prod & $\sim$ manage_index & 0.116 & 0.453 & 0.256 & 0.798 \\
cofee_soil_nutrients & $\sim$ coffee_bio_index & -0.486 & 0.416 & -1.167 & 0.243 \\
cofee_soil_nutrients & $\sim$ manage_index & 0.641 & 0.386 & 1.658 & 0.097 \\
coffee_soil_carbon & $\sim$ coffee_bio_index & 0.726 & 0.304 & 2.385 & 0.017 \\
coffee_soil_carbon & $\sim$ manage_index & -0.05 & 0.344 & -0.144 & 0.885 \\
coffee_bio_index & $\sim$ manage_index & 0.793 & 0.089 & 8.943 & 0.000 \\
\hline
\end{tabular}

Model B - Pasture

\begin{tabular}{llcccc}
\hline \multicolumn{1}{c}{ response variable } & $\begin{array}{c}\text { explanatory } \\
\text { variable }\end{array}$ & $\begin{array}{c}\text { standardized } \\
\text { estimate }\end{array}$ & $\begin{array}{c}\text { standard } \\
\text { error }\end{array}$ & $\begin{array}{c}\mathbf{z}- \\
\text { statistic }\end{array}$ & $\begin{array}{c}\text { p- } \\
\text { value }\end{array}$ \\
\hline \hline pasture_soil_nutrients & $\sim$ pasture_bio_index & 1.027 & 0.296 & 3.465 & 0.001 \\
pasture_soil_nutrients & $\sim$ manage_index & -1.254 & 0.201 & -6.236 & 0.000 \\
pasture_soil_texture & $\sim$ pasture_bio_index & -0.488 & 0.389 & -1.252 & 0.210 \\
pasture_soil_texture & $\sim$ manage_index & 0.517 & 0.377 & 1.373 & 0.170 \\
pasture_bio_index & $\sim$ manage_index & 0.755 & 0.105 & 7.188 & 0.000 \\
\hline
\end{tabular}


Chapter 4

Appendix 4.E - Matrix of residuals in correlational units (subtraction of the observed model and implied model matrices) for each structural equation model (Figure 4.3). Positive values exceeding 0.1 indicate that the model underpredicts the correlation; negative values less than -0.1 indicate that the model overpredicts the correlation.

Model A - Coffee

\begin{tabular}{lrrrrr}
\hline & cff_pr & cf_sl_ & cff_s_ & cff_b_ & mng_nd \\
\hline coffee_prod & -0.002 & & & & \\
cofee_soil_nutrients & 0.017 & 0 & & & \\
coffee_soil_carbon & 0.017 & -0.017 & 0 & & \\
coffee_bio_index & 0 & 0 & 0 & 0 & \\
manage_index & 0 & 0 & 0 & 0 & 0 \\
\hline
\end{tabular}

Model B - Pasture

\begin{tabular}{lrrrr}
\hline & pstr_sl_n & pstr_sl_t & pstr_b_ & mng_nd \\
\hline pasture_soil_nutrients & 0 & & & \\
pasture_soil_texture & 0 & 0 & & \\
pasture_bio_index & 0 & 0 & 0 & \\
manage_index & 0 & 0 & 0 & 0 \\
\hline
\end{tabular}


Management, biodiversity and ecosystem services

Appendix 4.F - Bivariate relationships individual variables that ilustrate the patterns observed in the structural equation models (Figure 4.3).

\section{Coffee}
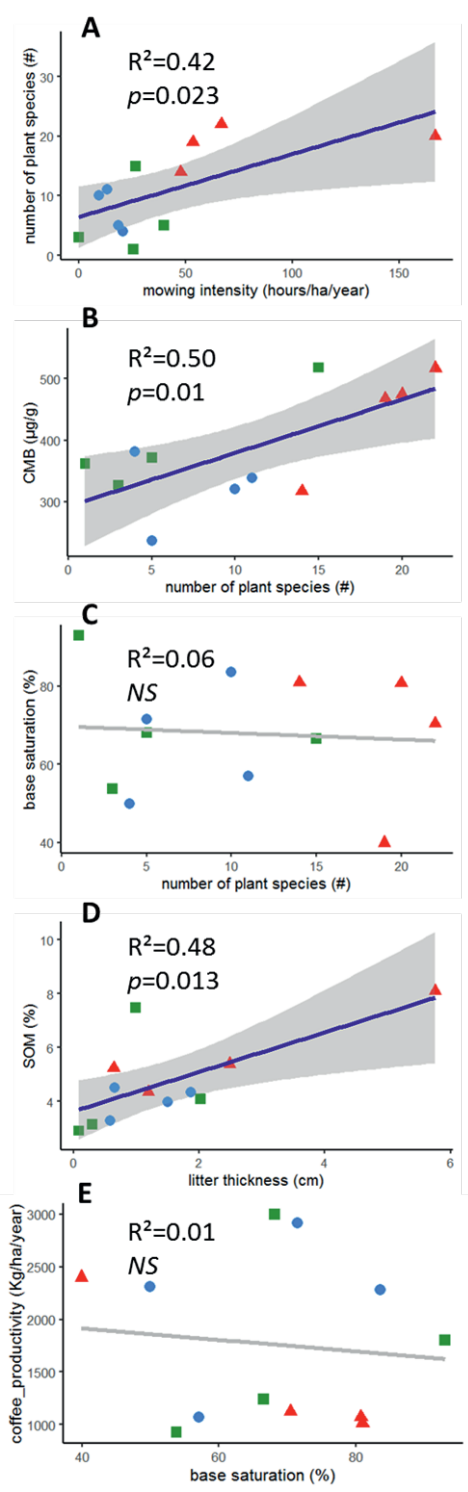

Pasture
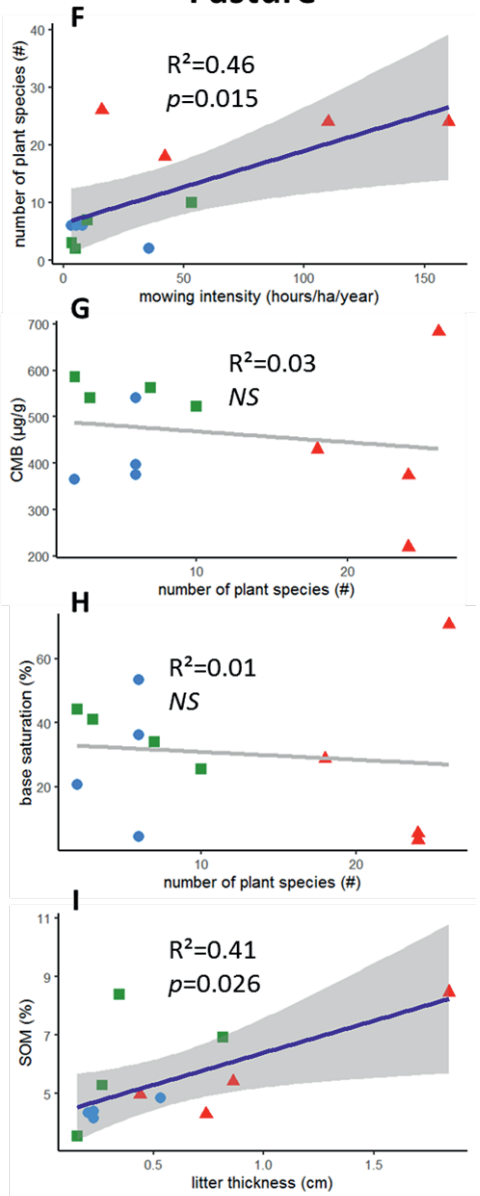

Farm type

- Conventional family

- Agroecological family

- Large 


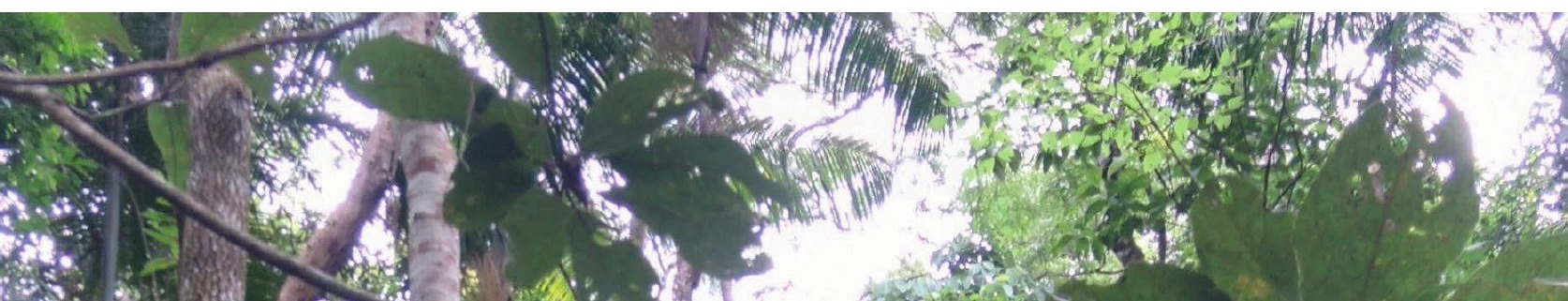

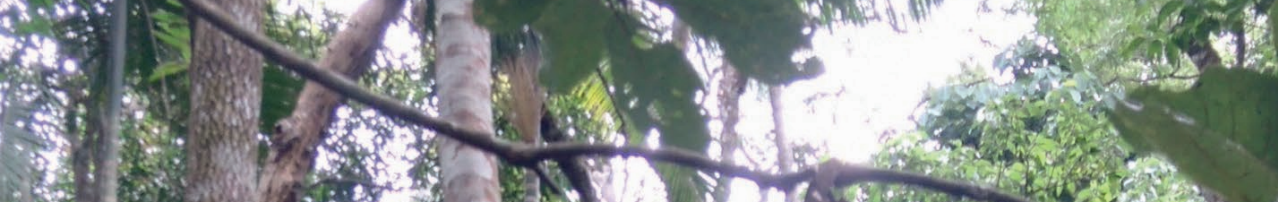

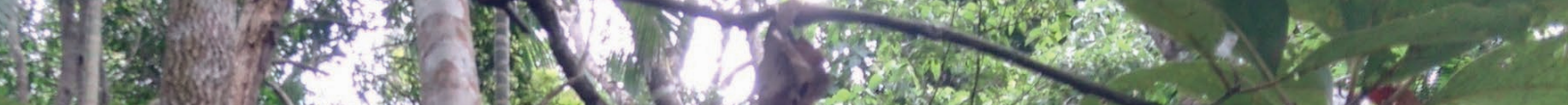

15.

25.

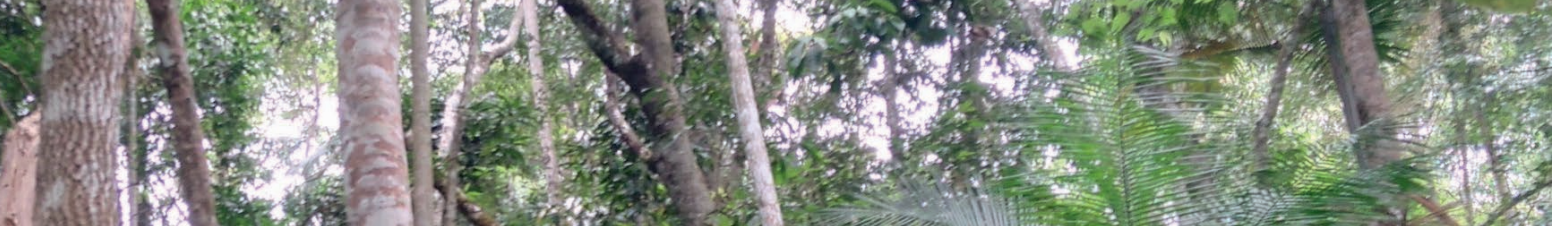

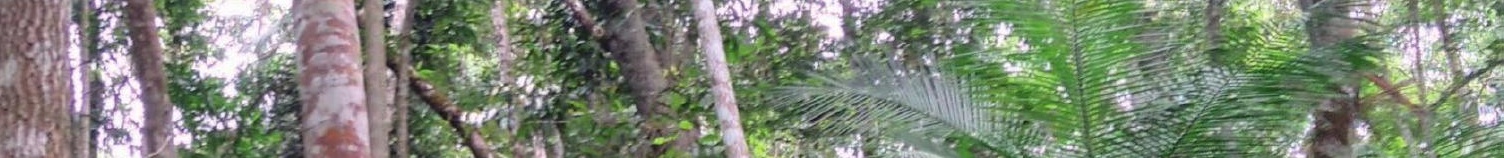

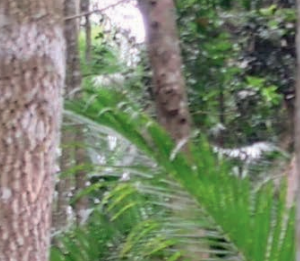

2.5int

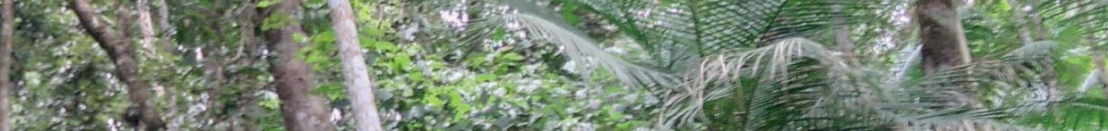

5.

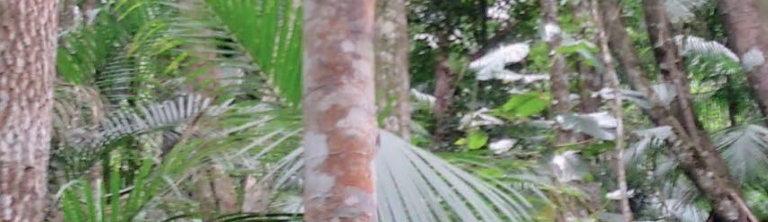

a

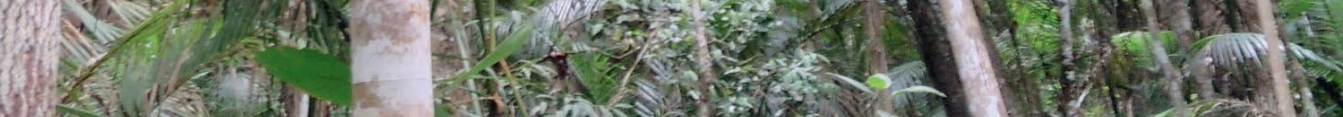

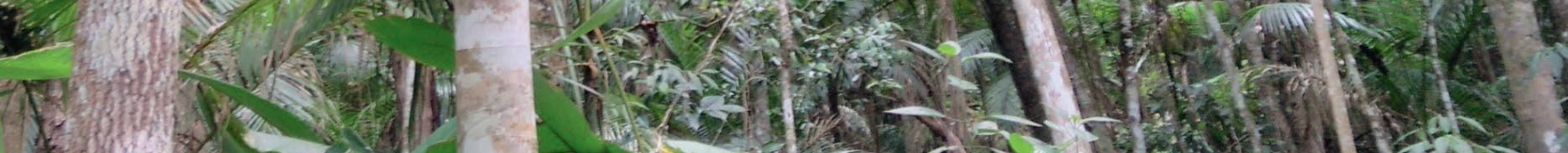

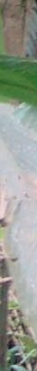

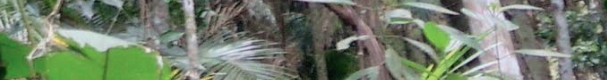

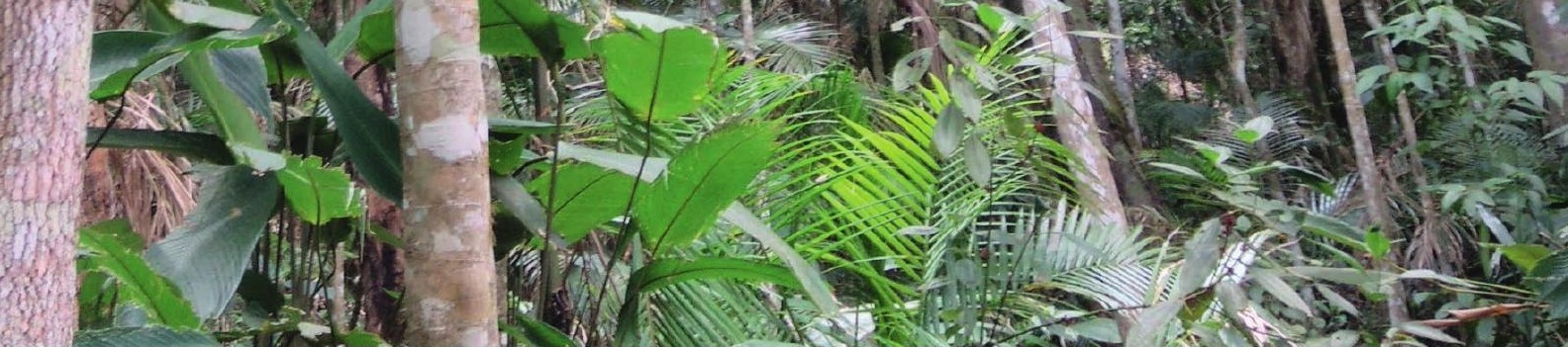




\section{Chapter 5}

\section{Linking vegetation and soil functions during secondary forest succession in the Atlantic forest}

This chapter was published as::

Heitor Mancini Teixeira, Irene Maria Cardoso, Felix J.J.A. Bianchi, Arthur da Cruz Silva, Delphin Jamme, Marielos Peña-Claros, 2019. Forest Ecology and Management, 457: 117696. 


\title{
Chapter 5
}

\begin{abstract}
Secondary forest succession can be an effective and low-cost strategy to increase forest cover and the associated biodiversity and soil functions. However, little is known about how soil functions develop during succession, and how vegetation attributes influence soil functions, especially in highly biodiverse and fragmented landscapes in the tropics. Here we assessed a wide range of indicators of taxonomic (e.g. number of tree species), structural (e.g. basal area, canopy openness) and functional diversity (e.g. community weighted means of functional traits) of tree species, as well as indicators for soil functions related to soil organic matter accumulation, nutrient cycling and soil cover in secondary forest patches ranging from 5 to 80 years. Two recently abandoned agricultural fields were included as the starting point of forest succession and two primary forest patches served as references for the end point of forest succession. Four ecological hypotheses, centred around the role of functional diversity, structural diversity and biomass, were tested to explore mechanisms in which forest vegetation may influence soil functions. Most measures of structural, taxonomic and functional diversity converged to values found in primary forests after 25-50 years of succession, whereas functional composition changed from acquisitive to conservative species. Soil carbon and nutrient cycling showed a quick recovery to the levels of primary forests after 15 years of succession. Although soil cover also increased during succession, levels of primary forests were not reached within 80 years. Variation in tree height and trait dominance were identified as aboveground drivers of carbon and nutrient cycling, while aboveground biomass was the main driver of litter accumulation, and the associated soil cover and water retention. Our results indicate that secondary forest succession can lead to a relative fast recovery of nutrient and carbon cycling functions, but not of soil cover. Our findings highlight the essential role of secondary forests in providing multiple ecosystem services. These results can be used to inform management and reforestation programmes targeted at strengthening soil functions, such as soil cover, nutrient and carbon cycling.
\end{abstract}




\section{Introduction}

Processes of ongoing deforestation and forest degradation pose a threat for biodiversity and the provision of ecosystem services (FAO, 2015), but at the same time, there is room for the restoration of 0.9 billion hectares of canopy cover worldwide (Bastin et al., 2019). Forest restoration can potentially revert environmental degradation (Reij and Garrity, 2016) and improve human well-being (Sansevero et al., 2016; Shimamoto et al., 2018). In areas where levels of disturbance are not extreme (e.g. after mining) and primary or old secondary forests as a source of seeds are present in the landscape (Sloan et al., 2016), the natural regeneration of the vegetation, also known as secondary succession, can be an effective and low-cost strategy to increase forest cover and the associated biodiversity and soil functions (Chazdon and Guariguata, 2016; Quijas et al., 2019; Shimamoto et al., 2018).

Global findings on secondary succession in the tropics indicate the high capacity of tropical forests to recover aboveground biomass after disturbances, and consequently, contribute to carbon storage and climate change mitigation (Chazdon et al., 2016; Poorter et al., 2016). Secondary forests can also be important biodiversity reservoirs, capable to restore species richness (but not floristic composition) to the level of primary forests within decades of succession (Rozendaal et al., 2019). Although global patterns of changes in vegetation composition and structure across secondary succession become more and more evident, the effects of succession on belowground properties and processes are less clear. On the one hand, organic carbon content and biological activity tend to increase with the aging of forest (Deng et al., 2013; Ferreira et al., 2018; Hall et al., 2017; Robinson et al., 2015; Yan et al., 2006). On the other hand, there are also reports that soil properties and processes are hardly influenced by successional stage, as in the case of mycorrhizal fungi species composition in the Brazilian 


\section{Chapter 5}

Amazon (Reyes et al., 2019), and organic carbon in the mid-Atlantic US (Yesilonis et al., 2016) and tropical China (Lu et al., 2015). Therefore, beyond focusing on how one or few variables respond to succession, new studies are needed to explore the ecological mechanisms that can explain changes on multiple soil functions, considering a wide variety of above and belowground indicators. For instance, changes in vegetation structure and/or composition during succession can affect the activity of enzymes and microorganisms in the soil that play a role in organic matter accumulation (Acosta-Martinez et al., 2018), which in turn, can limit soil erosion and water run-off (Liu et al., 2018). In addition, it is important to consider appropriate time scales at which forest-mediated functions recover, since belowground responses can rapidly occur in the first months or years of succession (Knelman et al., 2017), but can also take decades or even centuries to fully recover.

The effect of vegetation on the functioning of soils and ecosystems are complex, and therefore, a range of ecological indicators may be useful to capture the environmental responses to land use change and management (Fischer et al., 2019; Liu et al., 2018). Beyond species richness and floristic composition (taxonomical diversity), other vegetation attributes can also be relevant (Díaz et al., 2006). For example, structural diversity, typically assessed as the variance of total height and/or diameter, and functional composition, defined as the range and abundance of species traits, are considered main drivers of changes on ecosystem functions (Ali et al., 2016; Grigulis et al., 2007; Lavorel et al., 2011). Based on the current knowledge on vegetation and ecosystem functioning, four different ecological hypotheses are used to understand ecological mechanisms that can explain the influence of vegetation on soil functions during secondary forest succession. The niche complementarity hypothesis postulates that the greater the variability in species traits, the broader the spectrum of soil microorganisms that will be able to 
develop and cycle carbon and nutrients (Lange et al., 2015). The biomass ratio hypothesis states that functional traits of the most dominant species in the system, indicated by the community weighed means $(\mathrm{CWM})$, are the most important driver of soil ecosystem functions (Finegan et al., 2015; Grime, 1998). The structural diversity hypothesis proposes that the variance in height may have consequences for soil functions as it is a measure of the ability of the system to regenerate, efficiently capture light and retain water (Ali et al., 2016). Finally, the green soup hypothesis states that age of the forest, and consequently, the forest biomass, is the most direct driver of soil functions (Lohbeck et al., 2015). Despite the large theoretical background, few studies have shown empirical evidence on the mechanistic effect of different vegetation attributes on ecosystem functions. Besides, the focus of existing studies is often on soil chemical and physical properties, litter and other aboveground functions (Ali et al., 2016; Finegan et al., 2015; Lohbeck et al., 2015; van der Sande et al., 2017a), whereas the effects on soil microbiology remain poorly understood, especially in highly biodiverse and fragmented landscapes in the tropics (Mendes et al., 2019; Shimamoto et al., 2018).

In our paper, a combination of above and belowground properties and processes were used as indicators of the soil functions: (i) soil cover, (ii) carbon regulation, and (iii) phosphorus cycling. The study was conducted in Zona da Mata, a mountainous region located in the south eastern area of the state of Minas Gerais, Brazil. The region is a highly fragmented and human modified landscape that is part of the Atlantic forest biome, recognised as the 5th hotspot of biodiversity in the world (Myers et al., 2000). The recovery of secondary forests in Zona da Mata can be an efficient strategy to increase the provision of ecosystem services of local and global importance, such as such as water regulation, soil erosion control, carbon storage and production of forest 


\section{Chapter 5}

products. The general aim of this paper is to assess the effect of secondary succession on vegetation and soil functioning. Two specific research questions were addressed:

(i) How do vegetation and soil functions change in response to forest age?

(ii) What ecological mechanisms can explain the influence of vegetation on soil functions during secondary forest succession?

\section{Material and methods}

\subsection{Study site}

The Atlantic forest biome is considered a hotspot of biodiversity (Myers et al., 2000). Currently only around $6 \%$ of the original total cover of the Atlantic forest still remains (SOS Mata Atlântica and INPE, 2013), mainly due to illegal logging and expansion of the agricultural frontiers in the last 200 years. The Zona da Mata region is located within the Atlantic forest and its vegetation is classified as seasonal semi-deciduous (SOS Mata Atlântica and INPE, 2013) because the vegetation is conditioned by two well-defined seasons along the year: a dry cold versus rainy warm period and because up to $50 \%$ of the tree species can lose (part of) their leaves during the dry period (IBGE, 2012). The average temperature in the region is $19^{\circ} \mathrm{C}$ and average precipitation is $1300 \mathrm{~mm}$ (de Mello et al., 2007; Golfari, 1975). The landscape is mountainous, leading to heterogeneous bio-physical conditions, predominance of family farmers and limiting mechanization, as heavy machinery is hard to operate in steep areas (Andrade et al., 2012; Valverde, 1958). The main soil type dominating the upper slopes is classified as Oxisol, which is highly weathered, deep, well-drained and acidic (Sarcinelli et al., 2009). The landscape in Zona da Mata can be understood as a dynamic mosaic of land uses (Vandermeer and Perfecto, 2007) predominated by pastures, coffee fields and secondary forest patches. The study was conducted in a community located in the municipality of Divino. The 
municipality has a strong tradition with coffee and milk production, as in the rest of the region. More than $75 \%$ of the farms are considered family farmers (IBGE, 2006) and forest cover is around 30\% (Carvalho, in review). The altitude of the study area ranges from 900 to 1305 m.a.s.l. We selected this particular study area because there is an active farmer community that is interested in maintaining and increasing forest cover to improve the provision of ecosystem services, such as soil erosion control and water regulation.

\subsection{Selection of forest patches and allocation of plots}

A chronosequence approach was used for studying the temporal dynamics of plant communities and soil functions across secondary forest succession after agricultural abandonment. A chronosequence consists of space-for-time substitutions, enabling the assessment of changes across long time-scales (Walker et al., 2010). Our time series included the following areas: two recently abandoned pasture and coffee fields ( 0.5 and 1 year), eight secondary forest patches with age ranging from 5 to 80 years, and two forest patches of primary forest ( $>100$ years). The latter plots were used to provide a baseline for "desirable" or optimum indicator values (Rozendaal et al., 2019). Our sample size was restricted because of the limited availability of forest patches in the study area that matched our selection criteria (see below).

The criteria for plot selection were forest age and position in the landscape. The specific age of each patch since abandonment (age) was assessed by interviewing farmers who were knowledgeable about the history of the sites. We interviewed farmers individually, which allowed us to triangulate and validate the information provided by farmers. We chose this method because tropical trees often do not show clear distinction between year rings and because satellite images often fail to provide accurate information (i.e. first years since abandonment 


\section{Chapter 5}

cannot be detected). In each of the twelve areas, a $45 \times 20 \mathrm{~m}$ plot was established. The longest central axis of the plot $(45 \mathrm{~m})$ was allocated uphill, in the convex part of the soil landscape to standardize soil type and natural conditions among plots. The starting point of the central axis was randomly defined using the Random Number App. This plot size was small enough to be established in the sometimes small forest patches. Each plot was then divided into three subplots of $15 \times 20 \mathrm{~m}$ to assess the relationship between vegetation composition and structure and soil functions. In contrast to vegetation composition and structure, variation in soil properties and processes unfolds typically at a much smaller scale than at the size of our plots (900 m2), and therefore, calculating an average of three soil composite samples for the whole plot would not be appropriate.

\subsection{Forest structure and diversity metrics}

We assessed three main attributes of tree diversity: taxonomical, structural, and functional diversity in all subplots (Table 5.1). All individuals with diameter $\geq 5 \mathrm{~cm}$ at $1.3 \mathrm{~m}$ height (DBH) were tagged, measured and taxonomically identified. Taxonomical diversity was assessed in terms of the number of tree species (total_species) and Shannon-Weiner index (shannon). Species composition similarity among subplots was assessed using a Jaccard distance based cluster dendrogram (Appendix 5.B). Forest structure was assessed in terms of aboveground biomass, total basal area and variance in basal area and height. DBH was measured with a metric tape and height was measured using a Vertex IV and Transponder T3. Aboveground biomass (above_biomass) of trees was estimated using an allometric equation developed for secondary

forests classified as seasonal semi-deciduous Atlantic forest, using height and DBH as explanatory variables $(\mathrm{AGB}=0,024530 * \mathrm{DBH} 2,443356 *$ Height0,423602; R2=95.0) (Amaro, 2010). Canopy images were taken from the forest understorey using a fish-eye lens mounted on 
Table 5.1. Overview of all variables used as metrics of vegetation composition and structure and soil functions. Data were collected in plots differing in age since agricultural abandonment (from 0.5 to 80 years) and primary forests, in Zona da Mata, Brazil. All trees $>5 \mathrm{~cm}$ in DBH were sampled in the plots.

\begin{tabular}{|c|c|c|c|c|}
\hline & Variable & Code & Unit & Indicator of \\
\hline \multicolumn{5}{|c|}{ Vegetation composition and structure } \\
\hline \multirow[t]{5}{*}{$\begin{array}{l}\text { Structural } \\
\text { diversity }\end{array}$} & Aboveground biomass & aboveground_biomass & ton/ha & $\begin{array}{l}\text { Aboveground tree } \\
\text { biomass }\end{array}$ \\
\hline & Total basal area & basal_area & $\mathrm{m}^{2} / \mathrm{ha}$ & Tree basal area \\
\hline & $\begin{array}{l}\text { Basal area standard } \\
\text { deviation }\end{array}$ & sd_basal_area & $\mathrm{m}^{2} / \mathrm{ha}$ & $\begin{array}{l}\text { Variance in tree basal } \\
\text { area }\end{array}$ \\
\hline & Height standard deviation & sd_height & $\mathrm{m}$ & Variance in tree height \\
\hline & Canopy openness & canopy_open & $\%$ & $\begin{array}{l}\text { Light incidence in the } \\
\text { forest understorey }\end{array}$ \\
\hline \multirow[t]{2}{*}{$\begin{array}{l}\text { Taxonomical } \\
\text { diversity }\end{array}$} & Number of tree species & total_species & \# & Tree species richness \\
\hline & Shannon-Weiner index & shannon & - & $\begin{array}{l}\text { Tree species richness and } \\
\text { evenness }\end{array}$ \\
\hline \multirow[t]{6}{*}{$\begin{array}{l}\text { Functional } \\
\text { diversity }\end{array}$} & Leaf Area - CWM & CWM.LA & $\mathrm{cm}^{2}$ & $\begin{array}{l}\text { Average leaf size in the } \\
\text { community }\end{array}$ \\
\hline & $\begin{array}{l}\text { Chlorophyll content - } \\
\text { CWM }\end{array}$ & CWM.Clo & SPAD units & $\begin{array}{l}\text { Average leaf chlorophyll } \\
\text { content in the community }\end{array}$ \\
\hline & $\begin{array}{l}\text { Leaf dry matter content - } \\
\text { CWM }\end{array}$ & CWM.LDMC & $\mathrm{mg} / \mathrm{g}$ & $\begin{array}{l}\text { Average leaf dry matter } \\
\text { content in the community }\end{array}$ \\
\hline & $\begin{array}{l}\text { Specific Leaf Area - } \\
\text { CWM }\end{array}$ & CWM.SLA & $\mathrm{m}^{2} / \mathrm{kg}$ & $\begin{array}{l}\text { Average leaf specific leaf } \\
\text { area in the community }\end{array}$ \\
\hline & Leaf thickness - CWM & CWM.LT & $\mathrm{mm}$ & $\begin{array}{l}\text { Average leaf thickness in } \\
\text { the community }\end{array}$ \\
\hline & $\begin{array}{l}\text { Functional attribute } \\
\text { diversity }\end{array}$ & MFAD & - & Functional trait diversity \\
\hline \multicolumn{5}{|l|}{ Soil functions } \\
\hline \multirow[t]{6}{*}{ Carbon cycling } & Metabolic quotient & $\mathrm{qCO} 2$ & $\mu \mathrm{g} \mathrm{CO}_{2} . / \mu \mathrm{g} \mathrm{C}-\mathrm{mic} / \mathrm{h}$ & $\begin{array}{l}\text { Ecosystem development } \\
\text { and disturbance }\end{array}$ \\
\hline & $\begin{array}{l}\text { Microbial biomass } \\
\text { carbon }\end{array}$ & $\mathrm{MBC}$ & $\mu \mathrm{g} / \mathrm{g}$ dry soil & $\begin{array}{l}\text { Carbon contained in the } \\
\text { living component of the } \\
\text { soil }\end{array}$ \\
\hline & Soil basal respiration & basal_respiration & $\mu \mathrm{mol} \mathrm{CO}_{2} / \mathrm{g} / \mathrm{h}$ & $\begin{array}{l}\text { Microbiological activity } \\
\text { due to mineralisation of } \\
\text { organic matter }\end{array}$ \\
\hline & Beta glucosidase activity & beta_glucosidase & $\mu \mathrm{g}$ p-nitrophenol/g dry soil/h & $\begin{array}{l}\text { Enzyme activity which } \\
\text { results in release of } \\
\text { glucose }\end{array}$ \\
\hline & Soil organic matter & SOM & $\mathrm{dag} / \mathrm{kg}$ & $\begin{array}{l}\text { Soil organic matter } \\
\text { accumulation }\end{array}$ \\
\hline & Soil water & water_soil & $\%$ & Water retained in the soil \\
\hline \multirow[t]{2}{*}{$\begin{array}{l}\text { Phosphorus } \\
\text { cycling }\end{array}$} & $\begin{array}{l}\text { Alkaline } \\
\text { phosphomonoesterase } \\
\text { activity }\end{array}$ & alk_phosphatase & $\mu \mathrm{g}$ p-nitrophenol/g dry soil/h & $\begin{array}{l}\text { Enzyme activity which } \\
\text { results in release of } \\
\text { phosphate }\end{array}$ \\
\hline & Soil phosphorus content & $\mathrm{P}$ & $\mathrm{mg} / \mathrm{dm}^{3}$ & $\begin{array}{l}\text { Available phosphorus in } \\
\text { the soil; soil fertility }\end{array}$ \\
\hline \multirow[t]{2}{*}{ Soil cover } & $\begin{array}{l}\text { Soil leaf litter carbon per } \\
\text { area }\end{array}$ & litter_leaf_carbon & $\mathrm{g} / \mathrm{m}^{2}$ & Soil litter cover \\
\hline & $\begin{array}{l}\text { Water in soil leaf litter } \\
\text { per area }\end{array}$ & litter_water & $\mathrm{ml} / \mathrm{m}^{2}$ & $\begin{array}{l}\text { Water retained in soil } \\
\text { litter }\end{array}$ \\
\hline
\end{tabular}




\section{Chapter 5}

a camera at a fixed height of $130 \mathrm{~cm}$. Images were analysed using the Gap Light Analyzer software for calculating canopy openness (canopy_open) (Fraser, 1999). Standard deviations of tree height (sd_height) and basal area (sd_basal_area) were used as proxies for structural diversity. For estimating functional diversity, five leaf traits of 70 tree species that covered on average $92.6 \%$ (range $84.3-99.4 \%$ ) of the total basal area per plot were measured. Four to ten adult and healthy individuals of each tree species were selected for functional traits measurements. When possible, all samples were taken from trees in the established plots, otherwise additional samples were taken from nearby trees in similar growing conditions. The sampling and measurement of leaves followed standardized protocols proposed by PérezHarguindeguy et al. (2013). The leaf petiole was included in the measurements. In the case of compound leaves, the leaflet was considered as the unit of analysis. A hand-held chlorophyll meter (SPAD - Soil-Plant Analysis Development) was used to obtain leaf chlorophyll content (Chlo). Leaves were flattened and photographed, and leaf area (LA) calculated with the software ImageJ, based on pixel counting. Leaf thickness (LT) was obtained using a digital micrometer. Leaf fresh mass was measured using a precise scale of five decimal places. Then leaves were dried in the oven at $65^{\circ} \mathrm{C}$ until constant weight to obtain leaf dry mass. Leaf dry matter content (LDMC) was calculated as the ratio between dry mass (mg) and fresh mass (g). Specific Leaf Area (SLA) was calculated as the ratio between leaf area $(\mathrm{m} 2)$ and leaf dry mass $(\mathrm{kg})$. The use of species average trait values was chosen for the purpose of the present study because all plots were allocated under very similar climatic and pedogenetic conditions, and therefore low intraspecific trait variation was expected. Functional trait data at species level was scaled to the community level using indices of functional diversity and functional composition. As an indicator of functional diversity, the multi-trait index Modified Functional Attribute Diversity (MFAD) was calculated based on the dissimilarity between the functional trait values of all 
selected species in each plot. For functional composition the aggregate value of leaf traits in each plot was measured using Community Weighed Mean (CWM) for each leaf trait. All diversity indices were calculate using the FDiversity software and FD package (Casanoves et al., 2011) in R 3.3.3.

\subsection{Soil-related functions and properties}

Leaf litter samples were taken in a 1-m2 quadrant in the centre of each 15 x 20 m subplot. The woody material (diameter $>2 \mathrm{~cm}$ ) was separated from the leaves. The litter fresh and dry weight were measured, before and after drying at $65^{\circ} \mathrm{C}$ until constant mass. The water content in the litter per area (litter_water) was calculated as the difference between the fresh and dry mass. As carbon content within plant dried material is rather constant, the amount of litter carbon per area was calculated by using the formula litter_leaf_carbon $=$ dry mass $(\mathrm{g}) \times 0.475 / 1 \mathrm{~m} 2$ (the area of the quadrant) (Magnussen and Reed, 2004).

In each subplot, five soil sub-samples were collected from the $0-10 \mathrm{~cm}$ depth layer. The five soil sub-samples were placed in a bucket and thoroughly mixed to create one single composite soil sample per subplot. The sample was divided in two parts, one half was immediately stored for the microbiological analysis in a cooler box with ice packs and stored at $4^{\circ} \mathrm{C}$ until processing in the laboratory. The other half was stored at room temperature for the chemical analysis. The microbial analyses were performed within one week of storage at the laboratory of Biotechnology and Biodiversity for the Environment at the Universidade Federal de Viçosa (UFV), Brazil. The chemical analyses were performed at the laboratory of Soil Fertility, also at UFV. All litter and soil samples were collected on the same day, in the beginning of the rainy season (September 2018), six days after a rain fall $(>10 \mathrm{~mm})$ in the study site. 


\section{Chapter 5}

Microbial biomass carbon (MBC) in the soil was determined using the fumigation and extraction method (Vance et al., 1987). Soil basal respiration (basal_respiration) was estimated from the respiration values obtained after incubation of the samples in flasks coupled to a respirometer (Sable Systems - Mod. TR-RM8 Respirometer Multiplexer), equipped with an infrared CO2 detector (Alef and Nannipieri, 1995; Heinemeyer et al., 1989). The enzyme activities were determined by colorimetry. Paranitrophenylphosphate was used as the substrate in the enzymatic reaction to determine Alkaline phosphomonoesterase activity (alk_phosphatase) (Margenot et al., 2018; Tabatabai, 1994), while p-nitrophenyl-beta-D-glucoside was used as the substrate to measure the activity of beta-glucosidase (beta_glucosidase) from the concentration of p-nitrophenol resulting from the enzyme activity after incubation of the soil samples in modified universal buffer (Eivazi and Tabatabai, 1988). The microbial metabolic quotient (qCO2) was calculated as soil basal respiration divided by microbial biomass carbon. The gravimetric method was used to calculate soil water content (water_soil), expressed as percentage of soil water to dry soil weight (Dobriyal et al., 2012). Soil phosphorus (P) was determined using a spectophotometer and Melich-1 as extractor (Mylavarapu et al., 2002). The determination of soil organic matter (SOM) was based on the Walkley-Black chromic acid wet oxidation method (Walkley and Black, 1933).

\subsection{Data analysis}

To assess how vegetation, soil properties and soil processes change during secondary forest succession (Figure 5.1) mixed effect linear models were used. Each vegetation and soil variable was included in the model as the response variable, age was included as the explanatory variable and plot was included as random factor to take into account for the lack of independence between subplots. A separate model was constructed for each response variable (Table 5.1). The 
statistical significance was assessed according to the p-values for F-tests computed using the Satterthwaite approximation. The marginal and conditional coefficients of determination $\left(\mathrm{R}^{2} \mathrm{~m}\right.$ and $\mathrm{R}^{2} \mathrm{c}$ ) were used to estimate the explained variance of each model (Nakagawa and Schielzeth, 2013). We tested both linear and log-linear responses of each variable to forest age. The model with best fit, based on p-values and coefficients of determination, was selected. Primary forest plots were not included in the regression analysis as it was not possible to determine their exact age. Instead, these data were used as reference values for the end point of secondary forest succession. The analysis was performed using the packages lme4 (Bates et al., 2015), lmerTest (Kuznetsova et al., 2017) and MuMIn (Barton, 2019) of R 3.5.3.

For the plots without trees (recently abandoned pasture and coffee fields), it was not possible to obtain values for the CWM leaf traits. For allowing the inclusion of these plots without trees in the sub-sequent analysis, two alternative mixed linear models were tested for each trait. In the first model, the plots with missing data on CWM were excluded of the analysis. In the second model, projected values for the plots with missing data based on the estimates from the first model were included. As there was no meaningful change in the estimates, we here report the second model because this allows incorporation of early succession data in the structural equation models (see below). Hence, CWM values for the first year of succession are based on extrapolation and should be interpreted with care.

To assess which diversity attributes are driving key soil functions we developed structural equation models because these models can be used to make inferences about causal relationships between multiple variables. Four alternative ecological hypotheses were used to explain changes in soil functioning in response to vegetation composition and structure: niche complementarity, 


\section{Chapter 5}

biomass ratio, structural diversity and greensoup (Figure 5.1). As there are more than one variable that can be used as indicator for each ecological hypothesis (e.g. CWM of specific leaf area and CWM of leaf dry matter content for the biomass ratio hypothesis), one representative variable was selected based on ecological knowledge and the correlation between variables (Appendix 5.A). Functional diversity was selected for the niche complementarity hypothesis because of the high correlation with indices of species diversity $(\mathrm{R}>0.9)$ (Appendix 5.A, Figure 5.4) and because functional diversity is suggested to play a larger role on ecosystem functions than taxonomical diversity (Díaz et al., 2006). For the biomass ratio hypothesis CWM of specific leaf area (CWM.SLA) was selected because of the high correlation with the other traits $(\mathrm{R}>0.7)$ and because SLA is obtained by combining two of the other traits (leaf area and leaf dry matter content) (Figure 5.4, Appendix 5.A). Variation in height (sd_height) was selected for the multilayer strata hypothesis because the other candidate variable, variance in basal area, was highly correlated with aboveground biomass $(\mathrm{R}=0.9)$ and also very sensitive to the presence of trees with very large DBH in the mature forest plots. Finally, for the greensoup hypothesis, aboveground biomass was included because it is the most direct and logical indicator of plant biomass and it was highly correlated with total basal area ( $\mathrm{R}=0.9$, Figure 5.4, Appendix 5.A). The soil functions: (i) carbon cycling, (ii) phosphorus cycling and (iii) soil cover were assessed using different measurements of soil properties and processes (Schulte et al., 2015). Metabolic quotient (qCO2), basal respiration (basal_respiration), microbial biomass carbon (MBC) and beta-glucosidase activity (beta_glucosidase) were considered as intermediate soil processes related to soil organic matter accumulation; phosphomonoesterase activity (alk_phosphatase) as an intermediate processes related to soil available phosphorus; and litter carbon per area (litter_carbon) as an intermediate soil processes related to water retention in the litter. Structural equation models were developed for each of the six intermediate soil processes. All the six 
models had the four selected diversity indicators as explanatory variables and one soil process as response variable. According to the intermediate soil process, one specific soil property was selected in each model as the final response variable (SOM, P, litter_water) (Figure 5.1).

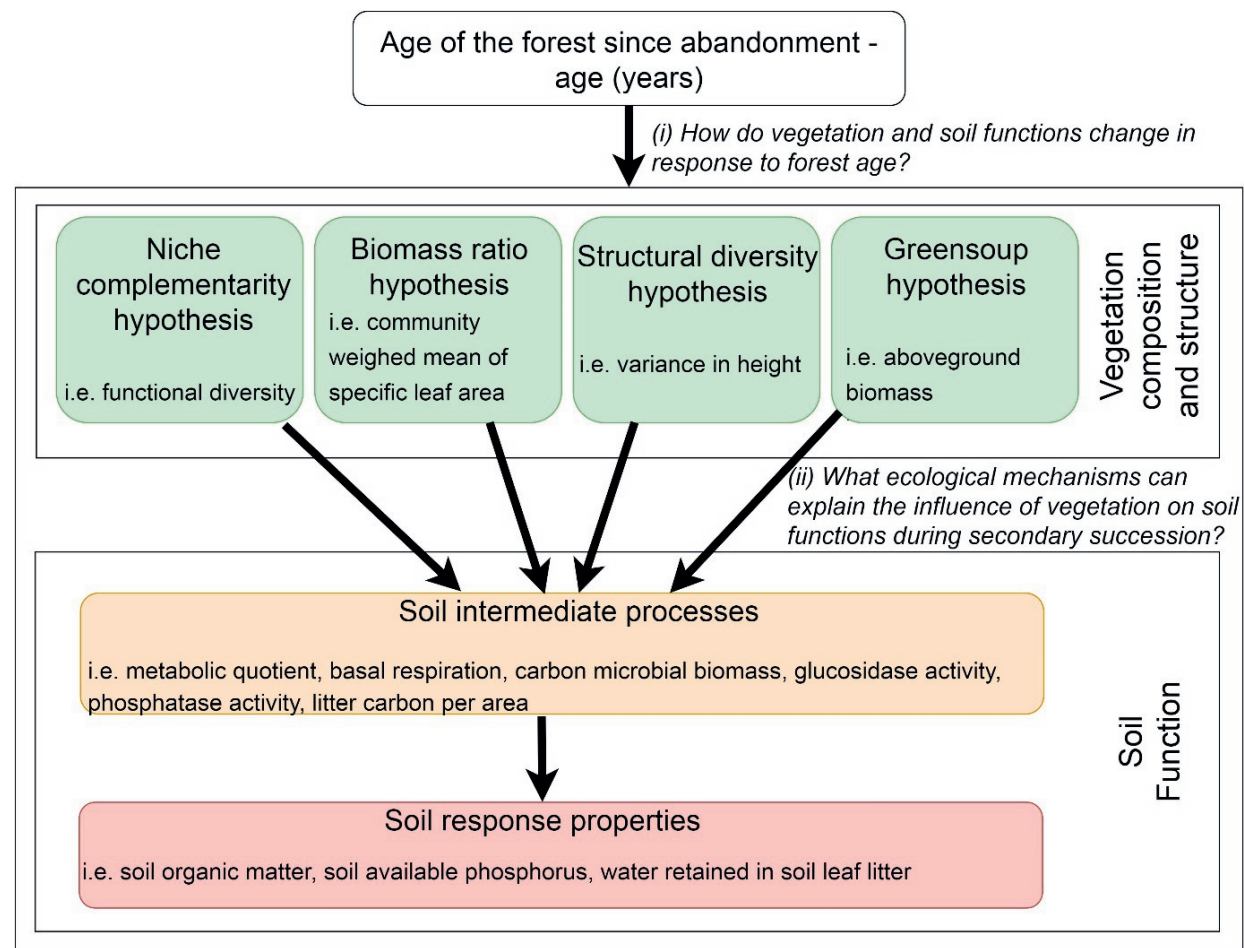

Figure 5.1. Schematic representation of the outline of the study. In the first research question, we assess the response of each above and belowground variable to forest age. In the second research question, we evaluate four hypotheses to explain how aboveground vegetation attributes influence soil functions.

The direct influence of diversity indicators on the final response variables was not tested in the model because we targeted the indirect effect of vegetation on soil properties through soil processes. In addition, we built relatively simple models (only five tested associations per model) to avoid biased estimation of path coefficients due to our relatively small sample size. We also only accepted models with a high fit $(\mathrm{CFI}>0.95$; SRMR $<0.08$; chi-square p-value 


\section{Chapter 5}

$>0.8$; Appendix 5.D) and we confirmed the significance of associations identified in the structural equation models in separate linear models.

To account for the lack of independence among subplots, adjustments to point and variance estimator were calculated using the package lavaan.survey in R (Oberski, 2014). The strength of causal relationships between variables was assessed using standardized parameter values. Relationships were considered significant when the p-value was $\leq 0.05$. The residuals of the correlational units obtained by subtracting the observed and model-implied matrices were further assessed to confirm that the model is not over or under-predicting (res $>0.1$ ) the association between variables. Calculations were made using the packages lavaan (Rosseel, 2012) and lavaan.survey (Oberski, 2014) in R 3.5.3. Correlations between the variables were calculated based on Pearson`s method (Appendix 5.A).

\section{Results}

3.1. Changes in tree diversity, tree composition, soil functions and properties during secondary succession

In total, 1639 trees (diameter $\geq 5 \mathrm{~cm}$ ) were measured, $94 \%$ of all individuals were identified at species level, $4 \%$ at genus level, $0.5 \%$ at family level and $1.5 \%$ were not identified. A total of 46 taxonomical families and 159 species were identified.

All vegetation attributes were significantly associated with age (Table 5.2). Aboveground biomass (above_biomass) and total basal area (basal_area) showed linear responses to age (Figure 5.2A, B). Standard deviation of basal area (sd_basal_area) and height (sd_height) 
Table 5.2 . Results of mixed effect linear models of vegetation and soil attributes in response to forest age (years). Age of the forest in years is the fixed effect explanatory variable, vegetation and soil attributes are response variables and plot was added as random effect variable. The marginal $\mathrm{R} 2 \mathrm{~m}$ and conditional R2c coefficients of determination indicate the explained variance of the fixed factor (age) and of the fixed and random effect (plot) of each model, respectively. p-values were obtained using Satterthwaite approximation. p-values $<0.05$ are marked in bold.

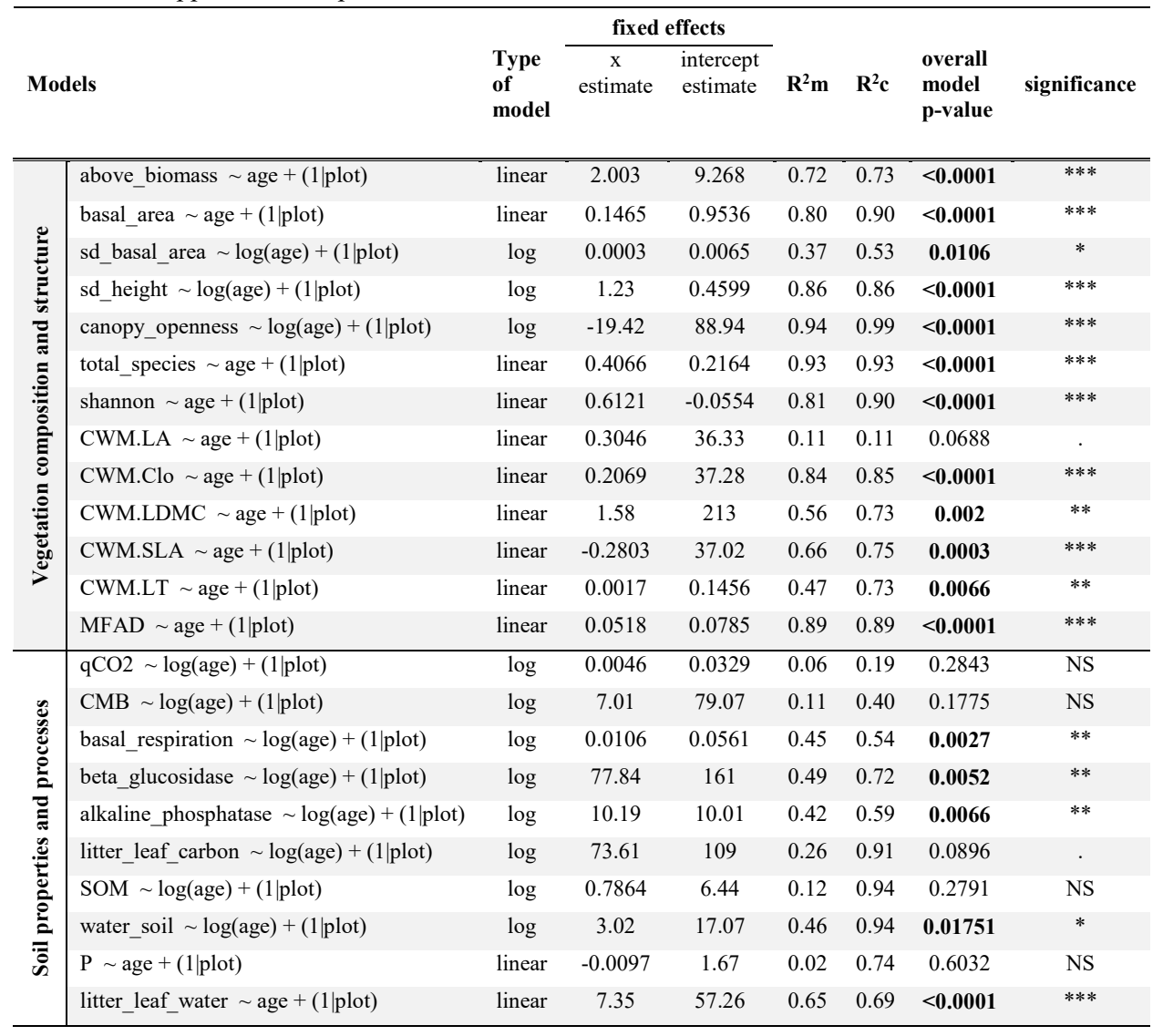

increased, and canopy openness (canopy_open) decreased in the first 30 years of secondary forest succession, and showed less prominent changes in later succession (log-linear response; Figure 5.2C, D, E). Yet, sd_height and canopy_open reached values similar to primary forests after 40 years of succession, whereas this was not the case for sd_basal_area, which values found in primary forests remain higher than values found in secondary forests. The indices of taxonomic (total_species and shannon) and functional diversity (MFAD) showed similar 


\section{Chapter 5}

responses to age, increasing through succession, and reached values similar or higher than primary forests (Figure 5.2F, G, H). Regarding functional composition, CWM of leaf area (CWM.LA), leaf chlorophyll (CWM.Clo), leaf dry matter content (CWM.LDMC) and leaf thickness (CWM.LT) increased with age, whilst specific leaf area (CWM.SLA) decreased (Figure 5.2I, J, K L, M). All functional composition variables reached in late successional stages similar values than primary forests.
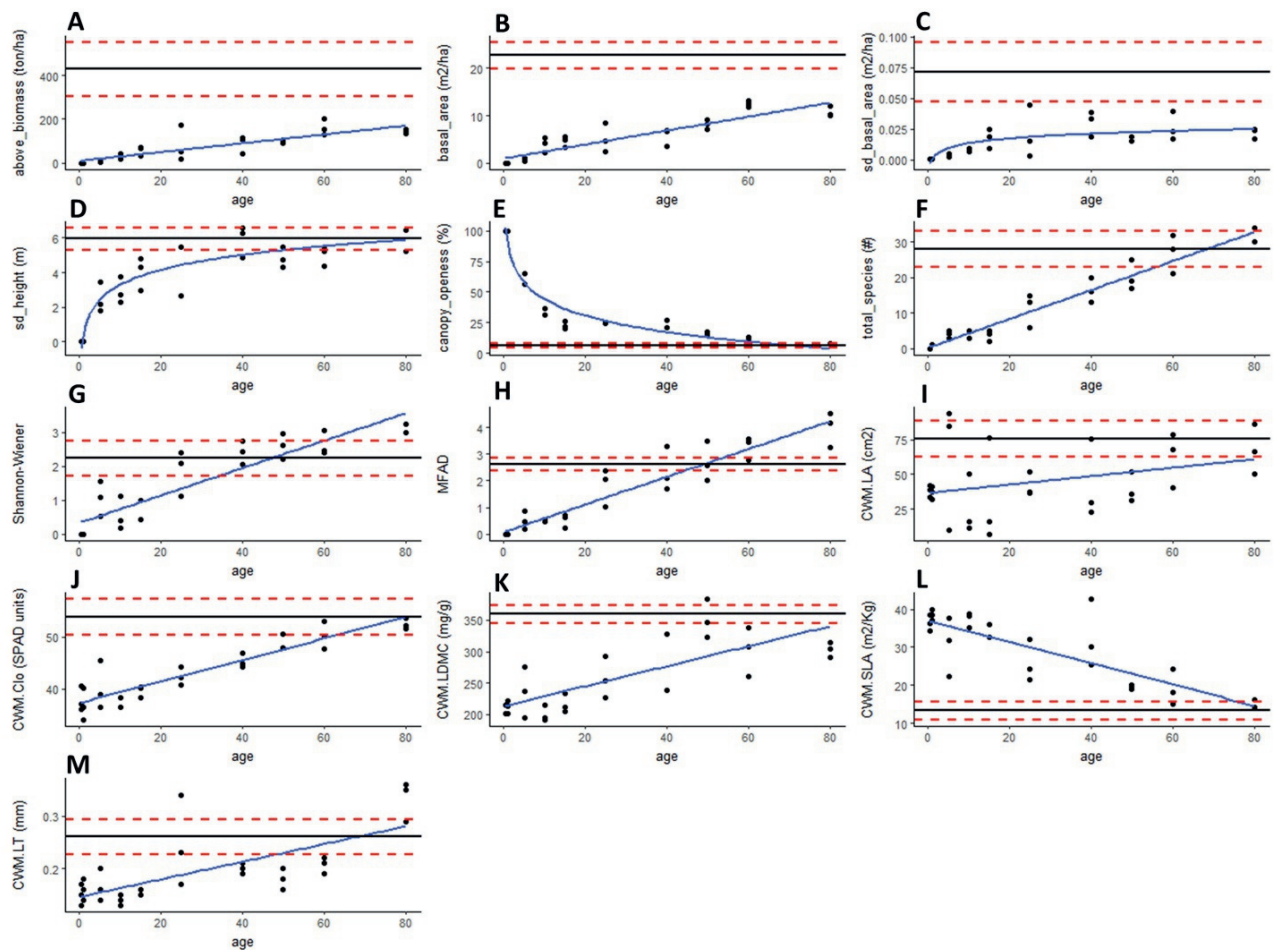

Figure 5.2. Changes in vegetation attributes in response to forest age (years). Vegetation attributes are response variables, age of the forest is the fixed effect explanatory variable, and plot is added as random effect variable. Average and standard deviation of values found in primary forests are displayed as reference values with the horizontal black (average) and dotted (standard deviation) red lines. Each dot represents one subplot. CWM leaf area had a marginally significant association with age $(\mathrm{p}<0.07)$, while all other variables had a significant response $(\mathrm{p}<0.05)$. For more information on statistical results see Table 5.2, and for full name of vegetation parameters see Table 5.1. 
Changes in species composition also showed a clear pattern across secondary succession as evidenced by the change in species dominance (Appendix 5.B - Dissimilarity cluster dendrogram). In the first years of succession, Piptadenia gonacantha is the species with greatest proportion of basal area. Across the years, the relative dominance of $\mathrm{P}$. gonacantha drops sharply until the species is no longer present in the systems after 60 years of secondary succession. In contrast, the species Euterpe edulis appears after 25 years of succession and becomes a more dominant species in primary forests (Appendix 5.C).
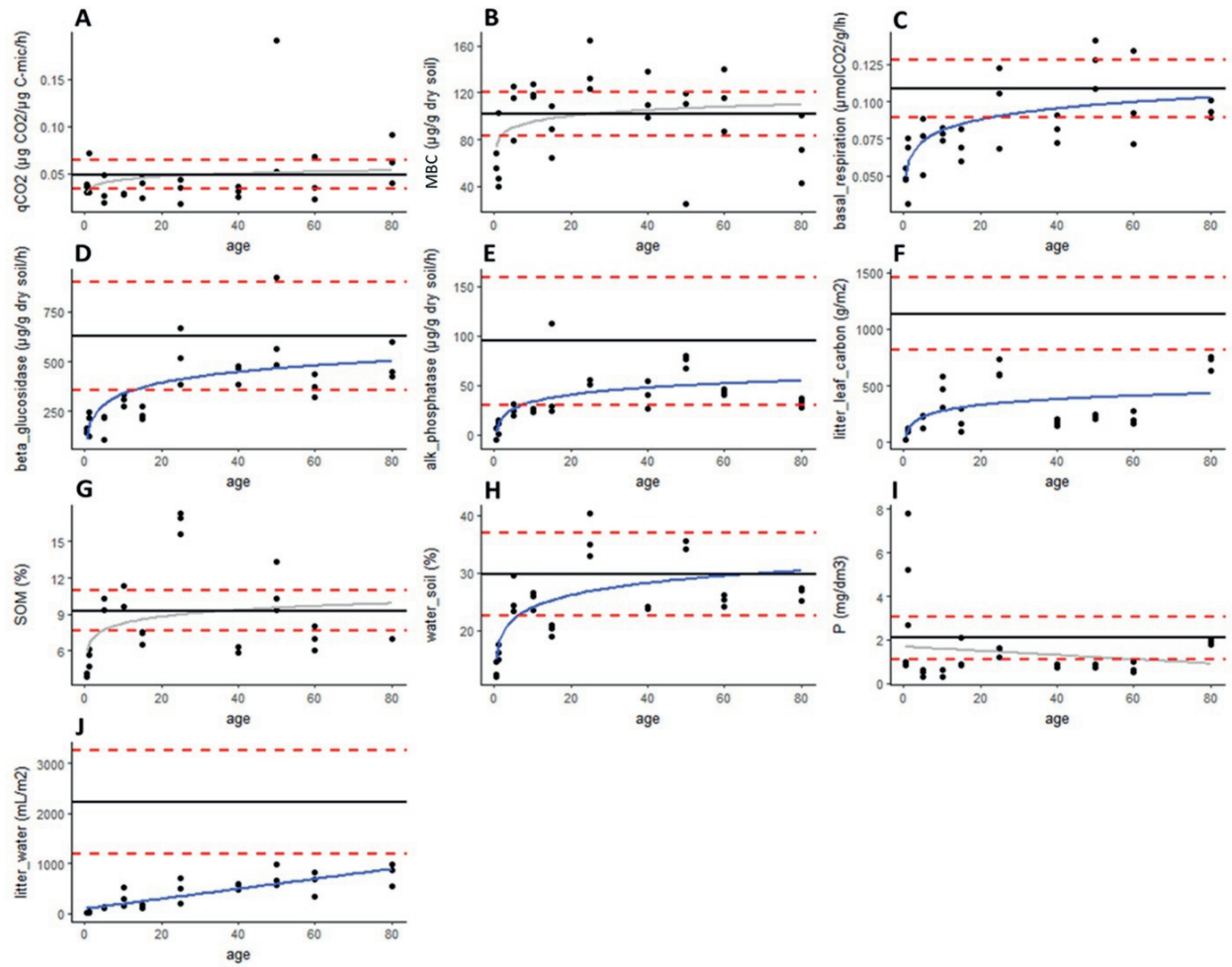

Figure 5.3. Changes in soil properties and processes in response to forest age (years). Soil properties and processes are response variables, age of the forest is the fixed effect explanatory variable, and plot is added as random effect variable. Primary forest plots were not included in the regressions. Average and standard deviation of values found in primary forests are displayed as reference values with the horizontal black (average) and dotted red (standard deviation) lines. Each dot represents one subplot. Carbon litter per area (litter_carbon) had a marginally significant association with age $(\mathrm{p}<0.09)$. Soil 


\section{Chapter 5}

metabolic quotient (qCO2), microbial biomass carbon (MBC), organic matter (SOM) and phosphorus (P) and were not significantly associated with age and indicated by grey regression lines $(\mathrm{p}>0.1)$. All other variables had a significant response $(\mathrm{p}<0.05)$. For more information on statistical results see Table 5.2, and for full name of soil parameters see Table 5.1.

The response of soil functions and properties to age were not always linear (Table 5.2). In the case of soil basal respiration (basal_respiration), enzymatic activity of beta-glucosidase (beta_glucosidase), alkaline-phosphatase (alkaline-phosphatase) and soil water (water_soil) a $\log$ linear response was observed, with a sharp increase in the first 15-20 years of succession (Figure 5.3B, C, D, E, H). Litter carbon per area (litter_carbon) had a marginally significant log linear response to age and litter water (litter_water) had a positive and linear response to age. For both variables, values found in primary forests were not reached even after 80 years of succession (Figure 5.3F, J). In contrast, soil metabolic quotient (qCO2), microbial biomass carbon $(\mathrm{MBC})$, organic matter (SOM) and phosphorus $(\mathrm{P})$ were not significantly associated with age (Figure 5.3A, G, I). Yet, soil organic matter was highly correlated with soil water $(\mathrm{R}=0.8)$.

\subsection{Drivers of soil functions across secondary succession}

Six different structural equation models were developed to assess the effects of vegetation composition and structure on each soil function (Figure 5.4). CWM.SLA was the only diversity indicator that significantly explained variations in basal_respiration (-0.615) and alk_phosphatase (-0.522). Variance in height was the only diversity indicator that explained MBC $(+0.793)$ and beta_glucosidase $(+0.660)$, which are metrics related to carbon cycling. MBC, beta_glucosidase and basal_respiration had positive effects on SOM $(+0.449 ;+0.472$; +0.432 ), while qCO2 did not. No significant effects of alk_phosphatase on soil $\mathrm{P}$ was detected. Above_biomass was the only significant driver of soil cover, positively influencing litter_leaf_carbon $(+0.542)$, which in turn had a strong effect $(+0.884)$ on litter_water. 


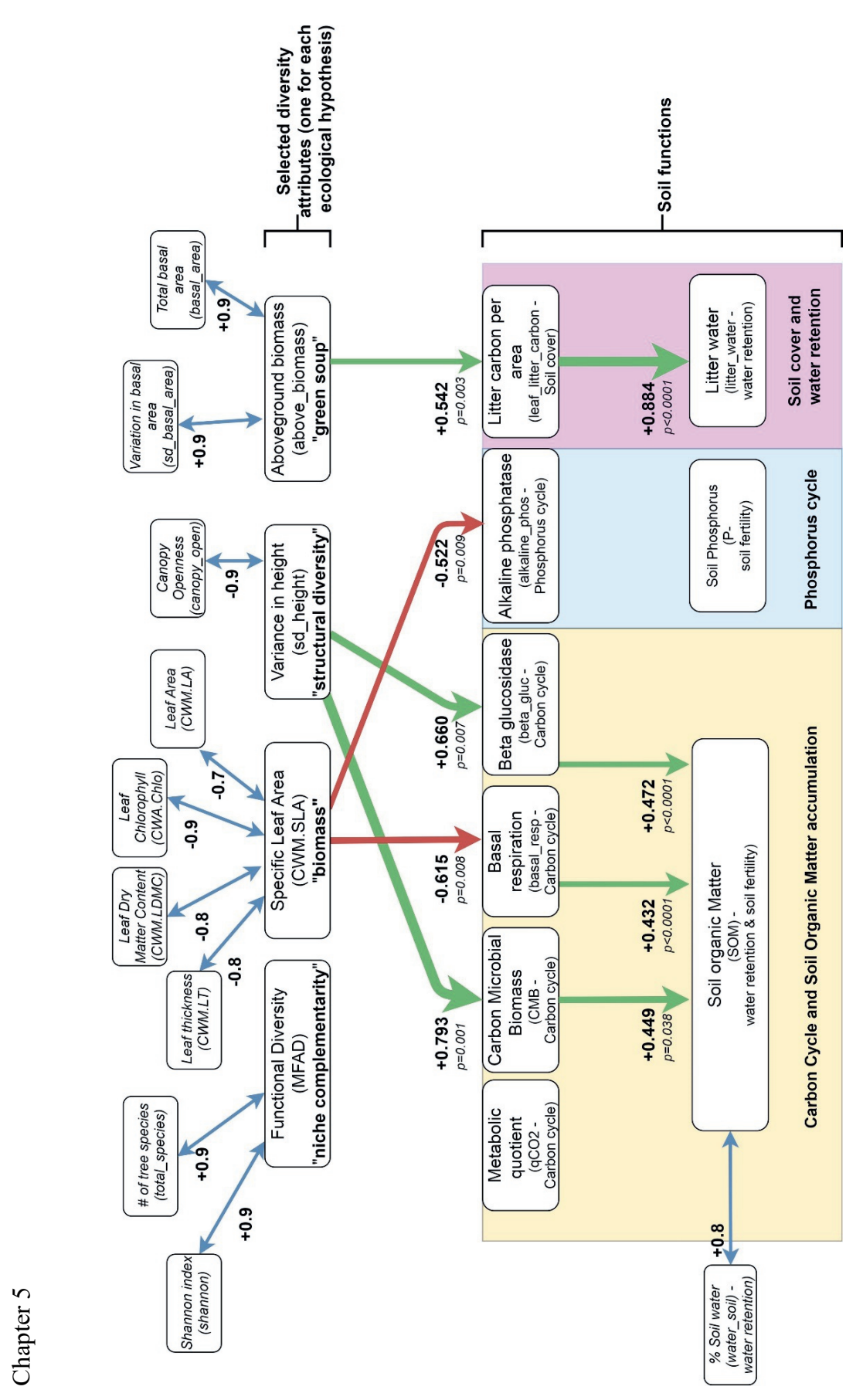

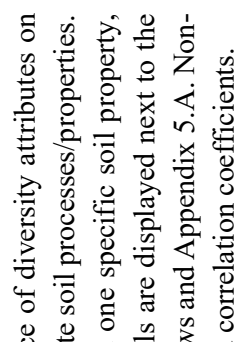

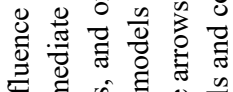

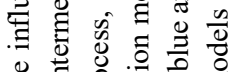
‡. : 寻希 궁

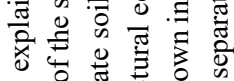
월 ปั

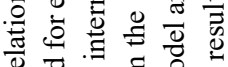
गั0

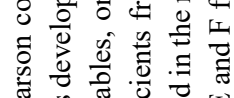
ప च्ञ 卷苋

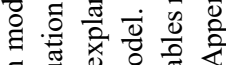
.

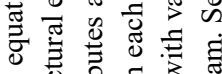

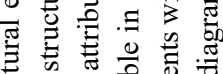

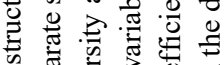

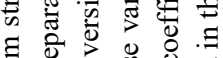

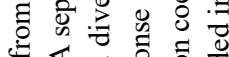

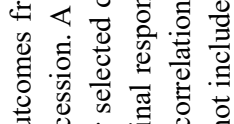
总导离

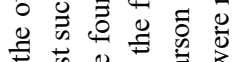

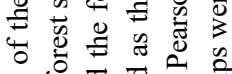

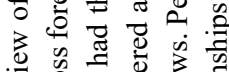

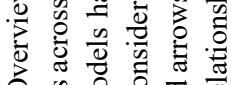
ర)

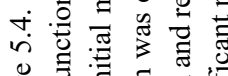

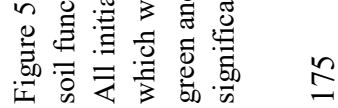




\section{Discussion}

In the present paper, a wide variety of above and belowground metrics were assessed to inform how biodiversity and soil functions change and interact during forest secondary succession. Patterns of aboveground change showed the decrease in canopy openness and an increase on biomass and biodiversity in response to forest age. Furthermore, we observed a sharp increase of soil microbiological processes associated with carbon and nutrient cycling in the first years of succession, suggesting that soils are resilient and can rapidly respond to changes in vegetation and land use. Soil litter cover and litter water also increased during succession, but values found in primary forest were not reached even eight decades after agricultural abandonment. In general, although vegetation indexes were highly correlated and presented clear patterns of change across secondary succession, only trait dominance (i.e. CWM.SLA) and structural heterogeneity of the forest (i.e. sd_height) explained changes in carbon and nutrient cycling (Figure 5.4). In the case of soil cover, the only significant driver was aboveground biomass (Figure 5.4).

\subsection{Changes in different measures of diversity during forest succession}

Changes through secondary succession in structural, taxonomical and functional diversity converged towards values found in primary forests, supporting the equilibrium model of successional dynamics and reinforcing the importance of secondary forests for biodiversity conservation (Norden et al., 2009; Rozendaal et al., 2019). Structural diversity in terms of the standard deviation in tree height showed a sharp increase in the first 25 years of succession and then, slowly increased towards values found in primary forests (Figure 5.2D). This finding reflects the establishment of multi-layer strata already at early stages of forest vegetation development, which allow the forest system to efficiently capture nutrients, light, water and 
other resources (Danescu et al., 2016; Potzelsberger and Hasenauer, 2015). Although basal area, variance in basal area and aboveground biomass also increased during succession, they did not reach the same values found in primary forests. The higher variance in basal area in primary forests compared to old secondary forests can be explained by the presence of very large, and probably centenary trees only found in primary forests (Lucas-borja et al., 2016), which is also reflected in higher basal area and aboveground biomass (Figure 5.2A, B, C). These results contrast with results obtained elsewhere (Lohbeck et al., 2012; Lu et al., 2015; Poorter et al., 2016). The slower recovery rates of basal area and aboveground biomass in Zona da Mata than in other tropical regions may be due to higher landscape fragmentation and relatively low rainfall (1300mm/year). In addition, the small size of subplots may have overestimated basal area, variation in basal area and aboveground biomass in primary forests.

Taxonomical diversity attributes (shannon and total_species) took longer to recover than structural diversity (i.e. sd_height), reaching values found in primary forests after 40-50 years of succession (Figure 5.2F, G). Although the identical sampling design for all plots was necessary to enable a fair comparison, the inclusion criteria of trees with $\mathrm{DBH} \geq 5 \mathrm{~cm}$ may have underestimated species diversity of very young stands. Nevertheless, the recovery of taxonomical diversity in secondary forests in Zona da Mata is in line with other studies (Guariguata and Ostertag, 2001; Martin et al., 2013; Rozendaal et al., 2019) probably due to proximity between secondary forest plots and propagule sources (e.g. primary forests), and because land use before abandonment is characterized by low intensity management (e.g. permanent fields and no use of heavy machinery). In addition, the slightly higher species richness observed in older secondary forest plots compared to primary forests can possibly be explained due to the co-existence of pioneer and late successional species in secondary forests 


\section{Chapter 5}

(Bongers et al., 2009; Huston and Smith, 1987). When soils are too degraded and there are no sources of seeds in the landscape, the recovery of secondary forests can be much slower, as new species are not able to arrive and/or establish (Chazdon, 2008a; Sloan et al., 2016). Therefore, the conservation of key stone species (e.g. Euterpe edulis) both in primary and old secondary forest remnants and in the agricultural matrix, can be crucial to support seed dispersal and the successful development of secondary forests in highly fragmented landscapes (Bechara et al., 2016; Norden et al., 2009; Perfecto and Vandermeer, 2010).

Functional diversity (i.e. MFAD) had a similar response to age than taxonomic attributes (Figure 5.2H), suggesting that niche overlap among species was low (Díaz and Cabido, 2001). In terms of functional composition, pioneers species dominating early stage forests had a more acquisitive strategy, associated with higher leaf turn-over and relatively high growth rate (Boukili and Chazdon, 2017; Craven et al., 2015). Later succession species had a more conservative strategy, displaying tougher leaves (higher LDMC and LT and lower SLA), with lower turn-over and higher capacity to resist herbivory and absorb light (higher Chlo) (Figure 5.2I, J, K L, M) (Lu et al., 2015; Poorter and Bongers, 2006; Rijkers et al., 2000). Dynamics in functional composition across succession are probably due to increased competition for resources among tree individuals (Boukili and Chazdon, 2017; Chazdon, 2008b). For instance, canopy openness decreased during succession (Figure 5.2E), which indicates lower light availability for trees and, therefore, increased competition.

\subsection{Changes in soil properties and processes during forest succession}

Our results indicate that soil microbiological processes related to carbon and nutrient cycling show a sharp recovery in the first 15 years of secondary succession and then tend to stabilize to 
the levels of primary forests (Figure 5.3B, C, D, E). Soil functions linked to microbial activity tend to recover faster than above-ground vegetation diversity (Winbourne et al., 2018), suggesting that soils are more resilient than the vegetation. Besides, feedback loops between vegetation and soil functions may be crucial for the success of secondary succession as the fast recovery of soil functions in the beginning of succession can play a role in improving edaphic conditions (e.g. water content, nutrient availability and organic matter) to enable the germination and growth of new species (i.e. typical of primary forests) (Chua and Potts, 2018; Qiu et al., 2018). Furthermore, knowledge about soil conditions prior reforestation can assist the selection of adequate interventions, while monitoring soil conditions during reforestation can help to assess the recovery of soil-related ecosystem services as well as the identification of soil processes that may be limiting the development of the vegetation. Therefore, to maximize the success of restoration efforts, soil indicators of environmental quality must also be addressed, which is rarely done, especially for soil microorganisms (Mendes et al., 2019).

Soil carbon or organic matter is considered a key indicator of soil quality (Minasny et al., 2017), and is associated with provision of a range of ecosystem services, such as carbon sequestration, water retention, soil fertility, erosion control, amongst others (Adhikari and Hartemink, 2016). Most studies reported a general increase of soil organic matter (SOM) and soil carbon during succession (Deng et al., 2013; Hall et al., 2017; Lu et al., 2015; Robinson et al., 2015; Yan et al., 2006; Yesilonis et al., 2016). In our study, SOM was not significantly associated to forest age, although SOM was apparently lower in recently abandoned agricultural fields than in forested areas (Figure 5.3G). Considering all plots, SOM was highly correlated to water_soil (Appendix 5.A), evidencing the role of organic matter for enhancing water retention and 


\section{Chapter 5}

lowering water run-off, one of the main causes of soil, water and nutrient losses in hilly landscapes (Liu et al., 2018).

Our results suggest a quick recovery of alk_phosphatase activity after agricultural abonnement, with a sharp increase in the first years, and then, tending to stabilize. Phosphorus is one of the main limiting nutrients in tropical highly weathered landscapes (Cleveland et al., 2002) and thus, understanding the processes regulating phosphorus cycling can be an important step to promote vegetation health and recovery (Qiu et al., 2018). Although phosphorus cycling across secondary succession is poorly understood, changes in litter and soil nutrient content during succession may drive the response of phosphatase activity to forest age (Zhang et al., 2015). Our results support similar studies conducted in tropical forests, showing a general increase of phosphatase activity in response to forest age (Huang et al., 2011; Zhang et al., 2015). In contrast, completely different patterns were observed in pine forests in Spain (Lucas-borja et al., 2016), where alk_phosphatase activity decreased in response to secondary succession, suggesting that phosphorus dynamics can differ in temperate and tropical secondary succession.

\subsection{Linking biodiversity to soil functions}

Our study is the first to our knowledge to test the effect of different vegetation attributes on key soil processes during secondary succession (Figure 5.4). Our findings indicate that variance in height is the only vegetation attribute driving beta_glucosidase and MBC (Figure 5.4), highlighting the role of multi-layered strata vegetation to capture and efficiently use carbon, water and light (Danescu et al., 2016; Potzelsberger and Hasenauer, 2015), creating favourable conditions for microbiological activity. The recovery of structural heterogeneity is rather fast in the first years of secondary succession tending to stabilize afterwards (Figure 5.2D), which 
means that levels of MBC and beta_glucosidase can also recover quickly after agricultural abandonment (Figure 5.3B, D). Both MBC and beta_glucosidase had a significant positive effect on SOM (Figure 5.4). Additionally, trait dominance (i.e. CWM.SLA) was the main aboveground driver of basal respiration (Figure 5.4), which also had a positive significant effect on SOM (Figure 5.4). These results indicate that tougher leaves with lower SLA are harder to decompose, demanding more energy from soil microorganisms (i.e., higher basal respiration). Although respiration and consequently the emission rate of $\mathrm{CO} 2$ increases across succession, apparently this is compensated by the amount of carbon incorporated in the soil, as basal_respiration had a positive effect on SOM (Figure 5.4) (Yan et al., 2006). Yet, our results show strong evidence that the structural diversity and biomass ratio hypotheses can better explain changes in carbon cycling than the other tested hypotheses. In contrast to our findings, experiments using manipulated plant communities with low number of species, supported the niche complementarity hypothesis to explain soil microbiological responses such as increased MBC and basal_respiration (Lange et al., 2015; Zak et al., 2003). Possibly, a low number of species can mask the role of different vegetation attributes, because it tends to result in a more uniform occupation of niche space than in species rich communities, resulting in lower functional redundancy and higher correlation between species richness and other diversity metrics (Díaz and Cabido, 2001). Besides, studies often do not test for different vegetation attributes as possible drivers of ecosystem functions, processes and/or properties, which may lead to biased results (Nadrowski et al., 2010). Therefore, we highlight the need to disentangle different indicators of vegetation composition and structure to better understand the ecological mechanisms that can explain changes in ecosystem functioning. 


\section{Chapter 5}

Our results show that leaf trait dominance (i.e. CWM.SLA) is the main vegetation attribute driving alk_phosphatase activity (Figure 5.4). According to the worldwide leaf economics spectrum, tougher leaves with lower SLA tend to have lower P concentrations (Boukili and Chazdon, 2017; Wright et al., 2004). In that case, the lower availability of P in the leaves could induce microorganisms to increase $\mathrm{P}$ cycling, as ecological theories indicate that organisms invest energy to cycle and/or capture most limiting resources (Bloom and Mooney, 1985; Fujii et al., 2018). However, soil P was not significantly influenced by alk_phosphatase and did not show a clear pattern across succession (Figure 5.3I and 5.4). These findings highlight the complexity of P dynamics in the soil due to uptake and fixation processes (Fujii et al., 2018) and need further studies to assess which plant traits are related to $\mathrm{P}$ cycling as well as better soil indicators of $\mathrm{P}$ availability.

Litter_leaf_carbon was only influenced by aboveground_biomass (Figure 5.4), showing that forest age and biomass are important drivers of litter accumulation (Lohbeck et al., 2015). Thus, litter accumulation can be explained by decades and even centuries of input from the tree canopies, showing the importance of primary forests to provide high levels of soil cover, that cannot be attained by secondary forests even after decades of succession. The strong effect of leaf_litter_carbon on litter_water(Figure 5.4), underline the role of carbon to retain water and avoid losses by superficial run-off.

Although in our models we postulated soil functions were driven by vegetation characteristics, in reality there could be feedback mechanisms, in which soil respond to vegetation and viceversa across time (Duncan et al., 2015). The high dominance of Piptadenia gonoachanta in the first years of succession (Domingos et al., 2015; Marangon et al., 2008) indicate the potential 
role of this leguminous species to colonize degraded landscapes and improve soil conditions for other species to establish. During secondary succession in our study area, P. gonoachanta is gradually replaced by other species, such as Euterpe edulis, which become more dominant later in succession (Appendix 5.C). E. edulis can be considered as a keystone species for the conservation of the Atlantic forest (Reis et al., 2000), since its fruits are very much appreciated by birds and other animals that bring seeds from other species to the system, increasing local biodiversity (Silva and Reis, 2018).

\subsection{Implications for management}

The fast recovery of biodiversity and soil functions indicates the potential of secondary succession as an strategy that farmers can use to convert new areas into forest for increasing the provision of ecosystem services valued by society, such as water and climate regulation, erosion control, forest products and aesthetics (Chazdon, 2008a; Ninan and Inoue, 2013; Yuliani et al., 2015). In Brazil, the conservation of forest areas in agricultural land has a major role for increasing national forest cover and is supported by the current Forest Law, which requires farmers to maintain or restore native vegetation in certain areas of their properties (i.e. hilltops, steep slopes, around water springs and along the riparian buffer) (Calmon et al., 2011; Taniwaki et al., 2018). Yet, for the successful restoration of new forest areas, farmers need support from programs, legislation and public policies. It is necessary not only to raise awareness on the importance of forests for the provision of ecosystem services, but also to provide technical guidance and financial subsidies, such as adequate extension services and payments for ecosystem services (Díaz et al., 2019). Despite the high potential to increase forest cover and the associated ecosystem services through secondary succession, primary forests should be conserved and maintained, especially in fragmented landscapes. This is important not only due 


\section{Chapter 5}

to the historical and cultural value of primary forests (Garnett et al., 2018), but also because they can serve as propagule source (Robinson et al., 2015; Sloan et al., 2016) and provide ecosystem services that cannot be attained even after decades of succession (Watson et al., 2018). Finally, our results found strong support in the role of multi-layered strata for increasing carbon cycling. Therefore, analogously to forests, the incorporation of trees and shrubs in agricultural fields can increase structural heterogeneity of the systems and consequently, enhance soil processes responsible for soil organic matter accumulation and soil fertility (Altieri, 1999).

\section{Conclusions}

Our results demonstrated the potential role of secondary forests to relatively quickly restore tree diversity and soil functions to the level of primary forests. Therefore, conservation efforts in highly fragmented and human modified landscapes should consider secondary forest succession as a viable and efficient strategy to increase forest cover and enhance biodiversity conservation and the associated ecosystem services. In Brazil, farmers and land owners can play a key role for successfully increasing forest cover via secondary succession since a great part of the forest areas are located (or must be regenerated) on private properties. Metrics of biodiversity had distinct recovery patterns, showing the importance to disentangle and measure several vegetation attributes. By measuring several soil properties and processes we can gain new insights on the effects of tree diversity on soil functioning. These relationships should be further explored in future studies to get a better understanding on how ecosystem services are recovered through forest succession along climatic and edaphic gradients as well as in different landscape conditions. 
Secondary forest succession

\section{Acknowledgements}

This work is part of the FOREFRONT programme, funded by the Interdisciplinary Research and Education Fund (INREF) of Wageningen University \& Research. We thank Stichting Het Kronendak, FAPEMIG and CNPq for the additional funding support. We thank Talita Guarçoni, Maria Alencar Victer, Niara Rutte, Bruna Carolina da Silva Goulart and other students for their help with the forest inventory and the measurements of functional traits in the lab. We thank Pablo Tittonell for valuable meetings to discuss the content and concepts of the paper. We specially thank the farmers Adriano and Renata Silvestre, whom provided shelter and food during fieldwork, and all the Frossard community members, who shared their knowledge and supported access to the research plots. Finally, we would like to thank the CTA-ZM, farmers and farmer organisations' in Zona da Mata for supporting our research. 


\section{Chapter 5}

\section{Appendices}

Appendix 5.A - Pearson correlation between all variables of the study. Non-significant relationships are crossed. The colours and numbers indicate the strength of the correlation (+1 to -1$)$.

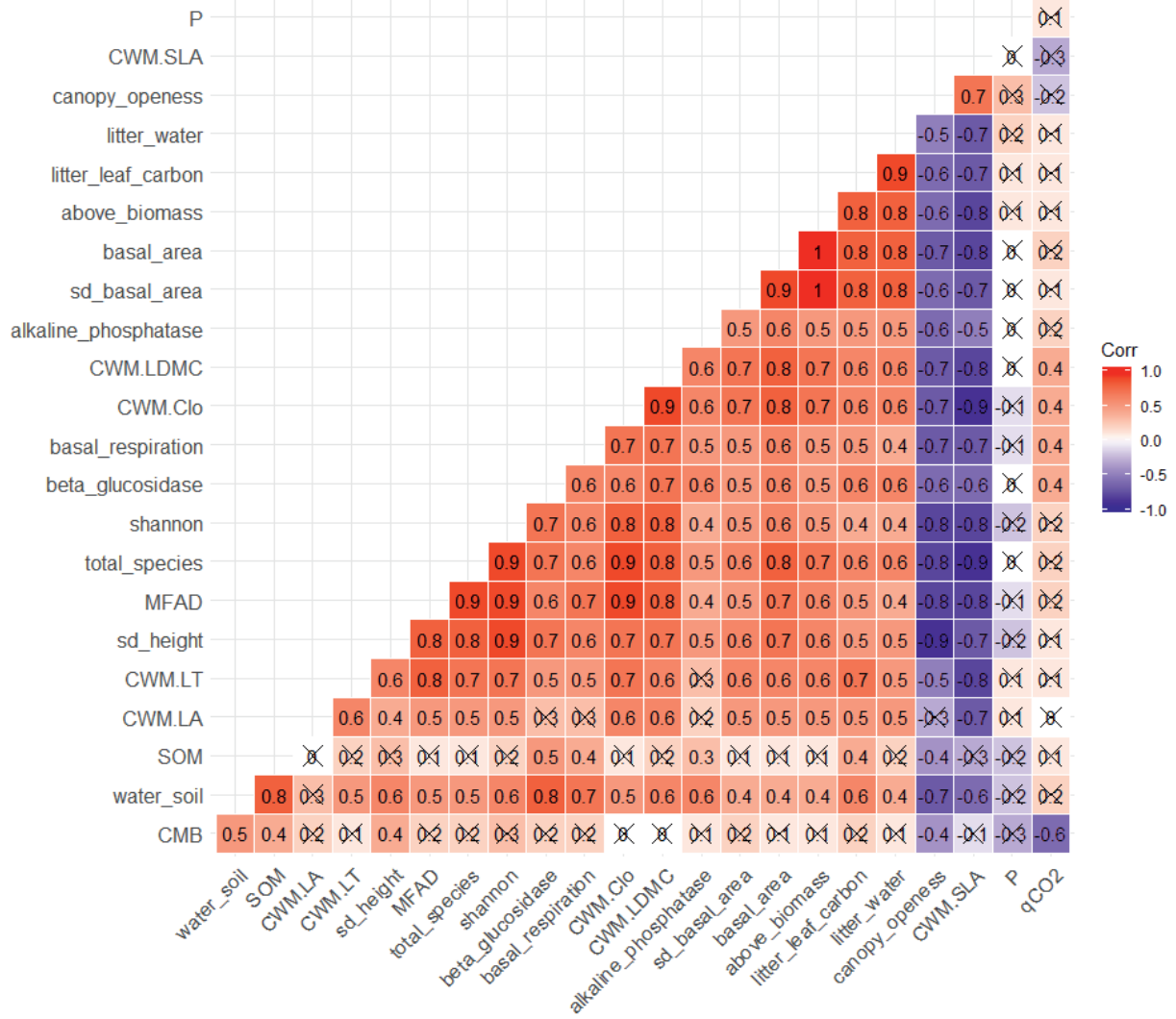


Appendix 5.B - Dissimilarity cluster dendrogram of species composition among subplots. Terminal nodes display the age of the subplot. Plots with no trees are not included in the dendrogram.

\section{Cluster Dendrogram}

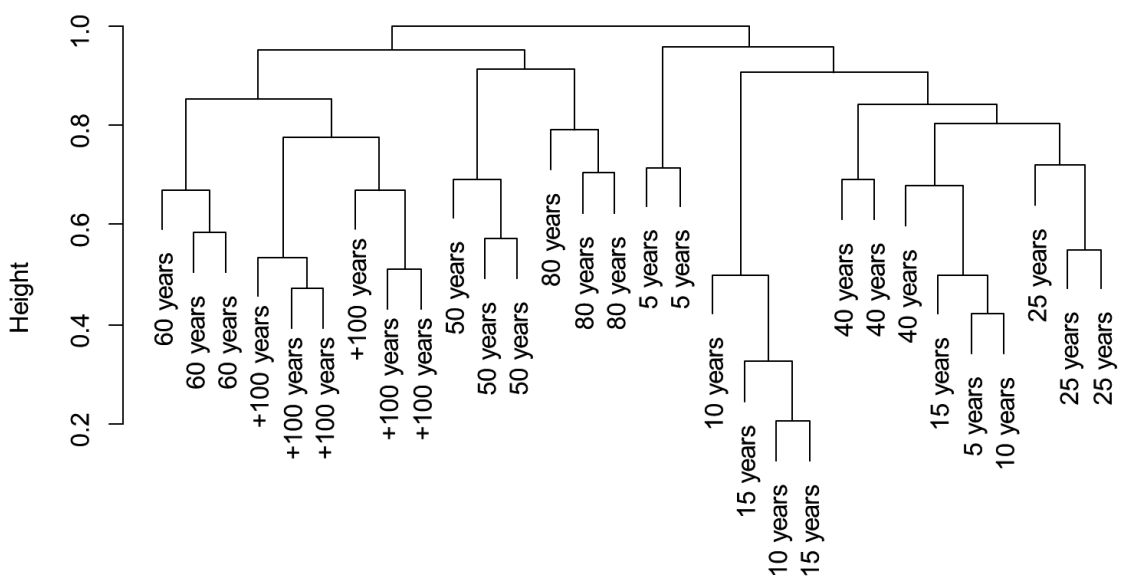




\section{Chapter 5}

Appendix 5.C - Results of the mixed linear models with forest age as explanatory variable and relative dominance of Euterpe edulis and Piptadenia gonoachanta as response variables.

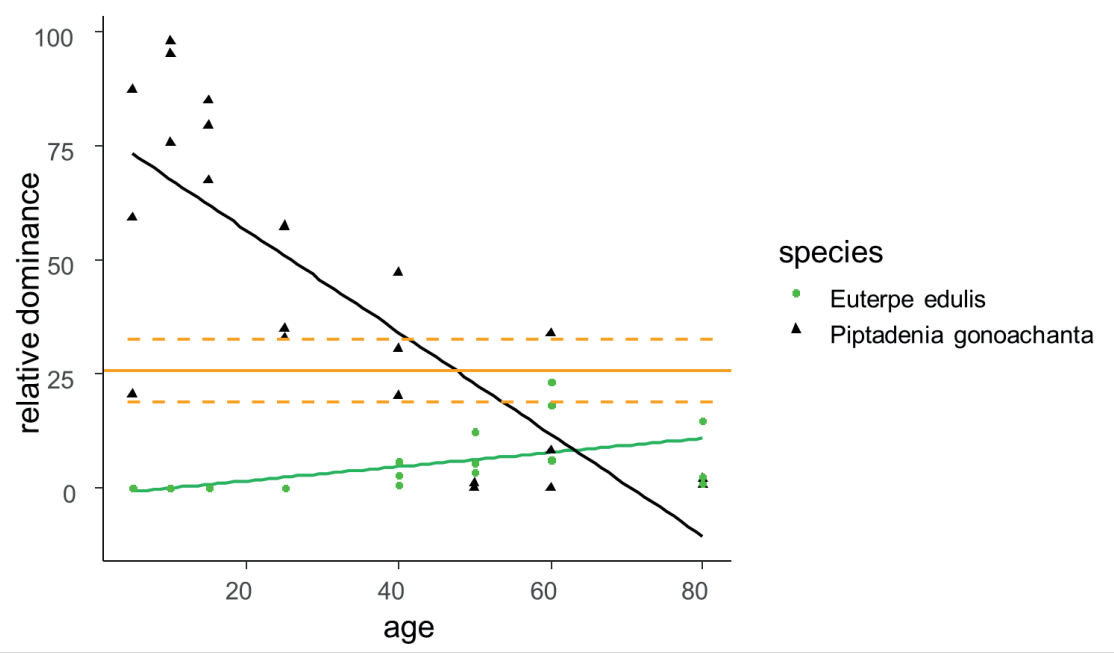

Figure 5.C. Relative dominance of the two most dominant species in early and late secondary succession (5-80 years). In black the pioneer species Piptadenia gonoachanta and in green the shade tolerant species Euterpe edulis. E. edulis dominance in primary forests is displayed as reference values with the horizontal (average) and dotted (standard deviation) orange lines. P. gonoachanta was not found in primary forests. Both responses were significant $(\mathrm{p}<0.01)$.

Table 5.C. Detailed output of the mixed linear models with forest age as explanatory variable and relative dominance of Euterpe edulis and Piptadenia gonoachanta as response variables.

\begin{tabular}{|c|c|c|c|c|c|c|c|}
\hline \multirow[t]{2}{*}{ Models } & \multirow{2}{*}{$\begin{array}{c}\text { Type } \\
\text { of } \\
\text { model }\end{array}$} & \multicolumn{2}{|c|}{ fixed effects } & \multicolumn{2}{|c|}{ random effects } & \multirow{2}{*}{$\begin{array}{l}\text { p- } \\
\text { value }\end{array}$} & \multirow[t]{2}{*}{ significance } \\
\hline & & $\begin{array}{c}\mathrm{x} \\
\text { estimate }\end{array}$ & $\begin{array}{l}\text { intercept } \\
\text { estimate }\end{array}$ & $\begin{array}{c}\text { plot } \\
\text { variance }\end{array}$ & $\begin{array}{l}\text { residual } \\
\text { variance }\end{array}$ & & \\
\hline $\begin{array}{l}\text { rel_dominance_piptadenia } \sim \text { age }+ \\
(1 \mid \text { plot })\end{array}$ & linear & -1.1184 & 78.9827 & 209.00 & 255.60 & $<<0.001$ & $* * *$ \\
\hline $\begin{array}{l}\text { rel_dominance_euterpe } \sim \text { age }+ \\
(1 \mid \text { plot })\end{array}$ & linear & 0.1562 & -1.5559 & 9.48 & 20.44 & $<0.01$ & $* *$ \\
\hline
\end{tabular}


Appendix 5.D - Results of the structural equation models for the effects of vegetation composition and structure on soil functions. Standardized Root Mean Square Residual (SRMR), Comparative Fit Index (CFI) and chi-square p-value of robust models are given as parameters for determining the fit of each model.

\begin{tabular}{lccc}
\hline & SRMR & CFI & chi-square p-value \\
\hline model 1 - Beta glucosidase & 0.039 & 1 & 0.825 \\
model 2 - Alkaline phosphatase & 0.054 & 1 & 0.963 \\
model 3 - Basal respiration & 0.039 & 1 & 0.869 \\
model 4 - Microbial biomass carbon & 0.048 & 1 & 0.865 \\
model 5 - Metabolic quotient & 0.074 & 1 & 0.835 \\
model 6 - Litter carbon per area & 0.024 & 1 & 0.959 \\
\hline
\end{tabular}




\section{Chapter 5}

Appendix 5.E - Results of the structural equation models for the effects of vegetation composition and structure on soil functions. Standardized estimates (regression coefficients), standard errors, z-statistic and p-values are given for all relationships tested in each structural equation model.

Model 1 - Beta glucosidase

\begin{tabular}{ccccccc}
\hline response variable & & $\begin{array}{c}\text { explanatory } \\
\text { variable }\end{array}$ & $\begin{array}{c}\text { standardized } \\
\text { estimate }\end{array}$ & $\begin{array}{c}\text { standard } \\
\text { error }\end{array}$ & $\begin{array}{c}\mathbf{z}- \\
\text { statistic }\end{array}$ & $\begin{array}{c}\text { p- } \\
\text { value }\end{array}$ \\
\hline \hline SOM & $\sim$ & beta_glucosidase & 0.472 & 0.116 & 4.08 & 0 \\
beta_glucosidase & $\sim$ & CWM.SLA & -0.573 & 0.372 & -1.542 & 0.123 \\
beta_glucosidase & $\sim$ & sd_height & 0.66 & 0.244 & 2.706 & 0.007 \\
beta_glucosidase & $\sim$ & MFAD & -0.39 & 0.375 & -1.042 & 0.297 \\
beta_glucosidase & $\sim$ & above_biomass & -0.105 & 0.233 & -0.453 & 0.651 \\
\hline
\end{tabular}

Model 2 - Alkaline phosphatase

\begin{tabular}{ccccccc}
\hline response variable & explanatory variable & $\begin{array}{c}\text { standardized } \\
\text { estimate }\end{array}$ & $\begin{array}{c}\text { standard } \\
\text { error }\end{array}$ & $\begin{array}{c}\text { z- } \\
\text { statistic }\end{array}$ & $\begin{array}{c}\text { p- } \\
\text { value }\end{array}$ \\
\hline \hline P & $\sim$ & alkaline_phosphatase & 0.001 & 0.236 & 0.006 & 0.995 \\
alkaline_phosphatase & $\sim$ & CWM.SLA & -0.522 & 0.199 & -2.617 & 0.009 \\
alkaline_phosphatase & $\sim$ & sd_height & 0.384 & 0.213 & 1.799 & 0.072 \\
alkaline_phosphatase & $\sim$ & MFAD & -0.398 & 0.274 & -1.452 & 0.146 \\
alkaline_phosphatase & $\sim$ & above_biomass & 0.099 & 0.242 & 0.412 & 0.681 \\
\hline
\end{tabular}

Model 3 - Basal respiration

\begin{tabular}{ccccccc}
\hline response variable & & $\begin{array}{c}\text { explanatory } \\
\text { variable }\end{array}$ & $\begin{array}{c}\text { standardized } \\
\text { estimate }\end{array}$ & $\begin{array}{c}\text { standard } \\
\text { error }\end{array}$ & $\begin{array}{c}\mathbf{Z}- \\
\text { statistic }\end{array}$ & $\begin{array}{c}\mathbf{p}- \\
\text { value }\end{array}$ \\
\hline \hline SOM & $\sim$ & basal_respiration & 0.432 & 0.119 & 3.624 & 0 \\
basal_respiration & $\sim$ & MFAD & -0.002 & 0.252 & -0.007 & 0.994 \\
basal_respiration & $\sim$ & sd_height & 0.267 & 0.148 & 1.809 & 0.07 \\
basal_respiration & $\sim$ & CWM.SLA & -0.615 & 0.233 & -2.645 & 0.008 \\
basal_respiration & $\sim$ & above_biomass & -0.12 & 0.183 & -0.656 & 0.512 \\
\hline
\end{tabular}


Model 4 -Microbial biomass carbon

\begin{tabular}{ccccccc}
\hline $\begin{array}{c}\text { response } \\
\text { variable }\end{array}$ & & $\begin{array}{c}\text { explanatory } \\
\text { variable }\end{array}$ & $\begin{array}{c}\text { standardized } \\
\text { estimate }\end{array}$ & $\begin{array}{c}\text { standard } \\
\text { error }\end{array}$ & $\begin{array}{c}\mathbf{z}- \\
\text { statistic }\end{array}$ & $\begin{array}{c}\mathbf{p}- \\
\text { value }\end{array}$ \\
\hline \hline SOM & $\sim$ & MBC & 0.449 & 0.216 & 2.077 & 0.038 \\
MBC & $\sim$ & sd_height & 0.793 & 0.233 & 3.406 & 0.001 \\
MBC & $\sim$ & CWM.SLA & 0.108 & 0.433 & 0.248 & 0.804 \\
MBC & $\sim$ & MFAD & -0.323 & 0.493 & -0.655 & 0.513 \\
MBC & $\sim$ & above_biomass & -0.088 & 0.241 & -0.366 & 0.715 \\
\hline
\end{tabular}

Model 5 - Metabolic quotient

\begin{tabular}{ccccccc}
\hline $\begin{array}{c}\text { response } \\
\text { variable }\end{array}$ & explanatory & $\begin{array}{c}\text { standardized } \\
\text { variable }\end{array}$ & $\begin{array}{c}\text { standard } \\
\text { error }\end{array}$ & $\begin{array}{c}\mathbf{z}- \\
\text { statistic }\end{array}$ & $\begin{array}{c}\mathbf{p}- \\
\text { value }\end{array}$ \\
\hline \hline $\mathrm{SOM}$ & $\sim$ & $\mathrm{qCO} 2$ & 0.136 & 0.22 & 0.617 & 0.537 \\
$\mathrm{qCO} 2$ & $\sim$ & sd_height & -0.24 & 0.217 & -1.107 & 0.268 \\
$\mathrm{qCO} 2$ & $\sim$ & CWM.SLA & -0.645 & 0.408 & -1.58 & 0.114 \\
$\mathrm{qCO} 2$ & $\sim$ & MFAD & 0.041 & 0.434 & 0.095 & 0.924 \\
$\mathrm{qCO} 2$ & $\sim$ & above_biomass & -0.247 & 0.235 & -1.05 & 0.294 \\
\hline
\end{tabular}

Model 6 - Litter carbon per area

\begin{tabular}{ccccccc}
\hline response variable & & $\begin{array}{c}\text { explanatory } \\
\text { variable }\end{array}$ & $\begin{array}{c}\text { standardized } \\
\text { estimate }\end{array}$ & $\begin{array}{c}\text { standard } \\
\text { error }\end{array}$ & $\begin{array}{c}\mathbf{z}- \\
\text { statistic }\end{array}$ & $\begin{array}{c}\text { p- } \\
\text { value }\end{array}$ \\
& & & & & & \\
\hline \hline litter_water & $\sim$ & litter_leaf_carbon & 0.884 & 0.032 & 27.266 & 0 \\
litter_leaf_carbon & $\sim$ & sd_height & 0.251 & 0.179 & 1.406 & 0.160 \\
litter_leaf_carbon & $\sim$ & CWM.SLA & -0.408 & 0.243 & -1.674 & 0.094 \\
litter_leaf_carbon & $\sim$ & MFAD & -0.395 & 0.302 & -1.308 & 0.191 \\
litter_leaf_carbon & $\sim$ & above_biomass & 0.542 & 0.180 & 3.009 & 0.003 \\
\hline
\end{tabular}




\section{Chapter 5}

Appendix 5.F - Matrix of residuals in correlational units (subtraction of the observed model and implied model matrices) for each structural equation model. Large positive values $(>0.1)$ indicate the model underpredicts the correlation; large negative values $(<-0.1)$ suggest the model overpredicts the correlation.

Model 1 - Beta glucosidase

\begin{tabular}{l|llllll}
\hline & SOM & bt_glc & CWM.SL & sd_hgh & MFAD & abv_bm \\
\hline SOM & 0 & & & & & \\
beta_glucosidase & 0 & 0 & & & & \\
CWM.SLA & 0.04 & 0 & 0 & & & \\
sd_height & -0.022 & 0 & 0 & 0 & & \\
MFAD & -0.144 & 0 & 0 & 0 & 0 & \\
above_biomass & -0.134 & 0 & 0 & 0 & 0 & 0 \\
\hline
\end{tabular}

Model 2 - Alkaline phosphatase

\begin{tabular}{l|llllll}
\hline & P & alkln_ & CWM.SL & sd_hgh & MFAD & abv_bm \\
\hline \hline P & 0 & & & & & \\
alkaline_phosphatase & 0 & 0 & & & & \\
CWM.SLA & 0.031 & 0 & 0 & & & \\
sd_height & -0.24 & 0 & 0 & 0 & & \\
MFAD & -0.13 & 0 & 0 & 0 & 0 & \\
above_biomass & 0.055 & 0 & 0 & 0 & 0 & 0 \\
\hline
\end{tabular}

Model 3 - Basal respiration

\begin{tabular}{l|llllll}
\hline & SOM & bsl_rs & MFAD & sd_hgh & CWM.SL & abv_bm \\
\hline \hline SOM & 0 & & & & & \\
basal_respiration & 0 & 0 & & & & \\
MFAD & -0.16 & 0 & 0 & & & \\
sd_height & 0.025 & 0 & 0 & 0 & & \\
CWM.SLA & 0.046 & 0 & 0 & 0 & 0 & 0 \\
above_biomass & -0.113 & 0 & 0 & 0 & 0 & \\
\hline
\end{tabular}


Model 4-Microbial biomass carbon

\begin{tabular}{l|llllll}
\hline & SOM & MBC & sd_hgh & CWM.SL & MFAD & abv_bm \\
\hline SOM & 0 & & & & & \\
MBC & 0 & 0 & & & & \\
sd_height & 0.124 & 0 & 0 & & & \\
CWM.SLA & -0.206 & 0 & 0 & 0 & & \\
MFAD & 0.04 & 0 & 0 & 0 & 0 & \\
above_biomass & 0.046 & 0 & 0 & 0 & 0 & 0 \\
\hline
\end{tabular}

Model 5 - Metabolic quotient

\begin{tabular}{l|llllll}
\hline & SOM & qCO2 & sd_hgh & CWM.SL & MFAD & abv_bm \\
\hline \hline SOM & 0 & & & & & \\
qCO2 & 0 & 0 & & & & \\
sd_height & 0.286 & 0 & 0 & & & \\
CWM.SLA & -0.22 & 0 & 0 & 0 & & \\
MFAD & 0.096 & 0 & 0 & 0 & 0 & \\
above_biomass & 0.088 & 0 & 0 & 0 & 0 & 0 \\
\hline
\end{tabular}

Model 6 - Litter carbon per area

\begin{tabular}{l|llllll}
\hline & Ittr_w & lttr_ & sd_hgh & CWM.SL & MFAD & abv_bm \\
\hline \hline litter_water & 0 & & & & & \\
litter_leaf_carbon & 0 & 0 & & & & \\
Sd_height & 0.039 & 0 & 0 & & & \\
CWM.SLA & -0.067 & 0 & 0 & 0 & & \\
MFAD & 0.022 & 0 & 0 & 0 & 0 & \\
above_biomass & 0.094 & 0 & 0 & 0 & 0 & 0 \\
\hline
\end{tabular}




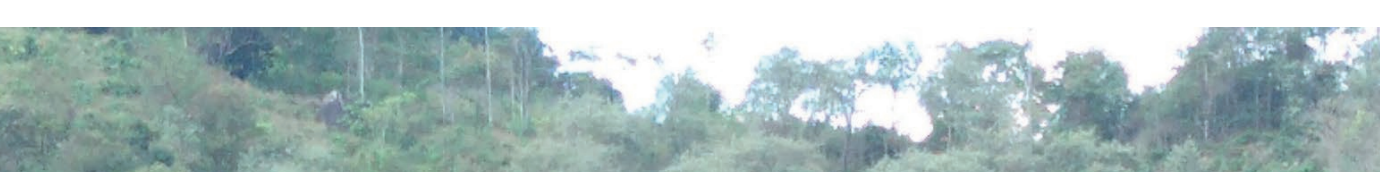$$
\text { ( }
$$$$
\sin 2
$$

\section{8.}

\section{nep}

Lin

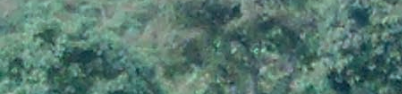

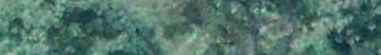
and

A.
$21 / 2+1 / 2$

sisat.

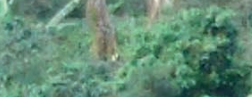

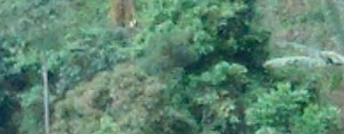

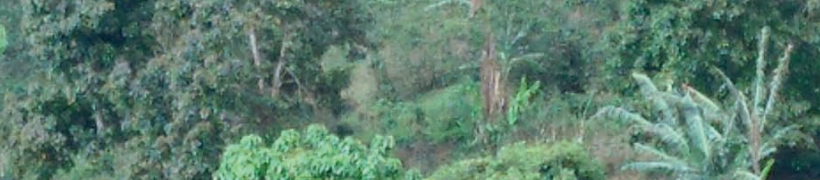

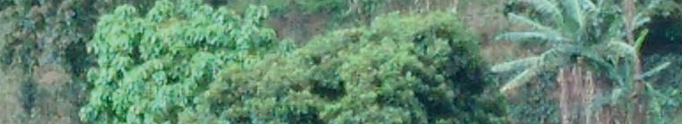

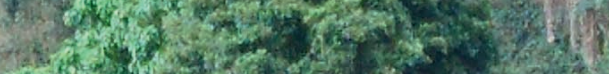

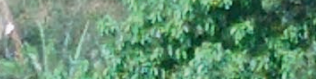

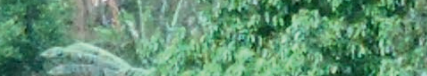

4.

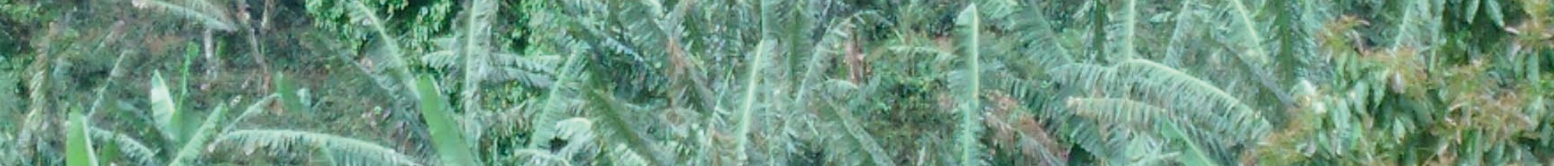

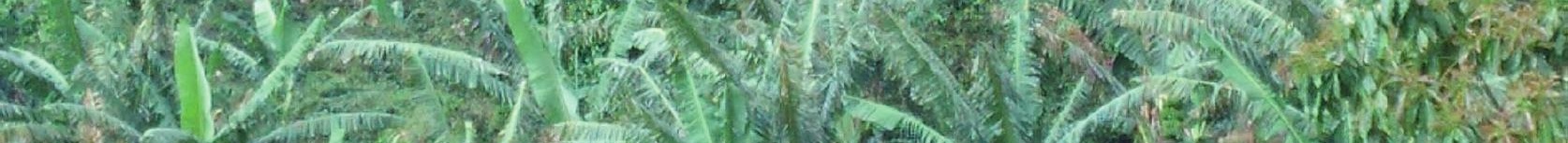
(25)

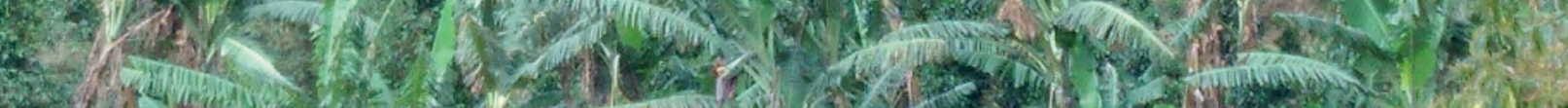
6.

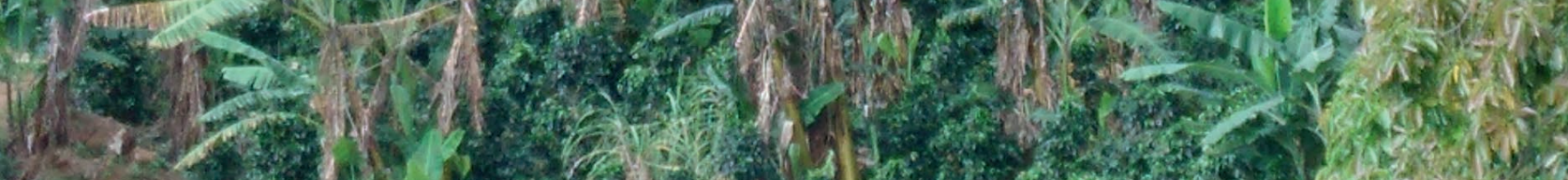

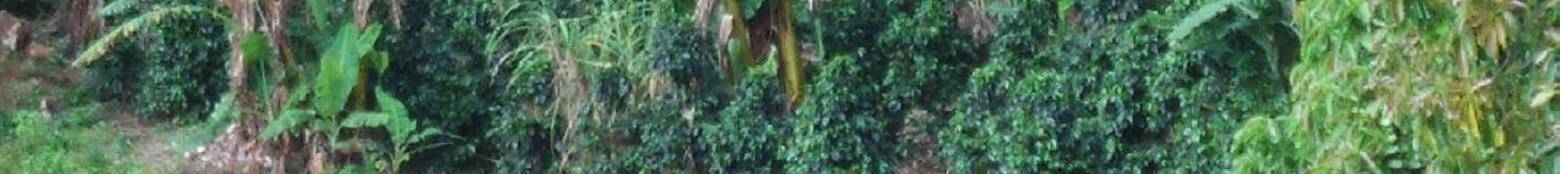

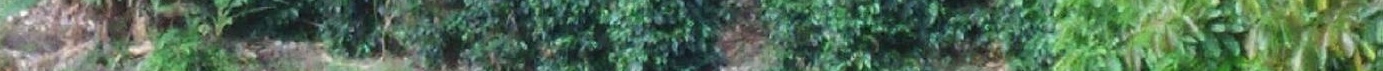


Chapter 6

\section{General Discussion}

Heitor Mancini Teixeira 
Chapter 6 
The interdisciplinary assessment of agroecosystems is crucial for identifying and re-designing realistic management strategies that contribute to biodiversity conservation and the provision of multiple ecosystem services that are important for human well-being (Balvanera et al., 2014; Costanza et al., 2017b; Díaz et al., 2018). Such management strategies should consider the multiple externalities caused by agriculture as well as to move beyond the productivist paradigm towards multi-functional systems, where biodiversity can play a central role for supporting and regulating ecosystem functioning (Altieri, 1999; Isbell et al., 2017b; Reynolds et al., 2014; Steffen et al., 2015). In this thesis I developed and applied an interdisciplinary methodological framework to assess the links among social actors, biodiversity and ecosystem services (Figure 1.4, Chapter 1). In this framework, farm diversity and knowledge systems are central to understand different management strategies applied by farmers and their consequences for biodiversity and ecosystem services.

The transition from industrial to biodiversity-based systems is strongly embedded in the concept of agroecological transitions. Agroecological transitions can be defined as a paradigm shift in agriculture, from systems characterized by monocultures, high use of industrial inputs and mostly contracted labour to systems that are biodiversity-based with a focus on family labour and on the integration between scientific and local knowledge (Chapter 2). Beyond changes at farm scale, agroecological transitions also aim for changes at regional, national and international levels, through changes in public policies, legal regulations, access to land and credits, emancipatory education systems and development of fair markets. The threads that connect all these different levels of transition are the social organisations working with agroecology, such as farmers' unions and cooperatives, non-governmental organizations (NGOs), companies, social movements and international organisations. 


\section{Chapter 6}

The present study was conducted in Zona da Mata, where an ongoing process of agroecological transition started more than 30 years ago. I used a combination of social and ecological methods (i) to assess farm diversity and its implications for management and for promoting agroecological transitions; (ii) to understand and contrast farmers' perceptions on ecosystem services and their management; (iii) to evaluate the direct and indirect impact of management on biodiversity and soil-based ecosystem services in coffee and pastures; and (iv) to determine the relationship between biodiversity and soil functions during secondary forest succession. The results show that changes in the cognitive perception of farmers on ES led to changes in management strategies, that in turn, influenced biodiversity and the provision of ES. Agroecological farmers had a more complex perception on ES than other farm types, which was associated to greater access to public policies and participation in social organisations, as well as higher biodiversity in their agroecosystems. Thus, the transition to agroecology in Zona da Mata was successful to help a group of a farmers to enhance biodiversity-based ecological processes in their production areas, moving away from the dependence of industrial inputs without compromising soil and water quality and plant health. In the following sections I discuss the links between biodiversity, ecosystem services and social actors to promote agroecological transitions, including management recommendations and reflections about the methodological aspects used in this thesis.

\section{The transition from external inputs to biodiversity-based agroecosystems: the case of coffee}

The increasing use of external inputs in agriculture, such as pesticides and chemical fertilizers, is the basis of crop production in industrial agricultural systems. Due to environmental, social and economic constrains resulting from these practices, agroecological systems aim to reduce 
the use of external inputs using a systemic and multi-functional approach (Gliessman, 2018; Schutter, 2010). Yet, the transition from input-based to agroecological management is complex and should consider as primordial: who are the actors who manage the land? What incentives do they have? How do the social, cultural, political, economic and technological contexts influence the development of contrasting farming systems? (Huber-sannwald et al., 2012; Lovell et al., 2010). To help addressing these issues, I combined participatory and quantitative approaches for the development of a farm typology for Zona da Mata, Brazil. Combining both approaches can provide empirical evidence on farm type characteristics and at the same time integrate the broad knowledge of local actors (Chapter 2). I showed that farm types in Zona da Mata differ in their management, and that according to their functional and structural characteristics, farms are positioned along a transition continuum. As such, farm types can be understood as reference points along this continuum, and farms can move towards one farm type or another in response to agencies, such as public policies, institutions and collective organisations (Chapter 2; Palomo-Campesino et al., 2018). Six main farm types were identified in Zona da Mata: conventional family, agroecological family, traditional family, large-scale, partial and landless farmers (Table 2.1, Chapter 2). Except the agroecological farms, all the other farm types rely, to some degree, on pesticides and herbicides to control pests, diseases and weeds in coffee plantations.

Coffee cultivation is part of the history of the Zona da Mata region and it has economic importance as the main cash crop produced by the farmers (IBGE, 2006). In Chapter 4, I found that functional, structural and taxonomical dimensions of biodiversity had an important role to enhance soil microbial biomass, while maintaining coffee yields and soil chemical fertility when compared to systems that rely on pesticides and strong input of chemical fertilizers, such as 


\section{Chapter 6}

large-scale and conventional family farms (Figure 4.2, Chapter 4). Therefore, it becomes relevant to understand what are the management strategies adopted by agroecological farmers that can help other farmers to abandon the use of pesticides while maintaining coffee productivity. One of the strategies is the use of alternative pest control inputs made of nonsynthetic materials, such as neem and tobacco leaf extracts. Such practice was adopted by nearly half of the farms identified as agroecological in our typology (Chapter 2). However, agroecological management goes beyond mere input substitution, towards a more systemic and complex perception on the agroecosystem, which can help farmers to break the dependence on pesticides and develop strategies that consider the interconnectedness among different system components that can influence plant health (Chapter 3). The first step for developing such strategies is to recognise and understand the many externalities caused by the use of chemical pesticides, such as water and air contamination, negative impact on human health, wildlife and soil quality. These externalities were mainly highlighted in the perception of family farmers, as they apply pesticides in the field themselves in contrast to large-scale farmers who have contracted labour to do so (Chapter 3). Secondly, it becomes important to understand the role of increased plant diversity in agroecological coffee systems (Chapter 4), identified by farmers as a way to enhance natural pest control (Chapter 3). The increased diversity is associated with the growth and cultivation of plants that can either repel pests or attract natural enemies of pests. For instance, tree species integrated in coffee agroforestry systems in Zona da Mata, such as Inga sp., can provide food resources that attract natural enemies of important coffee pests (i.e. coffee leaf miners and berry borers) (Rezende et al., 2014). The presence of trees in agroecological coffee systems can also promote microclimatic stability (Gomes et al., 2016), reduce soil erosion (Franco et al., 2002) and, therefore, increase the activity and suppressive potential of entomopathogenic fungi (Moreira et al., 2019). Thirdly, management practices 
compatible with a high plant diversity (Chapter 4) can indirectly help to control pests, diseases and weeds. For instance, to manage the spontaneous vegetation with mowing instead of intensive weeding can help to increase habitat quality for natural enemies of pests (KovácsHostyánszki et al., 2017).

Compared to other categories of pesticides, the use of herbicides is the most adopted by farmers due to high labour requirements of manual weeding. Yet, access to light machinery adapted to mountainous landscapes is becoming increasingly popular among farmers. Mechanical weed mowing is considered as an efficient strategy to replace the use of herbicides and is widely adopted by agroecological farmers and at smaller degree by other farmer types (Chapters 2 and 4). Mowing can reduce labour requirements compared to manual weeding and at the same time it can enhance soil quality as the weed roots remain in the soil and the chopped plant material can serve as litter cover (Chapter 4). In terms of soil quality, our results show that although the use of chemical fertilizers was reduced in agroecological coffee systems compared to largescale and conventional family farmers, it did not significantly affect soil chemical properties, such as $\mathrm{pH}$, calcium, nitrogen and phosphorus content. Instead of relying on chemical fertilizers, agroecological farms enhanced ecological processes of nutrient cycling by increasing plant functional, taxonomical and structural diversity. For instance, trees with different leaf characteristics can perform different roles to improve soil quality, soft leaves with a high specific leaf area and nutrient content, such as leaves of Solanum mauritianum, are expected to easily decompose and provide nutrients to the soil, while tougher leaves with low specific leaf area and low nutrient content, such as leaves of Handroanthus chrysotricha, can take longer to decompose and, therefore, contribute to soil cover (Chapter 4). Moreover, increased plant diversity in coffee systems was associated with higher levels of soil microbial biomass carbon 


\section{Chapter 6}

(Chapter 4). Favourable conditions to microorganisms indicated by high levels microbial biomass can increase biological processes such as nitrogen fixation (Duarte et al., 2013), phosphorus absorption (Cardoso et al., 2003b) as well as nutrient solubilisation and mineralization.

I suggest that future studies should further explore the links between management, biodiversity and ecosystem services. For that, it is necessary to test the direct and indirect effect of particular management practices on different vegetation attributes and interconnected ecosystem functions and services across various land uses as well as multiple temporal and spatial scales. In addition, recent metagenomic and metatranscriptomic sequencing techniques can take the understanding on the contribution of microorganisms to soil functions to a higher level (Lemanceau et al., 2015). Such progress to understand ecosystem functioning for the re-design of agroecosystems requires enormous efforts from researchers to collect comparable and consistent field data and highlight the need to integrate different knowledge fields as functional ecology, microbiology, soil science, entomology, economics and sociology.

\section{Biodiversity and management practices for the re-design of pasture systems}

Although pasture systems are managed for milk and meat production and occupy almost $70 \%$ of the landscape in Zona da Mata, they receive little investments in terms of management. For instance, regardless the farm type, no inputs were applied in pastures during the seasons when this study was conducted. Indeed, the difficulties to manage pastures are reflected in lower soil biological and chemical quality in comparison with coffee systems (Figure 6.1), highlighting the need to re-design and restore pastures in Zona da Mata. 
General Discussion

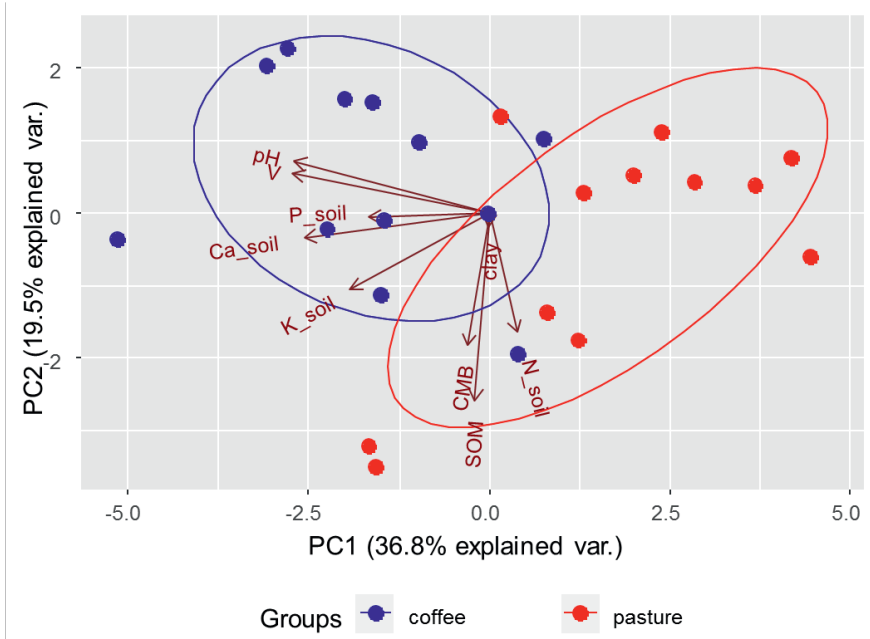

Figure 6.1. Principal component analysis based on soil quality indicators measured in twelve coffee and twelve pastures. Most pastures are located in the upper right corner of the graph. The position in the upper right part indicates lower levels of soil $\mathrm{pH}$, base saturation $(\mathrm{V})$, phosphorus, calcium, potassium, microbial biomass carbon, soil organic matter and nitrogen.

The restoration of pastures should address not only productivity issues, but also the provision of other ecosystem services such as water regulation. Water regulation was identified as the most important ES considering the whole group of farmers involved in Chapter 3. Besides, one of the main impacts of poor pasture management is soil compaction and erosion, which can reduce water infiltration and increase water run-off (Lunka and Patil, 2016; Russell and Bisinger, 2015). According to preliminary meetings with farmers and researchers to elaborate on the re-design of pasture systems in Zona da Mata, a few general strategies were identified. First, the division of pastures and the practice of rotational grazing can reduce soil compaction and soil erosion, which is especially important during dry periods in the winter season (Ermgassen et al., 2018; Teague, 2017). Second, during the dry season in Zona da Mata, grazing 


\section{Chapter 6}

should not be the only source of energy to livestock. Providing additional feed during the dry season can keep the animals healthy and avoid soil compaction and erosion in the pastures. The feed can be developed based on source material found on the farm, such as banana stems, tree leaves and fruits, sugar cane, maize and silage, among others. The diversification of other land uses on the farm (i.e. coffee agroforestry systems) can provide input for the additional animal feed (Romualdo and Cardoso, 2017). Third, the moderate use of limestone and fertilizers can help to boost system regeneration and avoid the growth of undesirable species, especially in cases when the soil is too acidic and levels of degradation are high (Ermgassen et al., 2018). One option is to spray fertilizers produced from on-farm materials such as animal manure and urine. If necessary, other inputs can be purchased, such as limestone, natural phosphate and other kinds of rock powder. The use of inputs are expected to be reduced as the recovery process advances. Soil quality as well as milk and/or meat productivity and quality should be monitored along the re-design process. Fourth, the increase in plant diversity in pastures can have a positive effect in soil quality (Chapter 4) and other ES.

Although agroecological management in pastures did not result in increased soil quality, we found an indirect positive effect through increased diversity (Chapter 4), indicating the need to re-configure farming practices, while maintaining or increasing biodiversity. One of the ways to increase biodiversity is to plant trees and/or allow native trees to regenerate in the pastures (Chapter 4). Trees can provide shade to the animals, improve nutrient cycling and soil quality and supply products, such as wood and fruits. In the case of planted species, protective structures must be implemented to avoid the animals to damage the seedlings. In addition, the diversification of forage species can increase functional diversity in pastures to balance animal nutrition and improve the resilience of the system (Wade, 2015). 
The results of this thesis reinforce that biodiversity as a result of agroecological management should be targeted for the re-design of more sustainable and agroecological systems. In chapter 2, we showed that agroecological family farms had a higher agrobiodiversity than other farms; in chapter 3 we found that agroecological farmers valued on-farm trees more than other farmer types; and in chapter 4 we showed a positive association between taxonomical, functional and structural plant diversity and soil quality in coffee and pastures. These findings align with reports of a positive association between biodiversity and a range of ES, such as crop yields, yield stability, pollination and weed and pest suppression (Isbell et al., 2017a). However, the ongoing process of agroecological transition in Zona da Mata and other studies worldwide (Duru et al., 2015b; Isbell et al., 2017a) highlight the need to combine diversification with other management strategies to achieve desirable outcomes. The increase in diversity should not drastically reduce crop yields, and therefore, it is crucial to identify and maintain optimal species composition and abundance. Such optimal designs, should be co-developed by scientists, farmers, technicians and other stakeholders (Chapter 1). In the case of Zona da Mata, for instance, the number of trees in productive coffee systems can range from 100-200 trees/hectare without compromising coffee yields (Chapter 4). Furthermore, diversification should be combined with other practices, such as mowing, use of organic fertilizers and reduced use of industrial inputs (Chapters 2 and 4) to enhance the attraction of plant and animal species from the surrounding environments (i.e. associated biodiversity). And finally, diversification should take into account local specificities and conditions. Therefore, the generalization of specific results to other environmental and social conditions must be carefully considered. 


\section{Chapter 6}

The redesign of agroecosystems is also important to the forest fragments present in the landscape, as an ecological agricultural matrix can reduce the negative impacts of agriculture on natural resources and enhance the conservation and flux of species among forest patches (Perfecto and Vandermeer, 2010). The three municipalities included in this study, Araponga, Divino and Espera Feliz, are ecologically relevant as they connect two important nature reserves: the National park "Caparaó" and the state park "Serra do Brigadeiro" (Figure 1.2, Chapter 1). Therefore, combining the agroecological re-design of agroecosystems and the increase in forest cover can help to create an ecological corridor between these two nature reserves and optimize the provision of ES in the landscape.

\section{Conversion of agriculture into forest}

Certain areas currently covered by pastures and coffee systems are of crucial importance to avoid soil erosion and enable water infiltration at the top of the hills, steep slopes $\left(\geq 45^{\circ}\right)$ and buffering zones along rivers or water springs. One alternative for protecting these areas is to fence the animals out and allow the natural regeneration of the native vegetation. Indeed, studies in Zona da Mata show that there was an increase in forest cover in the last decades due to the conversion of pastures and coffee areas into forest (Carvalho, in review). The increase of onfarm forest area is enforced by legal regulations and can enhance the provision of crucial forestmediated ES, such as water regulation (Taniwaki et al., 2018). In chapter 5, I assessed the consequences of converting agricultural fields into forest through secondary forest succession to the recovery of biodiversity and soil functions. The results suggest that secondary forest succession can be an efficient reforestation technique in regions like Zona da Mata. Plant taxonomical, structural and functional diversity converged to values found in primary forests after 25-50 years of succession. Soil carbon and nutrient cycling had a faster recovery, reaching 
levels found in primary forests after 15 years of succession. Yet, although soil cover also increased during succession, soil cover levels found in primary forests were not reached in secondary forests within 80 years. The results also allowed a better understanding of the mechanistic effects of vegetation on soil functions during succession. I found that variance in height and trait dominance of trees (i.e. structural diversity and biomass ratio hypotheses) were the main drivers of nutrient and carbon cycling. In contrast, the main driver of soil cover was aboveground biomass (greensoup hypothesis). Therefore, the importance of different biodiversity attributes increases as more ecosystem functions are considered in the study. For instance, if we consider only the function carbon sequestration, Eucalyptus plantations with little structural, functional and taxonomical diversity are likely to perform better than natural tropical forests due to the high growth rate of Eucalyptus. However, other functions, such as soil carbon and nutrient cycling and water regulation, may respond differently to vegetation diversity attributes. Therefore, future studies should carefully select plant traits that can possibly be associated with the functions of interest. Besides, to disentangle the concept of biodiversity is important to unravel the ecological role of different vegetation attributes. For instance, I identified structural diversity, which is a simple and easy indicator to be measured, as one of the main drivers of soil functions. Still, very few studies linking biodiversity and ecosystem functioning consider the structural diversity hypotheses as an ecological pathway to explain ecosystem change (Ali et al., 2016).

Although secondary succession was pointed out as an efficient strategy to enhance the provision of ES (Chapter 5), the conversion of agricultural fields into forest remains a challenge to farmers. One of the main reasons is that farmers often have a limited farm area and resources and, therefore, it becomes unfeasible to reduce production areas. Therefore, for the successful 


\section{Chapter 6}

reforestation through secondary succession, it is important to consider the value that farmers give to the forest and their willingness to restore forest areas on their farms. As a preliminary study, we constructed a fuzzy cognitive map with a group of farmers in the Frossard community (forest research site of Chapter 5) to understand their perceptions on the ecosystem services provided by the forest (Figure 6.2.). We found that provision of water was the most important direct ES for farmers (as also observed in Chapter 3), followed by aesthetics, provision of clean air and medicinal plants. The only intermediate ES identified was soil quality, which was strongly associated with the provision of water $(+0.7)$. The positive association between soil quality and water regulation was also observed in Chapter 5, in which soil organic matter and soil cover were positively associated, respectively, with soil water content and water retained in the litter. Human health and peace were considered by farmers as final benefits that can be understood as human well-being components. Biodiversity of plants in the forest was identified as the most central factor in the map, acting as an important positive driver for all ES. In our ecological study of Chapter 5, we further explored those links, showing the significant influence of vegetation on soil functions. According to farmers, biodiversity was also positively associated to wildlife, which in turn, can have negative consequences for agricultural production. Several human interventions were perceived by farmers to affect positively and negatively the provision of ES. On one hand, the protection of water springs, development of ecological water treatment, infiltration ditches, use of level contours in agricultural land and people environmental awareness are positively influencing the provision of ES directly and indirectly. On the other hand, hunting, cattle grazing, use of chemical pesticides (increased by the presence of monocultures in the landscape), human waste and fire were identified as negative drivers of ES. 


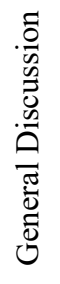
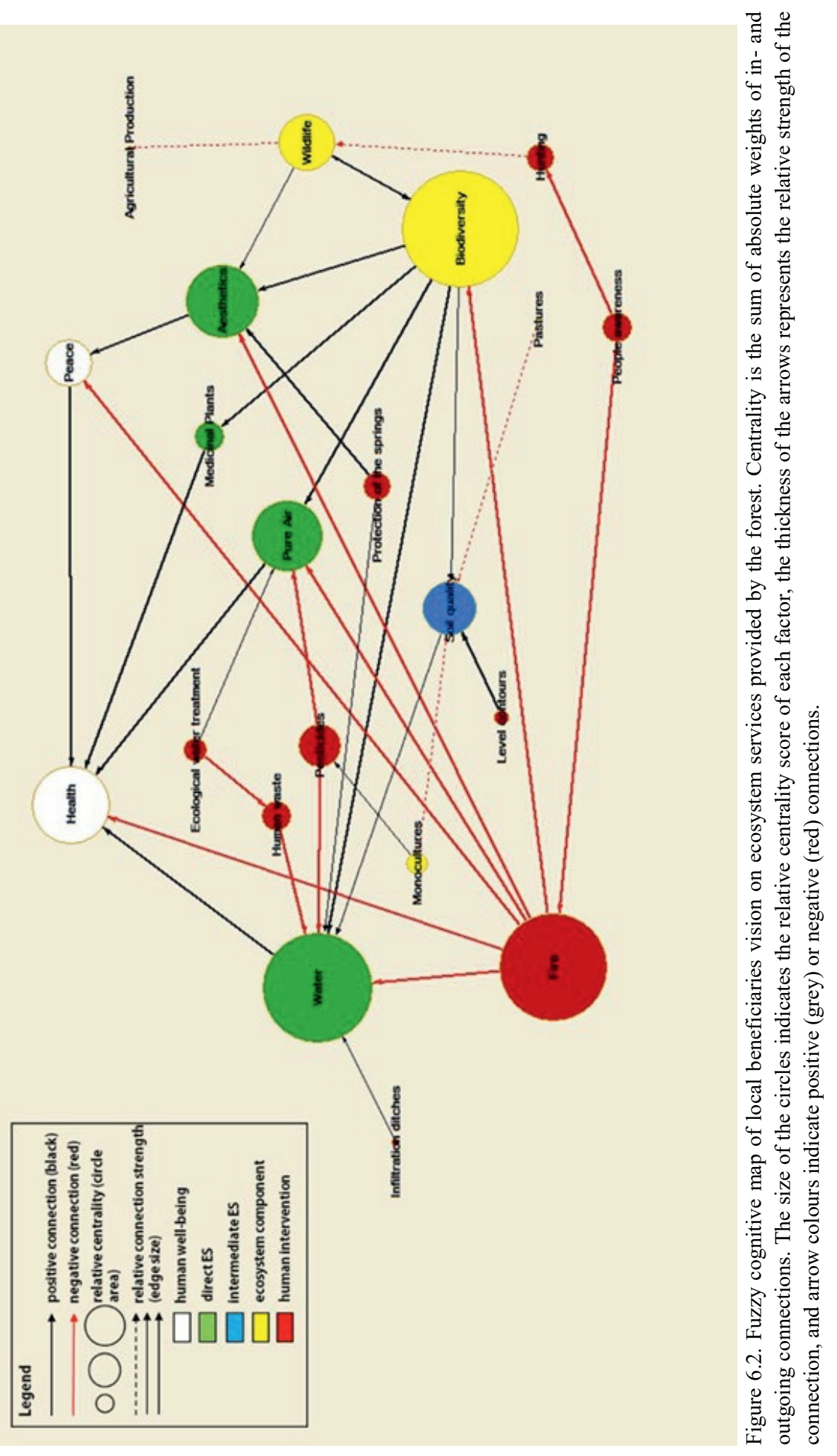


\section{Chapter 6}

Fire was the most central negative driver, directly influencing human well-being, ES and biodiversity. Further studies are needed to better understand farmers' knowledge and needs, and also to explore the ecological impact of on-farm reforestation on other ES than soil quality.

Another important factor that should be considered for the reforestation of new areas is the financial implications for farmers. Because forest patches on hill tops in Zona da Mata are fragmented and have difficult access, developing sustainable management for timber products is challenging. A possible strategy can be the promotion of economic incentives for farmers to increase or maintain forest areas. For example, the "Programa Bolsa Verde" was a public policy launched by the state of Minas Gerais (Brazil) that attempted to give a financial compensation for farmers for each hectare of forest maintained or restored in their farms. Moreover, the great biodiversity found in the Atlantic forest (Chapter 5) as well as the knowledge of farmers on how to use non-timber forest products (e.g. medicinal plants) can be an effective strategy to support sustainable forest management and even increase the income of farmers. Lastly, the conversion of new areas into forest should take a landscape approach and consider the connectivity among forest patches and nature reserves.

\section{Scaling up agroecological transitions}

Agroecology as a feasible approach for developing sustainable agroecosystems, capable to conserve biodiversity and provide multiple ecosystem services for human well-being, is increasingly recognised by social movements, scientific and political communities (FAO, 2018; Pretty, 2008; Rosset et al., 2011; Schutter, 2010). In this thesis, I described the outcomes of an agroecological transition process. First, agroecological farmers were engaged in a network composed of farmers' organisations, universities and NGOs (Chapter 2). Second, agroecological 
farms showed greater potential to provide a wide range of ecosystem services as they featured high crop diversity and high number of crops for self-consumption (Chapter 2). Third, agroecological farmers had a more complex perception on ecosystem services than large-scale and conventional family farmers and this was associated with increased diversity and ecological management in their systems (Chapter 3). Fourth, coffee fields under agroecological management had increased plant diversity, which in turn was associated to increased microbial biomass carbon. Furthermore, although the use of external inputs was reduced in coffee fields under agroecological management, it did not result in reduced coffee yields and soil chemical fertility than large-scale and conventional family farms (Chapter 4). In pastures, the increased biodiversity associated with agroecological management was also positively associated with soil quality. However, in pastures, agroecological management did not result in increased soil quality, indicating the need to adapt and re-design management strategies (Chapter 4) using practices, such as rotational grazing, soil fertilization and diversification of trees and forage species.

In general, despite strong evidence on its social, ecological and agronomic benefits, agroecological approaches are still not widely adopted across the globe (Pretty et al., 2018; Schutter, 2010) and also not in Zona da Mata, as only $30 \%$ of family farmers were considered agroecological (Chapter 2). Therefore, agroecological transitions need to "scale up", which entails increasing the beneficial outcomes of agroecology by reaching more farmers, communities and regions across the globe. Moreover, the concept of agroecological transitions can go beyond the re-design at farm level and also consider transformations in the entire agrifood system, including markets, social relations, governance and policies (Chapter 2, Gliessman, 2018). Therefore, the agroecological transition process should be understood as a 


\section{Chapter 6}

dynamic, adaptable and continued process that aims to change the agricultural paradigm towards fair, sustainable and efficient agri-food systems.

To scale up agroecological transition, I suggest that other issues besides technical ones should be considered, as well as the development of an enabling framework for farmers (Schutter, 2010). Recent scientific frameworks suggest that the design of agroecological transitions should involve multiple stakeholders using participatory methodologies (Duru et al., 2015a; Lacombe et al., 2018; Martin et al., 2018). For instance, Duru et al. (2015a) presents a review on agroecological transitions where five steps are proposed to engage multiple stakeholders and achieve the ultimate goal of co-designing more sustainable agroecosystems. Apart from the stepwise logic, the approach suggests useful strategies for promoting agroecological transitions that were applied in this thesis, such as the identification of challenges faced by farmers associated with different farm types (Farm typology - Chapter 2) as well as the construction of conceptual representations of the functioning of agroecosystems (Fuzzy cognitive maps - Chapter 3). The farm typology, fuzzy cognitive maps and other methodological approaches used in this thesis provided insights on the challenges that can be addressed for making current frameworks more useful and efficient on the ground. First, agroecological transitions must be understood beyond a linear process conceptualized as the efficiency-substitution-redesign model at field or farm scale (Ollivier et al., 2018). The concept of a linear set of actions (steps) are difficult to apply in complex and contrasting local conditions. Instead, the development of a set of principles and methodological tools can be established to guide and facilitate transition processes according to the needs and conditions of particular farming realities. For instance, the agroecological transition in Zona da Mata was developed as a non-linear on-going process, where the implementation of new practices was not adopted in the same way by all farmers and 
management strategies were continuously evaluated and adapted (Chapters 1 and 2). Therefore, agroecological transitions should be interpreted as an infinite process without a clear end point, as there are multiple pathways of transition and even successful and sustainable agroecological farms may not perform optimally in all social, cultural, technological, environmental and economic aspects that entail agroecology.

Second, social organisations and networks that include a variety of social actors should take a central role in the transition process, which is often not highlighted in conceptual frameworks (Lacombe et al., 2018). Researchers should actively engage as co-creators in these networks, and facilitate, support, systematize and underpin the learning process based on empirical data (Chapters 2, 3, 4 and 5). Yet, the long-term continuation of agroecological transitions cannot fully depend on researchers as science is often limited to short-term funding and availability of projects. In addition, farmers should play a central role, as they are the ones who own and manage the land and have great knowledge and complex perceptions on local culture, social dynamics and the environment (Chapter 3).

Third, adequate public policies are needed to catalyse the transition to agroecology. For instance, agroecological farmers in Zona da Mata had greater access to public policies (Chapter 2), which is associated to access to subsidies and land, as well as the development of short chain markets. Therefore, public policies should direct credit and subsidies for family farming and agroecological agriculture to help to develop alternative markets that allow farmers to create a more direct link with consumers, to sell a diversity of products and to obtain a higher price for organic or agroecological products (Valencia et al., 2019). Moreover, public policies should be directed to provide farmers access to land, resources and knowledge through local and national 


\section{Chapter 6}

programs, such as the National Policy on Agroecology and Organic Production, which was launched in Brazil in 2013 and developed in cooperation with farmers, social movements and civil society organisations (Petersen et al., 2013).

Fourth, lock-in of narratives that place industrial agriculture as the only feasible way to produce food and live out of farming need to be challenged (Louah et al., 2017; Magrini et al., 2016; Vanloqueren and Baret, 2009). The multilevel view of transitions describes this lock-in as a process that hampers niche innovations to get consolidated as part of the socio-technical regime (Ollivier et al., 2018). In the case of agroecological transitions, the lock-in is reflected in many different ways, when retailers are only interested in a single commodity crop and do not make a distinction between agroecological and non-agroecological products (Macfadyen et al., 2016); when credits are only allowed for the purchase of chemical fertilizers and pesticides; when advisory services take a top-down approach offering one-size-fits-all solutions; when family farming is treated as an old and inefficient way of doing agriculture whereas large-scale farming is set as an example of the wealth that can be obtained following the dominant discourse on agriculture (Chapter 2).

Fifth, agroecological practices are knowledge intensive and require adaptation, experimentation as well as a process of sharing and co-creation of knowledge (Chantre and Cardona, 2014). Such process of knowledge co-creation is not easy, and requires deep practical and theoretical knowledge on the functioning of agroecosystems. Therefore, to promote agroecological transitions it is necessary not only to show robust ecological and agronomic evidence on its benefits, but also to develop methodologies that bring farmers and local actors together to cocreate knowledge (Chapters 2 and 3) and learn from successful experiences. 
The Zona da Mata region has a great potential to scale up agroecological and organic production and become a reference in Brazil and in the world due to its favourable environmental conditions, the predominance of family farming and the presence of strong social organisations and movements. Indeed, a state law stablished in the end of 2018 appointed the Zona da Mata region as a centre of agroecology and organic production (Pimentel, 2018), with the goal to give visibility, support and subsidize agroecological initiatives with the participation of farmers as well as public and private organisations. For helping to scale up agroecological transitions in Zona da Mata it remains crucial to guarantee the continuation of public policies directed to family farmers, to strength local markets and the access to niche markets for organic and agroecological products, the organisation of farmer-to-farmer meetings to allow knowledge sharing, the strengthening and funding of social organisations and networks, and the development of collaborative research involving researchers from different disciplines.

\section{The (in)visible components of participatory action research}

In this thesis, I used participatory action research as a collaborative approach for engaging local actors in the research process. The importance of transdisciplinary collaboration and the incorporation of different worldviews in research is increasingly recognised (Brandt et al., 2013; Cundill et al., 2019; Mauser et al., 2013), especially in scientific studies attempting to assess and design complex social ecological systems (Díaz et al., 2019; Hatt et al., 2016; Keesstra et al., 2016). Despite the importance to engage scientists from different fields and local actors as co-creators in the research process using transdisciplinary and participatory approaches, few studies present and assess effective approaches for doing so. The focus of research is often on data collection and interpretation, while social values and strategies to approach local actors and build a relationship of mutual trust, respect and collaboration have received less attention. This 


\section{Chapter 6}

$\mathrm{PhD}$ research developed in Zona da Mata was conducted within a long-term local network involving organisations as the University (UFV), NGOs (CTA-ZM) and farmer`s organizations, such as unions, cooperatives and associations. The engagement in such a network facilitates the process of participatory research and allows current researchers to benefit from on-going activities and to build on previous experiences and methodologies. Based on my experience within a team of researchers part of the FOREFRONT program, I identified six main components that were crucial for implementing participatory action research and collaboration among researchers:

(i) Collective articulation of research questions, for aligning researchers and local actors' interests. To start the research program in Zona da Mata, we organised introduction workshops with groups of farmers and representatives from farmers' organisations in each of the municipalities included in the study. During these workshops, we presented the general outline of the FOREFRONT program and using participatory approaches the participants were encouraged to suggest problems or ideas that research could help to address. The suggestions were clustered in broader topics and the outcomes of all workshops were systematized and organised by the research team. Together, our group of $\mathrm{PhD}$ candidates reflected on how we could link and shape our research questions to tackle the issues pointed out by farmers. Then we organised our research questions in a way that all topics raised by farmers were tackled by at least one researcher.

(ii) Participatory methodologies for building scientific knowledge. During the course of the research project, we organised interactive and participatory workshops with farmers to further discuss, explore and analyse the topics and research questions originated from the introduction 
meetings. The outcomes of the workshop can be used as a source of data for researchers and help to integrate local and scientific knowledge. In this thesis, for instance, the farm typology developed in Chapter 2 was partly based on participatory workshops with local actors.

(iii) Sharing and discussing research results with local actors. To make research outcomes useful and meaningful for local actors it is crucial to organise workshops during the research process to share and discuss the results. Returning research outcomes gradually along the research process allows local actors to provide feedback and creates a relationship of trust and mutual respect. If scientists go to local communities to collect data and do not return to share the results, farmers can become sceptical about research, which can create barriers for future development of other research projects and increase the distance between science and local actors. We shared the results with farmers gradually along the research process through the organisation of several meetings and workshops. During the activities, we presented the main results with power point presentations followed by discussions. We also used participatory methodologies based on the pedagogy of Paulo Freire, such as artistic pedagogical installation and circle of culture (Freire, 1983).

(iv) Integration between research and education can create synergies and strengthen research outcomes. The integration within our research program was done in many ways, such as bringing students to research study sites, creating interactions between students and local actors, involving students in the organisation of workshops with farmers, training students on research methods and enabling them to have practical experiences in the field. BSc and MSc students participated in these activities as part of their university program. 


\section{Chapter 6}

(v) Strengthening capacity building and interdisciplinary team work. It is very hard for just one or few scientists from the same field to develop interdisciplinary research. Hence, for the successful development of inter- and transdisciplinary studies it is important to create and manage an efficient and collaborative team of researchers and students with multiple skills and capacities. However, the scientific community in general is not very used to collaborative and interdisciplinary approaches so it is necessary to organise activities that help the team members to develop their ability to work and embrace diversity in a group (Cundill et al., 2019). In addition, methodological tools are necessary to help to deal with power asymmetries and to enable the horizontal participation of all members of the research team. For that, training workshops for team members, periodic team meetings and the use of participatory methods were crucial in the research process in Zona da Mata.

(vi) Social engagement with farmers can help researchers to better understand local realities, get to know the local community and to develop a relationship of mutual trust. Furthermore, such engagement can facilitate the research process as it can help researchers to identify research gaps and needs. Researchers can engage with local actors by participating in community events (e.g. peasant-to-peasant meetings, local markets); organising more practical workshops for farmers based on scientific evidence (e.g. workshop on sustainable soil management practices); and working together with farmers in their daily agricultural tasks.

I suggest that building a team of researchers with different theoretical backgrounds and learning styles can be effective to engage with farmers and their organisations and to make research outcomes more relevant on the ground. The use of participatory methodologies is crucial not only to make this process possible, but also to generate knowledge that is credible, salient, and 
legitimate for stakeholders (Clark et al., 2016). However, engaging with farmers and different knowledge disciplines require extra effort and time from individual researchers, which is not always valued or recognized by academic systems.

\section{Concluding remarks and recommendations for future studies}

The framework developed and operationalised in this thesis to assess the links between biodiversity, ecosystem services and social actors (Figure 1.4, Chapter 1) was based on interdisciplinary methods that can be applied in other regions and derive applicable recommendations. I suggest that the framework, and its applicability can contribute to the current knowledge on ES and agroecological transitions because: (i) it shows concrete research and participatory tools that can be used and combined within the framework; (ii) it provides a holistic assessment of ecological, technological and socioeconomic aspects of agroecosystems; (ii) it allows the co-construction of knowledge with local actors as part of the research process; (iii) it informs management recommendations based not only on ecological knowledge, but also on social and cultural aspects of farming systems; (iv) it provides clear outcomes that help farmers to better understand their reality and the functioning of their agroecosystems; and (v) it explores the mechanisms behind the effects of biodiversity on ecosystem services. The framework can be used both to answer more fundamental research questions (e.g. what are the aboveground drivers of soil functions?) and also to support land users, managers, policy-makers, technicians and other actors to take informed decisions based on a multilevel scientific assessment of agroecosystems. (e.g. how to reduce the use of pesticides, and what are the consequences for crop productivity and other ecosystem services?). Yet, the framework can benefit from improvement, as it does not focus on the specific role of individual households and is limited in terms of geographical, spatial and time scales. 
Chapter 6

I conclude that participatory action research, interdisciplinary and collaborative research are crucial to operationalise the ecosystem services framework. Therefore, methodological approaches and strategies to engage with local actors and facilitate collaboration among researchers should be highlighted in future research. My findings suggest that agroecology is a promising approach to engage farmers and other actors for the development of more sustainable and diversified agroecosystems. The development of such systems requires complex knowledge on ES and their management. Therefore, changes in the cognitive perception of agroecological farmers on their agroecosystem was key for leading changes in management strategies, that in turn, influenced biodiversity and the provision of ES. In both coffee and pastures, agroecological management practices resulted in increased plant diversity, which in turn, was key to maintain or increase the provision of ecosystem services. In other words, the association between agroecological management and ecosystem services was mediated by biodiversity. Therefore, the increase of biodiversity as a result of agroecological management should be targeted for the re-design of more sustainable agroecosystems. Yet, to further advance the agroecological transition it becomes crucial to go beyond ecological management and to develop improved strategies for processing and marketing crop products; to develop adequate public policies; to provide farmers access to land, knowledge and infrastructure; to empower women and youth; to value local traditions, culture and knowledge; to strengthen social organisations, movements and networks and at last; to promote the integration between science, education, policies and practice. 
General Discussion 


\section{References}

Acosta-Martinez, V., Cano, A., Johnson, J., 2018. Simultaneous determination of multiple soil enzyme activities for soil health-biogeochemical indices. Appl. Soil Ecol. 126, 121-128. doi:10.1016/j.apsoil.2017.11.024

Adhikari, K., Hartemink, A.E., 2016. Linking soils to ecosystem services - A global review. Geoderma 262, 101-111. doi:10.1016/j.geoderma.2015.08.009

Alef, K., Nannipieri, P., 1995. Methods in applied soil microbiology and biochemistry, Academic Press. Academic Press.

Ali, A., Yan, E.R., Chen, H.Y.H., Chang, S.X., Zhao, Y.T., Yang, X.D., Xu, M.S., 2016. Stand structural diversity rather than species diversity enhances aboveground carbon storage in secondary subtropical forests in Eastern China. Biogeosciences 13, 4627-4635. doi:10.5194/bg-13-4627-2016

Altieri, M., Toledo, V.M., 2011. The agroecological revolution in Latin America: rescuing nature, ensuring food sovereignty and empowering peasants. J. Peasant Stud. 38, 587-612. doi:10.1080/03066150.2011.582947

Altieri, M., Merrick, L.C., 1987. In situ conservation of crop genetic resources through maintenance of traditional farming systems. Econ. Bot. 41, 86-96.

Altieri, M., 1999. The ecological role of biodiversity in agroecosystems. Agric. Ecosyst. Environ. 74, 19-31. doi:10.1016/S0167-8809(99)00028-6

Altieri, M., Nicholls, C.I., 2017. Agroecology : a brief account of its origins and currents of thought in Latin America. Agroecol. Sustain. Food Syst. 41, 231-237. doi:10.1080/21683565.2017.1287147

Amaro, M.A., 2010. Quantificaçao do estoque volumétrico, de biomassa e de carbono em uma floresta estacional semidecidual no município de Viçosa-MG. Tese (Doutorado em Ciência Florestal) - Univ. Fed. Viçosa. Universidade Federal de Viçosa.

Andrade, F.T. de, Júnior, L.G. de C., Costa, C.H.G., 2012. Assessment of coffee sector by the variable costing approach in properties of the main production regions of Brazil. Organ. Rurais Agroindustriais 14, 356-366.

Bakker, M.A., Carreño-Rocabado, G., Poorter, L., 2011. Leaf economics traits predict litter 
decomposition of tropical plants and differ among land use types. Funct. Ecol. 25, 473483. doi:10.1111/j.1365-2435.2010.01802.x

Balvanera, P., Siddique, I., Dee, L., Paquette, A., Isbell, F., Gonzalez, A., Byrnes, J., O’Connor, M.I., Hungate, B.A., Griffin, J.N., 2014. Linking biodiversity and ecosystem services: current uncertainties and the necessary next steps. Bioscience 64, 49-57. doi:10.1093/biosci/bit003

Barman, M., Paul, S., Choudhury, A.G., Roy, P., Sen, J., 2017. Biofertilizer as prospective input for sustainable agriculture in India. Int. J. Curr. Microbiol. Appl. Sci. 6, 1177-1186. doi:10.20546/ijcmas.2017.611.141

Barnosky, A.D., Matzke, N., Tomiya, S., Wogan, G.O.U., Swartz, B., Quental, T.B., Marshall, C., McGuire, J.L., Lindsey, E.L., Maguire, K.C., Mersey, B., Ferrer, E.A., 2011. Has the Earth's sixth mass extinction already arrived? Nature 471, 51-57. doi:10.1038/nature09678

Barton, K., 2019. MuMIn: Multi-Model Inference, Version 1.43.6.

Bastian, M., Heymann, S., 2009. Gephi: an open source software for exploring and manipulating networks, in: proceedings of the Third International ICWSM Conference. pp. 361-362.

Bastin, J.F., Finegold, Y., Garcia, C., Mollicone, D., Rezende, M., Routh, D., Zohner, C.M., Crowther, T.W., 2019. The global tree restoration potential. Science 365, 76-79. doi:10.1126/science.aax0848

Bates, D., Mächler, M., Bolker, B.M., Walker, S.C., 2015. Fitting linear mixed-effects models using lme4. J. Stat. Softw. 67. doi:10.18637/jss.v067.i01

Batish, D.R., Singh, H.P., Kohli, R.K., Kaur, S., 2008. Eucalyptus essential oil as a natural pesticide. For. Ecol. Manage. 256, 2166-2174. doi:10.1016/j.foreco.2008.08.008

Baudron, F., Giller, K.E., 2014. Agriculture and nature: trouble and strife? Biol. Conserv. 170, 232-245. doi:10.1016/j.biocon.2013.12.009

Bechara, F.C., Dickens, S.J., Farrer, E.C., Larios, L., Spotswood, E.N., Mariotte, P., Suding, K.N., 2016. Neotropical rainforest restoration: comparing passive, plantation and nucleation approaches. Biodivers. Conserv. 25, 2021-2034. doi:10.1007/s10531-016$1186-7$

Benjamini, Y., Hochberg, Y., 1995. Controlling the false discovery rate: a practical and powerful approach to multiple testing. J. R. Stat. Soc. Ser. B 57, 289-300. 


\section{References}

Bennett, E.M., Cramer, W., Begossi, A., Cundill, G., Díaz, S., Egoh, B.N., Geijzendorffer, I.R., Krug, C.B., Lavorel, S., Lazos, E., Lebel, L., Martín-López, B., Meyfroidt, P., Mooney, H.A., Nel, J.L., Pascual, U., Payet, K., Harguindeguy, N.P., Peterson, G.D., Prieur-Richard, A.H., Reyers, B., Roebeling, P., Seppelt, R., Solan, M., Tschakert, P., Tscharntke, T., Turner, B.L., Verburg, P.H., Viglizzo, E.F., White, P.C.L., Woodward, G., 2015. Linking biodiversity, ecosystem services, and human well-being: three challenges for designing research for sustainability. Curr. Opin. Environ. Sustain. 14, 76-85. doi:10.1016/j.cosust.2015.03.007

Bernard, B., Lux, A., 2017. How to feed the world sustainably: an overview of the discourse on agroecology and sustainable intensification. Reg. Environ. Chang. 17, 1279-1290. doi:10.1007/s10113-016-1027-y

Bernués, A., Tello-garcía, E., Rodríguez-ortega, T., Ripoll-bosch, R., Casasús, I., 2016. Land use policy agricultural practices, ecosystem services and sustainability in high nature value farmland : unraveling the perceptions of farmers and nonfarmers. 59, 130-142.

Berthet, E.T.A., Barnaud, C., Girard, N., Labatut, J., Martin, G., 2016. How to foster agroecological innovations? A comparison of participatory design methods. J. Environ. Plan. Manag. 59, 280-301. doi:10.1080/09640568.2015.1009627

Beudou, J., Martin, G., Ryschawy, J., 2017. Cultural and territorial vitality services play a key role in livestock agroecological transition in France. Agron. Sustain. Dev. 37, 1-11. doi:10.1007/s13593-017-0436-8

Birkhofer, K., Diehl, E., Andersson, J., Ekroos, J., Früh-Müller, A., Machnikowski, F., Mader, V.L., Nilsson, L., Sasaki, K., Rundlöf, M., Wolters, V., Smith, H.G., 2015. Ecosystem services - current challenges and opportunities for ecological research. Front. Ecol. Evol. 2, 1-12. doi:10.3389/fevo.2014.00087

Blesh, J., Wolf, S.A., 2014. Transitions to agroecological farming systems in the Mississippi River Basin : toward an integrated socioecological analysis. Agric. Human Values 31, 621635. doi:10.1007/s10460-014-9517-3

Bloom, A.J., Mooney, H.A., 1985. Resource limitation in plants - an economic analogy. Annu. Rev. Ecol. Syst. 16, 363-392. doi:10.1146/annurev.es.16.110185.002051

Boerema, A., Rebelo, A.J., Bodi, M.B., Esler, K.J., Meire, P., 2016. Are ecosystem services adequately quantified? J. Appl. Ecol. doi:10.1111/1365-2664.12696 
Bonaudo, T., Bendahan, A.B., Sabatier, R., Ryschawy, J., Bellon, S., Leger, F., Magda, D., Tichit, M., 2014. Agroecological principles for the redesign of integrated crop-livestock systems. Eur. J. Agron. 57, 43-51. doi:10.1016/j.eja.2013.09.010

Bonetti, J. de A., Anghinoni, I., Gubiani, P.I., Cecagno, D., Moraes, M.T. de, 2019. Soil \& tillage research impact of a long-term crop-livestock system on the physical and hydraulic properties of an Oxisol. Soil Tillage Res. 186, 280-291. doi:10.1016/j.still.2018.11.003

Bongers, F., Poorter, L., Hawthorne, W.D., Sheil, D., 2009. The intermediate disturbance hypothesis applies to tropical forests, but disturbance contributes little to tree diversity. Ecol. Lett. 12, 798-805. doi:10.1111/j.1461-0248.2009.01329.x

Botelho, M.I.V., Cardoso, I.M., Otsuki, K., 2015. "I made a pact with God, with nature, and with myself': exploring deep agroecology. Agroecol. Sustain. Food Syst. 40, 116-131. doi:10.1080/21683565.2015.1115798

Boukili, V.K., Chazdon, R.L., 2017. Environmental filtering, local site factors and landscape context drive changes in functional trait composition during tropical forest succession. Perspect. Plant Ecol. Evol. Syst. 24, 37-47. doi:10.1016/j.ppees.2016.11.003

Braat, L.C., Groot, R. de, 2012. The ecosystem services agenda: bridging the worlds of natural science and economics, conservation and development, and public and private policy. Ecosyst. Serv. 1, 4-15. doi:10.1016/j.ecoser.2012.07.011

Brandt, P., Ernst, A., Gralla, F., Luederitz, C., Lang, D.J., Newig, J., Reinert, F., Abson, D.J., Wehrden, H. Von, 2013. A review of transdisciplinary research in sustainability science. Ecol. Econ. 92, 1-15.

Browder, J., 1995. Redemptive communities: indigenous knowledge colonist farming systems and conservation of tropical forests. Agric. Human Values 12, 17-30.

Buchanan, S., Isaac, M.E., Van den Meersche, K., Martin, A.R., 2019. Functional traits of coffee along a shade and fertility gradient in coffee agroforestry systems. Agrofor. Syst. 93, 12611273. doi:10.1007/s10457-018-0239-1

Bünemann, E.K., Bongiorno, G., Bai, Z., Creamer, R.E., De Deyn, G., Goede, R. de, Fleskens, L., Geissen, V., Kuyper, T.W., Mäder, P., Pulleman, M., Sukkel, W., Willem, J., Groenigen, V., Brussaard, L., 2018. Soil quality - a critical review. Soil Biol. Biochem. 120, 105-125. doi:10.1016/j.soilbio.2018.01.030

Caceres, D.M., Tapella, E., Quetier, F., Diaz, S., 2015. The social value of biodiversity and 


\section{References}

ecosystem services from the perspectives. Ecol. Soc. 20, 62. doi:10.5751/ES-07297200162

Calmon, M., Brancalion, P.H.S., Paese, A., Aronson, J., Castro, P., Silva, S.C. da, Rodrigues, R.R., 2011. Emerging threats and opportunities for large-scale ecological restoration in the Atlantic forest of Brazil. Restor. Ecol. 19, 154-158. doi:10.1111/j.1526100X.2011.00772.X

Campos, A.P.T. de, 2006. Conquista de terras em conjunto: redes sociais e confianca: a experiencia dos agricultures e agricultoras familiares de Araponga. MSc thesis, Universidade Federal de Viçosa.

Cardinale, B.J., Duffy, J.E., Gonzalez, A., Hooper, D.U., Perrings, C., Venail, P., Narwani, A., Mace, G.M., Tilman, D., Wardle, D.A., Kinzig, A.P., Daily, G.C., Loreau, M., Grace, J.B., Larigauderie, A., Srivastava, D.S., Naeem, S., 2012. Biodiversity loss and its impact on humanity. Nature 486, 59-67. doi:10.1038/nature11373

Cardoso, I.M., Boddington, C., Janssen, B.H., Oenema, O., Kuyper, T.W., 2003a. Distribution of mycorrhizal fungal spores in soils under agroforestry and monocultural coffee systems in Brazil. Agrofor. Syst. 58, 33-43. doi:10.1023/A:1025479017393

Cardoso, I.M., Guijt, I., Franco, F.S., Carvalho, A.F., Ferreira Neto, P.S., 2001. Continual learning for agroforestry system design: university, $\mathrm{NGO}$ and farmer partnership in Minas Gerais, Brazil. Agric. Syst. 69, 235-257. doi:10.1016/S0308-521X(01)00028-2

Cardoso, I.M., Mendes, F., 2014. People managing landscapes: agroecology and social processes, in: agroecology for food security and nutrition - proceedings of the FAO International Symposium. FAO, Rome, Italy.

Cardoso, I.M., Van Der Meer, P., Oenema, O., Janssen, B.H., Kuyper, T.W., 2003b. Analysis of phosphorus by 31PNMR in Oxisols under agroforestry and conventional coffee systems in Brazil. Geoderma 112, 51-70. doi:10.1016/S0016-7061(02)00293-8

Cardozo Junior, F.M., Carneiro, R.F.V., Rocha, S.M.B., Nunes, L.A.P.L., dos Santos, V.M., Feitoza, L. de L., de Araújo, A.S.F., 2018. The impact of pasture systems on soil microbial biomass and community-level physiological profiles. L. Degrad. Dev. 29, 284-291. doi:10.1002/ldr.2565

Carmo, C.A.F. de S. do, Araújo, W.S. de, Bernardi, A.C. de C., Saldanha, M.F.C., 2000. Métodos de análises de tecidos vegetais utilizados na Embrapa Solos, Embrapa Solos 
Circular Técnica.

Carneiro, J.J., 2013. Sistemas agroecológicos conservam solo e água. MSc thesis, Universidade Federal de Viçosa.

Casanoves, F., Pla, L., Di Rienzo, J.A., Díaz, S., 2011. FDiversity: a software package for the integrated analysis of functional diversity. Methods Ecol. Evol. 2, 233-237. doi:10.1111/j.2041-210X.2010.00082.x

Castro, A.M., Tapias, J., Ortiz, A., Benavides, P., Góngora, C.E., 2017. Identification of attractant and repellent plants to coffee berry borer, Hypothenemus hampei. Entomol. Exp. Appl. 164, 120-130. doi:10.1111/eea.12604

Catarino, R., Gaba, S., Bretagnolle, V., 2019. Experimental and empirical evidence shows that reducing weed control in winter cereal fields is a viable strategy for farmers. Sci. Rep. 9, 9004. doi:10.1038/s41598-019-45315-8

Ceballos, G., Ehrlich, P.R., Dirzo, R., 2017. Biological annihilation via the ongoing sixth mass extinction signaled by vertebrate population losses and declines. Proc. Natl. Acad. Sci. U. S. A. 114, E6089-E6096. doi:10.1073/pnas.1704949114

Chambers, R., 1994. The origins and practice of participatory rural appraisal. World Dev. 22, 953-969. doi:10.1016/0305-750X(94)90141-4

Chan, K.M.A., Satterfield, T., Goldstein, J., 2012. Rethinking ecosystem services to better address and navigate cultural values. Ecol. Econ. 74, 8-18. doi:10.1016/j.ecolecon.2011.11.011

Chantre, E., Cardona, A., 2014. Trajectories of french field crop farmers moving toward sustainable farming practices: change, learning, and links with the advisory services. Agroecol. Sustain. Food Syst. 38, 573-602. doi:10.1080/21683565.2013.876483

Chavarria, D.N., Pérez-Brandan, C., Serri, D.L., Meriles, J.M., Restovich, S.B., Andriulo, A.E., Jacquelin, L., Vargas-Gil, S., 2018. Response of soil microbial communities to agroecological versus conventional systems of extensive agriculture. Agric. Ecosyst. Environ. 264, 1-8. doi:10.1016/j.agee.2018.05.008

Chavassieux, D.C.M., 2012. Control of Fusarium wilt in an agroforestry system with Banana Maçã (Musa acuminata) in Pedra Dourada, Minas Gerais, Brazil.

Chaza, C., Sopheak, N., Mariam, H., David, D., Baghdad, O., Moomen, B., 2018. Assessment of pesticide contamination in Akkar groundwater, northern Lebanon. Environ. Sci. Pollut. 


\section{References}

Res. 25, 14302-14312. doi:10.1007/s11356-017-8568-6

Chazdon, R.L., 2008a. Beyond deforestation: restoring forests and ecosystem services on degraded lands. Science 320, 1458-1460. doi:10.1126/science.1155365

Chazdon, R.L., 2008b. Chance and determinism in tropical forest succession, in: Carson, W.P., Schnitzer, S.A. (Eds.), Tropical Forest Community Ecology. pp. 384-408.

Chazdon, R.L., Broadbent, E.N., Rozendaal, D.M.A., Bongers, F., Zambrano, A.M.A., Aide, T.M., Balvanera, P., Becknell, J.M., Boukili, V., Brancalion, P.H.S., Craven, D., AlmeidaCortez, J.S., Cabral, G.A.L., de Jong, B., Denslow, J.S., Dent, D.H., DeWalt, S.J., Dupuy, J.M., Durán, S.M., Espírito-Santo, M.M., Fandino, M.C., César, R.G., Hall, J.S., Hernández-Stefanoni, J.L., Jakovac, C.C., Junqueira, A.B., Kennard, D., Letcher, S.G., Lohbeck, M., Martínez-Ramos, M., Massoca, P., Meave, J.A., Mesquita, R., Mora, F., Muñoz, R., Muscarella, R., Nunes, Y.R.F., Ochoa-Gaona, S., Orihuela-Belmonte, E., PeñaClaros, M., Pérez-García, E.A., Piotto, D., Powers, J.S., Rodríguez-Velazquez, J., RomeroPérez, I.E., Ruíz, J., Saldarriaga, J.G., Sanchez-Azofeifa, A., Schwartz, N.B., Steininger, M.K., Swenson, N.G., Uriarte, M., van Breugel, M., van der Wal, H., Veloso, M.D.M., Vester, H., Vieira, I.C.G., Bentos, T.V., Williamson, G.B., Poorter, L., 2016. Carbon sequestration potential of second-growth forest regeneration in the Latin American tropics. Sci. Adv. 2, 1-10. doi:10.1126/sciadv.1501639

Chazdon, R.L., Guariguata, M.R., 2016. Natural regeneration as a tool for large-scale forest restoration in the tropics: prospects and challenges. Biotropica 48, 716-730. doi:10.2493/jjspe.74.155

Chua, S.C., Potts, M.D., 2018. The role of plant functional traits in understanding forest recovery in wet tropical secondary forests. Sci. Total Environ. 642, 1252-1262. doi:10.1016/j.scitotenv.2018.05.397

Clark, W.C., Tomich, T.P., Van Noordwijk, M., Guston, D., Catacutan, D., Dickson, N.M., McNie, E., 2016. Boundary work for sustainable development: natural resource management at the Consultative Group on International Agricultural Research (CGIAR). PNAS 113, 4615-4622. doi:10.1073/pnas.0900231108

Cleveland, C.C., Townsend, A.R., Schmidt, S.K., 2002. Phosphorus limitation of microbial processes in moist tropical forests : evidence from short-term laboratory incubations and field studies. Ecosystems 5, 680-691. doi:10.1007/s10021-002-0202-9 
Copeland, N., 2018. Meeting peasants where they are: cultivating agroecological alternatives in neoliberal Guatemala. J. Peasant Stud. 1-22. doi:10.1080/03066150.2017.1410142

Cornwell, W.K., Schwilk, D.W., Ackerly, D.D., 2006. A Trait-Based test for habitat filtering: convex hull volume. Ecology 87, 1465-1471. doi:10.1890/00129658(2006)87[1465:ATTFHF]2.0.CO;2

Cortez-Arriola, J., Rossing, W.A.H., Massiotti, R.D.A., Scholberg, J.M.S., Groot, J.C.J., Tittonell, P., 2015. Leverages for on-farm innovation from farm typologies? An illustration for family-based dairy farms in north-west. Agric. Syst. 135, 66-76. doi:10.1016/j.agsy.2014.12.005

Costanza, R., Groot, R. de, Braat, L., Kubiszewski, I., Fioramonti, L., Sutton, P., Farber, S., Grasso, M., 2017a. Twenty years of ecosystem services : how far have we come and how far do we still need to go? Ecosyst. Serv. 28, 1-16.

Costanza, R., Groot, R. de, Kubiszewski, I., 2017b. Twenty years of ecosystem services: How far have we come and how far do we still need to go? Ecosyst. Serv. 28, 1-16. doi:10.1016/j.ecoser.2017.09.008

Craven, D., Hall, J.S., Berlyn, G.P., Ashton, M.S., van Breugel, M., 2015. Changing gears during succession: shifting functional strategies in young tropical secondary forests. Oecologia 179, 293-305. doi:10.1007/s00442-015-3339-x

Cundill, G., Currie-Alder, B., Leone, M., 2019. The future is collaborative. Nat. Clim. Chang. 9, 343-345. doi:10.1038/s41558-019-0447-3

Danescu, A., Albrecht, A.T., Bauhus, J., 2016. Structural diversity promotes productivity of mixed, uneven-aged forests in southwestern Germany. Oecologia 182, 319-333. doi:10.1007/s00442-016-3623-4

David, C., Bell, M.M., 2018. Agroecology and Sustainable Food Systems New challenges for education in agroecology. Agroecol. Sustain. Food Syst. 42, 612-619. doi:10.1080/21683565.2018.1426670

Dean, W., 1997. With broadax and firebrand: the destruction of the brazilian Atlantic forest, 1st ed. University of California Press Books.

Dendoncker, N., Boeraeve, F., Crouzat, E., Barnaud, C., 2018. How can integrated valuation of ecosystem services help understanding and steering agroecological transitions? Ecol. Soc. 23. 


\section{References}

Deng, L., Wang, K.B., Chen, M.L., Shangguan, Z.P., Sweeney, S., 2013. Soil organic carbon storage capacity positively related to forest succession on the Loess Plateau, China. Catena 110, 1-7. doi:10.1016/j.catena.2013.06.016

Díaz-reviriego, A.I., González-segura, L., Fernández-llamazares, Á., Howard, P.L., Molina, J.L., Reyes-garcía, V., 2018. Social organization influences the exchange and species richness of medicinal plants in Amazonian homegardens. Ecol. Soc. 21. doi:10.5751/ES07944-210101

Díaz, B.S., Pascual, U., Stenseke, M., Martín-lópez, B., Watson, R.T., Molnár, Z., Hill, R., Chan, K.M.A., Baste, I.A., Brauman, K.A., Polasky, S., Church, A., Lonsdale, M., Larigauderie, A., Leadley, P.W., Alexander, P.E., Oudenhoven, V., Plaat, F. Van Der, Schröter, M., Lavorel, S., Aumeeruddy-thomas, Y., Bukvareva, E., Davies, K., Demissew, S., Erpul, G., Failler, P., Guerra, C.A., Hewitt, C.L., Keune, H., Lindley, S., Shirayama, Y., 2018. Assessing nature's contributions to people. Science (80-. ). 359, 270-272.

Díaz, S., Demissew, S., Carabias, J., Joly, C., Lonsdale, M., Ash, N., Larigauderie, A., Adhikari, J.R., Arico, S., Báldi, A., Bartuska, A., Baste, I.A., Bilgin, A., Brondizio, E., Chan, K.M.A., Figueroa, V.E., Duraiappah, A., Fischer, M., Hill, R., Koetz, T., Leadley, P., Lyver, P., Mace, G.M., Martin-Lopez, B., Okumura, M., Pacheco, D., Pascual, U., Pérez, E.S., Reyers, B., Roth, E., Saito, O., Scholes, R.J., Sharma, N., Tallis, H., Thaman, R., Watson, R., Yahara, T., Hamid, Z.A., Akosim, C., Al-Hafedh, Y., Allahverdiyev, R., Amankwah, E., Asah, T.S., Asfaw, Z., Bartus, G., Brooks, A.L., Caillaux, J., Dalle, G., Darnaedi, D., Driver, A., Erpul, G., Escobar-Eyzaguirre, P., Failler, P., Fouda, A.M.M., Fu, B., Gundimeda, H., Hashimoto, S., Homer, F., Lavorel, S., Lichtenstein, G., Mala, W.A., Mandivenyi, W., Matczak, P., Mbizvo, C., Mehrdadi, M., Metzger, J.P., Mikissa, J.B., Moller, H., Mooney, H.A., Mumby, P., Nagendra, H., Nesshover, C., Oteng-Yeboah, A.A., Pataki, G., Roué, M., Rubis, J., Schultz, M., Smith, P., Sumaila, R., Takeuchi, K., Thomas, S., Verma, M., Yeo-Chang, Y., Zlatanova, D., 2015. The IPBES conceptual framework connecting nature and people. Curr. Opin. Environ. Sustain. 14, 1-16. doi:10.1016/j.cosust.2014.11.002

Díaz, S., Fargione, J., Chapin, F.S., Tilman, D., 2006. Biodiversity loss threatens human wellbeing. PLoS Biol. 4, 1300-1305. doi:10.1371/journal.pbio.0040277

Díaz, S., Pascual, U., Stenseke, M., Martín-López, B., Watson, R.T., Molnár, Z., Hill, R., Chan, 
K.M.A., Baste, I.A., Brauman, K.A., Polasky, S., Church, A., Lonsdale, M., Larigauderie, A., Leadley, P.W., van Oudenhoven, A.P.E., van der Plaat, F., Schröter, M., Lavorel, S., Aumeeruddy-Thomas, Y., Bukvareva, E., Davies, K., Demissew, S., Erpul, G., Failler, P., Guerra, C.A., Hewitt, C.L., Keune, H., Lindley, S., Shirayama, Y., 2018. Assessing nature's contributions to people. Science (80-. ). 359, 270-272. doi:10.1126/science.aap8826

Díaz, S., Quétier, F., Cáceres, D.M., Trainor, S.F., Pérez-Harguindeguy, N., Bret-Harte, M.S., Finegan, B., Peña-Claros, M., Poorter, L., 2011. Linking functional diversity and social actor strategies in a framework for interdisciplinary analysis of nature's benefits to society. Proc. Natl. Acad. Sci. U. S. A. 108, 895-902. doi:10.1073/pnas.1017993108

Díaz, S., Settele, J., Brondízio, E., 2019. Summary for policymakers of the global assessment report on biodiversity and ecosystem services, Intergovernmental Science-Policy Platform on Biodiversity and Ecosystem Services (IPBES).

Díaz, S., Cabido, M., 2001. Vive la différence: plant functional diversity matters to ecosystem processes. Trends Ecol. Evol. 16, 646-655. doi:10.1016/S0169-5347(01)02283-2

Dobriyal, P., Qureshi, A., Badola, R., Hussain, S.A., 2012. A review of the methods available for estimating soil moisture and its implications for water resource management. J. Hydrol. 458-459, 110-117. doi:10.1016/j.jhydrol.2012.06.021

Dogliotti, S., García, M.C., Peluffo, S., Dieste, J.P., Pedemonte, A.J., Bacigalupe, G.F., Scarlato, M., Alliaume, F., Alvarez, J., Chiappe, M., Rossing, W.A.H., 2014. Co-innovation of family farm systems: a systems approach to sustainable agriculture. Agric. Syst. 126, 7686. doi:10.1016/j.agsy.2013.02.009

Domingos, M., Bulbovas, P., Camargo, C.Z.S., Aguiar-silva, C., Paula, A., Dias, L., Dafr, M., Brand, S.E., Engela, M.R.G.S., Gagliano, J., Moura, B.B., Alves, E.S., Rinaldi, M.C.S., Gomes, E.P.C., Furlan, C.M., Maria, A., Figueiredo, G., 2015. Searching for native tree species and respective potential biomarkers for future assessment of pollution effects on the highly diverse Atlantic Forest in SE-Brazil. Environ. Pollut. 202, 85-95. doi:10.1016/j.envpol.2015.03.018

Dromard, C.R., Guéné, M., Bouchon-Navaro, Y., Lemoine, S., Cordonnier, S., Bouchon, C., 2018. Contamination of marine fauna by chlordecone in Guadeloupe: evidence of a seaward decreasing gradient. Environ. Sci. Pollut. Res. 25, 14294-14301. 


\section{References}

doi:10.1007/s11356-017-8924-6

Duarte, E.M.G., Cardoso, I.M., Stijnen, T., Mendonça, M.A.F.C., Coelho, M.S., Cantarutti, R.B., Kuyper, T.W., Villani, E.M.A., Mendonça, E.S., 2013. Decomposition and nutrient release in leaves of Atlantic rainforest tree species used in agroforestry systems. Agrofor. Syst. 87, 835-847. doi:10.1007/s10457-013-9600-6

Duncan, C., Thompson, J.R., Pettorelli, N., 2015. The quest for a mechanistic understanding of biodiversity-ecosystem services relationships. Proc. R. Soc. B 282, 20151348. doi:10.1098/rspb.2015.1348

Dupré, M., Michels, T., Le Gal, P., 2017. Diverse dynamics in agroecological transitions on fruit tree farms. Eur. J. Agron. 90, 23-33. doi:10.1016/j.eja.2017.07.002

Duru, M., Therond, O., Fares, M., 2015a. Designing agroecological transitions; A review. Agron. Sustain. Dev. 35, 1237-1257. doi:10.1007/s13593-015-0318-X

Duru, M., Therond, O., Martin, G., Martin-clouaire, R., Magne, M., Justes, E., Journet, E., Aubertot, J., Savary, S., Bergez, J., Sarthou, J.P., 2015b. How to implement biodiversitybased agriculture to enhance ecosystem services : a review. Agron. Sustain. Dev. 35, 1259 1281. doi:10.1007/s13593-015-0306-1

Eivazi, F., Tabatabai, M.A., 1988. Glucosidases and galactosidases in soils. Soil Biol. Biochem. 20, 601-606. doi:10.1016/0038-0717(88)90141-1

El Mujtar, V., Muñoz, N., Prack Mc Cormick, B., Pulleman, M., Tittonell, P., 2019. Role and management of soil biodiversity for food security and nutrition; where do we stand? Glob. Food Sec. 20, 132-144. doi:10.1016/j.gfs.2019.01.007

Embrapa, 2011. Manual de métodos de análise de solo, Embrapa. Rio de Janeiro.

Ermgassen, E.K.H.J., Alcântara, M.P. de, Balmford, A., Barioni, L., Neto, F.B., Bettarello, M.M.F., Brito, G.D., Carrero, G.C., Florence, E.D.A.S., Garcia, E., Gonçalves, E.T., Trajano, C., Mallman, G.M., 2018. Results from On-The-Ground efforts to promote sustainable cattle ranching in the brazilian Amazon. Sustain. 10, 1031. doi:10.3390/su10041301

FAO, 2018. FAO`s work on agroecology: a pathway to achieving the SDG`s. Rome, Italy.

FAO, 2015. Global Forest Resources Assessment 2015, Rome, Italy.

FAO, 2013. Advancing agroforestry on the policy agenda, by G. Buttoud, in collaboration with O. Ajayi, G. Detlefsen, F. Place \& E. Torquebiau. Agroforestry (No. 1). Rome. 
Faucon, M., Houben, D., Lambers, H., 2017. Plant functional traits: soil and ecosystem services. Trends Plant Sci. 22, 385-394.

Fearnside, P.M., Laurance, W.F., 2004. Tropical deforestation and greenhouse-gas emissions. Ecol. Appl. 14, 982-986. doi:10.1890/03-5225

Fenetahun, Y., Eshetu, G., Worku, A., Abdella, T., 2017. A survey on medicinal plants used by traditional healers in Harari regional State, East Ethiopia. J. Med. Plants Stud. 5, 85-90.

Fernandes, J.M., 2007. Taxonomia e etnobotânica de Leguminosae Adans. em fragmentos florestais e sistemas agroflorestais na Zona da Mata mineira. Universidade Federal de Viçosa.

Ferreira, C.R., Correia, M.E., Camara, R., Resende, A.S., Anjos, L.H. dos, Pereira, M.G., 2018. Soil fauna changes across Atlantic forest succession. Comun. Sci. 9, 162-174. doi:10.14295/CS.v9i2.2388

Field, A., 2017. Discovering statistics using IBM SPSS, 5th editio. ed. Sage Publications Ltda. Figueroa-helland, L., Thomas, C., Aguilera, A.P., 2018. Decolonizing food systems : food sovereignty, indigenous revitalization, and agroecology as Counter-Hegemonic Movements. Perspect. Glob. Dev. Technol. 17, 173-201. doi:10.1163/1569149712341473

Finegan, B., Pena-Claros, M., Oliveira, A. de, Ascarrunz, N., Bret-Harte, M.S., CarrenoRocabado, G., Casanoves, F., Diaz, S., Velepucha, P.E., Fernandez, F., Licona, J.C., Lorenzo, L., Negret, B.S., Vaz, M., Poorter, L., 2015. Does functional trait diversity predict above-ground biomass and productivity of tropical forests? Testing three alternative hypotheses. J. Ecol. 103, 191-201. doi:10.1111/1365-2745.12346

Fischer, C., Leimer, S., Roscher, C., Hans, R., Yvonne, D.K., Jussi, K., Holger, B., Eisenhauer, B.N., Weigelt, A., Mommer, L., Wilcke, W., Schröder, B., 2019. Plant species richness and functional groups have different effects on soil water content in a decade - long grassland experiment. Jounral Ecol. 107, 127-141. doi:10.1111/1365-2745.13046

Fischer, J., Abson, D.J., Bergsten, A., Collier, N.F., Dorresteijn, I., Hanspach, J., Hylander, K., Schultner, J., Senbeta, F., 2017. Reframing the food - biodiversity challenge. Trends Ecol. Evol. 32, 335-345. doi:10.1016/j.tree.2017.02.009

Fisher, B., Turner, R.K., Morling, P., 2009. Defining and classifying ecosystem services for decision making. Ecol. Econ. 68, 643-653. doi:10.1016/j.ecolecon.2008.09.014 


\section{References}

Foley, J.A., Ramankutty, N., Brauman, K.A., Cassidy, E.S., Gerber, J.S., Johnston, M., Mueller, N.D., O’Connell, C., Ray, D.K., West, P.C., Balzer, C., Bennett, E.M., Carpenter, S.R., Hill, J., Monfreda, C., Polasky, S., Rockström, J., Sheehan, J., Siebert, S., Tilman, D., Zaks, D.P.M., O’Connell, C., 2011. Solutions for a cultivated planet. Nature 478, 337-42. doi:10.1038/nature10452

Food and Agriculture Organsiation of the United Nations, 2015. Global Forest Resources Assessment 2015, Desk Reference. doi:10.1002/2014GB005021

Franco, F.S., Couto, L., Carvalho, A.F. De, Jucksch, I., Fernandes Filho, E.I., Silva, E., Meira Neto, J.A.A., 2002. Quantificação de erosão em sistemas agroflorais e convencionais na Zona da Mata de Minas Gerais. Rev. Árvore 26, 751-760. doi:10.1590/S010067622002000600011

Fraser, S., 1999. Gap Light Analyzer - user manual and program documentation. New York.

Freire, J., 2009. Escravidão e família escrava na Zona da Mata mineira oitocentista. Universidade Estadual de Campinas.

Freire, P., 1983. Extensão ou comunicação?, 7th ed. Paz e Terra, Rio de Janeiro.

Fujii, K., Shibata, M., Kitajima, K., Ichie, T., Kitayama, K., Turner, B.L., 2018. Plant - soil interactions maintain biodiversity and functions of tropical forest ecosystems. Ecol. Res. 33, 149-160. doi:10.1007/s11284-017-1511-y

Gana, K., Broc, G., 2018. Structural equation modeling with lavaan. John Wiley \& Sons.

Garibaldi, L.A., Gemmill-Herren, B., D’Annolfo, R., Graeub, B.E., Cunningham, S.A., Breeze, T.D., 2017. Farming approaches for greater biodiversity, livelihoods, and food security. Trends Ecol. Evol. 32, 68-80. doi:10.1016/j.tree.2016.10.001

Garnett, S.T., Burgess, N.D., Fa, J.E., Fernández-llamazares, Á., Molnár, Z., Robinson, C.J., Watson, J.E.M., Zander, K.K., Austin, B., Brondizio, E.S., Collier, N.F., Duncan, T., Ellis, E., Geyle, H., Jackson, M. V, 2018. Indigenous lands for conservation. Nat. Sustain. 1, 369-374. doi:10.1038/s41893-018-0100-6

Garnier, E., Lavorel, S., Ansquer, P., Castro, H., Cruz, P., Dolezal, J., Eriksson, O., Fortunel, C., Freitas, H., Golodets, C., Grigulis, K., Jouany, C., Kazakou, E., 2007. Assessing the effects of land-use change on plant traits, communities and ecosystem functioning in grasslands: a standardized methodology and lessons from an application to 11 European sites. Ann. Bot. 99, 967-985. doi:10.1093/aob/mcl215 
Geertsema, W., Rossing, W.A., Landis, D.A., Bianchi, F.J., van Rijn, P.C., Schaminée, J.H., Tscharntke, T., van der Werf, W., 2016. Actionable knowledge for ecological intensification of agriculture. Front. Ecol. Environ. 14, 209-216. doi:10.1002/fee.1258

Gichangi, E.M., Njarui, D.M.G., Gatheru, M., Magiroi, K.W.N., Ghimire, S.R., 2016. Effects of Brachiaria grassess on soil microbial biomass carbon, nitrogen and phosphorus in soils of the semi arid tropics of Kenya. Trop. Subtrop. Agroecosystems 19, 193-203.

Gliessman, S., 2018. Defining agroecology. Agroecol. Sustain. Food Syst. 42, 599-600. doi:10.1080/21683565.2018.1432329

Gliessman, S., 2016. Transforming food systems with agroecology. Agroecol. Sustain. Food Syst. 40, 187-189. doi:10.1080/21683565.2015.1130765

Golfari, L., 1975. Zoneamento ecológico do Estado de Minas Gerais para reflorestamento. Centro de Pesquisa Florestal da Região do Cerrado, Belo Horizonte.

Gomes, L. de C., Cardoso, I.M., Mendonça, E. de S., Fernandes, R.B.A., Lopes, V.S., Oliveira, T.S., 2016. Trees modify the dynamics of soil CO2 efflux in coffee agroforestry systems. Agric. For. Meteorol. 224, 30-39. doi:10.1016/j.agrformet.2016.05.001

Goris, M., van den Berg, L., Lopes, I. da S., Behagel, J., Verschoor, G., Turnhout, E., 2019. Resignification practices of youth in zona da mata, Brazil in the transition toward agroecology. Sustain. 11. doi:10.3390/su11010197

Greenfield, S.M., 1977. Patronage, politics, and the articulation of local community and national society in Pre- 1968 Brazil. J. Inter. Am. Stud. World Aff. 19, 139-172.

Grigulis, K., Robson, T.M., Lavorel, S., Bello, F. de, Quétier, F., 2007. Incorporating plant functional diversity effects in ecosystem service assessments. PNAS 104, 20684-20689. doi:10.1073/pnas.0704716104

Grime, J.P., 1998. Benefits of plant diversity to ecosystems: immediate, filter and founder effects. J. Ecol. 86, 902-910. doi:10.1046/j.1365-2745.1998.00306.x

Guariguata, M.R., Ostertag, R., 2001. Neotropical secondary forest succession: changes in structural and functional characteristics. For. Ecol. Manage. 148, 185-206. doi:10.1016/S0378-1127(00)00535-1

Guzmán, G.I., López, D., Román, L., Alonso, A.M., 2013. Participatory action research in agroecology: building local organic food networks in Spain. Agroecol. Sustain. Food Syst. 37, 127-146. doi:10.1080/10440046.2012.718997 


\section{References}

Hall, R.L. Van, Cammeraat, L.H., Keesstra, S.D., Zorn, M., 2017. Impact of secondary vegetation succession on soil quality in a humid Mediterranean landscape. Catena 149, 836-843. doi:10.1016/j.catena.2016.05.021

Hassanali, A., Herren, H., Khan, Z.R., Pickett, J.A., Woodcock, C.M., 2008. Integrated pest management: the push-pull approach for controlling insect pests and weeds of cereals, and its potential for other agricultural systems including animal husbandry. Philos. Trans. R. Soc. B Biol. Sci. 363, 611-621. doi:10.1098/rstb.2007.2173

Hatt, S., Artru, S., Brédart, D., Lassois, L., Francis, F., Haubruge, É., Garré, S., Stassart, P.M., Dufrêne, M., Monty, A., Boeraeve, F., 2016. Towards sustainable food systems: the concept of agroecology and how it questions current research practices. A review. Biotechnol. Agron. Soc. Env. 20, 215-224.

Haynes, R.J., Naidu, R., 1998. Influence of lime, fertilizer and manure applications on soil organic matter. Nutr. Cycl. Agroecosystems 51, 123-137. doi:10.1023/A:1009738307837

Hein, L., Van Koppen, C.S.A.K., Van Ierland, E.C., Leidekker, J., 2016. Temporal scales, ecosystem dynamics, stakeholders and the valuation of ecosystems services. Ecosyst. Serv. 21, 109-119. doi:10.1016/j.ecoser.2016.07.008

Heinemeyer, O., Insam, H., Kaiser, E.A., Walenzik, G., 1989. Technique based on infra-red gas analysis. Plant Soil 195, 191-195. doi:10.1007/BF02214547

Henry, M., Tittonell, P., Manlay, R.J., Bernoux, M., Albrecht, A., Vanlauwe, B., 2009. Biodiversity, carbon stocks and sequestration potential in aboveground biomass in smallholder farming systems of western Kenya. Agric. Ecosyst. Environ. 129, 238-252. doi:10.1016/j.agee.2008.09.006

Holt-Giménez, E., 2002. Measuring farmers' agroecological resistance after Hurricane Mitch in Nicaragua: A case study in participatory, sustainable land management impact monitoring. Agric. Ecosyst. Environ. 93, 87-105. doi:10.1016/S0167-8809(02)00006-3

Hooper, D.U., Adair, E.C., Cardinale, B.J., Byrnes, J.E.K., Hungate, B.A., Matulich, K.L., Gonzalez, A., Duffy, J.E., Gamfeldt, L., O’Connor, M.I., 2012. A global synthesis reveals biodiversity loss as a major driver of ecosystem change. Nature 486, 105-108. doi:10.1038/nature11118

Huang, W., Liu, J., Zhou, G., Zhang, D., Deng, Q., 2011. Effects of precipitation on soil acid phosphatase activity in three successional forests in southern China. Biogeosciences 8 , 
1901-1910. doi:10.5194/bg-8-1901-2011

Huber-sannwald, E., Palacios, M.R., Moreno, J.T.A., Braasch, M., Peña, R.M.M., Verduzco, J.G. de A., Santos, K.M., 2012. Navigating challenges and opportunities of land degradation and sustainable livelihood development in dryland social - ecological systems: a case study from Mexico Navigating challenges and opportunities of land degradation and sustainable livelihood dev. doi:10.1098/rstb.2011.0349

Huston, M., Smith, T., 1987. Plant succession: life history and competition. Am. Nat. 130, 168198.

IBGE, 2012. Manual técnico da vegetação brasileira, Instituto Brasileiro de Geografia e Estatística. Rio de Janeiro. doi:ISSN 0101-4234

IBGE, 2006. Censo Agropecuário 2006. Rio de Janeiro. Available at: http://www.sidra.ibge.gov.br/bda/orcfam/default.asp

Isbell, F., Adler, P.R., Eisenhauer, N., Fornara, D., Kimmel, K., Kremen, C., Letourneau, D.K., Liebman, M., Polley, H.W., Quijas, S., Scherer-Lorenzen, M., 2017a. Benefits of increasing plant diversity in sustainable agroecosystems. J. Ecol. 105, 871-879. doi:10.1111/1365-2745.12789

Isbell, F., Gonzalez, A., Loreau, M., Cowles, J., Díaz, S., Hector, A., Mace, G.M., Wardle, D.A., O’Connor, M.I., Duffy, J.E., Turnbull, L.A., Thompson, P.L., Larigauderie, A., 2017 b. Linking the influence and dependence of people on biodiversity across scales. Nature 546, 65-72. doi:10.1038/nature22899

Iverson, A.L., Marín, L.E., Ennis, K.K., Gonthier, D.J., Connor-Barrie, B.T., Remfert, J.L., Cardinale, B.J., Perfecto, I., 2014. Do polycultures promote win-wins or trade-offs in agricultural ecosystem services? A meta-analysis. J. Appl. Ecol. 51, 1593-1602. doi:10.1111/1365-2664.12334

Jackson, L., van Noordwijk, M., Bengtsson, J., Foster, W., Lipper, L., Pulleman, M., Said, M., Snaddon, J., Vodouhe, R., 2010. Biodiversity and agricultural sustainagility: from assessment to adaptive management. Curr. Opin. Environ. Sustain. 2, 80-87. doi:10.1016/j.cosust.2010.02.007

Jetter, A.J., Kok, K., 2014. Fuzzy cognitive maps for futures studies - a methodological assessment of concepts and methods. Futures 61, 45-57. doi:10.1016/j.futures.2014.05.002 Jezeer, R.E., Santos, M.J., Boot, R.G.A., Junginger, M., Verweij, P.A., 2018. Effects of shade 


\section{References}

and input management on economic performance of small-scale Peruvian coffee systems. Agric. Syst. 162, 179-190. doi:10.1016/j.agsy.2018.01.014

Kamiyama, C., Hashimoto, S., Kohsaka, R., Saito, O., 2016. Non-market food provisioning services via homegardens and communal sharing in satoyama socio-ecological production landscapes on Japan's Noto peninsula. Ecosyst. Serv. 17, 185-196. doi:10.1016/j.ecoser.2016.01.002

Kansiime, M.K., van Asten, P., Sneyers, K., 2018. Farm diversity and resource use efficiency: Targeting agricultural policy interventions in East Africa farming systems. NJAS Wageningen J. Life Sci. 85, 32-41. doi:10.1016/j.njas.2017.12.001

Kaur, J., Gosal, S.K., Walia, S.S., 2018. Correlation of microbial population with enzymatic activities and nutrient levels of soil during Paddy Growth. Curr. J. Appl. Sci. Technol. 29, 1-9. doi:10.9734/cjast/2018/44347

Keesstra, S.D., Bouma, J., Wallinga, J., Tittonell, P., Smith, P., Cerdà, A., Montanarella, L., Quinton, J.N., Pachepsky, Y., Van Der Putten, W.H., Bardgett, R.D., Moolenaar, S., Mol, G., Jansen, B., Fresco, L.O., 2016. The significance of soils and soil science towards realization of the United Nations Sustainable Development Goals. Soil 2, 111-128. doi:10.5194/soil-2-111-2016

Kepkiewicz, L., Dale, B., Kepkiewicz, L., Dale, B., 2018. Keeping 'our' land: property, agriculture and tensions between indigenous and settler visions of food sovereignty in Canada in Canada. J. Peasant Stud. 0, 1-20. doi:10.1080/03066150.2018.1439929

Khadse, A., 2017. Women, agroecology \& gender equality. Focus on the global south, New Delhi, India.

Khadse, A., Rosset, P.M., Morales, H., Ferguson, B.G., 2018. Taking agroecology to scale: the zero Budget Natural Farming peasant movement in Karnataka, India. J. Peasant Stud. 45, 192-219. doi:10.1080/03066150.2016.1276450

Klingen, K.E., Graaff, J. De, Botelho, M.I.V., Kessler, A., 2016. Farmers’ Visions on Soils: a case study among agroecological and conventional smallholders in Minas Gerais, Brazil. J. Agric. Educ. Ext. 8622. doi:10.1080/1389224X.2012.655969

Knelman, J.E., Graham, E.B., Ferrenberg, S., Labrado, A., Darcy, J.L., Nemergut, D.R., Schmidt, S.K., 2017. Rapid shifts in soil nutrients and decomposition enzyme activity in early succession following Forest fire. Forests 8, 1-12. doi:10.3390/f8090347 
Kok, K., 2009. The potential of Fuzzy Cognitive Maps for semi-quantitative scenario development, with an example from Brazil. Glob. Environ. Chang. 19, 122-133. doi:10.1016/j.gloenvcha.2008.08.003

Kovács-Hostyánszki, A., Espíndola, A., Vanbergen, A.J., Settele, J., Kremen, C., Dicks, L. V., 2017. Ecological intensification to mitigate impacts of conventional intensive land use on pollinators and pollination. Ecol. Lett. 20, 673-689. doi:10.1111/ele.12762

Kuivanen, K.S., Alvarez, S., Michalscheck, M., Adjei-nsiah, S., Descheemaeker, K., 2016a. Characterising the diversity of smallholder farming systems and their constraints and opportunities for innovation: a case study from the Northern Region, Ghana. NJAS Wageningen J. Life Sci. 78, 153-166. doi:10.1016/j.njas.2016.04.003

Kuivanen, K.S., Michalscheck, M., Descheemaeker, K., Adjei-Nsiah, S., Mellon-Bedi, S., Groot, J.C.J., Alvarez, S., 2016b. A comparison of statistical and participatory clustering of smallholder farming systems - A case study in Northern Ghana. J. Rural Stud. 45, 184 198. doi:10.1016/j.jrurstud.2016.03.015

Kuznetsova, A., Brockhoff, P.B., Christensen, R.H.B., 2017. lmerTest package: tests in linear mixed effects models. J. Stat. Softw. 82, 1-26. doi:10.18637/jss.v082.i13

La Via Campesina, 2015. Peasant agroecology for food sovereignty and mother earth, Notebook 7.

Lacombe, C., Couix, N., Hazard, L., 2018. Designing agroecological farming systems with farmers: A review. Agric. Syst. 165, 208-220. doi:10.1016/j.agsy.2018.06.014

Lamarque, P., Meyfroidt, P., Nettier, B., Lavorel, S., 2014. How ecosystem services knowledge and values influence farmers' decision-making. PLoS One 9, e107572. doi:10.1371/journal.pone.0107572

Lamarque, P., Tappeiner, U., Turner, C., Steinbacher, M., Bardgett, R.D., Szukics, U., Schermer, M., Lavorel, S., 2011. Stakeholder perceptions of grassland ecosystem services in relation to knowledge on soil fertility and biodiversity. Reg. Environ. Chang. 11, 791804. doi:10.1007/s10113-011-0214-0

Lange, M., Eisenhauer, N., Sierra, C.A., Bessler, H., Engels, C., Griffiths, R.I., Malik, A.A., Roy, J., Scheu, S., Steinbeiss, S., Mellado-va, P.G., Thomson, B.C., Trumbore, S.E., Gleixner, G., 2015. Plant diversity increases soil microbial activity and soil carbon storage. Nat. Commun. 6, 1-8. doi:10.1038/ncomms7707 


\section{References}

Lavorel, S., 2013. Plant functional effects on ecosystem services. J. Ecol. 101, 4-8. doi:10.1111/1365-2745.12031

Lavorel, S., Grigulis, K., Lamarque, P., Colace, M.P., Garden, D., Girel, J., Pellet, G., Douzet, R., 2011. Using plant functional traits to understand the landscape distribution of multiple ecosystem services. J. Ecol. 99, 135-147. doi:10.1111/j.1365-2745.2010.01753.x

Lavorel, S., Grigulis, K., McIntyre, S., Williams, N.S.G., Garden, D., Dorrough, J., Berman, S., Quétier, F., Thébault, A., Bonis, A., 2008. Assessing functional diversity in the field Methodology matters! Funct. Ecol. 22, 134-147. doi:10.1111/j.1365-2435.2007.01339.x

Leakey, R.R.B., 2014. The role of trees in agroecology and sustainable agriculture in the Tropics. Annu. Rev. Phytopathol. 1-21. doi:10.1146/annurev-phyto-102313-045838

Lechenet, M., Dessaint, F., Py, G., Makowski, D., Munier-Jolain, N., 2017. Reducing pesticide use while preserving crop productivity and profitability on arable farms. Nat. Plants $3,1-$ 6. doi:10.1038/nplants.2017.8

Leeuwis, C., Van den Ban, A., 2004. Communication for rural innovation, 3rd ed. Blackwell Publishing, London.

LEI N ${ }^{\circ} 11.326$. Brazil, 2006. National policy on family farming and rural family enterprises.

Lemanceau, P., Maron, P., Mazurier, S., Mougel, C., Pivato, B., Plassart, P., Ranjard, L., Revellin, C., Tardy, V., Wipf, D., 2015. Understanding and managing soil biodiversity: a major challenge in agroecology. Agron. Sustain. Dev. 35, 67-81. doi:10.1007/s13593-0140247-0

Lescourret, F., Magda, D., Richard, G., Adam-Blondon, A.-F., Bardy, M., Baudry, J., Doussan, I., Dumont, B., Lefevre, F., Litrico, I., Martin-Clouaire, R., Montuelle, B., Pellerin, S., Plantegenest, M., Tancoigne, E., Thomas, A., Guyomard, H., Soussana, J.-F., 2015. A social - ecological approach to managing multiple agro-ecosystem services. Curr. Opin. Environ. Sustain. 14, 68-75. doi:10.1016/j.cosust.2015.04.001

Liere, H., Jha, S., Philpott, S.M., 2017. Intersection between biodiversity conservation, agroecology, and ecosystem services. Agroecol. Sustain. Food Syst. 41, 723-760. doi:10.1080/21683565.2017.1330796

Liu, J., Gao, G., Wang, S., Jiao, L., Wu, X., Fu, B., 2018. The effects of vegetation on runoff and soil loss : Multidimensional structure analysis and scale characteristics. J. Geogr. Sci. 28, 59-78. doi:10.1007/s11442-018-1459-z (C) 
Lohbeck, M., Poorter, L., Martínez-ramos, M., Bongers, F., 2015. Biomass is the main driver of changes in ecosystem process rates during tropical forest succession. Ecology 96, 12421252. doi:10.1890/14-0472.1

Lohbeck, M., Poorter, L., Paz, H., Pla, L., van Breugel, M., Martínez-Ramos, M., Bongers, F., 2012. Functional diversity changes during tropical forest succession. Perspect. Plant Ecol. Evol. Syst. 14, 89-96. doi:10.1016/j.ppees.2011.10.002

Lohbeck, M., Vågen, T., Aynekulu, E., 2017. Trait-based approaches for guiding the restoration of degraded agricultural landscapes in East Africa. J. Appl. Ecol. 1-10. doi:10.1111/13652664.13017

Lorenzi, H., 2016. Árvores brasileiras, Editora Plantarium. Editora Plantarum.

Lorenzi, H., 2008. Plantas daninhas do brasil: terresttres, aquáticas, parasitas e tóxicas, 4th edition, ed. Instituto Plantarum.

Louah, L., Visser, M., Blaimont, A., de Cannière, C., 2017. Barriers to the development of temperate agroforestry as an example of agroecological innovation: mainly a matter of cognitive lock-in? Land use policy 67, 86-97. doi:10.1016/j.landusepol.2017.05.001

Lovell, S.T., DeSantis, S., Nathan, C.A., Olson, M.B., Ernesto Méndez, V., Kominami, H.C., Erickson, D.L., Morris, K.S., Morris, W.B., 2010. Integrating agroecology and landscape multifunctionality in Vermont: an evolving framework to evaluate the design of agroecosystems. Agric. Syst. 103, 327-341. doi:10.1016/j.agsy.2010.03.003

Lu, X.H., Zang, R.G., Huang, J.H., 2015. Relationships between community level functional traits of trees and seedlings during secondary succession in a tropical lowland rainforest. PLoS One 10, 1-12. doi:10.1371/journal.pone.0132849

Lucas-borja, M.E., Hedo, J., Cerdá, A., Candel-pérez, D., Viñegla, B., 2016. Unravelling the importance of forest age stand and forest structure driving microbiological soil properties, enzymatic activities and soil nutrients content in Mediterranean Spanish black pine (Pinus nigra Ar. ssp. Salzmanii). Sci. Total Environ. 562, 145-154. doi:10.1016/j.scitotenv.2016.03.160

Lunka, P., Patil, S.D., 2016. Impact of tree planting configuration and grazing restriction on canopy interception and soil hydrological properties: Implications for flood mitigation in silvopastoral systems. Hydrol. Process. 30, 945-958. doi:10.1002/hyp.10630

Macfadyen, S., Tylianakis, J.M., Letourneau, D.K., Benton, T.G., Tittonell, P., Perring, M.P., 


\section{References}

Gómez-creutzberg, C., Báldi, A., Holland, J.M., Broadhurst, L., Okabe, K., Renwick, A.R., Gemmill-herren, B., Smith, H.G., 2016. The role of food retailers in improving resilience in global food supply. Glob. Food Sec. 1-8. doi:10.1016/j.gfs.2016.01.001

Magnussen, S., Reed, D., 2004. Knowledge reference for national forest assessments - modeling for estimation and monitoring. FAO, United Nations.

Magrini, M.B., Anton, M., Cholez, C., Corre-Hellou, G., Duc, G., Jeuffroy, M.H., Meynard, J.M., Pelzer, E., Voisin, A.S., Walrand, S., 2016. Why are grain-legumes rarely present in cropping systems despite their environmental and nutritional benefits? Analyzing lock-in in the French agrifood system. Ecol. Econ. 126, 152-162. doi:10.1016/j.ecolecon.2016.03.024

Marangon, L.C., Soares, J.J., Patriota, A.L.P., Brandão, L. e S., Frederico, C., 2008. Regeneração natural em um fragmento de floresta estacional semidecidual em Viçosa, Minas Gerais. Árvore 32, 183-191. doi:10.1590/S0100-67622008000100020

Margenot, A.J., Nakayama, Y., Parikh, S.J., 2018. Methodological recommendations for optimizing assays of enzyme activities in soil samples. Soil Biol. Biochem. 125, 350-360. doi:10.1016/j.soilbio.2017.11.006

Martin, A.R., Isaac, M.E., 2015. Plant functional traits in agroecosystems: a blueprint for research. J. Appl. Ecol. 52, 1425-1435. doi:10.1111/1365-2664.12526

Martin, G., Allain, S., Bergez, J., Burger-leenhardt, D., Constantin, J., Duru, M., Id, L.H., Lacombe, C., Magne, M., Ryschawy, J., Th, V., 2018. How to address the sustainability transition of farming systems? A conceptual framework to organize research. Sustainability 10, 1-20. doi:10.3390/su10062083

Martin, P.A., Newton, A.C., Bullock, J.M., 2013. Carbon pools recover more quickly than plant biodiversity in tropical secondary forests. Proc. R. Soc. B Biol. Sci. 280, 1-8. doi:10.1098/rspb.2013.2236

Martius, C., Höfer, H., Garcia, M.V.B., Römbke, J., Förster, B., Hanagarth, W., 2004. Microclimate in agroforestry systems in central Amazonia: does canopy closure matter to soil organisms? Agroforestry Sys. 60, 291-304. doi: 10.1023/B:AGFO.0000024419.20709.6c

Mas, A.H., Dietsch, T. V., 2003. An index of management intensity for coffee agroecosystems to evaluate butterfly species richness. Ecol. Appl. 13, 1491-1501. doi:10.1890/01-5229 
Mastrangelo, M.E., Laterra, P., 2015. From biophysical to social-ecological trade-offs: integrating biodiversity conservation and agricultural production in the Argentine Dry Chaco. Ecol. Soc. 20, 20. doi:10.5751/ES-07186-200120

Matos, E.D.S., Cardoso, I.M., Souto, R.L., de Lima, P.C., Mendonça, E.D.S., 2011. Characteristics, Residue Decomposition, and Carbon Mineralization of Leguminous and Spontaneous Plants in Coffee Systems. Commun. Soil Sci. Plant Anal. 42, 489-502. doi:10.1080/00103624.2011.546927

Mauser, W., Klepper, G., Rice, M., Schmalzbauer, B.S., Hackmann, H., Leemans, R., Moore, H., 2013. Transdisciplinary global change research: The co-creation of knowledge for sustainability. Curr. Opin. Environ. Sustain. 5, 420-431. doi:10.1016/j.cosust.2013.07.001

Mccune, N., Rosset, P.M., Salazar, T.C., Moreno, A.S., Morales, H., 2017. Mediated territoriality: rural workers and the efforts to scale out agroecology in Nicaragua. J. Peasant Stud. 44, 354-376. doi:10.1080/03066150.2016.1233868

Mccune, N., Sánchez, M., 2018. Teaching the territory : agroecological pedagogy and popular movements. Agric. Human Values. doi:10.1007/s10460-018-9853-9

MEA, 2005. Drivers of ecosystem change: summary chapter, Ecosystems and Human Wellbeing: Current State and Trends.

Meena, V.S., Maurya, B.R., Verma, J.P., Meena, R.S., 2016. Potassium solubilizing microorganisms for sustainable agriculture. Springer. doi:10.1007/978-81-322-2776-2

de Mello, C.R., De Sá, M.A.C., Curi, N., De Mello, J.M., Viola, M.R., Da Silva, A.M., 2007. Erosividade mensal e anual da chuva no Estado de Minas Gerais. Pesqui. Agropecu. Bras. 42, 537-545. doi:10.1590/S0100-204X2007000400012

Mendes, M.S., Latawiec, A.E., Sansevero, J.B.B., Crouzeilles, R., Moraes, L.F.D., Castro, A., Alves-Pinto, H.N., Brancalion, P.H.S., Rodrigues, R.R., Chazdon, R.L., Barros, F.S.M., Santos, J., Iribarrem, A., Mata, S., Lemgruber, L., Rodrigues, A., Korys, K., Strassburg, B.B.N., 2019. Look down - there is a gap — the need to include soil data in Atlantic Forest restoration. Restor. Ecol. 27, 361-370. doi:10.1111/rec.12875

Méndez, V.E., Caswell, M., Gliessman, S.R., Cohen, R., 2017. Integrating Agroecology and Participatory Action Research (PAR): Lessons from Central America. Sustainability 9, 119. doi:10.3390/su9050705

Mendonça, E.S., Stott, D.E., 2003. Characteristics and decomposition rates of pruning residues 


\section{References}

from a shaded coffee system in Southeastern Brazil. Agrofor. Syst. 57, 117-125.

Meylan, L., Gary, C., Allinne, C., Ortiz, J., Jackson, L., Rapidel, B., 2017. Evaluating the effect of shade trees on provision of ecosystem services in intensively managed coffee plantations. Agric. Ecosyst. Environ. 245, 32-42. doi:10.1016/j.agee.2017.05.005

Miles, A., Delonge, M.S., Carlisle, L., Miles, A., Delonge, M.S., Carlisle, L., Miles, A., 2017. Triggering a positive research and policy feedback cycle to support a transition to agroecology and sustainable food systems. Agroecol. Sustain. Food Syst. 41, 855-879. doi:10.1080/21683565.2017.1331179

Minasny, B., Malone, B.P., McBratney, A.B., Angers, D.A., Arrouays, D., Chambers, A., Chaplot, V., Chen, Z.S., Cheng, K., Das, B.S., Field, D.J., Gimona, A., Hedley, C.B., Hong, S.Y., Mandal, B., Marchant, B.P., Martin, M., McConkey, B.G., Mulder, V.L., O’Rourke, S., Richer-de-Forges, A.C., Odeh, I., Padarian, J., Paustian, K., Pan, G., Poggio, L., Savin, I., Stolbovoy, V., Stockmann, U., Sulaeman, Y., Tsui, C.C., Vågen, T.G., van Wesemael, B., Winowiecki, L., 2017. Soil carbon 4 per mille. Geoderma 292, 59-86. doi:10.1016/j.geoderma.2017.01.002

Modernel, P., Dogliotti, S., Alvarez, S., Corbeels, M., Picasso, V., Tittonell, P., Rossing, W.A.H., 2018. Identification of beef production farms in the Pampas and Campos area that stand out in economic and environmental performance. Ecol. Indic. 89, 755-770. doi:10.1016/j.ecolind.2018.01.038

Mohri, H., Lahoti, S., Saito, O., Mahalingam, A., Gunatilleke, N., Irham, Hoang, V.T., Hitinayake, G., Takeuchi, K., Herath, S., 2013. Assessment of ecosystem services in homegarden systems in Indonesia, Sri Lanka, and Vietnam. Ecosyst. Serv. 5, 124-136. doi:10.1016/j.ecoser.2013.07.006

Moreira, C.C., 2012. Supressiveness mediated by entomopathogens in agroforestry and conventional soils. MSc thesis, Universidade Federal de Viçosa.

Moreira, C.C., Celestino, D., Sobrinho, T.G., Cardoso, I.M., Elliot, S.L., 2019. Agroforestry coffee soils increase the insect-suppressive potential offered by entomopathogenic fungi over full-sun soils: a case proposing a "bait-survival technique." Ecol. Evol. 00, 1-11. doi:10.1002/ece3.5598

Mossmann, M.P., Rosane, C., Arruda, P., Busato, M.A., Triches, R.M., 2017. Interface between family farming and school feeding: barriers and coping mechanisms from the perspective 
of different social actors. Rev. Econ. e Sociol. Rural 55, 325-342.

Mulder, C., Bennett, E.M., Bohan, D.A., Bonkowski, M., Carpenter, S.R., Chalmers, R., Cramer, W., Durance, I., Eisenhauer, N., Fontaine, C., Haughton, A.J., Hettelingh, J., Hines, J., Ibanez, S., Jeppesen, E., Krumins, J.A., Ma, A., Mancinelli, G., Massol, F., Mclaughlin, Ó., Naeem, S., Pascual, U., Peñuelas, J., Pettorelli, N., Pocock, M.J.O., Raffaelli, D., Rasmussen, J.J., Rusch, G.M., Scherber, C., Setälä, H., Sutherland, W.J., Vacher, C., Voigt, W., Vonk, J.A., Wood, S.A., Woodward, G., 2015. 10 years later: revisiting priorities for science and society a decade after the Millennium Ecosystem Assessment. Adv. Ecol. Res. 53, 1-53. doi:10.1016/bs.aecr.2015.10.005 \#

Müller, M.H.B., Polder, A., Brynildsrud, O.B., Karimi, M., Lie, E., Manyilizu, W.B., Mdegela, R.H., Mokiti, F., Murtadha, M., Nonga, H.E., Skaare, J.U., Lyche, J.L., 2017. Organochlorine pesticides (OCPs) and polychlorinated biphenyls (PCBs) in human breast milk and associated health risks to nursing infants in Northern Tanzania. Environ. Res. 154, 425-434. doi:10.1016/j.envres.2017.01.031

Myers, N., Mittermeier, R.A., Fonseca, Gustavo A B, Fonseca, G A B, Kent, J., 2000. Biodiversity hotspots for conservation priorities. Nature 403, 853-8. doi: $10.1038 / 35002501$

Mylavarapu, R.S., Sanchez, J.F., Nguyen, J.H., Bartos, J.M., 2002. Evaluation of Mehlich-1 and Mehlich-3 extraction procedures for plant nutrients in acid mineral soils of Florida. Commun. Soil Sci. Plant Anal. 33, 807-820. doi:10.1081/CSS-120003067

Nadrowski, K., Wirth, C., Scherer-lorenzen, M., 2010. Is forest diversity driving ecosystem function and service? Curr. Opin. Environ. Sustain. 2, 75-79. doi:10.1016/j.cosust.2010.02.003

Naeem, S., Duffy, J.E., Zavaleta, E., 2012. The functions of biological diversity in an age of extinction. Science 336, 1401-1406. doi:10.1126/science.1215855

Nair, P.K.R., 2017. Managed multi-strata tree + crop systems: an agroecological marvel. Front. Environ. Sci. 5, 1-5. doi:10.3389/fenvs.2017.00088

Nakagawa, S., Schielzeth, H., 2013. A general and simple method for obtaining R2 from generalized linear mixed-effects models. Methods Ecol. Evol. 4, 133-142. doi:10.1111/j.2041-210x.2012.00261.x

Nicholls, C.I., Altieri, M.A., 2018. Pathways for the amplification of agroecology. Agroecol. 


\section{References}

Sustain. Food Syst. 1-24. doi:10.1080/21683565.2018.1499578

Nicholls, C.I., Altieri, M.A., 2017. Agroecological principles for the conversion of farming systems: principles, applications and making the transition. J. Ecosyst. Ecography S5, 18. doi:10.1142/9781786343062

Nicholls, C.I., Altieri, M.A., L., V., 2016. Agroecology: principles for the conversion and redesign of farming systems. J. Ecosyst. Ecography S5. doi:10.4172/2157-7625.S5-010

Ninan, K.N., Inoue, M., 2013. Valuing forest ecosystem services: What we know and what we don’t. Ecol. Econ. 93, 137-149. doi:10.1016/j.ecolecon.2013.05.005

Norden, N., Chazdon, R.L., Chao, A., Jiang, Y.H., Vílchez-Alvarado, B., 2009. Resilience of tropical rain forests: Tree community reassembly in secondary forests. Ecol. Lett. 12, 385394. doi:10.1111/j.1461-0248.2009.01292.x

Nunes, W.A.G.A., Ker, J.C., Schaefer, C.E.G.R., Fernandes Filho, E.I., Gomes, F.H., 2001. Relação solo-paisagem-material de origem e gênese de alguns solos no domínio do "Mar de Morros”, Minas Gerais. Rev. Bras. Ciência do Solo 25, 341-354. doi:10.1590/s010006832001000200011

Nzeyimana, I., Hartemink, A.E., Ritsema, C., Stroosnijder, L., Lwanga, E.H., Geissen, V., 2017. Mulching as a strategy to improve soil properties and reduce soil erodibility in coffee farming systems of Rwanda. Catena 149, 43-51. doi:10.1016/j.catena.2016.08.034

Oberski, D., 2014. lavaan.survey: an R package for complex survey analysis of structural equation models. J. Stat. Softw. 57, 1-27. doi:10.18637/jss.v057.i01

Olimpi, E.M., Philpott, S.M., 2018. Agroecological farming practices promote bats. Agric. Ecosyst. Environ. 265, 282-291. doi:10.1016/j.agee.2018.06.008

Oliveira, A.C.C. de, 2013. Sistemas agroflorestais com café: fixação e neutralização de carbono e outros serviços ecossistêmicos. MSc thesis, Universidade Federal de Viçosa.

Oliveira, R.M. de, 2015. Quintais e uso do solo em propriedades familiares. Viçosa. MSc Thesis, Universidade Federal de Viçosa. doi:10.1017/CBO9781107415324.004

Oliver, T.H., Heard, M.S., Isaac, N.J.B., Roy, D.B., Procter, D., Eigenbrod, F., Freckleton, R., Hector, A., Orme, C.D.L., Petchey, O.L., Proença, V., Raffaelli, D., Suttle, K.B., Mace, G.M., Martín-lópez, B., Woodcock, B.A., Bullock, J.M., 2015. Biodiversity and resilience of ecosystem functions. Trends Ecol. Evol. 30, 673-684.

Ollivier, G., Plumecocq, G., Lamine, C., 2018. Agroecological transitions: what can 
sustainability transition frameworks teach us? An ontological and empirical analysis. Ecol. Soc. 23. doi:10.5751/ES-09952-230205

Ometto, J.P., Aguiar, A.P.D., Martinelli, L.A., 2011. Amazon deforestation in Brazil: effects, drivers and challenges. Carbon Manag. 2, 575-585. doi:10.4155/cmt.11.48

Oxfam, 2014. Building a new agricultural future. Oxfam issue Brief. 1-18.

Özesmi, U., Özesmi, S.L., 2004. Ecological models based on people 's knowledge: a multi-step fuzzy cognitive mapping approach. Ecol. Modell. 176, 43-64. doi:10.1016/j.ecolmodel.2003.10.027

Pahnke, A., 2015. Institutionalizing economies of opposition: explaining and evaluating the success of the MST' s cooperatives and agroecological repeasantization. J. Peasant Stud. 42, 1087-1107. doi:10.1080/03066150.2014.991720

Palomo-Campesino, S., González, J.A., García-Llorente, M., 2018. Exploring the connections between agroecological practices and ecosystem services: a systematic literature review. Sustain. 10. doi:10.3390/su10124339

Papageorgiou, E.I., Salmeron, J.L., 2013. A review of fuzzy cognitive maps research during the last decade. IEEE Trans. Fuzzy Syst. 21, 66-79. doi:10.1109/TFUZZ.2012.2201727

Paradelo, R., Virto, I., Chenu, C., 2015. Net effect of liming on soil organic carbon stocks: a review. Agric. Ecosyst. Environ. 202, 98-107. doi:10.1016/j.agee.2015.01.005

Pascual, U., Balvanera, P., Diaz, S., Roth, E., Stenseke, M., Watson, R.T., Ba, E., Islar, M., Kelemen, E., Maris, V., Quaas, M., Subramanian, S.M., Wittmer, H., Adlan, A., Ahn, S., Al-hafedh, Y.S., Amankwah, E., Asah, S.T., Berry, P., Bilgin, A., Breslow, S.J., Bullock, C., Ca, D., Figueroa, E., Golden, C.D., Keune, H., Kumar, R., Ma, K., May, P.H., Mead, A., Farrell, P.O., Pandit, R., Pengue, W., Preston, S., Pacheco-balanza, D., Saarikoski, H., 2017. Valuing nature's contributions to people: the IPBES approach. Curr. Opin. Environ. Sustain. 26, 7-16. doi:10.1016/j.cosust.2016.12.006

Pérez-Harguindeguy, N., Díaz, S., Lavorel, S., Poorter, H., Jaureguiberry, P., Bret-Harte, M.S., Cornwell, W.K., Craine, J.M., Gurvich, D.E., Urcelay, C., Veneklaas, E.J., Reich, P.B., Poorter, L., Wright, I.J., Ray, P., Enrico, L., Pausas, J.G., Vos, A.C. de, Buchmann, N., Funes, G., Quétier, F., Hodgson, J.G., Thompson, K., Morgan, H.D., Steege, H. ter, Heijden, M.G.A. van der, Sack, L., Blonder, B., Poschlod, P., Vaieretti, M. V., Conti, G., Staver, A.C., Aquino, S., Cornelissen, J.H.C., 2013. New Handbook for standardized 


\section{References}

measurment of plant functional traits worldwide. Aust. J. Bot. 23, 167-234. doi:http://dx.doi.org/10.1071/BT12225

Perfecto, I., Vandermeer, J., 2015. Coffee Agroecology: a new approach to understanding agricultural biodiversity, ecosystem services and sustainable development, First. ed. Routledge, New York.

Perfecto, I., Vandermeer, J., 2010. The agroecological matrix as alternative to the landsparing/agriculture intensification model. Proc. Natl. Acad. Sci. U. S. A. 107, 5786-91. doi:10.1073/pnas.0905455107

Petersen, P., Mussoi, E.M., dal Soglio, F., 2013. Institutionalization of the agroecological approach in Brazil: Advances and challenges. Agroecol. Sustain. Food Syst. 37, 103-114. doi:10.1080/10440046.2012.735632

Petersen, P.F., Silveira, L.M., 2017. Agroecology, public policies and labor-driven intensification: alternative development trajectories in the Brazilian Semi-Arid region. Sustainability 9, 1-18. doi:10.3390/su9040535

Pimbert, M., 2016. Agroecology as an alternative vision to conventional development and climate-smart agriculture. Development 58, 286-298. doi:10.1057/s41301-016-0013-5

Pimentel, F. da M., 2018. Institui o Polo Agroecológico e de Produção Orgânica na região da Zona da Mata. LEI No 23207, Brazil.

Pires, L.F., Araujo-Junior, C.F., Auler, A.C., Dias, N.M.P., Dias Junior, M.S., de Alcântara, E.N., 2017. Soil physico-hydrical properties changes induced by weed control methods in coffee plantation. Agric. Ecosyst. Environ. 246, 261-268. doi:10.1016/j.agee.2017.06.008

Pirsaheb, M., Hossini, H., Asadi, F., Janjani, H., 2017. A systematic review on organochlorine and organophosphorus pesticides content in water resources. Toxin Rev. 36, 210-221. doi:10.1080/15569543.2016.1269810

Pirsaheb, M., Limoee, M., Namdari, F., Khamutian, R., 2015. Organochlorine pesticides residue in breast milk: A systematic review. Med. J. Islam. Repub. Iran 29.

Poorter, L., Bongers, F., 2006. Leaf traits are good predictors of plant performance across 53 rain forest species. Ecology 87, 1733-43. doi:10.1890/00129658(2006)87[1733:LTAGPO]2.0.CO

Poorter, L., Bongers, F., Aide, T.M., Almeyda Zambrano, A.M., Balvanera, P., Becknell, J.M., Boukili, V., Brancalion, P.H., Broadbent, E.N., Chazdon, R.L., Craven, D., de Almeida- 
Cortez, J.S., Cabral, G.A., de Jong, B.H., Denslow, J.S., Dent, D.H., DeWalt, S.J., Dupuy, J.M., Duran, S.M., Espirito-Santo, M.M., Fandino, M.C., Cesar, R.G., Hall, J.S., Hernandez-Stefanoni, J.L., Jakovac, C.C., Junqueira, A.B., Kennard, D., Letcher, S.G., Licona, J.C., Lohbeck, M., Marin-Spiotta, E., Martinez-Ramos, M., Massoca, P., Meave, J.A., Mesquita, R., Mora, F., Munoz, R., Muscarella, R., Nunes, Y.R., Ochoa-Gaona, S., de Oliveira, A.A., Orihuela-Belmonte, E., Pena-Claros, M., Perez-Garcia, E.A., Piotto, D., Powers, J.S., Rodriguez-Velazquez, J., Romero-Perez, I.E., Ruiz, J., Saldarriaga, J.G., Sanchez-Azofeifa, A., Schwartz, N.B., Steininger, M.K., Swenson, N.G., Toledo, M., Uriarte, M., van Breugel, M., van der Wal, H., Veloso, M.D., Vester, H.F., Vicentini, A., Vieira, I.C., Bentos, T. V, Williamson, G.B., Rozendaal, D.M., 2016. Biomass resilience of Neotropical secondary forests. Nature 530, 211-214. doi:10.1038/nature16512

Potzelsberger, E., Hasenauer, H., 2015. Forest - water dynamics within a mountainous catchment. Nat Hazards 77, 625-644. doi:10.1007/s11069-015-1609-X

Pretty, J., 2008. Agricultural sustainability: Concepts, principles and evidence. Philos. Trans. R. Soc. B Biol. Sci. 363, 447-465. doi:10.1098/rstb.2007.2163

Pretty, J., Benton, T.G., Bharucha, Z.P., Dicks, L. V., Flora, C.B., Godfray, H.C.J., Goulson, D., Hartley, S., Lampkin, N., Morris, C., Pierzynski, G., Prasad, P.V.V., Reganold, J., Rockstrom, J., Smith, P., Thorne, P., Wratten, S., 2018. Global assessment of agricultural system redesign for sustainable intensification. Nat. Sustain. 1, 441-446. doi:https://doi.org/10.1038/s41893-018-0114-0

Pretty, J.N., Noble, A.D., Bossio, D., Dixon, J., Hine, R.E., De Vries, F.W.T.P., Morison, J.I.L., 2006. Resource-conserving agriculture increases yields in developing countries. Environ. Sci. Technol. 40, 1114-1119. doi:10.1021/es051670d

Qiu, K., Xie, Y., Xu, D., Pott, R., 2018. Ecosystem functions including soil organic carbon, total nitrogen and available potassium are crucial for vegetation recovery. Sci. Rep. 8, 1-11. doi:10.1038/s41598-018-25875-x

Quijas, S., Romero-Duque, L.P., Trilleras, J.M., Conti, G., Kolb, M., Brignone, E., Dellafiore, C., 2019. Linking biodiversity, ecosystem services, and beneficiaries of tropical dry forests of Latin America: review and new perspectives. Ecosyst. Serv. 36, 100909. doi:10.1016/j.ecoser.2019.100909

Rahn, E., Liebig, T., Ghazoul, J., van Asten, P., Läderach, P., Vaast, P., Sarmiento, A., Garcia, 


\section{References}

C., Jassogne, L., 2018. Opportunities for sustainable intensification of coffee agroecosystems along an altitudinal gradient on Mt. Elgon, Uganda. Agric. Ecosyst. Environ. 263, 31-40. doi:10.1016/j.agee.2018.04.019

Ramos, N.C., Gastauer, M., de Almeida Campos Cordeiro, A., Meira-Neto, J.A.A., 2015. Environmental filtering of agroforestry systems reduces the risk of biological invasion. Agrofor. Syst. 89, 279-289. doi:10.1007/s10457-014-9765-7

Reij, C., Garrity, D., 2016. Scaling up farmer-managed natural regeneration in Africa to restore degraded landscapes. Biotropica 48, 834-843. doi:10.1111/btp.12390

Reis, M.S. dos, Fantini, A.C., Nodari, R.O., Reis, A., Guerra, M.P., Mantovani, A., 2000. Management and conservation of natural populations in Atlantic Rain Forest: the case study of Palm heart (Euterpe edulis Martius). Biotropica 32, 894-902. doi:10.1111/j.17447429.2000.tb00627.x

Reydon, B.P., Fernandes, V.B., Telles, T.S., 2015. Land tenure in Brazil: the question of regulation and governance. Land use policy 42, 509-516.

Reyers, B., Biggs, R., Cumming, G.S., Elmqvist, T., Hejnowicz, A.P., Polasky, S., 2013. Getting the measure of ecosystem services: a social-ecological approach. Front. Ecol. Environ. 11, 268-273. doi:10.1890/120144

Reyes, H.A., Ferreira, P.F.A., Silva, L.C., da Costa, M.G., Nobre, C.P., Gehring, C., 2019. Arbuscular mycorrhizal fungi along secondary forest succession at the eastern periphery of Amazonia: seasonal variability and impacts of soil fertility. Appl. Soil Ecol. 136, 1-10. doi:10.1016/j.apsoil.2018.12.013

Reynolds, H.L., Smith, A.A., Farmer, J.R., 2014. Think globally, research locally: paradigms and place in agroecological research. Am. J. Bot. 101, 1631-1639. doi:10.3732/ajb.1400146

Rezende, M.Q., Venzon, M., Perez, A.L., Cardoso, I.M., Janssen, A., 2014. Extrafloral nectaries of associated trees can enhance natural pest control. Agric. Ecosyst. Environ. doi:10.1016/j.agee.2014.02.024

Rigal, C., Xu, J., Vaast, P., 2019. Young shade trees improve soil quality in intensively managed coffee systems recently converted to agroforestry in Yunnan Province, China. Plant Soil. doi:10.1007/s11104-019-04004-1

Righi, E., Dogliotti, S., Stefanini, F.M., Pacini, G.C., 2011. Capturing farm diversity at regional 
level to up-scale farm level impact assessment of sustainable development options. Agric. Ecosyst. Environ. 142, 63-74. doi:10.1016/j.agee.2010.07.011

Rijkers, T., Pons, T.L., Bongers, F., 2000. The effect of tree height and light availability on photosyntheltic leaf traits of four neotropical species differing in shade tolerance. Funct. Ecol. 14, 77-86. doi:10.1046/j.1365-2435.2000.00395.x

Robinson, S.J.B., van den Berg, E., Meirelles, G.S., Ostle, N., 2015. Factors influencing early secondary succession and ecosystem carbon stocks in Brazilian Atlantic Forest. Biodivers. Conserv. 24, 2273-2291. doi:10.1007/s10531-015-0982-9

Rodríguez, Á.G.P., López, M.I.R., Casillas, T.A.D., León, J.A.A., Prusty, B.A.K., Cervera, F.J.Á., 2017. Levels of persistent organic pollutants in breast milk of Maya women in Yucatan, Mexico. Environ. Monit. Assess. 189. doi:10.1007/s10661-017-5768-y

Roesch, A., Weisskopf, P., Oberholzer, H., Valsangiacomo, A., Nemecek, T., 2019. An approach for describing the effects of grazing on soil quality in life-cycle assessment. Sustain. 11, 4870.

Romualdo, P.L., Cardoso, I.M., 2017. Estratégias para otimizar o sistema agroecológico da pecuária leiteira na agricultura familiar. Rev. Bras. Agropecuária Sustentável 7, 9-18.

Rosseel, Y., 2012. lavaan: An R Package for Structural Equation Modeling. J. Stat. Softw. 48, 1-36. doi:10.18637/jss.v048.i02

Rosset, P., 2013. Re-thinking agrarian reform , land and territory in La Via Campesina. J. Peasant Stud. 40, 721-775. doi:10.1080/03066150.2013.826654

Rosset, P.M., Sosa, B.M., Jaime, A.M.R., Lozano, D.R.Á., 2011. The Campesino-to-Campesino agroecology movement of ANAP in Cuba: social process methodology in the construction of sustainable peasant agriculture and food sovereignty. J. Peasant Stud. 38, 161-191. doi:10.1080/03066150.2010.538584

Rozendaal, D.M.A., Bongers, F., Aide, T.M., Alvarez-dávila, E., Ascarrunz, N., Balvanera, P., Becknell, J.M., Bentos, T. V, Brancalion, P.H.S., Cabral, G.A.L., Calvo-rodriguez, S., Chave, J., César, R.G., Chazdon, R.L., Condit, R., Dallinga, J.S., Almeida-cortez, J.S. De, Jong, B. De, Oliveira, A. De, Denslow, J.S., Dent, D.H., Dewalt, S.J., Dupuy, J.M., Durán, S.M., Dutrieux, L.P., Espírito-santo, M.M., Fandino, M.C., Fernandes, G.W., Finegan, B., García, H., Gonzalez, N., Moser, V.G., Hall, J.S., Hernández-stefanoni, J.L., Hubbell, S., Jakovac, C.C., Hernández, A.J., Junqueira, A.B., Kennard, D., Larpin, D., Letcher, S.G., 


\section{References}

Licona, J., Lebrija-trejos, E., Marín-spiotta, E., Martínez-ramos, M., Massoca, P.E.S., Meave, J.A., Mesquita, R.C.G., Mora, F., Müller, S.C., Muñoz, R., Nolasco, S., Neto, D.O., Norden, N., Nunes, Y.R.F., Ochoa-gaona, S., Ortiz-malavassi, E., 2019. Biodiversity recovery of Neotropical secondary forests. Sci. Adv. 5, 1-10. doi:10.1126/sciadv.aau3114 Russell, J.R., Bisinger, J.J., 2015. Grazing system effects on soil compaction in Southern Iowa pastures, Animal Industry Report. doi:10.31274/ans_air-180814-1308

Salguero-Gómez, R., Jones, O.R., Jongejans, E., Blomberg, S.P., Hodgson, D.J., Mbeau-Ache, C., Zuidema, P.A., De Kroon, H., Buckley, Y.M., 2016. Fast-slow continuum and reproductive strategies structure plant life-history variation worldwide. Proc. Natl. Acad. Sci. 113, 230-235. doi:10.1073/pnas.1506215112

Sandel, B., Monnet, A.C., Vorontsova, M., 2016. Multidimensional structure of grass functional traits among species and assemblages. J. Veg. Sci. 27, 1047-1060. doi:10.1111/jvs.12422

Sansevero, J.B.B., Crouzeilles, R., Barros, F.S.M., Iribarrem, A., Feltran-Barbieri, R., Santos, J.S. dos, Latawiec, A.E., Alves-Pinto, H.N., Silva, D., Strassburg, B.B.N., 2016. The role of natural regeneration to ecosystem services provision and habitat availability: a case study in the Brazilian Atlantic Forest. Biotropica 48, 890-899. doi:10.1111/btp.12393

Sarcinelli, T.S., Schaefer, C.E.G.R., Lynch, L. de S., Arato, H.D., Viana, J.H.M., Filho, M.R. de A., Gonçalves, T.T., 2009. Chemical, physical and micromorphological properties of termite mounds and adjacent soils along a toposequence in Zona da Mata, Minas Gerais State, Brazil. Catena 76, 107-113. doi:10.1016/j.catena.2008.10.001

Sato, C.F., Strong, C.L., Holliday, P., Florance, D., Pierson, J., Lindenmayer, D.B., 2019. Environmental and grazing management drivers of soil condition. Agric. Ecosyst. Environ. 276, 1-7. doi:10.1016/j.agee.2019.02.003

Saylor, C.R., Alsharif, K.A., Torres, H., 2017. The importance of traditional ecological knowledge in agroecological systems in Peru. Int. J. Biodivers. Sci. Ecosyst. Serv. Manag. 13, 150-161. doi:10.1080/21513732.2017.1285814

Scherber, C., Eisenhauer, N., Weisser, W.W., Schmid, B., Voigt, W., Fischer, M., Schulze, E.D., Roscher, C., Weigelt, A., Allan, E., Beler, H., Bonkowski, M., Buchmann, N., Buscot, F., Clement, L.W., Ebeling, A., Engels, C., Halle, S., Kertscher, I., Klein, A.M., Koller, R., König, S., Kowalski, E., Kummer, V., Kuu, A., Lange, M., Lauterbach, D., Middelhoff, C., Migunova, V.D., Milcu, A., Müller, R., Partsch, S., Petermann, J.S., Renker, C., 
Rottstock, T., Sabais, A., Scheu, S., Schumacher, J., Temperton, V.M., Tscharntke, T., 2010. Bottom-up effects of plant diversity on multitrophic interactions in a biodiversity experiment. Nature 468, 553-556. doi:10.1038/nature09492

Schmitzberger, I., Wrbka, T., Steurer, B., Aschenbrenner, G., Peterseil, J., Zechmeister, H.G., 2005. How farming styles influence biodiversity maintenance in Austrian agricultural landscapes. Agric. Ecosyst. Environ. 108, 274-290. doi:10.1016/j.agee.2005.02.009

Schreiber, J.B., Stage, F.K., King, J., Nora, A., Barlow, E.A., 2006. Reporting structural equation modeling and confirmatory factor analysis results: a review. J. Educ. Res. 99, 323-337.

Schulte, R.P.O., Bampa, F., Bardy, M., Coyle, C., Creamer, R.E., Fealy, R., Gardi, C., Ghaley, B.B., Jordan, P., Laudon, H., Donoghue, C.O., Daire, Ó., Sullivan, L.O., 2015. Making the most of our land: managing soil functions from local to continental scale. Front. Environ. Sci. 3, 1-14. doi:10.3389/fenvs.2015.00081

Schutter, O. De, 2010. Agroecology and the right to food. United Nations.

Schwendler, S.F., Thompson, L.A., 2017. An education in gender and agroecology in Brazil's Landless Rural Workers' Movement. Gend. Educ. 29, 100-114. doi:10.1080/09540253.2016.1221596

Shimamoto, C.Y., Padial, A.A., Da Rosa, C.M., Marques, M.C.M., 2018. Restoration of ecosystem services in tropical forests: A global meta-analysis. PLoS One 13, 1-16. doi:10.1371/journal.pone.0208523

Silici, L., 2014. Agroecology: What it is and what it has to offer. IIED Issue Pap. IIED, London.

Silva, J.Z. da, Reis, M.S. dos, 2018. Consumption of Euterpe edulis fruit by wildlife: implications for conservation and management of the Southern Brazilian Atlantic Forest. Ann. Brazilian Acad. Sci. 91, e20180537. doi:10.1590/0001-3765201920180537

Silveira, M. da M., Silveira, P.S. da, Lopes, A. da S., Teixeira, R.S., Cardoso, I.M., Mauri, R., 2017. Núcleo de Educação do Campo e Agroecologia (ECOA): uma construção plural e coletiva. Cad. Agroecol. 12.

Silveira, P.S., Lopes, A.S., de Oliveira, L.A.D., Silveira, M. da M., Mauri, R., Sousa, T.F.C.W.L. de, Barbosa, W.A., Fernandes, R.B.A., Silva, L.H. da, Anjos, L.R.A. dos, Conte, G.M., Teixeira, R.S., Cardoso, I.M., 2018. Ecoando práticas e saberes: das raízes aos frutos do núcleo de Educação do Campo e Agroecologia. Rev. Bras. Agroecol. 13, 76 


\section{References}

89.

Siqueira, L.C., 2008. Levantamento floristico e etnobotanico do estrato arboreo em sistemas naturais e agroflorestais, araponga. Msc thesis, Universidade Federal de Viçosa.

Sloan, S., Goosem, M., Laurance, S.G., 2016. Tropical forest regeneration following land abandonment is driven by primary rainforest distribution in an old pastoral region. Landsc. Ecol. 31, 601-618. doi:10.1007/s10980-015-0267-4

Smith, H.F., Sullivan, C.A., 2014. Ecosystem services within agricultural landscapes Farmers' perceptions. Ecol. Econ. 98, 72-80.

Smukler, S.M., Sanchez-Moreno, S., Fonte, S.J., Ferris, H., Klonsky, K., O’Geen, A.T., Scow, K.M., Steenwerth, K.L., Jackson, L.E., 2010. Biodiversity and multiple ecosystem functions in an organic farmscape. Agric. Ecosyst. Environ. 139, 80-97. doi:10.1016/j.agee.2010.07.004

SOS Mata Atlântica, INPE, 2013. Atlas dos remanescentes florestais da Mata Atlântica período 2011-2012.

Sousa, T.F.C.W.L., 2014. Manejo agroecológico e qualidade da água no entorno do Parque Estadual da Serra do Brigadeiro. MSc thesis, Universidade Federal de Viçosa.

Souza, H.N., Cardoso, I.M., de Sá Mendonça, E., Carvalho, A.F., de Oliveira, G.B., Gjorup, D.F., Bonfim, V.R., 2012a. Learning by doing: A participatory methodology for systematization of experiments with agroforestry systems, with an example of its application. Agrofor. Syst. 85, 247-262. doi:10.1007/s10457-012-9498-4

Souza, H.N. De, Graaf, J. de, Pulleman, M.M., 2012b. Strategies and economics of farming systems with coffee in the Atlantic Rainforest Biome. Agrofor. Syst. 84, 227-242.

Souza, H.N., Cardoso, I.M., Fernandes, J.M., Garcia, F.C.P., Bonfim, V.R., Santos, A.C., Carvalho, A.F., Mendonça, E.S., 2010. Selection of native trees for intercropping with coffee in the Atlantic Rainforest biome. Agrofor. Syst. 80, 1-16. doi:10.1007/s10457-0109340-9

Steffen, W., Richardson, K., Rockström, J., Cornell, S., Fetzer, I., Bennett, E., Biggs, R., Carpenter, S., 2015. Planetary boundaries: Guiding human development on a changing planet. Science 347, 736-746. doi:10.1126/science.1259855

Symes, W.S., Edwards, D.P., Miettinen, J., Rheindt, F.E., Carrasco, L.R., 2018. Combined impacts of deforestation and wildlife trade on tropical biodiversity are severely 
underestimated. Nat. Commun. 9, 4052. doi:10.1038/s41467-018-06579-2

Tabatabai, M.A., 1994. Soil Enzymes, in: Weaver, R.W., Angle, J.S., Bottomley, P.S. (Eds.), Methods of Soil Analysis, Part 2 - Microbiological and Biochemical Properties. Soil Science Society of America Book Series 5, Madison, p. 1097.

Taniwaki, R.H., Forte, Y.A., Silva, G.O., Brancalion, P.H.S., Cogueto, C. V., Filoso, S., Ferraz, S.F.B., 2018. The Native Vegetation Protection Law of Brazil and the challenge for firstorder stream conservation. Perspect. Ecol. Conserv. 16, 49-53. doi:10.1016/j.pecon.2017.08.007

Teague, W.R., 2017. Whole-system approach: Managing grazing to restore soil health and farm livelihoods. J. Anim. Sci. 96, 1519-1530. doi:10.1093/jas/skx060

Teixeira, H.M., Van Den Berg, L., Cardoso, I.M., Vermue, A.J., Bianchi, F.J.J.A., Peña-Claros, M., Tittonell, P., 2018a. Understanding farm diversity to promote agroecological transitions. Sustainability 10, 4337. doi:10.3390/su10124337

Teixeira, H.M., Vermue, A.J., Cardoso, I.M., Peña Claros, M., Bianchi, F.J.J.A., 2018b. Farmers show complex and contrasting perceptions on ecosystem services and their management. Ecosyst. Serv. 33, 44-58. doi:10.1016/j.ecoser.2018.08.006

Tittonell, P., 2014. Ecological intensification of agriculture-sustainable by nature. Environ. Sustain. 8, 53-61. doi:10.1016/j.cosust.2014.08.006

Tittonell, P., Muriuki, A., Shepherd, K.D., Mugendi, D., Kaizzi, K.C., Okeyo, J., Verchot, L., Coe, R., Vanlauwe, B., 2010. The diversity of rural livelihoods and their influence on soil fertility in agricultural systems of East Africa - A typology of smallholder farms. Agric. Syst. 103, 83-97. doi:10.1016/j.agsy.2009.10.001

Tittonell, P., Vanlauwe, B., Leffelaar, P.A., Rowe, E.C., Giller, K.E., 2005. Exploring diversity in soil fertility management of smallholder farms in western Kenya: I. Heterogeneity at region and farm scale. Agric. Ecosyst. Environ. 110, 149-165. doi:10.1016/j.agee.2005.04.001

Torquebiau, E., Dosso, M., Nakaggwa, F., Philippon, O., 2012. Biodiversity conservation through farming: a landscape assessment in KwaZulu-Natal, South Africa. J. Sustain. Agric. 36, 296-318. doi:10.1080/10440046.2011.620227

Tscharntke, T., Clough, Y., Bhagwat, S.A., Buchori, D., Faust, H., Hertel, D., Hölscher, D., Juhrbandt, J., Kessler, M., Perfecto, I., Scherber, C., Schroth, G., Veldkamp, E., Wanger, 


\section{References}

T.C., 2011. Multifunctional shade-tree management in tropical agroforestry landscapes A review. J. Appl. Ecol. 48, 619-629. doi:10.1111/j.1365-2664.2010.01939.x

Tully, K., Ryals, R., 2017. Nutrient cycling in agroecosystems: balancing food and environmental objectives. Agroecol. Sustain. Food Syst. 41, 761-798. doi:10.1080/21683565.2017.1336149

Turnhout, E., Waterton, C., Neves, K., Buizer, M., 2013. Rethinking biodiversity: from goods and services to "living with." Conserv. Lett. 6, 154-161. doi:10.1111/j.1755263X.2012.00307.X

United Nations, 1992. Convention on biological diversity. Available at https://www.cbd.int/convention/text/default.shtml

Uphoff, N., 2017. SRI: An agroecological strategy to meet multiple objectives with reduced reliance on inputs. Agroecol. Sustain. Food Syst. 41, 825-854. doi:10.1080/21683565.2017.1334738

Valencia, V., Wittman, H., Blesh, J., 2019. Structuring markets for resilient farming systems. Agron. Sustain. Dev. 39, 1-14. doi:10.1007/s13593-019-0572-4

Valverde, O., 1958. Estudo regional da Zona da Mata de Minas Gerais. Rev. Bras. Geogr. 1, $1-$ 131.

van den Berg, L., Roep, D., Hebinck, P., Teixeira, H.M., 2018. Reassembling nature and culture: Resourceful farming in Araponga, Brazil. J. Rural Stud. 61, 314-322. doi:10.1016/j.jrurstud.2018.01.008

van der Ploeg, J.D., 2014. Peasant-driven agricultural growth and food sovereignty. J. Peasant Stud. 41, 999-1030. doi:10.1080/03066150.2013.876997

van der Ploeg, J.D, 2010. The peasantries of the twenty-first century: the commoditisation debate revisited. J. Peasant Stud. 37, 1-30. doi:10.1080/03066150903498721

van der Ploeg, J.D., 2008. The New Peasantries: Struggles for Autonomy and Sustainability in an Era of Empire and Globalization, 1st ed. Earthscan, London.

van der Sande, M.T., Peña-Claros, M., Ascarrunz, N., Arets, E.J.M.M., Licona, J.C., Toledo, M., Poorter, L., 2017a. Abiotic and biotic drivers of biomass change in a Neotropical forest. J. Ecol. 105, 1223-1234. doi:10.1111/1365-2745.12756

van der Sande, M.T., Poorter, L., Balvanera, P., Kooistra, L., Thonicke, K., Boit, A., Dutrieux, L.P., Equihua, J., Gerard, F., Herold, M., Kolb, M., Simões, M., Peña-Claros, M., 2017 b. 
The integration of empirical, remote sensing and modelling approaches enhances insight in the role of biodiversity in climate change mitigation by tropical forests. Curr. Opin. Environ. Sustain. 26-27, 69-76. doi:10.1016/j.cosust.2017.01.016

van Vliet, M., Kok, K., Veldkamp, T., 2010. Linking stakeholders and modellers in scenario studies: The use of Fuzzy Cognitive Maps as a communication and learning tool. Futures 42, 1-14. doi:10.1016/j.futures.2009.08.005

Vance, E.D., Brookes, P.C., Jenkinson, D.S., 1987. An extraction method for measuring soil microbial biomass C. Soil Biol. Biochem. 19, 703-707. doi:10.1016/0038-0717(87)900526

Vandandorj, S., Eldridge, D.J., Travers, S.K., Val, J., Oliver, I., 2017. Microsite and grazing intensity drive infiltration in a semiarid woodland. Ecohydrology 10, 1-10. doi:10.1002/eco.1831

Vandermeer, J., Perfecto, I., 2007. The agricultural matrix and a future paradigm for conservation. Conserv. Biol. 21, 274-277. doi:10.1111/j.1523-1739.2006.00582.x

Vanhaute, E., Cottyn, H., 2017. Into their land and labours . A comparative and global analysis of trajectories of peasant transformation. ICAS Rev. Pap. Ser. 1-21.

Vanloqueren, G., Baret, P. V., 2009. How agricultural research systems shape a technological regime that develops genetic engineering but locks out agroecological innovations. Res. Policy 38, 971-983. doi:10.4324/9781315666396

Vuillot, C., Coron, N., Calatayud, F., Sirami, C., Mathevet, R., Gibon, A., 2016. Ways of farming and ways of thinking: do farmers mental models of the landscape relate to their land management practices? Ecol. Soc. 21, art35. doi:10.5751/ES-08281-210135

Wade, L., 2015. Agroecological approaches to breeding: crop, mixture and system design for improved fitness, sustainable intensification, ecosystem services, and food and nutrition security. Proc. FAO Int. Symp. 90-103.

Walker, L.R., Wardle, D.A., Bardgett, R.D., Clarkson, B.D., 2010. The use of chronosequences in studies of ecological succession and soil development. J. Ecol. 98, 725-736. doi:10.1111/j.1365-2745.2010.01664.x

Walkley, A., Black, I.A., 1933. An examination of the Degtjareff method for determining soil organic matter, and a proposed modification of the chronic acid titration method. Soil Sci. 37, 29-38. doi:10.1097/00010694-193401000-00003 


\section{References}

Watson, J.E.M., Evans, T., Venter, O., Williams, B., Tulloch, A., Stewart, C., Thompson, I., Ray, J.C., Murray, K., Salazar, A., McAlpine, C., Potapov, P., Walston, J., Robinson, J.G., Painter, M., Wilkie, D., Filardi, C., Laurance, W.F., Houghton, R.A., Maxwell, S., Grantham, H., Samper, C., Wang, S., Laestadius, L., Runting, R.K., Silva-Chávez, G.A., Ervin, J., Lindenmayer, D., 2018. The exceptional value of intact forest ecosystems. Nat. Ecol. Evol. 2, 599-610. doi:10.1038/s41559-018-0490-x

Weltin, M., Zasada, I., Franke, C., Piorr, A., Raggi, M., Viaggi, D., 2017. Analysing behavioural differences of farm households: an example of income diversification strategies based on European farm survey data. Land use policy 62, 172-184. doi:10.1016/j.landusepol.2016.11.041

Wezel, a., Bellon, S., Doré, T., Francis, C., Vallod, D., David, C., 2009. Agroecology as a science, a movement and a practice. Sustain. Agric. 2, 27-43. doi:10.1007/978-94-0070394-03

Wezel, A., Goette, J., Lagneaux, E., Passuello, G., Reisman, E., Rodier, C., Turpin, G., 2018. Agroecology in Europe: research, education, collective action networks, and alternative food systems. Sustainability 10, 1-18. doi:10.3390/su10041214

Winbourne, J.B., Feng, A., Reynolds, L., Piotto, D., Hastings, M.G., Porder, S., 2018. Nitrogen cycling during secondary succession in Atlantic Forest of Bahia, Brazil. Sci. Rep. 8, 1-9. doi:10.1038/s41598-018-19403-0

Wittman, H., Blesh, J., Wittman, H., Blesh, J., 2017. Food sovereignty and Fome Zero : connecting public food procurement programmes to sustainable rural development in Brazil. J. Agrar. Chang. 17, 81-105. doi:10.1111/joac.12131

Wood, S.A., Karp, D.S., DeClerck, F., Kremen, C., Naeem, S., Palm, C.A., 2015. Functional traits in agriculture: agrobiodiversity and ecosystem services. Trends Ecol. Evol. 30, 531539. doi:10.1016/j.tree.2015.06.013

Wright, I.J., Reich, P.B., Westoby, M., Ackerly, D.D., Baruch, Z., Bongers, F., Cavender-Bares, J., Chapin, T., Cornelissen, J.H.C., Diemer, M., Flexas, J., Garnier, E., Groom, P.K., Gulias, J., Hikosaka, K., Lamont, B.B., Lee, T., Lee, W., Lusk, C., Midgley, J.J., Navas, M.-L., Niinemets, U., Oleksyn, J., Osada, N., Poorter, H., Poot, P., Prior, L., Pyankov, V.I., Roumet, C., Thomas, S.C., Tjoelker, M.G., Veneklaas, E.J., Villar, R., 2004. The worldwide leaf economics spectrum. Nature 428, 821-827. doi:10.1038/nature02403 
Yachi, S., Loreau, M., 2007. Does complementary resource use enhance ecosystem functioning? A model of light competition in plant communities. Ecol. Lett. 10, 54-62. doi:10.1111/j.1461-0248.2006.00994.X

Yan, J., Wang, Y., Zhou, G., Zhang, D., 2006. Estimates of soil respiration and net primary production of three forests at different succession stages in South China. Glob. Chang. Biol. 12, 810-821. doi:10.1111/j.1365-2486.2006.01141.x

Yesilonis, I., Szlavecz, K., Pouyat, R., Whigham, D., Xia, L., 2016. Historical land use and stand age effects on forest soil properties in the Mid-Atlantic US. For. Ecol. Manage. 370, 83-92. doi:10.1016/j.foreco.2016.03.046

Yuliani, E.L., Mulyana, A., Adnan, H., Manalu, P., Achdiawan, R., Tias, P., Moeliono, M., 2015. Local perceptions of forest ecosystem services and collaborative formulation of reward mechanisms in South and Southeast Sulawesi., ICRAF Working Paper - World Agroforestry Centre. Bogor, Indonesia. doi:http://dx.doi.org/10.5716/WP15721.PDF

Zak, D.R., Holmes, W.E., White, D.C., Peacock, A.D., Tilman, D., Zak, D.R., Holmes, W.E., White, D.C., Peacock, A.D., Tilman, D., 2003. Plant diversity, soil microbial communities, and ecosystem function: are there any links? Ecology 84, 2042-2050. doi:10.1890/02-0433

Zanelli, F.V., Lopes, A. da S., Cardoso, I.M., Fernandes, R.B.A., Silva, B. de M., 2015. Intercâmbios agroecológicos: aprendizado coletivo. Inf. Agropecuário 36, 104-113.

Zhang, W., Zhao, J., Pan, F., Li, D., Chen, H., Wang, K., 2015. Changes in nitrogen and phosphorus limitation during secondary succession in a karst region in southwest China. Plant soil 391, 77-91. doi:10.1007/s11104-015-2406-8 
Summary

\section{Summary}

Biodiversity loss as a consequence of human driven activities is altering the functioning of ecosystems and substantially reducing the provision of ecosystem services (i.e. benefits derived from nature to people). Within agricultural systems, the dominant industrial model based on monocultures and external inputs is often associated to a variety of externalities that cause environmental and social degradation. As a response to this dominant model, agroecology envisions a paradigm shift in agriculture towards more biodiverse, sustainable and equitable food systems. To foster this transition process it is crucial to develop adequate management strategies and to create a favourable social and institutional environment. Such institutional environment should support new coordination strategies by equally involving policy-makers, farmers, consumers, extension agents and researchers.

In the region of Zona da Mata (Minas Gerais, Brazil), an on-going process of agroecological transition has been initiated more than thirty years ago. The landscape in Zona da Mata region can be understood as a dynamic mosaic of land uses, including secondary forest, pastures and coffee. Spatial patterns of such mosaics are determined by heterogeneous physical landscape features and shaped by the different management practices and decision making processes of individual farmers. As a result, a gradient of diversified to simplified farms can be found in the region. These farming systems contribute differently to local livelihoods and to the provision of ecosystem services (ES). Currently, we lack understanding of the incentives that farmers have to manage agrobiodiversity and the consequences of management decisions for functional diversity and the provision of multiple ES. In this thesis, I developed and applied a combination 
of social and ecological methods in the context of Zona da Mata to assess the links between biodiversity, ecosystem services and social actors for informing the development of sustainable agroecological systems.

The challenges associated with agroecological transitions may be perceived differently by farmers, as they may face different social and bio-physical conditions. In Chapter 2, I developed a farm typology combining participatory and quantitative methodologies to assess and categorise farm diversity and its implications for developing strategies to promote agroecological transitions. The participatory typology was developed during workshops to acquire insights on local farmers' perceptions and knowledge, and to generate hypotheses on family farm diversity. The participatory-based hypotheses were tested in a quantitative farm characterisation, which provided information on household characteristics, production strategies, land use, participation in public policies and extension services. Six main farm types were identified in Zona da Mata: conventional family, agroecological family, traditional family, large-scale, part-time and landless farmers. I showed that in the face of agroecological transitions, farmers use different management strategies, practices and principles and that farmers identified as agroecological typically had stronger engagements in a network composed of farmers' organisations, universities and NGO's. Moreover, agroecological farms showed great potential to provide a wide range of ecosystem services as they featured a higher crop diversity and a higher number of crops for self-consumption than conventional and traditional family farms. I concluded that agroecological transitions can greatly benefit from involvement of social movements, support from public policies and funds, and the generation of integrated scientific and local knowledge for a more systemic view on the management of agroecosystems. 
Summary

Whereas farm management is a key factor for ecosystem services provision, farmers may widely differ in their awareness, ambition and skills to manage their systems. Currently there is a lack of understanding of farmers' perception on ES, and how this is related to their management. In chapter 3, I studied the management and perception of large scale farmers, conventional family farmers and agroecological family farmers. Farmers were interviewed and constructed fuzzy cognitive maps of their perception on ES. The fuzzy cognitive maps analysis revealed that in general, the perception of farmers on ES is highly complex and interconnected. Yet, agroecological family farmers showed a more complex perception on ES, which is associated with more diversified and autonomous agroecosystems. Both agroecological and conventional family farmers had a strong peasant identity as they recognised more cultural ecosystem services and relied more on production for consumption than large scale farmers. Initiatives that aim to strengthen on-farm ecosystem services provision should be sensitive to farmers' perceptions and may need to consider specific strategies for different farmer types.

Farmers manage their land for the provision of key ES, based on their perceptions, needs, capacities and assets. In chapter 4 I assessed the direct and indirect impacts of farmers' management practices on biodiversity, soil quality and crop productivity in coffee and pasture fields of agroecological, conventional, and large-scale farms. The study was carried out in twelve farms and for each of the total of 24 fields (twelve coffee and twelve pastures) we recorded 41 variables associated with management practices, measures of taxonomic (e.g. number of tree species), structural (e.g. basal area, canopy openness) and functional diversity (e.g. community weighted means of functional traits) and soil biological, chemical and physical quality. The direct and indirect effects of management on biodiversity, soil quality and in the case of coffee, crop productivity, was assessed using structural equation models. In the case of 
pastures, we found that increased plant diversity due to agroecological management resulted in higher soil quality, probably due to higher soil litter cover and plant structural heterogeneity. Yet, other agroecological management practices did not have a direct positive effect on soil quality, which indicates that increased plant diversity in pastures needs to be combined with better management practices than currently adopted. In the case of coffee, we show that despite the higher weeding intensity and higher use of external inputs in large-scale and conventional coffee farming systems, these practices did not result in higher soil quality or coffee productivity than in agroecological systems. In contrast, agroecological coffee management was associated with increased plant structural, functional and taxonomical diversity, which in turn, was positively associated with microbial biomass carbon. Our results highlight a causal pathway of agroecological management leading to increased plant diversity and, in turn, maintenance or increase in soil quality. While no causal link to coffee productivity could be demonstrated, this biodiversity-mediated pathway resulted in similar coffee productivity in agroecological farms as compared to conventionally managed farms, which relied on pesticides and increased mineral nutrient inputs.

Besides agricultural fields, (semi-)natural ecosystems, such as secondary forests, can provide important ES. The natural regeneration of secondary forests can be an effective and low-cost strategy to increase forest cover in the landscape and the associated biodiversity and soil functions. However, little is known about how soil functions develop during succession, and how vegetation attributes influence soil functions, especially in highly biodiverse and fragmented landscapes in the tropics. In chapter $5 \mathrm{I}$ assessed a wide range of indicators of taxonomic, structural and functional diversity of tree species, as well as indicators for soil functions related to soil organic matter accumulation, nutrient cycling and soil cover in 
Summary

secondary forest patches ranging from 5 to 80 years. Two recently abandoned agricultural fields were included as the starting point of forest succession and two primary forest patches served as references for the end point of forest succession. Four ecological hypotheses, centred around the role of functional diversity, structural diversity and biomass, were tested to explore mechanisms in which forest vegetation may influence soil functions. Most measures of structural, taxonomic and functional diversity converged to values found in primary forests after 25-50 years of succession, whereas functional composition changed from acquisitive to conservative species. Soil carbon and nutrient cycling showed a quick recovery to the levels of primary forests after 15 years of succession. Although soil cover also increased during succession, levels of primary forests were not reached within 80 years. Variation in tree height and trait dominance were identified as aboveground drivers of carbon and nutrient cycling, while aboveground biomass was the main driver of litter accumulation, and the associated soil cover and water retention. Our results indicate that secondary forest succession can lead to a relative fast recovery of nutrient and carbon cycling functions, but not of soil cover. Our findings highlight the essential role of secondary forests in providing multiple ecosystem services.

The results from this thesis show that changes in the cognitive perception of farmers on ES led to changes in management strategies, which, in turn, influenced biodiversity and the provision of ES. Agroecological farmers had a more complex perception on ES than other farm types, which was associated to greater access to public policies and participation in social organisations, as well as higher biodiversity in their agroecosystems. Thus, the agroecology movement in Zona da Mata supported a group of a farmers to become less dependent on the use of industrial inputs without compromising soil quality and plant health by strengthening biodiversity-based ecological processes. However, despite the mounting evidence on its 
ecological and agronomic benefits, agroecological approaches are still not widely adopted by farmers in the Zona da Mata, across Brazil and the globe. Therefore, I suggest that, besides technical issues, the scaling up of agroecological transitions can be hampered by other factors, such as the lock-in in the industrial model of agriculture. There is an urgent need to develop and apply better approaches to support farmers to get access to land, credits, markets and knowledge. The generation and sharing of actionable agroecological knowledge can inform scientificallyunderpinned management practices and public policies that are conducive to agroecological transitions. 
Sumário

\section{Sumário}

A perda de biodiversidade como consequência de atividades humanas está alterando o funcionamento dos ecossistemas e reduzindo substancialmente a provisão de serviços ecossistêmicos (isto é, benefícios derivados da natureza para os seres humanos). Nos sistemas agrícolas, o modelo industrial dominante, baseado em monoculturas e insumos externos, é frequentemente associado a uma variedade de externalidades que causam degradação ambiental e social. Como resposta a esse modelo dominante, a agroecologia prevê uma mudança de paradigma na agricultura em direção a sistemas alimentares mais biodiversos, sustentáveis e igualitários. O desenvolvimento de estratégias adequadas de manejo dos agroecossistemas e a criação de um ambiente social e institucional favorável são cruciais para a promoção do processo de transição agroecológica. Esse ambiente institucional deve apoiar novas estratégias de governança que envolva igualmente políticos, agricultores, consumidores, agentes de extensão e pesquisadores.

$\mathrm{Na}$ região da Zona da Mata (Minas Gerais, Brasil), um processo contínuo de transição agroecológica foi iniciado há mais de trinta anos. A paisagem da região da Zona da Mata pode ser entendida como um mosaico dinâmico de usos da terra que inclui florestas secundárias, pastagens, cafezais, quintais agroflorestais, dentre outros. Os padrões espaciais de tais mosaicos são determinados por características heterogêneas da paisagem física e moldados pelas diferentes práticas de manejo e processos de tomada de decisão de agricultores/as. Como resultado, um gradiente que vai de propriedades biodiversas a simplificadas pode ser encontrado na região. Esses sistemas agrícolas contribuem de maneira diferente para os meios de vida locais 
e para a provisão de serviços ecossistêmicos. Atualmente, existe pouco conhecimento de como políticas públicas podem incentivar os agricultores a manejar a agrobiodiversidade de forma a ampliar o a diversidade funcional e o fornecimento de múltiplos serviços ecossistêmicos. Nesta tese, desenvolvi e apliquei uma combinação de métodos sociais e ecológicos, no contexto da Zona da Mata, para avaliar a interação entre biodiversidade, serviços ecossistêmicos e atores sociais e apoiar o desenvolvimento de sistemas agroecológicos sustentáveis. Estudos científicos desta natureza podem contribuir para maiores entendimentos sobre a importância do manejo de sistemas biodiversos na provisão de serviços ecossistêmicos necessários a vida e também de políticas públicas e intervenções que possam incentivar os agricultores a seguirem o caminho da transição agroecológica.

Os desafios associados às transições agroecológicas podem ser percebidos de maneira diferente pelos agricultores, pois eles podem enfrentar diferentes condições sociais e biofísicas. No capítulo 2, desenvolvi uma tipologia agrícola combinando metodologias participativas e quantitativas para avaliar e categorizar a diversidade agrícola e suas implicações para o desenvolvimento de estratégias para promover transições agroecológicas. A tipologia foi realizada de forma participativa durante oficinas com os/as agricultores/as locais para obter uma maior compreensão sobre as percepções e conhecimentos dos mesmos sobre os tipos de agricultores em seus municípios e gerar hipóteses sobre a diversidade de meios de vida na agricultura familiar. Tais hipóteses foram testadas a partir de caracterizações quantitativas das propriedades da agricultura familiar da Zona da Mata, quando informações foram obtidas sobre características das famílias, estratégias de produção, uso da terra, participação em políticas públicas e serviços de extensão. Seis tipos principais de agricultura foram identificadas na Zona da Mata, sendo três categorias de agricultura familiar (convencional, agroecológica e 
Sumário

tradicional), agricultura de larga escala (ou fazendeiros), agricultura parcial (onde o agricultor/a exerce outras tarefas que não a agricultura) e agricultura desenvolvida pelos sem-terra. Eu mostrei que, diante das transições agroecológicas, os agricultores apresentam padrões distintos em termos de estratégias, práticas e princípios de manejo. e que os agricultores identificados como agroecológicos geralmente têm um engajamento mais forte em uma rede composta por organizações de agricultores, movimentos sociais, universidades e ONGs. Além disso, as propriedades agroecológicas potencialmente fornecem uma gama maior de serviços ecossistêmicos, pois apresentaram uma maior agrobiodiversidade, com maior diversidade de cultivos para a venda e para o auto-consumo do que as demais. Concluí que as transições agroecológicas podem se beneficiar muito do envolvimento em redes com a participação de movimentos sociais, instituições de ensino e de assessoria, para o que necessitam de apoio de políticas e fundos públicos para a geração de conhecimento que articule ciência e sabedoria popular, necessário ao manejo agroecológico e, portanto, sustentável dos agroecossistemas.

Enquanto o manejo do agroecossistema é um fator essencial para a povisão de serviços ecossistêmicos, os agricultores podem diferir amplamente em termos de habilidades, conhecimento e ambição para manejar seus sistemas, o que se associa com a percepção que os mesmos possuem sobre os serviços ecossistêmicos. Entretanto, há poucos estudos sobre a percepção dos agricultores sobre os serviços ecossistêmicos. No capítulo 3, estudei o manejo e a percepção de agricultores de larga escala, agricultores familiares convencionais e agricultores familiares agroecológicos sobre os serviços ecossistêmicos. Os agricultores foram entrevistados e construíram mapas mentais cognitivos de sua percepção sobre serviços ecossistêmicos. A análise de mapas mentais cognitivos revelou que, em geral, a percepção dos agricultores sobre serviços ecossistêmicos é altamente complexa e interconectada. Esta complexidade e 
interconexão, no entanto, é ainda maior entre os agricultores familiares agroecológicos, o que está associada com seus agroecossistemas mais diversificados e autônomos. Os agricultores familiares agroecológicos e convencionais apresentaram uma forte identidade camponesa, pois reconheceram mais serviços ecossistêmicos culturais e deram maior valor à produção para consumo do que os agricultores em larga escala. As iniciativas que visam fortalecer a prestação de serviços ecossistêmicos nas propriedades devem ser sensíveis às percepções dos agricultores e podem precisar considerar estratégias específicas para diferentes tipos de agricultores.

No capítulo 4, eu avaliei os impactos diretos e indiretos das práticas de manejo dos agricultores na biodiversidade, qualidade do solo e produtividade de cafezais e pastagens em propriedades agroecológicas, convencionais e de larga escala. $\mathrm{O}$ estudo foi realizado em doze propriedades e, para cada um dos 24 campos (doze cafezais e doze pastagens), registramos 41 variáveis associadas a práticas de manejo, indicadores de diversidade taxonômica (por exemplo, número de espécies arbóreas), estrutural (por exemplo, áreas basal e da copa) e funcional (por exemplo, médias das propriedades funcionais de folhas ponderadas para a comunidade vegetal) e qualidade biológica, química e física do solo. Os efeitos diretos e indiretos do manejo sobre a biodiversidade, a qualidade do solo e, no caso do café, produtividade, foram avaliados por meio de modelos de equações estruturais. No caso de propriedades agroecológicas, o aumento da diversidade de plantas, em especial de árvores, nas pastagens, devido ao manejo agroecológico, resultou em maior qualidade do solo, provavelmente devido à maior cobertura do solo e heterogeneidade estrutural da vegetação. No entanto, outras práticas de manejo adotas em pastagens em propriedades agroecológicas não tiveram um efeito positivo direto na qualidade do solo, o que indica que o aumento da diversidade de plantas nas pastagens, embora positivo, precisa ser combinado com melhores práticas de manejo do que as atualmente adotadas tanto 
Sumário

em sistemas agroecológicos como convencionais. No caso dos cafezais, por um lado, a maior intensidade de capina e maior uso de insumos externos nos sistemas cafeeiros convencionais e em larga escala não resultaram em maior qualidade química do solo ou produtividade do café, em relação aos sistemas agroecológicos. Por outro lado, o manejo agroecológico do café foi associado ao aumento da diversidade estrutural, funcional e taxonômica vegetal, que por sua vez foi positivamente associada ao carbono da biomassa microbiana, um indicador de qualidade biológica do solo. Nossos resultados indicam, portanto, que houve relação de causa e efeito entre o aumento da diversidade de plantas (incluindo árvores), devido ao manejo agroecológico dos cafezais e a manutenção e/ou aumento da qualidade do solo e não houve nenhuma relação de causa e efeito com a produtividade do café. Portanto, o aumento de biodiversidade, incluindo as árvores, nos cafezais em propriedades agroecológicas não diminuiu a produtividade dos cafezais em comparação com as propriedades manejadas de maneira convencional, que dependem do alto uso de pesticidas e fertilizantes químicos.

Além de áreas agrícolas, os ecossistemas (semi-) naturais, como florestas secundárias, podem fornecer importantes SE. A regeneração natural de florestas secundárias pode ser uma estratégia eficaz e de baixo custo para aumentar a cobertura florestal e a biodiversidade na paisagem, e com isto as funções ecossistêmicas associadas à biodiversidade, incluindo as funções do solo. No entanto, pouco se sabe sobre como as funções do solo se desenvolvem durante a sucessão e como os atributos da vegetação influenciam as funções do solo, especialmente em paisagens altamente biodiversas e fragmentadas nos trópicos. No capítulo 5 avaliei uma ampla gama de indicadores de diversidade taxonômica, estrutural e funcional de espécies arbóreas, bem como indicadores de funções do solo relacionados ao acúmulo de matéria orgânica do solo, ciclagem de nutrientes e cobertura do solo em áreas de floresta secundária que variam de 5 a 80 anos. 
Duas áreas agrícolas recentemente deixadas para reflorestamento natural foram incluídas como ponto de partida da sucessão florestal e dois fragmentos florestais primários serviram como referência para o ponto final da sucessão florestal. Quatro hipóteses ecológicas, centradas no papel de diversidade funcional, diversidade estrutural e biomassa, foram testadas para explorar mecanismos nos quais a vegetação florestal pode influenciar as funções do solo. A maioria das medidas de diversidade estrutural, taxonômica e funcional convergiu para valores encontrados em florestas primárias após 25-50 anos de sucessão, enquanto a composição funcional mudou de espécies aquisitivas (folhas com alta área folhiar específica) para espécies conservadoras (folhas com baixa área folhiar específica). A ciclagem de carbono e nutrientes no solo mostrou uma rápida recuperação aos níveis de florestas primárias após 15 anos de sucessão. Embora a cobertura do solo também tenha aumentado durante a sucessão, os níveis de cobertura do solo em florestas de 80 anos não atingiu os níveis de florestas primárias. Variações na altura das árvores e a dominância das características funcionais das folhas foram identificados como fatores que mais influenciaram o ciclo do carbono e nutrientes, enquanto a biomassa acima do solo foi o fator que mais influenciou o acúmulo de serapilheira e cobertura do solo, o que por sua vez associou-se a uma maior retenção de água no solo. Nossos resultados indicam que a sucessão secundária florestal pode levar a uma recuperação relativamente rápida de funções relacionados à ciclagem de nutrientes e do acúmulo de carbono. Entretanto, florestas primárias podem prover funções, como cobertura do solo, em níveis não alcançados em florestas secundárias mesmo após 80 anos de sucessão florestal.

Os resultados desta tese mostram que mudanças na percepção cognitiva dos agricultores sobre serviços ecossistêmicos levaram a mudanças nas estratégias de manejo, as quais, por sua vez, influenciaram a biodiversidade e a provisão destes serviços. Os agricultores agroecológicos 
Sumário

apresentaram uma percepção mais complexa sobre serviços ecossistêmcios do que outros tipos de agricultores, o que foi associado a uma maior participação em organizações sociais, maior biodiversidade em seus agroecossistemas e maior acesso a políticas públicas. Assim, o movimento agroecológico na Zona da Mata apoiou um grupo de agricultores a se tornar menos dependente do uso de insumos industriais, sem comprometer a produtividade do café e mantendo a qualidade do solo e a saúde das plantas, a partir do fortalecimento de processos ecológicos baseados na biodiversidade. Apesar das evidências técnicas crescentes sobre os benefícios ecológicos e agronômicos, as abordagens agroecológicas ainda não são amplamente adotadas por agricultores na Zona da Mata, em todo o Brasil e no mundo. Portanto, sugiro que, além de questões técnicas, a ampliação das transições agroecológicas possa ser dificultada por outros fatores, como o aprisionamento dos agricultores no modelo industrial de agricultura. Há uma necessidade urgente, portanto, de desenvolver e aplicar melhores abordagens para ampliar o conhecimento de todos, cientistas e agricultores, sobre o manejo agroecológico dos agroecossistemas e apoiar os agricultores a terem acesso à terra, créditos e mercados. A geração e o compartilhamento de conhecimentos agroecológicos aplicados à realidade local devem conter práticas de gestão e políticas públicas fundamentadas cientificamente e favoráveis ao processo de transição agroecológica, prevendo metodologias que reconhecem o saber dos agricultores como importantes no processo de transição. 


\section{Acknowledgments}

The $\mathrm{PhD}$ was an intense, but very pleasant journey thanks to all my family, friends and colleagues who accompanied me along the way. I would like to acknowledge the opportunity to live surrounded by so many good people from all parts of the world and to work with something I am passionate about. First, I would like to thank my parents, Estêvão Couto Teixeira and Liliam Nagem Mancini Teixeira, for always supporting me and providing me the basis for what I am today. I would like to thank my grandmother, Célia Couto Teixeira, for being an example on how to deal with life in a smooth and kind way, full of faith and always respecting and caring for all people. I also thank my grandparents Mozart Couto Teixeira, Leni Nagem Mancini e Joel Mancini (in memoriam) for all the good moments lived together and for incentivizing me to study. I thank my brother, Bruno Mancini Teixeira for being a friend during my whole life, supporting and caring for me despite knowing well my flaws. I thank my godparents Adelina e Henrique Teixeira for their support. I thank my aunt Maria do Carmo Couto Teixeira and my uncle Eugênio Ferrari, for hosting me during many times in Viçosa and for inspiring me with ways to build a better society. I thank all the Teixeira relatives, all my fourteen uncles and aunts and more than 60 cousins for being a great big family full of music, art, culture, creativity, happiness and unity that I love so much.

I would like to express a special gratitude for my partner, my love, Bruna Carolina da Silva Goulart, who was together with me during almost the whole $\mathrm{PhD}$. Bruna supported me during the hard moments, listening to my doubts and fears, encouraging me to try again, helping me with field and lab work and, most importantly, being a great and kind partner. Of course, she 
was also there for the good moments, during the celebrations, parties and trips in between Minas Gerais, Rio de Janeiro and Wageningen.

I thank the Universidade Federal de Viçosa and Wageningen University for their institutional support and for enabling students to follow a double degree, which I believe can strength the international cooperation between universities and advance science in the world. I also thank the Brazilian funding organisations, FAPEMIG, CNPq and CAPES, for their direct and indirect support and for their great role to develop and sustain science and technology in Brazil. I acknowledge the, now extinct, Program Science without Boarders (“Ciências sem fronteiras") launched by the federal Brazilian government in 2012, which allowed students like me to share and expand our knowledge internationally.

During my PhD trajectory, I had the chance to meet wonderful professionals, from whom I learned so much! First my supervisors: Irene Maria Cardoso, example of power and energy to fight for the things we believe with professionalism and dedication; Marielos Peña-Claros, who showed me how a researcher can be patient, careful and generous, and at the same time rigorous and critical; and Felix Bianchi, who taught me how to face challenges in a calm and elegant way and to write concisely and objectively. Thank you so much the three of you, for allowing me to develop my own thoughts and ideas. Thank you also for providing me with great scientific input, in a positive and constructive way. You were the best supervisory team I could wish for. I thank Pablo Tittonell for being a great and clever advisor during the whole $\mathrm{PhD}$. The little time we spent together made a big difference for me. I thank Maurício Dutra (microbiology lab at Universidade Federal de Viçosa), for opening the doors of his lab and allowing me to learn about microbiology. I also would like to thank all the FOREFRONT professors, in special Lijbert 


\section{Acknowledgments}

Brussaard, Thom Kuyper and Frans Bongers, for enabling us to develop interdisciplinary research in a collective and fun way. I thank Izabel Vieira and Felipe Simas for helping to bring the FOREFRONT Program to Brazil and for their theoretical contribution. I thank Arne Jansen for the help with statistics and housing in Wageningen. I also would like to thank all the PhD colleagues from FOREFRONT, from Mexico and Brazil. It was great to work in collaboration with all of you and I hope we keep our partnership in future work! I thank specially the colleagues Lucas Carvalho, Margriet Goris and Leonardo van den Berg, for initiating together our $\mathrm{PhD}$ projects with farmers in Zona da Mata. We were a very complementary and dynamic group. I also would like to thank all the students that helped and participated in my $\mathrm{PhD}$ project. I thank Ardjan Vermue for the great fun we had during the fieldwork, for his commitment with the research and farmers and for the great discussions in the beginning of my $\mathrm{PhD}$; Lisa Freitag, for all the adventures in the pastures and coffee fields in Zona da Mata and the many measurements in the lab; Delphin Jamme, for the efficiency in the work and the good times in Violeira; Niara Rutte, for the enthusiasm to work in the forest; Arthur Cruz Silva, for being a great and committed student in the project and for all the good moments with farmers and in the forest; Talita Guarçoni, for her help in the lab and for being always cheerful and interested in the mysteries of the plants; Tales Theodoro, for his help with the microbiological analysis, all the field trips together in Zona da Mata, the good music, the good conversations and reflections about life; Maria Clara Victer, for the enthusiasm and the energy of the new generation; and others who were together with me in the field and in the lab.

In Wageningen, I would like to acknowledge groups and friends who were part of my trajectory. I thank the chairgroup Farming Systems Ecology for presenting me new research approaches and for hosting me in a friendly and receptive working atmosphere. A special thanks to the 
group secretaries, Wampie and Gemma, and to all the colleagues with whom I shared the PhD room, including Yodit, Jonas, Victoria, Pablo, Lienneke, Roos, Daniel, Carl, Annemiek, Walter, Lenora, amongst others. I thank the chairgroup Forest Ecology and Management for hosting me during my visits to the group, for the international dinners and for all the interesting discussions about forest related issues. I thank people from the Boerengroep, especially the former coordinators Elske Hageraats and Klarien Klingen for bringing energy and life to the Dutch agroecological network. I also thank the organisations Otherwise and Ileia for introducing me to the Netherlands and for offering me an internship during my undergraduate studies. Of course, I also need to thank all the friends from Droevendaal, this beautiful collective community, where I had the chance to be myself in the Netherlands, finding people with common interests and passions. It was great to learn and share with each of you, during the many long and delicious dinners, walks in the forest, work and harvest in the garden, capoeira trainings, workshops, crazy parties, snowball fights, trips around Europe and so many adventures that are worth a whole book just for them. A special thanks to my friends from former 105, Loes, Carlo, Alexis, Fanny, Adri, Alba, Fruszi, Rowan, Sebas, Gabriele and Annika with whom I got to know Wageningen and the Netherlands before the $\mathrm{PhD}$. Also, a thanks to the former housemates from 91, Kristina, Aryo, Inez, Rollinde and Esteban, it was great to share the last bit of my $\mathrm{PhD}$ with you guys! I thank the friends from the farm as well, Raquel, Angel, Adri, Loes and many others with whom I lived together during the first months of the $\mathrm{PhD}$ and shared many nice moments in this house full of love and communion. Finally, I thank Edith van Walsum and Mans Lanting, for hosting me in the very first days in the Netherlands and inspiring me to work with agroecology and family farmers. 


\section{Acknowledgments}

I need to acknowledge all the friends and experiences I had in Viçosa and Zona da Mata, where I learned to be great part of who I am today. I thank the agroecological movement and the many groups I have been involved during my studies on Forest Engineering. I thank the friends from GAO and Mutirão Ciranda, Bela, Goiano, Ana Terra, Júlia, Olivia, Marquinhos, Bruno, Lucas, Matheus, and many others with whom I learned about agroecology in practice and to transform dreams in reality! I thank the friends and colleagues from CTA-ZM for all the knowledge exchange, in special Breno and Anginha for supporting my project and being always available to help. I thank the friends with whom I lived great part of my life in Viçosa before or during the PhD: André, Nicolas, Carioca (Guilherme), Baiano, Leo and Diogo. I thank also the many friends of Violeira for all the good conversations, rides to the city and parties and music in the countryside. It was a great pleasure to live in such a beautiful and nice community during the past years. Here I would like to mention so many names that I think the list would be become too long to be read. I thank my Capoeira professor Daniel da Silva and all the capoeiristas from Tribo do Morro, for allowing me to develop my body, mind and spirit with the art of capoeira. I thank colleagues and professors from the Soil Science Department for supporting the double degree process and for the help with equipment and labwork. And finally, I would like to thank the protagonists of this thesis and my research. For all the hard work to produce our food and for maintaining and sharing their ancestral knowledge about nature, I thank all the farmers that participated directly or indirectly in this $\mathrm{PhD}$ project. In Divino, I thank Adriano and Renata Sivestre, and their son and daughter Felipe and Sara, Renata Amorim, Gilberto and Luciana Correa, Eliete, Denil, Anacleto, Gilvânia, Gilvane, Queidiane, Dona Denira, Seu Norival, Paulinho and many others that hosted and inspired us. In Araponga, I thank Sr. Nenem, Paulinho and Fia, Vicente and Lucimar, Edmar, João dos Santos, Rosangela, Neide and many others who were willing to share their knowledge and experiences. In Espera Feliz, I thank Amauri and 
Vera, Fernanda, Tonho, João Lima and his sisters, Aparecida and many others who believed and contributed to my work. I also thank Dadin and Cida, in Pedra Dourada, for being open to share their incredible knowledge about nature. At last, I would like to thank all the farmers' organisations that supported our work, especially the Sindicato de Trabalhadores e Trabalhadoras Rurais na Agricultura Familiar de Araponga, Divino and Espera Feliz, who showed us that only together and socially organised we can achieve a better and sustainable agri-food system.

E, finalmente, gostaria de agradecer aos protagonistas da minha pesquisa. Por todo o trabalho duro para produzir nossos alimentos e por manter e compartilhar seus conhecimentos ancestrais sobre a natureza, agradeço a todos e todas agricultores e agricultoras que participaram direta ou indiretamente desse projeto de doutorado. Em Divino, agradeço a Adriano e Renata Sivestre, e seus filhos, Felipe e Sara, Renata Amorim, Gilberto e Luciana Correa, Eliete, Denil, Anacleto, Gilvânia, Gilvânia, Queidiane, Dona Denira, Seu Norival, Paulinho e muitos outros que nos receberam e inspiraram. Em Araponga, agradeço a Sr. Nenem, Paulinho e Fia, Vicente e Lucimar, Edmar, João dos Santos, Rosangela, Neide e muitos outros por estarem dispostos a compartilhar seus conhecimentos e experiências. Em Espera Feliz, agradeço Amauri e Vera, Fernanda, Tonho, João Lima e suas irmãs, Aparecida e muitos outros que acreditaram e contribuíram para o meu trabalho. Agradeço também a Dadin e Cida, em Pedra Dourada, por estarem abertos a compartilhar seu imenso conhecimento sobre a natureza. Por fim, gostaria de agradecer a todas as organizações de agricultores que apoiaram nosso trabalho, especialmente os Sindicatos dos Trabalhadores e Trabalhadoras Rurais na Agricultura Familiar de Araponga, Divino e Espera Feliz, que nos mostraram que somente juntos e socialmente organizados podemos alcançar um sistema agro-alimentar mais sustentável. 


\section{Short Biography}

My name is Heitor Mancini Teixeira, I was born on 18 February 1990 in Juiz de Fora, located in the region of Zona da Mata, state of Minas Gerais, Brazil. My parents are Liliam Nagem Mancini Teixeira and Estêvão Couto Teixeira. I studied my primary, secondary and high school in Juiz de Fora. In 2008 I was admitted to the Forest Engineer program at Universidade Federal de Viçosa, also located in the Zona da Mata region, Minas Gerais. Since the beginning of my studies in Viçosa, I got involved with the agroecological movement and participated in many extension, education and research projects.

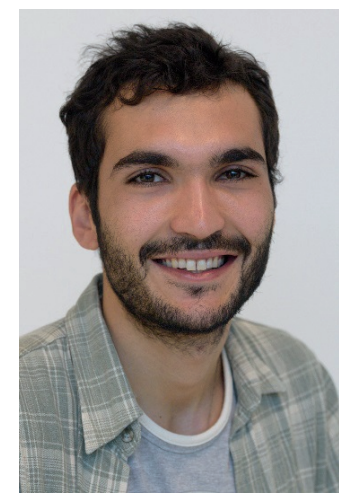
During my studies, I had the chance to participate in conferences and meetings in different parts of the country. I also conducted a one year internship in 2012/2013 at Wageningen University in the Netherlands, where I developed projects linked to agroecology and farmers. I got my Forest Engineer degree in 2015 and got a temporary scholarship in one of the University projects focused on soils, agroecology and education. I also spent one and a half month in the Amazon, following a course on Forest Management at the National Institute of Research in the Amazon (INPA). I got the PhD position at Wageningen University in 2016 and joined the FOREFRONT Program. During my PhD I spent two and a half years in Brazil doing fieldwork and also had the chance to participate in a research workshop in Mexico. I came back to the Netherlands in 2019 to finalize the $\mathrm{PhD}$. 


\section{List of Publications}

\section{Peer reviewed journal articles}

Teixeira, H.M., Van Den Berg, L., Cardoso, I.M., Vermue, A.J., Bianchi, F.J.J.A., Peña-Claros, M., Tittonell, P., 2018. Understanding Farm Diversity to Promote Agroecological Transitions. Sustainability, 10: 4337. doi:10.3390/su10124337

Teixeira, H.M., Vermue, A.J., Cardoso, I.M., Peña-Claros, M., Bianchi, F.J.J.A., 2018. Farmers show complex and contrasting perceptions on ecosystem services and their management. Ecosystem Services, 33: 44-58. doi:10.1016/j.ecoser.2018.08.006

Van den Berg, L., Roep, D., Hebinck, P., Teixeira, H.M., 2018. Reassembling nature and culture: Resourceful farming in Araponga, Brazil. Journal of Rural Studies, 61: 314-322. doi:10.1016/j.jrurstud.2018.01.008

Teixeira, H.M., Cardoso, I.M., Bianchi, F.J.J.A.,Silva, A.C., Delphin, J., Peña-Claros, M., 2020. Linking vegetation and soil functions during secondary forest succession in the Atlantic forest. Forest Ecology and Management, 457: 117696. doi: 10.1016/j.foreco.2019.117696

\section{To be Submitted}

Teixeira, H.M., Bianchi, F.J.J.A., Cardoso, I.M., Tittonell, P., Peña-Claros, M., 2019. Impact of agroecological management on biodiversity and soil-based ecosystem services in pasture and coffee systems in the Atlantic forest of Brazil. 
Conference/Symposium Proceedings

Teixeira, H.M., Vermue, A.J., Cardoso, I.M., 2017. Fuzzy cognitive maps as a tool to assess ecosystem services considering farmers' knowledge. Latin american congress on agroecology and Brazilian congress on agroecology.

Van den Berg, L., Simas, F., Cardoso, I.M., Gomes, L.C., Teixeira, H.M., Vermue, A.J., Goris, M., 2017. Participatory action research: learning from the Zona da Mata, Minas Gerais. Latin american congress on agroecology and Brazilian congress on agroecology.

Teixeira, H.M., Vermue, A.J., Goulart, B.C.S., Lopes, A.S., Van den Berg, L., Goris, M., Gomes, L.C., Cardoso, I.M., 2018. Interdisciplinary and participatory methodologies for education in soil science. World Congress of Soil Science.

Teixeira, H.M., Cardoso, I.M., Bianchi, F.J.J.A., Peña-Claros, M., 2018. Agroecological Transitions to Promote Biodiversity Conservation and Provision of Ecosystem Services. World Congress of Soil Science.

Lopes, A.S., Teixeira, H.M., Cardoso, I.M., Muggler, C.C., 2018. Contrasting female and male farmers' perceptions on soil ecosystem services. World Congress of Soil Science.

Teixeira, H.M., Goris, M., Van den Berg, L., Gomes, L.C., Bianchi, F.J.J.A., Peña-Claros, M., Cardoso, I.M., 2019. The (in)visible Components of Participatory Action Research. Tropentag conference. 


\section{PE\&RC Training and Education Statement}

With the training and education activities listed below the $\mathrm{PhD}$ candidate has complied with the requirements set by the C.T. de Wit Graduate School for Production Ecology and Resource Conservation (PE\&RC) which comprises of a minimum total of 32 ECTS (= 22 weeks of activities)

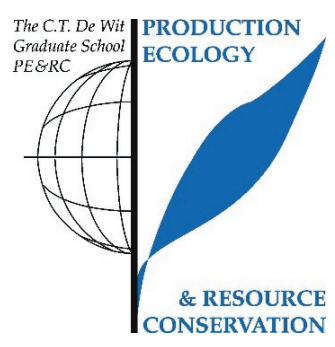

\section{Review of literature (4.5 ECTS)}

-Linking functional biodiversity and ecosystem services (2016)

\section{Writing of project proposal (4.5 ECTS)}

-Linking functional biodiversity and ecosystem services: towards more efficient and resilient agroecosystems in Brazil

\section{Post-graduate courses (4.3 ECTS)}

-Plant functional traits; INPA Instituto Nacional de Pesquisas na Amazônia, Brazil (2016)

-Dynamic models in R; PE\&RC and SENSE graduate schools; Wagenigen, the Netherlands (2019)

Deficiency, refresh, brush-up courses (14.1 ECTS)

-Analysis and design of organic farming systems; Wageningen University, the Netherlands (2016)

-Forest ecology and forest management; Wageningen University, the Netherlands (2016)

-Scientific methodologies for agroecology, with emphasis in soils; Universidade Federal de Viçosa, Brazil (2017)

\section{Invited review of (unpublished) journal manuscript (3 ECTS)}

-Society and Natural Resources: comparison of farmers and experts mental models on Ecosystem Services (2018) 
-Ecosystem Services: insights into the importance of ecosystem services to human well-being in semi-arid landscapes (2019)

-European Journal of Agronomy: a typology to understand the diversity of strategies of implementation of agroecological practices in the French West Indies (2019)

\section{Competence strengthening / skills courses (2.7 ECTS)}

-Competence assessment; WGS (2016)

-Brain friendly working and writing; WGS (2019)

-Career assessment; WGS (2019)

-Writing propositions for your PhD; WGS (2019)

-Last stretch of the PhD programme; WGS (2019)

-Brain training; WGS (2019)

-Presenting with impact; WGS (2019)

-Ethics for social sciences research; WGS (2019)

PE\&RC Annual meetings, seminars and the PE\&RC weekend (2.1 ECTS)

-PE\&RC First years weekend (2016)

-PE\&RC Last years weekend (2019)

\section{Discussion groups / local seminars / other scientific meetings (6.65 ECTS)}

-Sustainable Intensification of Agricultural Systems (SIAS); Wageningen, the Netherlands (2016)

-First international workshop of the FOREFRONT program; Wageningen, the Netherlands (2016)

-Second international workshop of the FOREFRONT program; Wageningen, the Netherlands (2016)

-Participatory tools for research; Wageningen, the Netherlands (2016)

-International workshop of the FOREFRONT program; Zona da Mata, Minas Gerais, Brazil (2017)

-Soils and agroecology discussion group; Universidade Federal de Viçosa (UFV); Brazil (2018) -International workshop of the FOREFRONT program; Morelia, Mexico (2018) 
-Master class, legume nitrogen fixation; Wageningen, the Netherlands (2019)

\section{International symposia, workshops and conferences (11.4 ECTS)}

-Voedsel anders conference; oral presentation; Wageningen, the Netherlands (2016)

-Latin american congress on agroecology and Brazilian congress on agroecology; poster and oral presentation; Brasilia, Brazil (2017)

-Brazilian ecology congress and international symposium on ecology and evolution; oral presentation; Viçosa, Brazil (2017)

-World congress of soil science; oral presentation; Rio de Janeiro, Brazil (2018)

-Workshop UTZ and rainforest alliance: adapting to climate change in sustainable coffee and cacao production; oral presentation; Viçosa, Brazil (2018)

-Tropentag conference; oral presentation; Kassel, Germany (2019)

-41st Session of the European Commission on Agriculture; oral presentation; Food and Agriculture Organization of the United Nations, Budapest, Hungary (2019)

\section{Societally relevant exposure (1.5 ECTS)}

-Summer school Links4soil; invited lecturer; Agricultural Institute of Slovenia (2019)

\section{Lecturing / supervision of practicals / tutorials (4.5 ECTS)}

-Agroecology; the Netherlands (2016)

-Farm Experience Internship; the Netherlands (2016)

-Levantamento, Aptidão, Manejo e Conservação do Solo; Brazil (2016-2017)

-Metodologia de Pesquisa em Agroecologia com ênfase em Solos; Brazil (2018)

\section{Supervision of MSc students (3 ECTS)}

-Ardjan Vermue: Farmers' perceptions on ecosystem services in the Atlantic Rainforest biome -Lisa Freitag: The effect of management on taxonomical and structural diversity in pastures and coffee systems in Zona da Mata

-Niara Rutte : The influence of management on tree diversity in secondary forests

-Delphin Jamme: Assessing soil quality along a forest succession gradient 
The research described in this thesis was financially supported by the FOREFRONT Program, a Program funded by the Interdisciplinary Research and Education Fund (INREF) of Wageningen University \& Research; and by the Fundação de Amparo à Pesquisa do Estado de Minas Gerais, Brasil (FAPEMIG); Conselho Nacional de Desenvolvimento Científico e Tecnológico do Brasil (CNPq); and Het Kronendak, the Netherlands.

Financial support from Wageningen University for printing this thesis is gratefully acknowledged.

Cover design by Studio Jardim (Thiago José Amaral and Amana Fares)

Printed by Proefschriftmaken 


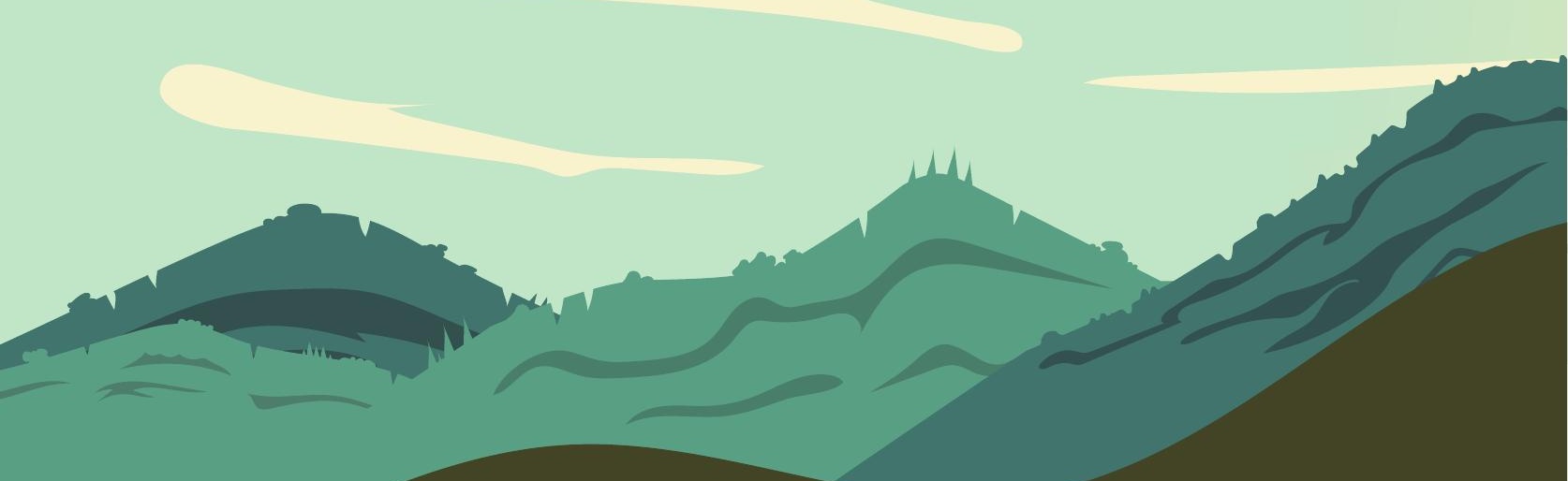
Propositions

1- The search for a global sustainable agri-food system must include local culture, knowledge and practices.

(this thesis)

2- Multiple metrics of biodiversity are needed to capture the numerous linkages between nature and people.

(this thesis)

3- While solidary scientific research is needed to develop sustainable agri-food systems, our current academic system reinforces solitary research.

4- Quantification of the economic value of nature overlooks the fact that for a person dying of thirst a glass of water is priceless.

5- Cultural and social diversity enhances biodiversity and human well-being.

6- Countries in the global south must take the lead in developing a research agenda for their own geographical region.

7- Yoga and capoeira bring physical, but also emotional strength and flexibility to deal with the $\mathrm{PhD}$.

Propositions belonging to the thesis entitled:

"Linking biodiversity, ecosystem services and social actors to promote agroecological transitions"

Heitor Mancini Teixeira

Wageningen, 31 January 2020 